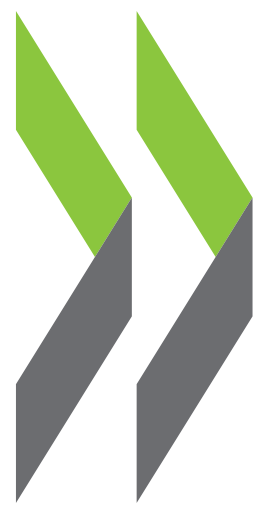

OECD Urban Studies

\title{
Cities in the World
}

A NEW PERSPECTIVE ON URBANISATION
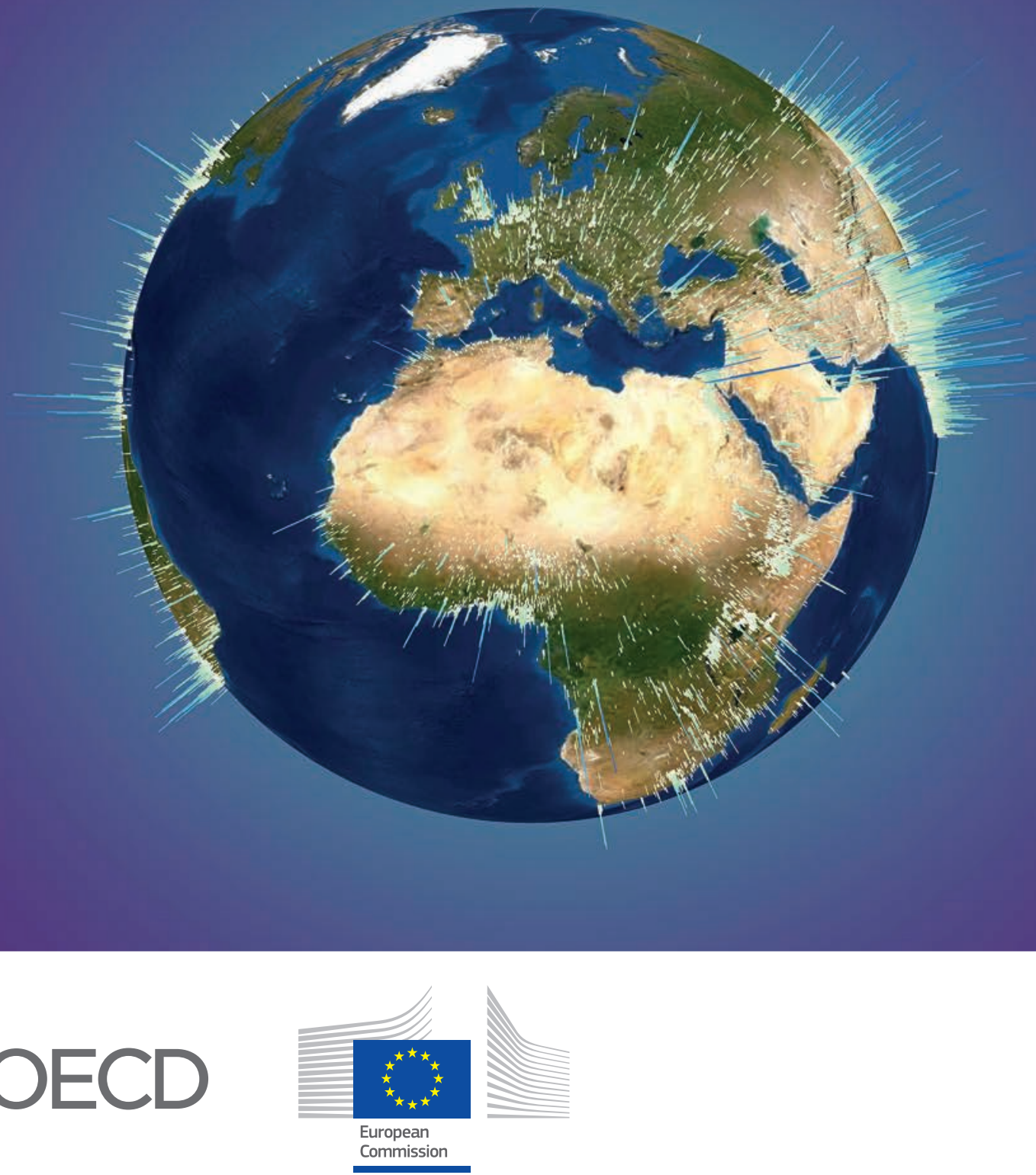

OECD Urban Studies

\section{Cities in the World}

A NEW PERSPECTIVE ON URBANISATION 
The opinions expressed and arguments employed herein do not necessarily reflect the official views of the European Union.

This document, as well as any data and map included herein, are without prejudice to the status of or sovereignty over any territory, to the delimitation of international frontiers and boundaries and to the name of any territory, city or area.

The statistical data for Israel are supplied by and under the responsibility of the relevant Israeli authorities. The use of such data by the OECD is without prejudice to the status of the Golan Heights, East Jerusalem and Israeli settlements in the West Bank under the terms of international law.

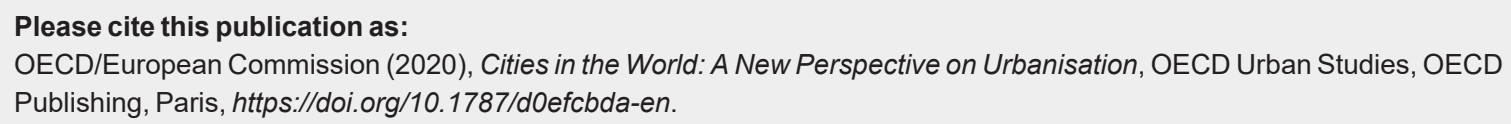

ISBN 978-92-64-51971-8 (print) ISBN 978-92-64-37666-3 (pdf) ISBN 978-92-64-68736-3 (HTML) ISBN 978-92-64-79498-6 (epub)

OECD Urban Studies ISSN 2707-3432 (print) ISSN 2707-3440 (online)

EU ISBN 978-92-76-15332-0 (print) EU ISBN 978-92-76-15333-7 (PDF) Catalogue number KN-03-20-040-EN-C (print) Catalogue number KN-03-20-040-EN-N (PDF)

Revised version, June 2020

Details of revisions available at: https://www.oecd.org/about/publishing/Corrigendum-Cities-in-the-World.pdf

Photo credits: Cover @ Olivier Draily. 


\section{Foreword}

Over the past 40 years, global population has almost doubled. As a result, the size of rural areas, towns and especially cities has also grown rapidly. Today, cities are home to almost half of the global population and this share is projected to reach $55 \%$ by 2050 . Global megatrends such as the climate emergency, demographic change and digitalisation will affect cities, towns and rural areas in different ways. This underlines the importance of designing efficient and coherent policy responses that are place-specific and cut across different policy domains.

The global scale and the urgency of these challenges require achieving consensus on common solutions, on data and approaches, facilitated and supported by the work of multilateral and international organisations such as the OECD and the European Commission (EC). Both the OECD and the EC possess a long tradition of analysing and building regional, urban and rural policies. Moreover, both aim to boost growth and improve well-being in all regions, cities and rural areas through dedicated platforms for the exchange of best practices. This includes, for example, the OECD Regional Development Committee (RDPC), and the EU's cohesion policy and rural development policy.

This study, Cities in the World, offers a valuable illustration of how such a collaboration can make a significant contribution to evidence-based policy and, ultimately, to better lives. Despite intense global discussions around urbanisation, a global definition of a 'city', 'urban area' and 'rural area' has been lacking, and thereby, limiting meaningful international comparisons. Cities in the World also offers a new perspective on urbanisation by analysing, for the first time, the growth of cities, towns and rural areas using the definition that the Statistical Commission of the United Nations endorsed in March 2020.

Cities in the World also sheds light on the drivers and the consequences of urbanisation. It highlights, for example, the advantages and disadvantages of living in cities, compared to towns and rural areas. On the one hand, this includes better employment opportunities as well as better access to healthcare and education; on the other, it includes a higher cost of living, air pollution, congestion and crime. Focusing on the growth of metropolitan areas, the study shows that the population of the largest metropolitan areas has grown fastest, while one fifth of metropolitan areas are shrinking. It also highlights the importance of towns in connecting cities and rural areas. Managing rapid population growth, but also population decline in some metropolitan areas, calls for new, efficient policies to provide public services, transport, infrastructure and affordable housing.

This study opens up new ways for future public policy. By categorising, measuring and comparing complex patterns of human settlements consistently across the world, it helps identify current and future needs to promote prosperous and inclusive cities, towns and rural areas. It also provides a new tool for policymakers to monitor and pursue the United Nations Sustainable Development Goals, and thus makes an active contribution to achieving economic, social, and environmental sustainable development in all areas.

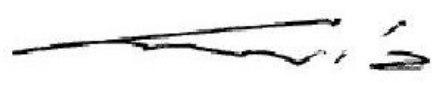

Angel Gurría

OECD Secretary-General

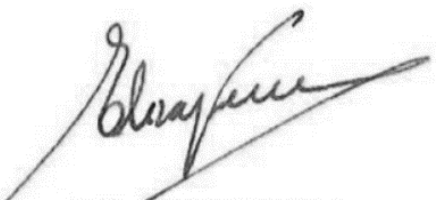

Elisa Ferreira

European Commissioner for Cohesion and Reforms 


\section{Acknowledgements}

This report was produced jointly by the OECD (Centre for Entrepreneurship, SMEs, Regions and Cities) led by Lamia Kamal-Chaoui and the European Commission (Directorate-General for Regional and Urban Policy and the Joint Research Centre). It benefited from the financial support by the European Commission, Directorate-General for Regional and Urban Policy.

From OECD side, the report was produced by Lukas Kleine-Rueschkamp and Paolo Veneri under the supervision of Rüdiger Ahrend and with the guidance of Joaquim Oliveira Martins. From European Commission side, the report was produced by Lewis Dijkstra. Professor J. Vernon Henderson (London School of Economics) and Professor Tony Venables (University of Oxford) provided scientific guidance on the project. The report was drafted by Lewis Dijkstra (EC), Dante Donati (OECD), Jared Gars (OECD), Lukas Kleine-Rueschkamp (OECD), and Paolo Veneri (OECD).

The report would not have been possible without the support of many. Aneta J. Florczyk, Sergio Freire, Thomas Kemper, Luca Maffenini, Michele Melchiorri, Martino Pesaresi and Marcello Schiavina (all ECJRC) made vital contributions to the report through analysis, data provision, and constant advice. The report also benefitted from the work of Ana Moreno-Monroy (OECD) and Marcello Schiavina (EC-JRC) on the global delineation of metropolitan areas. J. Vernon Henderson (London School of Economics), Vivian Liu (London School of Economics), Cong Peng (University of California, San Diego), and Adam Storeygard (Tufts University) provided analysis and inputs on demographic and health outcomes by degree of urbanisation in developing countries. Bryan Jones, Deborah Balk, Hasim Engin (all City University of New York), Stefan Leyk (University of Colorado, Boulder) and Mark Montgomery (Population Council) provided projections by Degree of Urbanisation. Eleni Papadimitriou (EC-JRC) produced data on well-being and quality of life, including by gender. Paolo Bolsi, Hugo Poelman (both EC-REGIO), Chris Jacobs-Crisioni, Mert Kompil, Andrius Kučas (all EC-JRC), Dimitrios Papaioannou (International Transport Forum) and Dennis Mwaniki (UN Habitat) all contributed to the transport analysis. Olivier Draily (EC-REGIO) produced the maps and the cover.

Special thanks are hereby conveyed to the following people for their valuable comments on various drafts of the report: Aziza Akhmouch, Enrique Garcilazo, Soo-Jin Kim, Oscar Huerta Melchor, Tadashi Matsumoto, Ana Moreno-Monroy (all OECD), and Chris Jacobs-Crisioni (EC-JRC). The OECD also thanks the delegates to the OECD Regional Development Policy Committee and its Working Parties on Territorial Indicators, on Urban Policy and on Rural Policy for comments and guidance throughout the project. Finally, delegates of the OECD Working Party on Territorial Indicators are thankfully acknowledged for their guidance in the development of the Degree of Urbanisation and the Functional Urban Area definitions.

Eleonore Morena provided editorial assistance, Claire Hoffmann provided statistical assistance, Nikolina Jonsson and Jeanette Duboys prepared the manuscript for publication and Pilar Philip coordinated the production process. 


\section{Table of contents}

Foreword

Acknowledgements 4

$\begin{array}{ll}\text { Executive summary } & 10\end{array}$

Reader's guide 13

1 A new perspective on urbanisation $\quad 15$

$\begin{array}{ll}\text { The global population increasingly lives in cities } & 16\end{array}$

$\begin{array}{ll}\text { City population and land area growth } & 20\end{array}$

A functional urban area or metropolitan area $\quad 22$

A comparison of national definitions and the two global definitions 25

Advantages of the new definitions $\quad 28$

References $\quad 29$

Annex 1.A. The degree of urbanisation level 1 and 2

Annex 1.B. Functional urban areas 34

Annex 1.C. The Global Human Settlement Population Grid (GHS-POP) 36

Annex 1.D. Population projections for the world 37

2 Life in cities, towns and semi-dense areas, and rural areas 39

Rural-city differences in quality of life $\quad 40$

Life satisfaction by degree of urbanisation $\quad 40$

Income, economic opportunities and employment $\quad 44$

$\begin{array}{ll}\text { Educational attainment and schooling } & 47\end{array}$

Health outcomes $\quad 49$

Access to services and utilities $\quad 55$

$\begin{array}{ll}\text { Crime, gender, violence, safety } & 60\end{array}$

Explaining differences in life satisfaction $\quad 62$

References $\quad 64$

$\begin{array}{ll}\text { Notes } & 67\end{array}$

Annex 2.A. Description of main variables $\quad 70$

Annex 2.B. The advantage of microdata: Addressing the sorting problem 71

Annex 2.C. Regression framework for micro data analysis $\quad 72$

3 Economic development and the metropolitan system 73

$\begin{array}{ll}\text { Economic development and the distribution of people over space } & 74\end{array}$

Regional economic development and the metropolitan system $\quad 81$

$\begin{array}{ll}\text { Migration as a mechanism of regional disparities } & 91\end{array}$ 
$\begin{array}{ll}\text { References } & 95\end{array}$

Notes $\quad 99$

Annex 3.A. Economic development and different measures of urbanisation 102

Annex 3.B. Economic development and metropolitan population by country size 104

Annex 3.C. Resource vs. non-resource exporters 106

$\begin{array}{ll}\text { Annex 3.D. Additional information and tables } & 108\end{array}$

4 The growth of metropolitan areas 111

Introduction 112

The emergence of 4000 new metropolitan areas $\quad 115$

Growth of the metropolitan population $\quad 118$

Shrinking metropolitan areas $\quad 123$

Determinants of metropolitan growth 127

References 132

Notes 133

Annex 4.A. Regression tables $\quad 135$

5 The shape of cities and sustainable development 137

Introduction 138

City densification and expansion $\quad 139$

Decentralisation $\quad 144$

Crowded metropolitan areas and sprawling metropolitan areas 149

Urban mobility and accessibility $\quad 153$

Access to high-frequency public transport varies strongly across cities $\quad 155$

Pollution, natural hazards and climate change $\quad 160$

References $\quad 165$

Notes $\quad 166$

$\begin{array}{lr}\text { Annex 5.A. Technical annex } & 167\end{array}$

\section{FIGURES}

Figure 1. Classification of countries in income classes $\quad 13$

Figure 2. World regions

Figure 1.1. World population shares by degree of urbanisation, 1975-2050 17

Figure 1.2. Changes in global population by degree of urbanisation, 1975-2050 18

Figure 1.3. Population by degree of urbanisation and World Bank income group, 2015

Figure 1.4. Cities by the period they emerged

Figure 1.5. Population density in cities by country income class and world region, 2015

Figure 1.6. Schema of the degree of urbanisation and FUA 23

Figure 1.7. World population in cities and commuting zones by World Bank income group, 2015

Figure 1.8. Population in metropolitan areas by size and income group, $2015 \quad 25$

Figure 1.9. Share of population in cities with at least 300000 inhabitants, $2015 \quad 26$

Figure 1.10. Population by degree of urbanisation and nationally defined urban areas by World Bank region, 2015

Figure 1.11. Population by degree of urbanisation by urban-rural national definition in 12 countries 28

Figure 2.1. Life satisfaction by degree of urbanisation, income group and gender 41

Figure 2.2. Difference between future and current life satisfaction 42

Figure 2.3. Life satisfaction and living standards by the size of metropolitan areas 43

Figure 2.4. Wage and income differences across the degree of urbanisation in Africa 45

Figure 2.5. Employment and self-employment by the degree of urbanisation and income level 46

Figure 2.6. Local conditions for starting a business $\quad 47$

Figure 2.7. Share of 16-year-olds with at least 8 years of schooling 48

Figure 2.8. Health problems by gender in cities, TSAs and rural areas $\quad 50$ 
Figure 2.9. Infant mortality, diarrhoea and DPT vaccination rates, by world regions and income classes

Figure 2.10. Relative changes (in percentage) in health outcomes, 2000-15, Sub-Saharan Africa and South

Asia

Figure 2.11. Distance as an impediment to medical services

Figure 2.12. Obesity and cough by region and degree of urbanisation

Figure 2.13. Use and regular access to the Internet 56

Figure 2.14. Share of individuals that have a mobile phone 56

Figure 2.15. Electricity and piped water across the degree of urbanisation 58

Figure 2.16. Access to safely managed drinking water across the degree of urbanisation 59

Figure 2.17. Theft and assault across the degree of urbanisation 60

Figure 2.18. Share of men and women feeling safe walking alone at night 61

Figure 2.19. Domestic violence by the degree of urbanisation 62

Figure 2.20. Regression analysis: Life satisfaction by degree of urbanisation 64

Figure 3.1. Economic development and population in metropolitan areas, 2015

Figure 3.2. As countries grow, the sectoral composition of the economy changes 78

Figure 3.3. Structural transformation and the metropolitan system in European Union and OECD countries, 2015

Figure 3.4. Economic development and the concentration of the metropolitan population 82

Figure 3.5. Income inequality and spatial concentration in developed countries 84

Figure 3.6. Income disparities between less and more metropolitan regions by stage of development 87

Figure 3.7. The share of metropolitan population and regional GDP per capita growth 88

Figure 3.8. Per capita income in metropolitan areas and their countries, 2015

Figure 3.9. Migration and the share of people in metropolitan areas 92

Figure 3.10. Human capital and migration by metropolitan population in regions 94

Figure 4.1. Share of metropolitan population by country income class 113

Figure 4.2. The share of the metropolitan area population by size and income in 2015

Figure 4.3. Total population growth rates and metropolitan area population growth rates by world region, 2000 and 2015

Figure 4.4. Age of metropolitan areas across income classes

115

Figure 4.6. Total fertility rates in cities, towns \& semi-dense areas, and rural areas

Figure 4.7. Growth of 20 largest metropolitan areas, 2000-15 122

Figure 4.8. Shrinking metropolitan areas across the world 124

Figure 4.9. Share of declining metropolitan areas relative to national population growth, 2000-15 125

Figure 4.10. Share of declining metropolitan areas by size and world region, 2000-15 126

Figure 4.11. Relationship between dispersion in metropolitan area growth rates and national population growth, 2000-15

Figure 4.12. Capitals grow faster than the national population in most world regions

Figure 4.13. Ratio of the population of the capital metropolitan area of a country relative to the largest noncapital metropolitan area

Figure 5.1. Population density of cities, 2015

Figure 5.2. Population density by city size and income, 1975-2015

Figure 5.3. Density by distance to the city centre by city size and by world region, 2015

Figure 5.4 Growth in city area by city size and income group, 1975-2015

Figure 5.5 Country income and importance of commuting zone, 2015

Figure 5.6 Population growth in cities and commuting zones in France, 2000-15

Figure 5.7. Built-up area per person in metropolitan areas, 2015

Figure 5.8. Difference in built-up area per person in metropolitan areas, 2000-15

Figure 5.9 Population within a $500 \mathrm{~m}$ walk to a public transport stop in selected cities in the world

Figure 5.10 Population by frequency of public transport departures in selected cities in the world

Figure 5.11. Accessible population, nearby population and public transport performance in selected cities in the world, 2019

Figure 5.12. Simulated public transport network length in 37 metropolitan areas, 2015 
Annex Figure 1.A.1. City, towns and semi-dense areas, and rural areas around Cape Town, South Africa 31 Annex Figure 1.A.2. Degree of urbanisation level 2 classification around Toulouse, France 33 Annex Figure 1.A.3. Population by degree of urbanisation level 2 and income group, 201533 Annex Figure 1.B.1. The metropolitan area of Medellin, Colombia 34 Annex Figure 3.A.1. Economic development and types of settlements, 2015 Annex Figure 3.B.1. Economic development and the geography of metropolitan areas by country size, 2015105 Annex Figure 3.C.1. Structural transformation and metropolitan population in developing countries 107 Annex Figure 3.C.2. The metropolitan system and manufacturing in resource-exporting and non-resource exporting developing countries Annex Figure 3.D.1. Per capita income in metropolitan areas relative to their countries, 2015

\section{TABLES}

Table 1.1. Sources of city population and area growth, percentage, 1975-2015 20

Table 1.2. Number of cities by country income group, 1975-2015 21

Table 4.1. Metropolitan areas size and population shares in 1990 and 2015

Table 4.2. Largest metropolitan areas of the world 121

Table 4.3. The largest metropolitan areas in 1975

Table 4.4. Shrinking metropolitan areas, 2000-15 123

Table 5.1. Sources of city population growth, 1975-2015 143

Table 5.2 Number of cities by income group, 1975-2015 143

Table 5.3. Metropolitan areas by growth or decline in the city and commuting zone, 2000-15 147

Table 5.4 Share of metropolitan areas by income group, built-up area per person and built-up area per person

change

Table 5.5 Share of metropolitan areas by built-up area per person levels, 2000, and change, 2000-15, by income group

Table 5.6. Cities with metro systems and their characteristics, 2018

Table 5.7 Metro system, ridership and access to a meto station in 12 selected cities, 2015

Table system, ridership and access to a metro station in 12 selected cities, 2015

Table 5.9. Top ten countries ranked by city population and city population share in the low elevation coastal zones, 2015

Annex Table 2.A.1. Main variables from Gallup World Poll

Annex Table 2.B.1. Differences in individual characteristics across the degree of urbanisation 71

Annex Table 2.C.1. Regression analysis: Life satisfaction by degree of urbanisation 72

Annex Table 3.C.1. Natural resources and the urban system, 2015

Annex Table 3.D.1. List of countries included in the regional dataset 108

Annex Table 4.A.1. Regression results on the determinants of metropolitan area size in 2015

Annex Table 4.A.2. Regression results on the determinants of metropolitan area growth between 2000 and 2015

\section{BOXES}

Box 1.1. The degree of urbanisation

Box 1.2. Why a global, people-based and internationally comparable definition of cities, towns and rural areas is needed

Box 1.3. Delineating metropolitan areas (aka functional urban areas) in the world

Box 1.4. Understanding national classifications of rural and urban

Box 2.1. Data for differences in quality of life by degree of urbanisation 44

Box 2.2. The effect of city status on the provision of utilities 59

Box 3.1. Agglomeration economies 77

Box 3.2. Income inequality and the concentration of the metropolitan population 83

Box 3.3. Economic growth and income convergence across regions 85

Box 3.4. Regional income according to share of the population in metropolitan areas 86 
Box 3.5. The economic performance of OECD metropolitan areas 89

Box 3.6. Human capital and regional development 93

Box 4.1. Large metropolitan areas versus small towns: Where to invest for greater poverty reduction? 116

Box 4.2. Fertility rates in cities in developing countries 120

Box 4.3. Policy options for managing smart decline 126

Box 5.1. Commuting zones grow faster than cities in France 148

Box 5.2. The GHS-BUILT multi-temporal classification of built-up areas 152

\section{Follow OECD Publications on:}

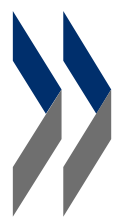

http://twitter.com/OECD_Pubs

http://www.facebook.com/OECDPublications

http://www.linkedin.com/groups/OECD-Publications-4645871

- http://www.youtube.com/oecdilibrary

http://www.oecd.org/oecddirect/

This book has...

Look for the StatLinks तiा st at the bottom of the tables or graphs in this book. To download the matching Excel ${ }^{\circledR}$ spreadsheet, just type the link into your Internet browser, starting with the https://doi.org prefix, or click on the link from the e-book edition. 


\section{Executive summary}

Cities are home to around half of the global population. Yet, definitions of what a city or a rural area is vary widely by country. Such differences hinder robust international comparisons and prevent accurate monitoring of the United Nation's Sustainable Development Goals (SDGs), as both are highly sensitive to the definitions of those areas. This report addresses this void and provides novel evidence on urbanisation throughout the world, using for the first time the definitions endorsed at the 2020 Statistical Commission of the United Nations.

The population living in cities, high-density places of at least 50000 inhabitants, has more than doubled over the last 40 years, going from 1.5 billion inhabitants in 1975 to 3.5 billion in 2015. It is projected to reach 5 billion and almost $55 \%$ of the world population by 2050 . According to the degree of urbanisation, which classifies the entire territory into three categories - cities, towns \& semi-dense areas, and rural areas - almost half the world's population (48\%) live in cities, a quarter live in rural areas $(24 \%)$ and the remainder live in towns \& semi-dense areas (28\%). By defining three types of areas, the Degree of Urbanisation captures the continuum between cities and rural areas and provides a more nuanced perspective than the traditional urban-rural dichotomy.

The report additionally uses a definition of metropolitan areas (aka functional urban areas), which consider cities together with their surrounding commuting zones to capture the full extent of a city's labour market. Metropolitan areas account for $54 \%$ of total world population, with commuting zones representing $17 \%$ of the overall metropolitan population, a share that rises to $31 \%$ in high-income countries

In using these two global definitions, this report presents a new perspective on urbanisation: it assesses quality of life along the urban-rural continuum; it examines the links between economic development and metropolitan areas; it describes the demographic growth (and decline) of metropolitan areas; and it shows how cities are both expanding and densifying, and how this affects sustainable development. Finally, the report demonstrates that towns \& semi-dense areas have distinct socio-economic properties, falling between those of a city and a rural area in numerous ways.

\section{Cities offer, on average, a higher quality of life}

- Overall, residents in cities record a higher life satisfaction than people in towns \& semi-dense areas or rural areas. Several well-being dimensions seem to drive a higher quality of life in cities. City residents benefit from higher incomes, greater employment opportunities, larger service provision and better access to modern technology. Similarly, educational attainment is considerably higher in cities than in rural areas, with towns \& semi-dense areas falling in between. These differences are most striking in Latin America, Southeast Asia and Sub-Saharan Africa, where the shares of individuals with at least 8 years of education are more than 20 percentage points higher in cities.

- While cities offer better conditions in many dimensions of life, there are notable exceptions. City residents are more exposed to crime, violence and air pollution than residents elsewhere. 
Furthermore, health problems such as blood pressure, asthma and diabetes are most pervasive in cities.

\section{Economic development and the rise of metropolitan areas go hand in hand}

- More developed countries have larger shares of people living in metropolitan areas, especially in the largest metropolitan areas. The population share living in metropolitan areas above 1 million is roughly four times higher in high-income $(47 \%)$ than in low-income countries $(12 \%)$. In advanced economies, urbanisation was historically linked to a structural shift from agriculture to manufacturing. More recently, urbanisation in these countries has typically occurred in tandem with a transition to the service sector. While Asia mainly urbanised through the traditional process of industrialisation, in many less advanced countries in Africa, Latin America and the Middle East, urbanisation has taken a different path, often backed by large natural resource rents.

- Higher levels of economic development not only correspond to larger metropolitan areas, but also to a different distribution of the metropolitan population within countries. In middle-income countries, a few large metro areas concentrate a high share of the metropolitan population. In contrast, the metropolitan population is more spread out across space in high-income countries. These patterns seem to be connected to the evolution of regional economic disparities, which are highest in middle-income countries.

\section{Globally, large metropolitan areas grow fastest while many mid-sized ones shrink}

- The global population is increasingly concentrated in large metropolitan areas. Metropolitan areas with more than 5 million inhabitants in 1990 experienced the fastest population growth, outpacing metropolitan areas with less than 1 million inhabitants by one percentage point per year. Since 1990, the number of metropolitan areas with more than 5 million inhabitants has also doubled and, in this context, 10 new "megacities" (metropolitan areas with more than 10 million inhabitants) have emerged, primarily in Asia and Sub-Saharan Africa.

- Population growth has not been limited to large metropolitan areas, however. In the developing world, many towns have grown rapidly in a context of national population growth, and breached the 50000 inhabitant threshold, thereby becoming cities. As a result, around 4000 new metropolitan areas emerged between 1975 and 2015. This trend was particularly strong in lowincome countries, where half of metropolitan areas that existed in 2015 had been towns in 1990 .

- Notwithstanding a widespread growth of metropolitan areas, globally, the population of one-fifth of metropolitan areas has been shrinking since 2000. Projections suggest that by 2050 the population of $30 \%$ of metropolitan areas will be shrinking. Most of the currently shrinking metropolitan areas are located in East Asia and Europe where the national population is growing slowly or shrinking. Metropolitan areas with less than a million inhabitants in East Asia and Europe are the most vulnerable to population loss, with over one-third of them already declining since 2000 . City decline raises new challenges as policy makers need to ensure that public services such as education or health remain accessible to residents in a situation of structurally decreasing budgets.

\section{The changing shape of cities affects sustainable development}

- The rapid population growth of cities over the past 40 years occurred through different channels. Overall, the densification of existing cities accounted for the majority of population growth, followed by spatial expansion. As a result, most cities have become denser over time. Within metropolitan 
areas, however, population growth has typically been faster in commuting zones than in the city itself, which can create planning challenges especially if that development is spatially dispersed.

- Virtually all metropolitan areas in low-income countries lack sufficient infrastructure and buildings. Moreover, in one out of four of these metropolitan areas, the construction of infrastructure and buildings fails to keep up with population growth, exacerbating already high levels of crowding and congestion. Most metropolitan areas in high-income countries, in contrast, have high levels of infrastructure, which in a context of population decline can easily turn into more than sufficient infrastructure. Furthermore, construction outpaces population growth in half of these metropolitan areas; in the case of low-density spatial expansion of larger metropolitan areas, this is likely to lead to high infrastructure costs. More generally, to promote public transport and to reduce pollution and congestion, some cities will need to expand their public transport networks, while others need to increase population densities, especially around public transport stops.

- Many city dwellers are exposed to high levels of air pollution, resulting in a considerable number of premature deaths each year and also higher COVID-19 mortality rates. Many cities are also highly exposed to floods and storm surges, with one in five city residents living in an area that would be submerged in a big flood and one in seven exposed to storm surges. Climate change is likely to increase the size and frequency of floods and storm surges. As a result, the material damage and the loss of life in cities due to floods and storms will balloon if no action is taken. A key challenge for cities in the next decades will be how to reduce air pollution, limit exposure to natural hazards and transition to a low-carbon economy. 


\section{Reader's guide}

This report uses two classifications of countries around the world. It makes use of the World Bank income classes that categorise economies into high-income, upper middle-income, lower middle-income, and lowincome countries. Countries with a gross national income (GNI) per capita of $\$ 1,025$ or less in 2018 are considered as low-income. Lower middle-income countries have a GNI per capita between $\$ 1,026$ and $\$ 3,995$. Upper middle-income countries have GNI per capita between $\$ 3,996$ and $\$ 12,375$. Finally, highincome countries have a GNI per capita of $\$ 12,376$ or more. Figure 1 illustrates how countries are categorised according to this classification.

Figure 1. Classification of countries in income classes

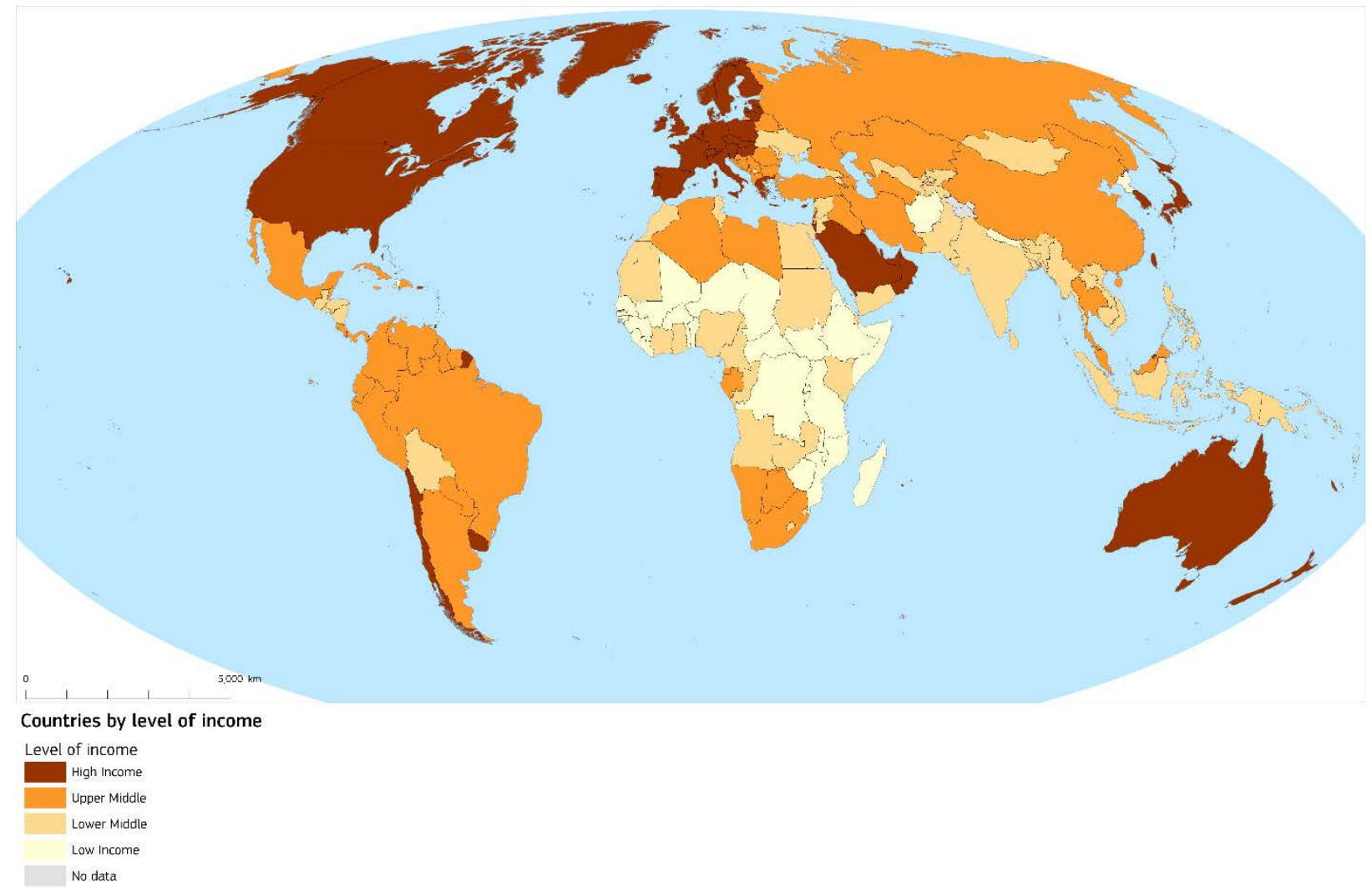

Source: Produced by EC and OECD based on the classification of the World Bank.

Additionally, the report presents evidence for world regions. It uses the World Bank regions, which consists of seven world regions: East Asia and the Pacific, Europe and Central Asia, Latin America and the Carribean, Middle East and North Africa, North America, South Asia, and Sub-Saharan Africa. Figure 2 presents those seven world regions. 
Figure 2. World regions

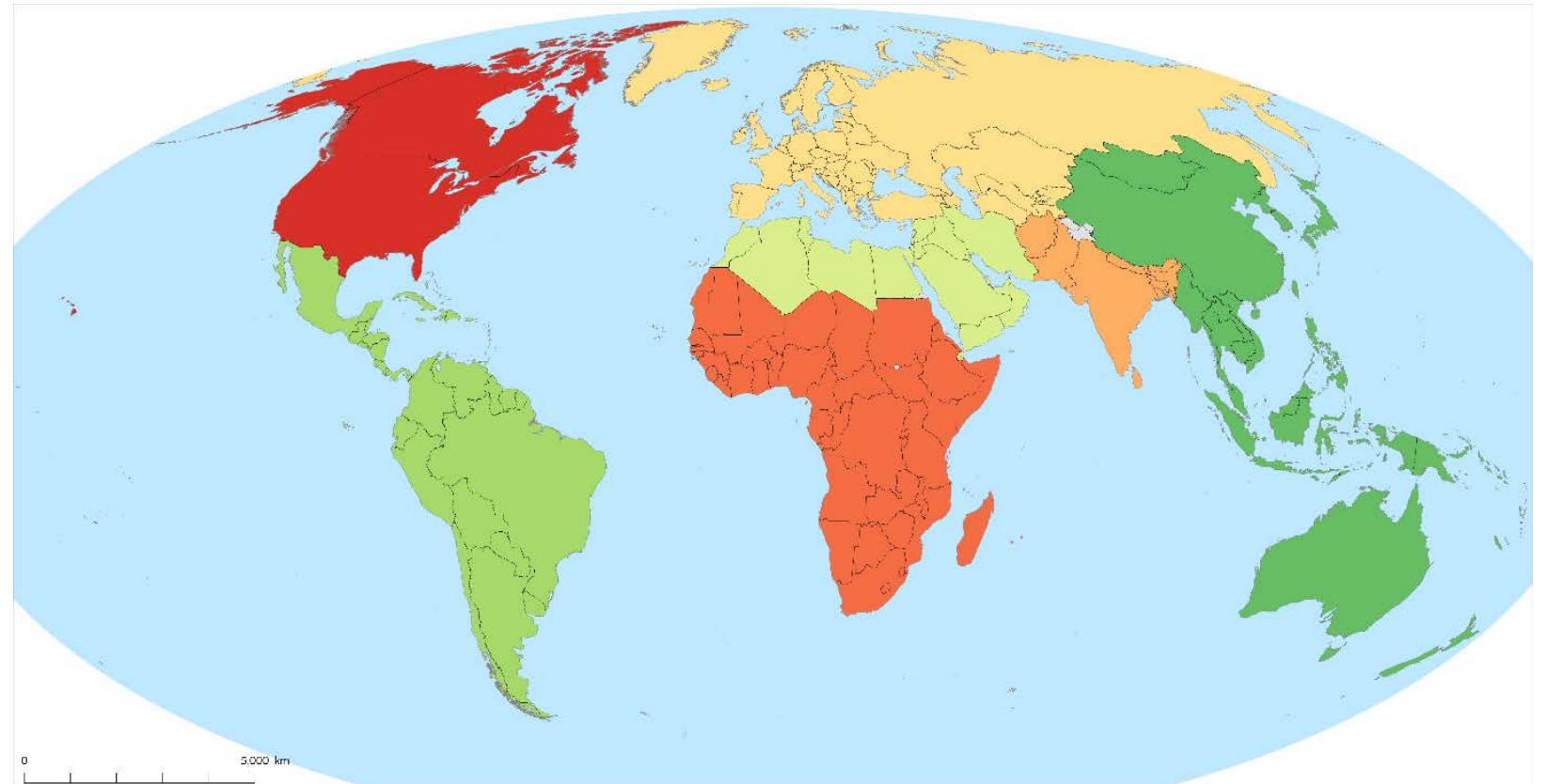

Countries by World Bank region

World Bank regions

$$
\begin{array}{l|l|l|}
\hline & \text { Sub-Saharan Africa } \\
\text { North America } & \text { South Asia } \\
\hline \text { Latin America and the Caribbean } & & \text { East Asia and Pacific } \\
\text { Europe and Central Asia } & \text { Disputed area } \\
\hline \text { Middle East and North Africa } &
\end{array}
$$

Source: Produced by EC and OECD based on the classification of the World Bank. 


\section{A new perspective on urbanisation}

This chapter presents novel findings on the number of people living in cities, towns and semi-dense areas, rural areas and metropolitan areas across the world. Furthermore, it illustrates how the population shares of those areas have changed over the last 40 years and how they are projected to change until 2050. This new perspective of urbanisation is based on the application to the entire world of two new, globally consistent definitions, the degree of urbanisation and the functional urban area. These two new definitions are also presented in the chapter. 


\section{Key messages}

- The population living in cities with more than 50000 inhabitants has more than doubled over the last 40 years, going from 1.5 billion in 1975 to 3.5 billion in 2015. It is projected to reach 5 billion by 2050 .

- The growth of this city population has occurred in three ways. One-quarter of this growth was due to the doubling of the number of cities with more than 50000 inhabitants from approximately 5000 to 10000 . Half of the growth occurred through densification within original city boundaries. The remaining quarter was due to the spatial expansion of existing cities, which almost doubled in area.

- As a result of these developments, the overall population density of cities has increased somewhat over the last 40 years. There remain, however, large differences in population densities, both by geographical world region and by level of development. For instance, the average population density of cities in low-income countries is four times higher than in high-income countries.

- Over the last 40 years, the population share in cities has increased from $37 \%$ to $48 \%$, while the population share in towns and semi-dense areas as well as rural areas has dropped. However, strong overall population growth has ensured that the overall level of the population has increased in all types of areas.

- Low-income countries have the lowest population share in cities and the highest in rural areas. The link between economic development and the population share in metropolitan areas (cities and their commuting zone) is even stronger than for cities. Only $33 \%$ of the population in low-income countries lives in a metropolitan area compared to $70 \%$ of the population of high-income countries. The difference is particularly striking for metropolitan areas of at least 1 million inhabitants. In low-income countries, only $12 \%$ of the population lives in such large metropolitan areas, while in high-income countries it is $47 \%$.

- The novel findings of this report are based on two new definitions, jointly developed by six international organisations and endorsed by the United Nations (UN) Statistical Commission in March 2020. These new definitions remedy a situation in which the lack of a global definition of cities, urban and rural areas greatly reduced the reliability of international comparisons; the definitions are meant to complement and not replace national definitions.

- The first definition, the degree of urbanisation, captures the urban-rural continuum. It classifies the entire territory of a country into cities, towns and semi-dense areas, and rural areas according to population size and density. The second definition, the functional urban area or metropolitan area, captures the full extent of a city's labour market by adding a commuting zone to each city.

- By relying on these two global harmonised definitions, this report provides a new perspective on urbanisation and new evidence on the shape and trends of metropolitan areas, cities, towns \& semidense areas and rural areas across the world.

\section{The global population increasingly lives in cities}

In $1975,37 \%$ of the world's population lived in cities (Figure 1.1). This share grew to $48 \%$ in 2015 . It is projected to further increase to $55 \%$ by 2050 . This shows that urbanisation is slowing down. Up to 2015 , the city population share increased by almost 3 percentage points in a decade, while up to 2050 it would be less than 2 percentage points.

The rural population share has been shrinking, from $30 \%$ in 1975 to $24 \%$ in 2015 . The projection indicates this reduction would also slow down. Up to 2015, rural population shares dropped by almost 2 percentage points per decade, while afterwards, this is likely to be less than 1 . The population in towns and semi- 
dense areas lost 1 percentage point per decade between 1975 and 2015 is projected to continue to do so up to 2050.

Figure 1.1. World population shares by degree of urbanisation, 1975-2050

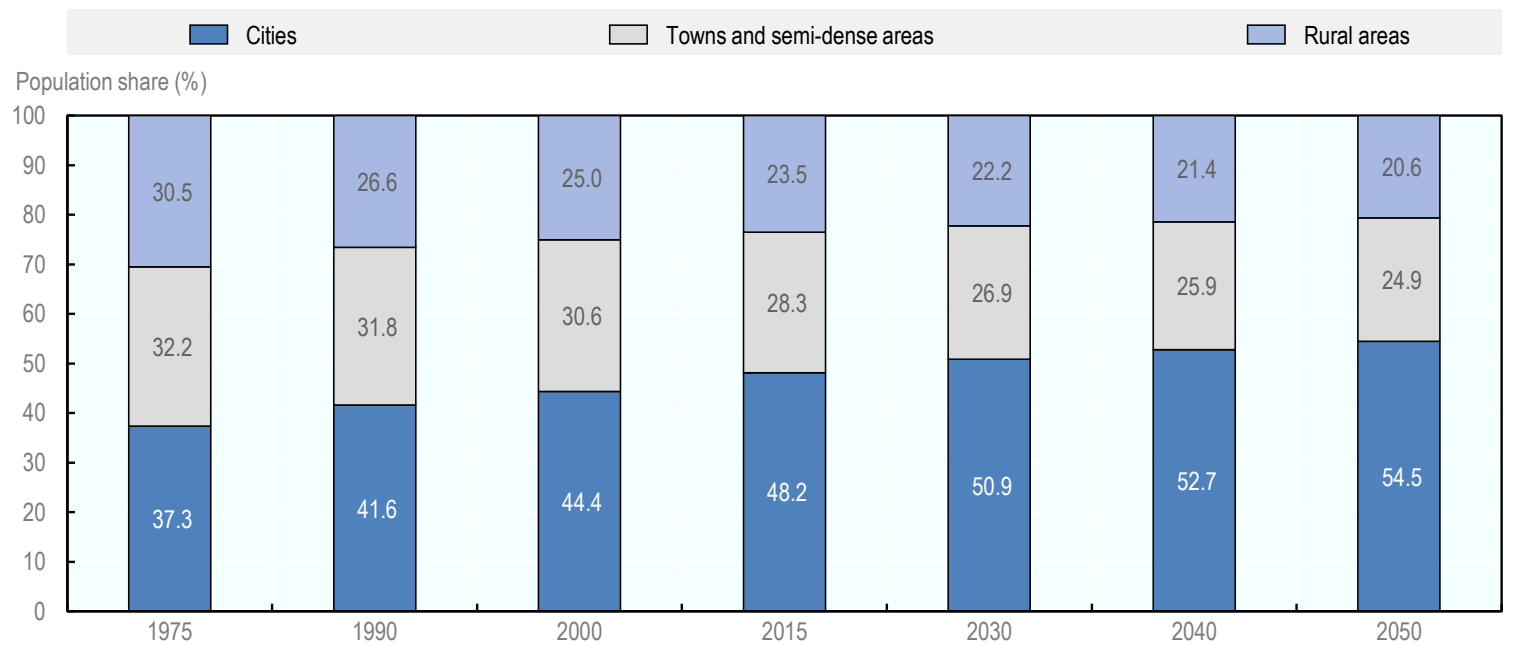

Source: Florczyk, A. et al. (2019[1]), GHSL Data Package 2019 (database), http://dx.doi.org/10.2760/06297; Jones, B. et al. (forthcoming[2]), Projecting Global Population Grids to 2100, Publications Office of the European Union.

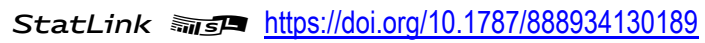

\section{Box 1.1. The degree of urbanisation}

This report offers novel findings on changes in urbanisation across the world. The degree of urbanisation (see Annex 1.A for a comprehensive definition) is applied to a global estimated population grid for the years 1975, 1990, 2000 and 2015 (see Annex 1.C) and projections up to 2050 (see Annex 1.D). This allows the report to show the trends in urbanisation over 75 years with unprecedented international comparability.

The degree of urbanisation was designed to create a simple and neutral method that could be applied in every country in the world. It relies primarily on population size and density thresholds applied to a population grid with cells of 1 by $1 \mathrm{~km}$. Roughly speaking:

1. Cities consist of contiguous grid cells that have a density of at least 1500 inhabitants per $\mathrm{km}^{2}$ or are at least $50 \%$ built up. They must have a population of at least 50000 .

2. Towns and semi-dense areas consist of contiguous grid cells with a density of at least 300 inhabitants per $\mathrm{km}^{2}$ and are at least $3 \%$ built up. They must have a total population of at least 5000.

3. Rural areas are cells that do not belong to a city or a town and semi-dense area. Most of these have a density below 300 inhabitants per $\mathrm{km}^{2}$.

The change in population shares, however, does not show how the total population changed. Global population has been changing rapidly. It increased from 4 billion in 1975 to 7.3 billion in 2015 and is projected to reach 9.1 billion in 2050. Between 1975 and 2015, the total population in cities, therefore, more than doubled (Figure 1.1) from 1.5 billion to 3.5 billion. This increase is projected to continue with a further increase to 5 billion by 2050 . 
The reducing population shares in rural areas and towns and semi-dense areas obscures that the total population in these areas is not shrinking. Population in towns and semi-dense areas increased from 1.3 billion to 2.1 billion between 1975 and 2015 and is projected to reach 2.3 billion by 2050 . Rural areas also experienced population growth between 1975 and 2015 from 1.2 billion to 1.7 billion, which is projected to increase to 1.9 billion by 2050 . Figure 1.2 shows that, while over the next decades, the population outside cities will be increasing, it will do so at a slowing rate. Population growth in cities is also slowing down but less noticeably so.

Figure 1.2. Changes in global population by degree of urbanisation, 1975-2050

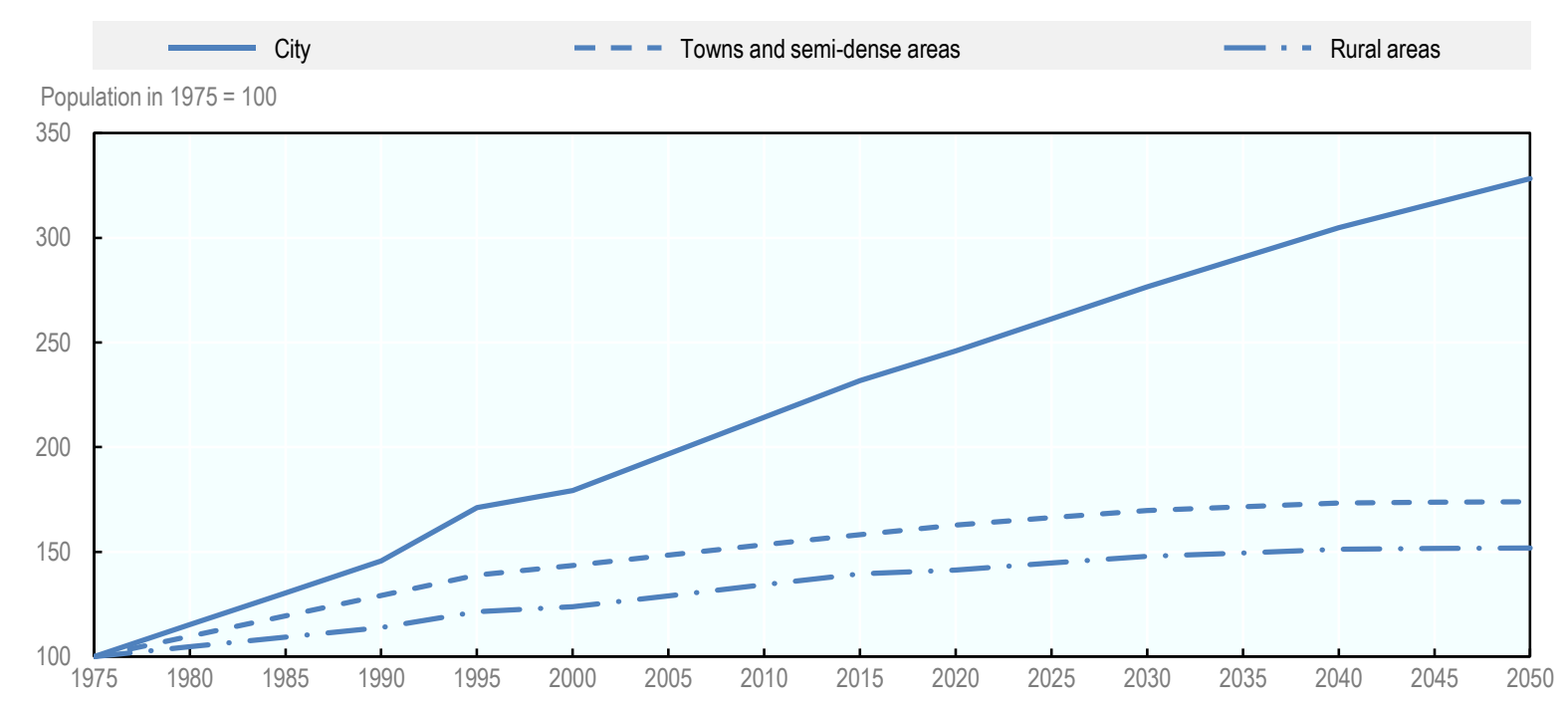

Source: Florczyk, A. et al. (2019[1]), GHSL Data Package 2019 (database), http://dx.doi.org/10.2760/06297; Jones, B. et al. (forthcoming[2]), Projecting Global Population Grids to 2100, Publications Office of the European Union.

StatLink ज्ञाज https://doi.org/10.1787/888934130208

The UN publishes population figures for urban and rural areas from 1950 up to 2100 in the World Urbanization Prospects (UN, 2018[3]). These figures show a considerably faster increase in urban population. The UN data shows the urban population quadrupling between 1975 and 2050, while this report estimates that the city population would triple over that period and the population in towns and semi-dense areas (which are considered urban by many national definitions) would increase by only $75 \%$. Finally, the UN data show an increase in the rural population of only by $20 \%$ over the $1975-2015$ period and rural population declining from 2025 onwards. In contrast, this report shows an increase of $50 \%$ and no population decline for the $2015-50$ period.

Box 1.2. Why a global, people-based and internationally comparable definition of cities, towns and rural areas is needed

The pursuit of the UN Sustainable Development Goals (SDGs) has so far been hampered by limited international comparability. While a detailed methodology has been provided for SDG indicators that should be collected for cities, urban and rural areas, no clear guidelines for the delineation of these areas exist. This lack of a harmonised definition reduces international comparability. That is why the European Union, the Food and Agriculture Organization of the United Nations (FAO), the International Labour Office (ILO), the OECD, UN-Habitat and the World Bank have joined forces to develop a global, 
people-based definition of cities, towns and semi-dense areas, and rural areas. The two resulting methods, the degree of urbanisation and the functional urban area, were endorsed by the UN Statistical Commission in March 2020. This report presents the first global analysis using these two definitions.

The degree of urbanisation was designed to reflect the urban-rural continuum and proposes three classes instead of only two. The three classes are: i) cities; ii) towns and semi-dense areas; and iii) rural areas. By using three classes, areas that are neither cities nor rural get their own category. This helps to create a global consensus, as countries disagree on how to split settlements into urban and rural ones. Most countries classify towns as urban, but some classify them as rural. By grouping these medium-sized settlements into an intermediate category (towns and semi-dense areas) we acknowledge the intermediate nature of these settlements.

The population share by degree of urbanisation differs by income group (as defined by the World Bank income categories in 2015). Low-income countries have the lowest population share in cities and the highest in rural areas (Figure 1.3). The difference between the middle- and high-income countries is small, but this reflects a change in the type of urbanisation. As countries develop, commuting to the city from the surrounding area becomes more common. This allows the labour market of a city to grow without the population of the city itself to grow. Including this commuting zone (see below) shows that high-income countries have a significantly higher share of the population in cities and their commuting zones than middle-income countries.

Figure 1.3. Population by degree of urbanisation and World Bank income group, 2015

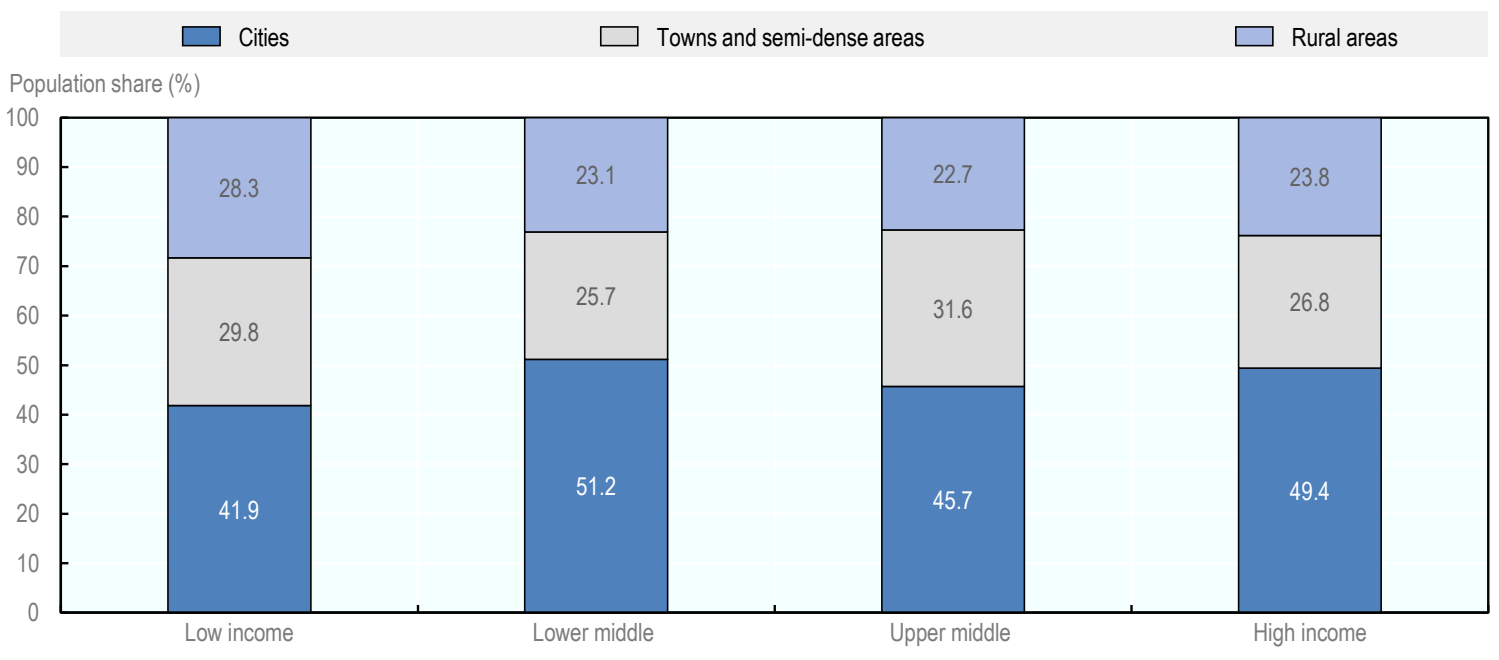

Source: Florczyk, A. et al. (2019[1]), GHSL Data Package 2019 (database), http://dx.doi.org/10.2760/06297.

StatLink *illst https://doi.org/10.1787/888934130227

\section{Cities and towns expand to accommodate more people}

Globally, the vast majority of the population lives on a tiny fraction of land. As a consequence, the distribution of land across the degrees of urbanisation is highly skewed. Almost all land is classified as rural. In 1975, rural areas covered $99.2 \%$ of the world's land. Over the next 40 years, this declined slightly to $98.5 \%$. Projections show that this would only drop to $98.3 \%$ by 2050 . 
By contrast, cities occupied just $0.2 \%$ of the total land area in 1975 . The increase of city residents by 2 billion meant that cities needed more space for their residents to live, work and play. As a result, the share of land covered by cities increased to $0.5 \%$ in 2015 . Projections indicate that this would increase at a slower rate reaching $0.7 \%$ in 2050 .

Similar to cities, the total population in towns and semi-dense areas has increased significantly between 1975 and 2015. As these people also needed space, the land area of towns and semi-dense areas doubled from $0.5 \%$ to $1 \%$. Projections indicate that this area would barely increase by 2050 .

\section{City population and land area growth}

By using a consistent city definition over time, this report can identify three sources of city population growth: i) towns growing into cities; ii) city expansion; and iii) city densification (Table 1.1). Towns can grow into cities (as defined by the degree of urbanisation) by reaching a population of at least 50000 inhabitants. City expansion occurs through the building of new dense neighbourhoods at the edge of the city or the densification of existing suburbs. City densification means that the population grows within the initial boundary of the city.

Table 1.1. Sources of city population and area growth, percentage, 1975-2015

\begin{tabular}{l|c|c|c|c}
\hline & Towns growing into cities & City expansion & City densification & Total \\
\hline \multicolumn{5}{|c|}{ Population change } \\
\hline $1975-90$ & 23.9 & 26.4 & 49.7 & 100 \\
\hline $1990-2000$ & 18.3 & 29.3 & 52.4 & 100 \\
\hline $2000-15$ & 15.5 & 24.8 & 59.7 & 100 \\
\hline \multicolumn{5}{|c|}{ Area change } \\
\hline $1975-90$ & 30.5 & 69.5 & 0.0 & 100 \\
\hline $1990-2000$ & 22.8 & 77.2 & 0.0 & 100 \\
\hline $2000-15$ & 22.6 & 77.4 & 0 & 100 \\
\hline Source: EC and OECD calculations & based & on Florczyk, A. et al. (2019[1]), GHSL Data Package 2019 (database), \\
http://dx.doi.org/10.2760/06297. & & &
\end{tabular}

\section{Five thousand towns grew into a city}

From 1975-90, towns (see Annex 1.A for an explanation) growing into cities accounted for a quarter of the city population growth. ${ }^{1}$ Over time, as total population growth slowed, this has become a less important source of city population growth. Between 2000 and 2015, it only accounted for $16 \%$ of that growth. In terms of area growth, the emergence of new cities only accounted for around a quarter of the new land covered by a city.

Towns growing into cities has a bigger impact on the number of cities than on city population. Between 1975 and 2015, the number of cities doubled from approximately 5000 to 10000 (Figure 1.4). The growth in the number of cities is linked to the income of a country. Low-income countries saw their number of cities triple between 1975 and 2015, compared to a doubling in middle-income countries and an increase of 50\% in high-income countries (Table 1.2). The 5000 cities that emerged since 1975 had half a billion residents by 2015.

City expansion has accounted for roughly a quarter of city population growth (Table 1.1) but it has accounted for two-thirds of new land becoming part of a city. In part, city expansions account for such a 
large share of new city land because city densification does not require any land to be converted. City expansion means a new area that will require investments to build new infrastructure and to provide public services. The high speed of city expansion in low-income countries is especially challenging as these countries need to invest large amounts quickly merely to keep providing the same level of service in their growing cities.

Figure 1.4. Cities by the period they emerged

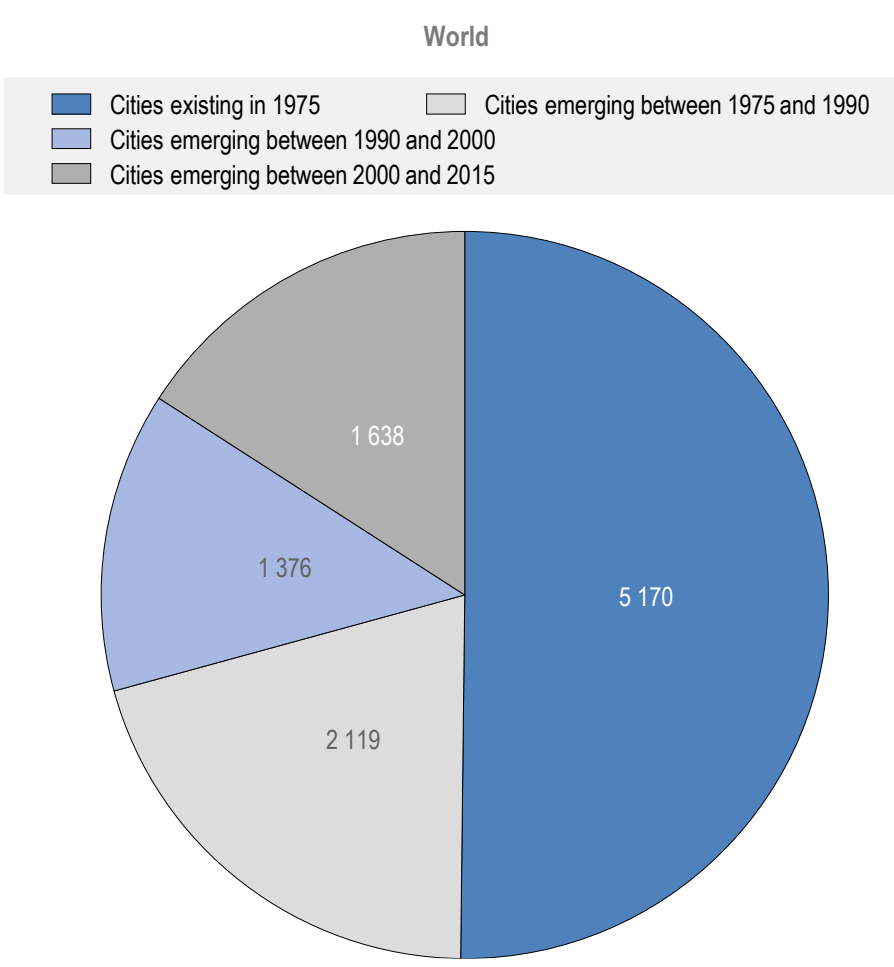

Source: Calculated by EC, based on the Urban Centre Database GHS-UCDB R2019A, Florczyk, A. et al. (2019[1]), GHSL Data Package 2019 (database), http://dx.doi.org/10.2760/06297.

Table 1.2. Number of cities by country income group, 1975-2015

\begin{tabular}{|c|c|c|c|c|c|}
\hline \multirow{2}{*}{ Income group } & \multicolumn{4}{|c|}{ Number of cities } & \multirow[b]{2}{*}{$2015 / 1975$} \\
\hline & 1975 & 1990 & 2000 & 2015 & \\
\hline Low & 326 & 518 & 703 & 942 & 2.9 \\
\hline Lower middle & 2025 & 2981 & 3577 & 4266 & 2.1 \\
\hline Upper middle & 1908 & 2740 & 3201 & 3704 & 1.9 \\
\hline High & 911 & 1050 & 1184 & 1391 & 1.5 \\
\hline World & 5170 & 7289 & 8665 & 10303 & 2.0 \\
\hline
\end{tabular}

Note: The row 2015/1975 displays the ratio of the number of cities in the 2 time periods.

Source: Calculated by EC, based on Urban Centre Database GHS-UCDB R2019A (Florczyk et al., 2019[4]). 


\section{City densification is the main source of city population growth}

City densification has accounted for $50 \%$ to $60 \%$ of the global city population growth (Table 1.1). City densification - increases in the density within the original boundary of the city - by definition does not require any additional land. However, additional investments are still needed to provide more housing, more places to work and more services.

Globally, the combination of city expansion and city densification has led to a slight increase in the average population density of cities. Nevertheless, large discrepancies remain in the population density of cities between income groups and across world regions (Figure 1.5). Cities in low-income countries are four times denser than those in high-income countries. The population density of cities in North America is less than 2000 inhabitants, while in Sub-Saharan Africa and South Asia it is around 8000 inhabitants per $\mathrm{km}^{2}$.

Figure 1.5. Population density in cities by country income class and world region, 2015

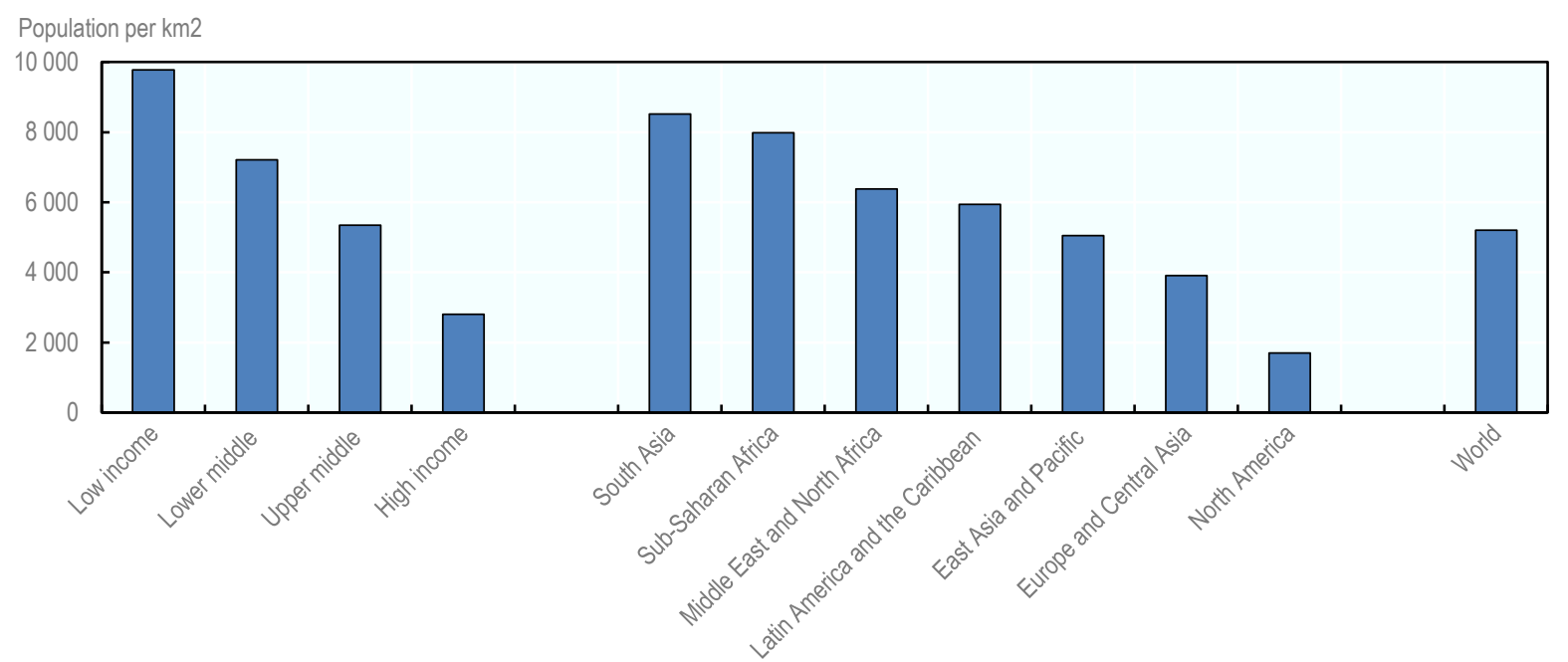

Source: Calculated by EC, based on the Urban Centre Database GHS-UCDB R2019A, Florczyk, A. et al. (2019[1]), GHSL Data Package 2019 (database), http://dx.doi.org/10.2760/06297.

\section{A functional urban area or metropolitan area}

Several national statistical offices complement their urban and rural area definition with a metropolitan area definition. Metropolitan areas generally encompass cities together with their adjacent communities that have a high degree of economic and social integration with the city. These adjacent communities represent a commuter belt that generates a daily flow of people into the city and back. The concept of metropolitan areas is often referred to as "functional" because it captures the full economic function of a city. A metropolitan area definition is particularly useful to inform policymaking in a number of domains, including transport, economic development and planning.

In this report, metropolitan areas are delineated in all countries in the world using the same definition (see Box 1.3). Metropolitan areas build on the degree of urbanisation as they consist of cities (as defined in the degree of urbanisation) and their surrounding areas that are connected to the city in terms of labour market interactions (commuting zones). Differently from the degree of urbanisation, the functional urban area (FUA) does not encompass the entire national territory and focuses on cities and their economic area of influence. 


\section{Box 1.3. Delineating metropolitan areas (aka functional urban areas) in the world}

The metropolitan areas used in this report are approximations at the grid level of the functional urban areas (FUAs) definition developed by the European Union and the OECD (Dijkstra, Poelman and Veneri, 2019 $\left.9_{[5]}\right)$. This definition specifies that an FUA consists of a cluster of local administrative units that are either part of a city or the commuting zones of that city. Local units in the commuting zones have at least $15 \%$ of their working population commuting to the city for work.

Because commuting data and local administrative unit boundaries are not available for most countries, this report relies on estimated metropolitan areas using globally available gridded data. The method delineates about 9000 estimated FUAs for at least 50000 inhabitants worldwide (Moreno-Monroy, Schiavina and Veneri, 2020[6]). For more precise information please see Annex 1.B.

The residential population of an administratively defined city does not take into account the people who work in the city but those who live in the surrounding commuting zone. This problem is particularly prominent in high-income countries, where commuting is quite common. To reflect the full extent of its labour market, the FUA consists of both the city and its commuting zone. Through commuting, this definition incorporates the economic function of a city. The area defined by commuting is also likely to be used for many other functions such as education, healthcare and transport. That is why it is called a functional urban area. This concept is often referred to as a metropolitan area.

Several countries have one definition for urban and rural areas and another for their metropolitan areas. This report uses the same dual approach and two definitions, one for capturing the urban-rural continuum - the degree of urbanisation -, and one for metropolitan areas, the FUA. These two definitions are linked because they use the same definition of a city (see Figure 1.6).

\section{Figure 1.6. Schema of the degree of urbanisation and FUA}

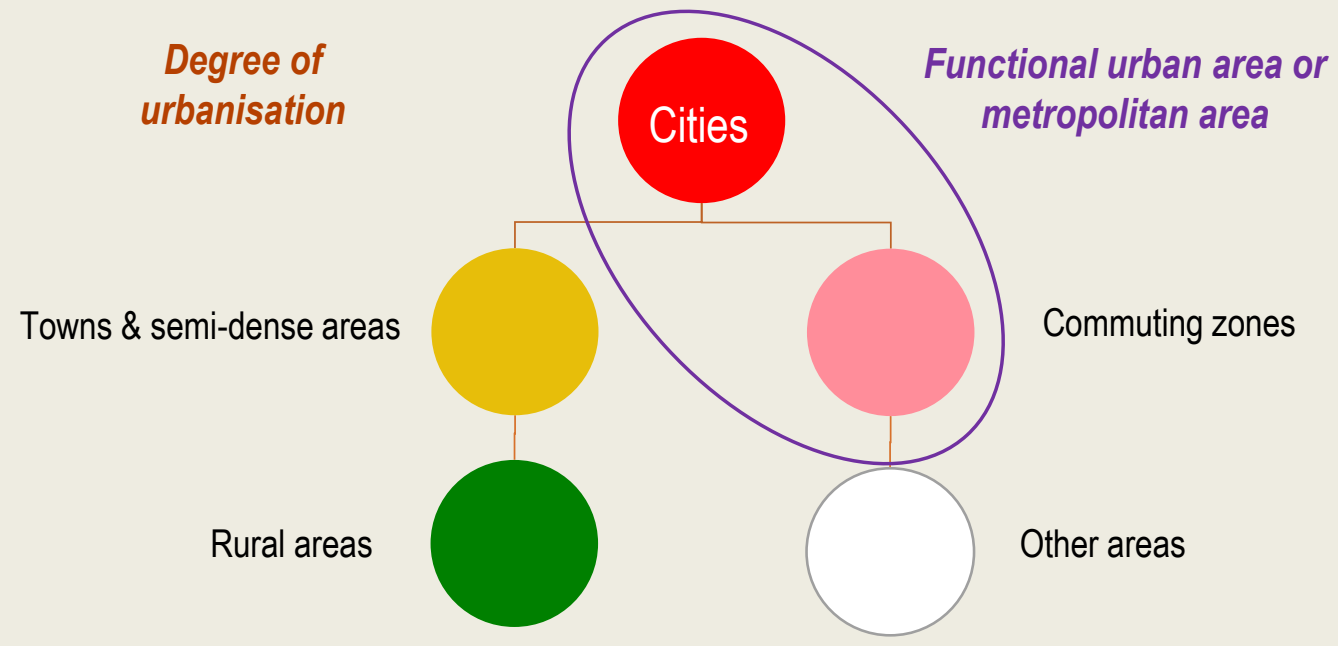

Source: Figure produced by EC and OECD, 2020; Dijkstra, L., H. Poelman and P. Veneri (2019[5]), "The EU-OECD definition of a functional urban area", https://doi.org/10.1787/d58cb34d-en (accessed on 21 October 2019); Moreno-Monroy, A., M. Schiavina and P. Veneri (2020[6]), "Metropolitan areas in the world. Delineation and population trends", http://dx.doi.org/10.1016/j.jue.2020.103242. 


\section{In richer countries, more people live in metropolitan areas and especially in their commuting zones}

The concentration of people in metropolitan areas is linked to economic development. The population share in metropolitan areas in high-income countries at $71 \%$ is more than double that of low-income countries (Figure 1.7). The difference in the population share in commuting zones is even bigger: $21 \%$ in high- and only $1 \%$ in low-income countries. Middle-income countries are positioned in between, with around $50 \%$ of their population in metropolitan areas and between $5 \%-10 \%$ in a commuting zone.

Figure 1.7. World population in cities and commuting zones by World Bank income group, 2015

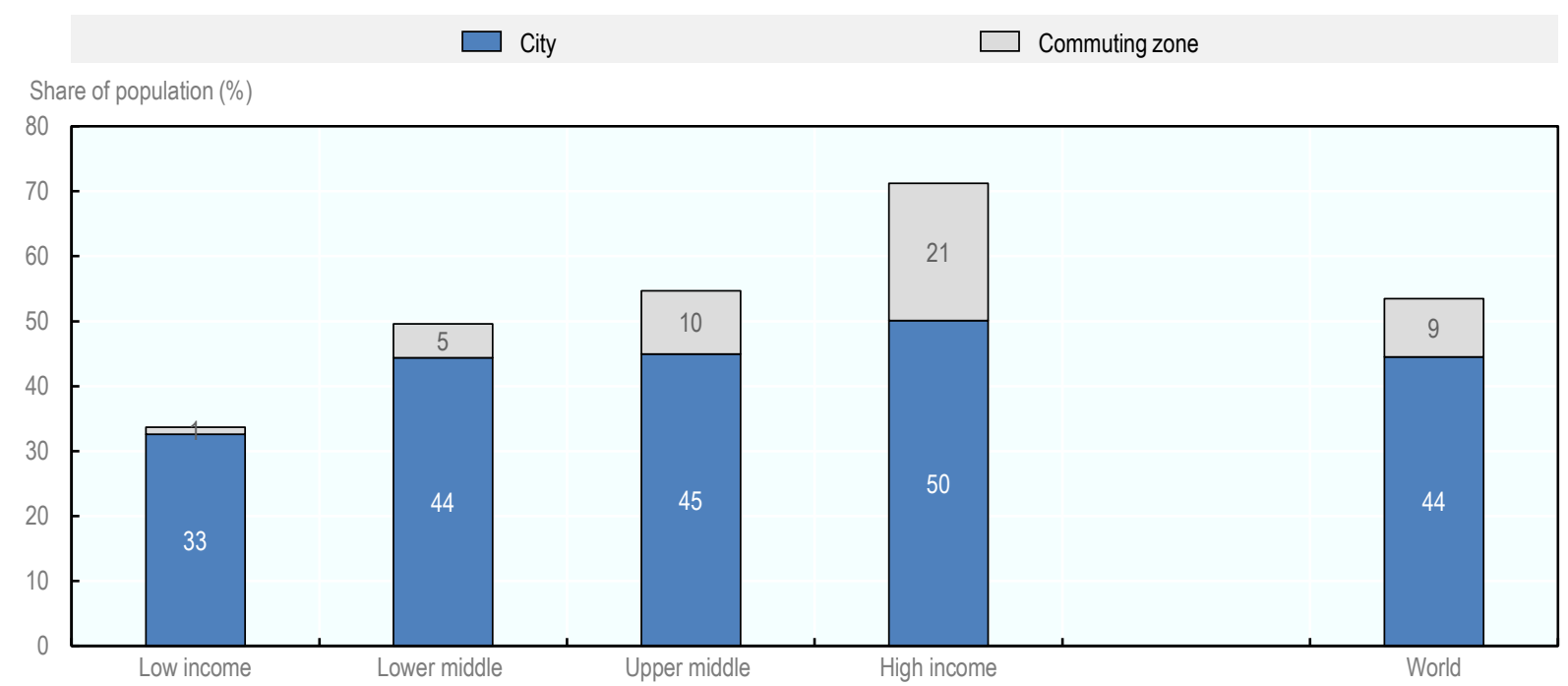

Source: Calculated by EC, based on GHSL Data Package 2019, Florczyk, A. et al. (2019[1]), GHSL Data Package 2019 (database), http://dx.doi.org/10.2760/06297 and the boundaries of Moreno-Monroy, A., M. Schiavina and P. Veneri (2020[6]), "Metropolitan areas in the world. Delineation and population trends", http://dx.doi.org/10.1016/j.jue.2020.103242.

\section{More people live in large metropolitan areas in rich countries}

Low-income countries have a high share of their population in small metropolitan (metro) areas (under 250000 inhabitants) and a low share in very large metropolitan areas (at least 5 million inhabitants) (Figure 1.8). In contrast, high-income countries concentrate very large shares of their population in large and very large metropolitan areas but lower shares in small metropolitan areas. The two middle-income groups occupy an in-between position: each of the four size classes of the metro areas have approximately the same population share.

In the middle- and high-income countries, the population share in commuting zones of metro areas with between 250000 and 5 million inhabitants is higher than for metropolitan areas of more than 5 million. In general, one would expect bigger cities to have bigger commuting zones. Cities with more than 5 million inhabitants, however, may be so big and so time-consuming to travel into that people are less willing to live in a commuting zone as this would further add time to their commute. 
Figure 1.8. Population in metropolitan areas by size and income group, 2015

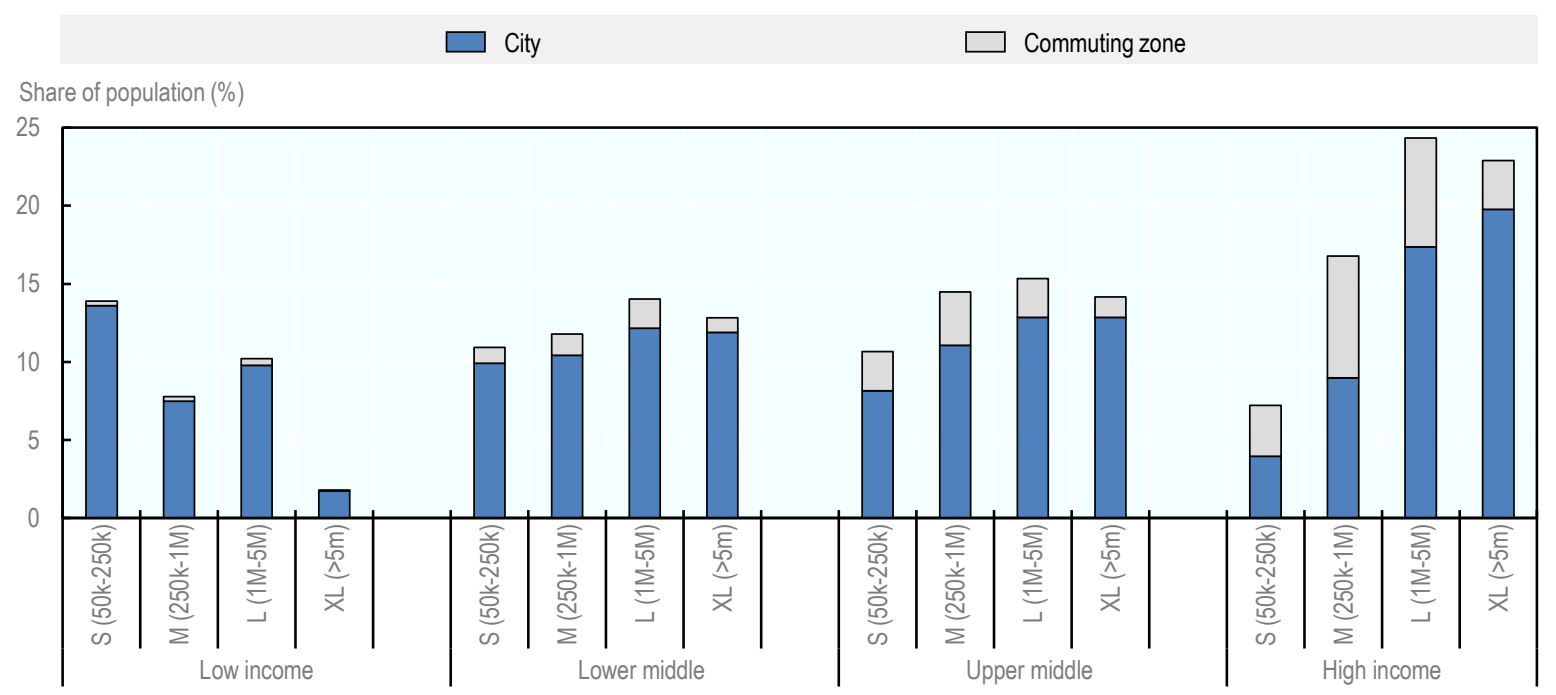

Source: Calculated by EC, based on GHSL Data Package 2019, Florczyk, A. et al. (2019 $\left.{ }_{[1]}\right)$, GHSL Data Package 2019 (database), http://dx.doi.org/10.2760/06297 and the boundaries of Moreno-Monroy, A., M. Schiavina and P. Veneri (2020[6]), "Metropolitan areas in the world. Delineation and population trends", http://dx.doi.org/10.1016/.j.jue.2020.103242.

\section{A comparison of national definitions and the two global definitions}

The global population is distributed across a wide range of settlement sizes. This urban-rural continuum ranges from a village with a few hundred inhabitants to mega-cities of more than 10 million inhabitants. Within this continuum, different countries use different thresholds to distinguish urban from rural. These thresholds range from 200 in Denmark to 100000 in China. This wide range of thresholds reduces the international comparability of these definitions and makes analysis of global urbanisation based on these definitions less reliable.

The two global definitions presented in this report are meant to complement national definitions, not replace them. National definitions have the benefit that they can be tailored to the country's specific circumstances and policy needs. They can take into account a wider set of data than is available at the global level. National definitions, however, cannot be easily applied to another country, which is why a global definition is needed to enable international comparisons.

\section{National and global definitions tend to agree on large cities}

The degree of urbanisation and national definitions essentially agree on the classification of cities above 300000 inhabitants. According to the UN World Urbanization Prospects, 1772 nationally defined cities had at least 300000 inhabitants in 2015 . Of these cities, 1662 or $95 \%$ matched a city as defined by the degree of urbanisation.

In most regions, the population in nationally defined cities with at least 300000 inhabitants is similar to the share in cities of that size as defined by the degree of urbanisation (Figure 1.9). The difference is less than 5 percentage points in Central Asia and Europe, the Middle East and North Africa, East Asia and the Pacific and Sub-Saharan Africa. In Latin America and the Caribbean, the national definition reports a slightly higher population share in cities with at least 300000 inhabitants: $47 \%$ as compared to $40 \%$ using the degree of urbanisation. In part, this may be due to the difference in spatial resolution (municipalities versus $1 \mathrm{~km}^{2}$ grid cells). South Asia shows a bigger difference in the other direction: 19\% of the population in nationally defined cities with at least 300000 inhabitants as compared to $29 \%$ using the degree of 
urbanisation. This is primarily because in India the degree of urbanisation finds more cities with at least 300000 inhabitants as compared to the national definition.

Figure 1.9. Share of population in cities with at least 300000 inhabitants, 2015

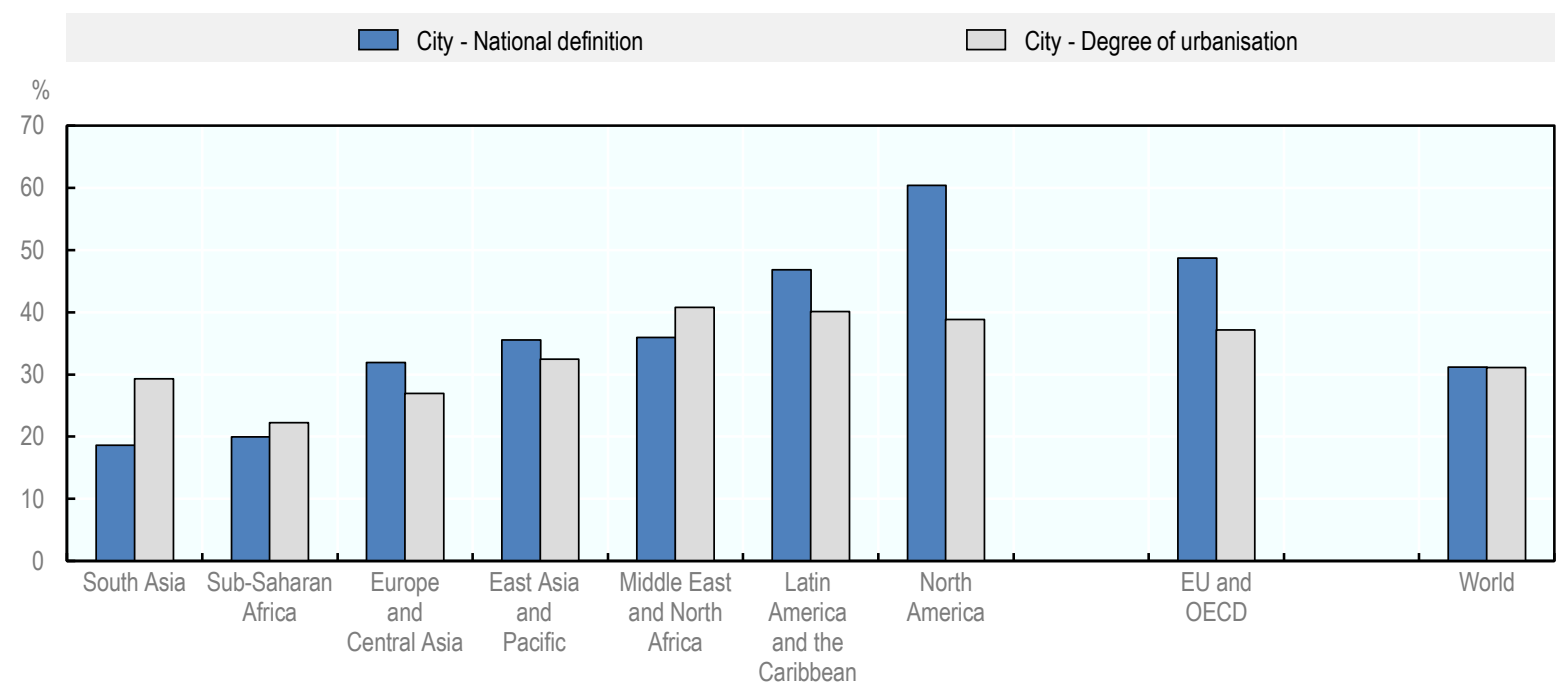

Source: EC Calculations based on GHSL Data Package 2019, Florczyk, A. etal. (2019[1]), GHSL Data Package 2019 (database), http://dx.doi.org/10.2760/06297 and UN (2018[3]), World Urbanization Prospects, United Nations.

In North America, the difference between the approaches is largest. National definitions show $60 \%$ of people living in a city with at least 300000 inhabitants, compared to only $39 \%$ according to the degree of urbanisation. The difference is primarily due to the use of a different spatial concept. Canada and the United States report the population for urban agglomerations, i.e. city plus its adjacent suburbs. By considering metropolitan areas, i.e. cities and their commuting zones, the results become much more comparable. The population in metropolitan areas with at least 300000 inhabitants is $65 \%$; a result that is markedly closer to $60 \%$ in nationally defined urban agglomerations. Metropolitan areas typically include the adjacent suburbs and may also include some rural areas if commuting flows are high enough.

\section{National definitions disagree on the classification of towns}

The standard dichotomy that classifies places into either urban or rural cannot capture the urban-rural continuum. Maybe unsurprisingly, countries, therefore, disagree where on this continuum rural ends and urban starts. The degree of urbanisation is more nuanced than the simple dichotomy between rural and urban and identifies a middle category: towns and semi-dense areas. In Chapters 2 and 5, the findings of this report will demonstrate that towns and semi-dense areas have a distinct character and thus merit a separate category. Interestingly, the classification of these settlements differs across regions of the world. Most towns are classified as urban in the Americas and Europe, while in Africa and Asia most towns are classified as rural (see Figure 1.10). As a result, the nationally defined rural population share is very similar to the share in rural areas as defined by the degree of urbanisation in the Americas, Europe and Central Asia. In the other regions, the population in nationally defined rural population share is closer to the share in rural areas plus towns and semi-dense areas. 
Figure 1.10. Population by degree of urbanisation and nationally defined urban areas by World Bank region, 2015

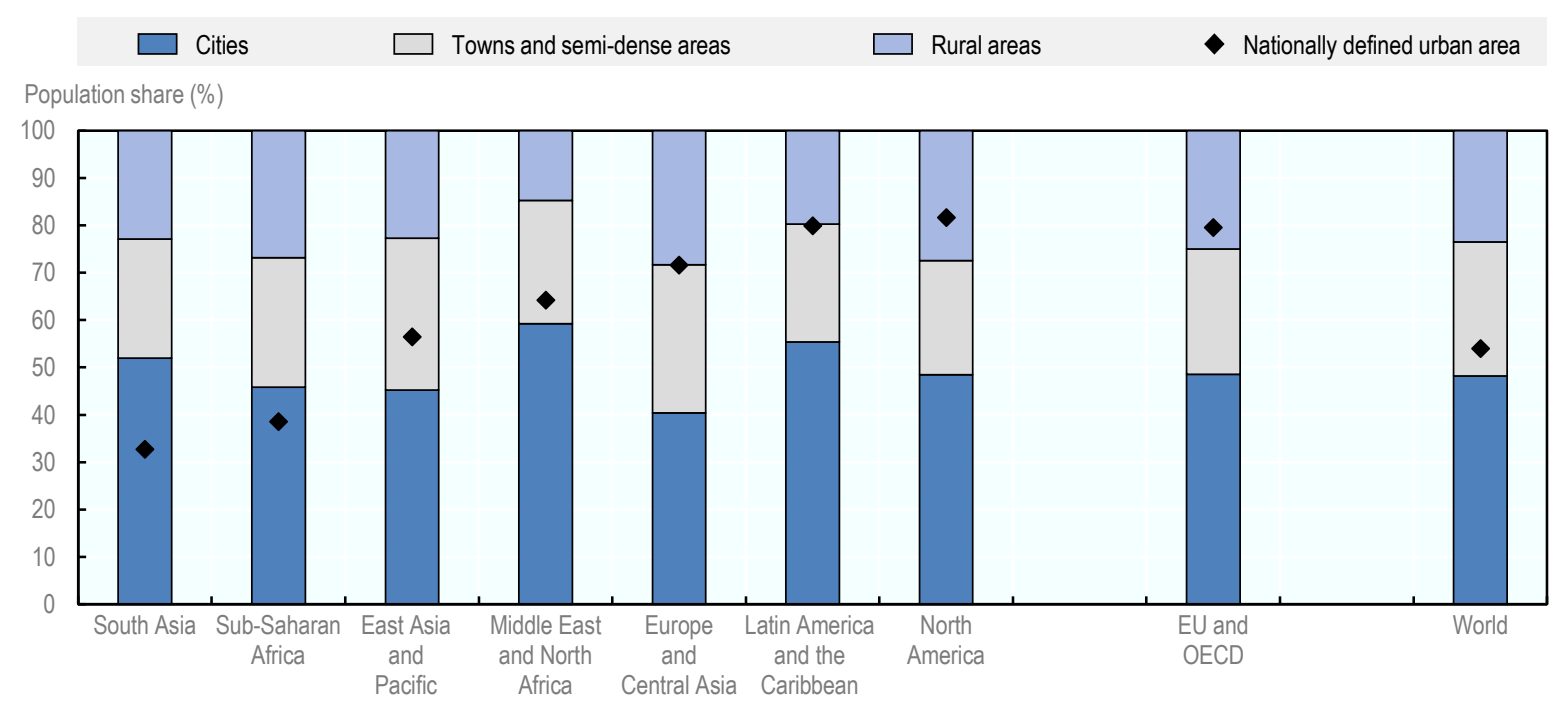

Source: EC Calculations based on GHSL Data Package 2019, Florczyk, A. etal. (2019[1]), GHSL Data Package 2019 (database), http://dx.doi.org/10.2760/06297 and UN (2018[3]), World Urbanization Prospects, United Nations.

\section{Box 1.4. Understanding national classifications of rural and urban}

Most of the minimum population thresholds used in national definitions would agree with the degree of urbanisation by classifying towns as urban. Out of the 103 countries with such a threshold, 85 use a threshold between 200 and 5000 inhabitants. In these countries, one would expect a town to be classified as urban. Some definitions, however, combine a minimum population threshold with other criteria that may lead some towns to be classified as rural. For example, several definitions include a maximum share of male employment in agriculture for urban areas. If a town has a population above a minimum size threshold, it will still be classified as rural if it has a high share of employment in agriculture. Furthermore, a few countries use a high minimum population size threshold to classify a settlement as urban, which might cause a deviation from the degree of urbanisation. For example, Japan uses 50000 and China 100000 inhabitants, indicating that towns will be classified as rural and only large settlements will be classified as urban.

Administrative designations are another reason for differences across countries and between national classifications and the degree of urbanisation. More than half of the world's urban and rural national definitions rely (entirely or in part) on such administrative designations, i.e. (some) areas are simply declared urban or rural. Administrative designations can produce an accurate classification of a country, but they cannot be replicated in another country. They are often the results of long-standing institutional or political history, often without a clear set of criteria to distinguish the urban status from the rural one. In these countries, the description of the definition does not indicate whether all, some or none of the towns will be defined as urban.

A comparison of national definitions of urban and rural areas to the degree of urbanisation for 12 countries provides further insights (Figure 1.11). It shows that cities, as defined by the degree of urbanisation, are typically classified as urban by the national definition and that rural areas as defined by the degree of urbanisation are almost entirely classified as rural by national definitions. Some differences do appear, with some of the population in rural areas classified as urban by the respective 
national definition. In part, this is due to the use of a different population threshold. For example, the United States (US) uses 2500 as the minimum population for an urban area and France and Portugal use 2000.

The biggest differences, however, are found in the way national definitions classify towns and semidense areas. Brazil, France, Portugal and the US classify more than $90 \%$ of the population in towns and semi-dense areas as urban. India, Morocco, Uganda and Viet Nam classify more than $80 \%$ of this population as rural (Figure 1.11).

Figure 1.11. Population by degree of urbanisation by urban-rural national definition in 12 countries

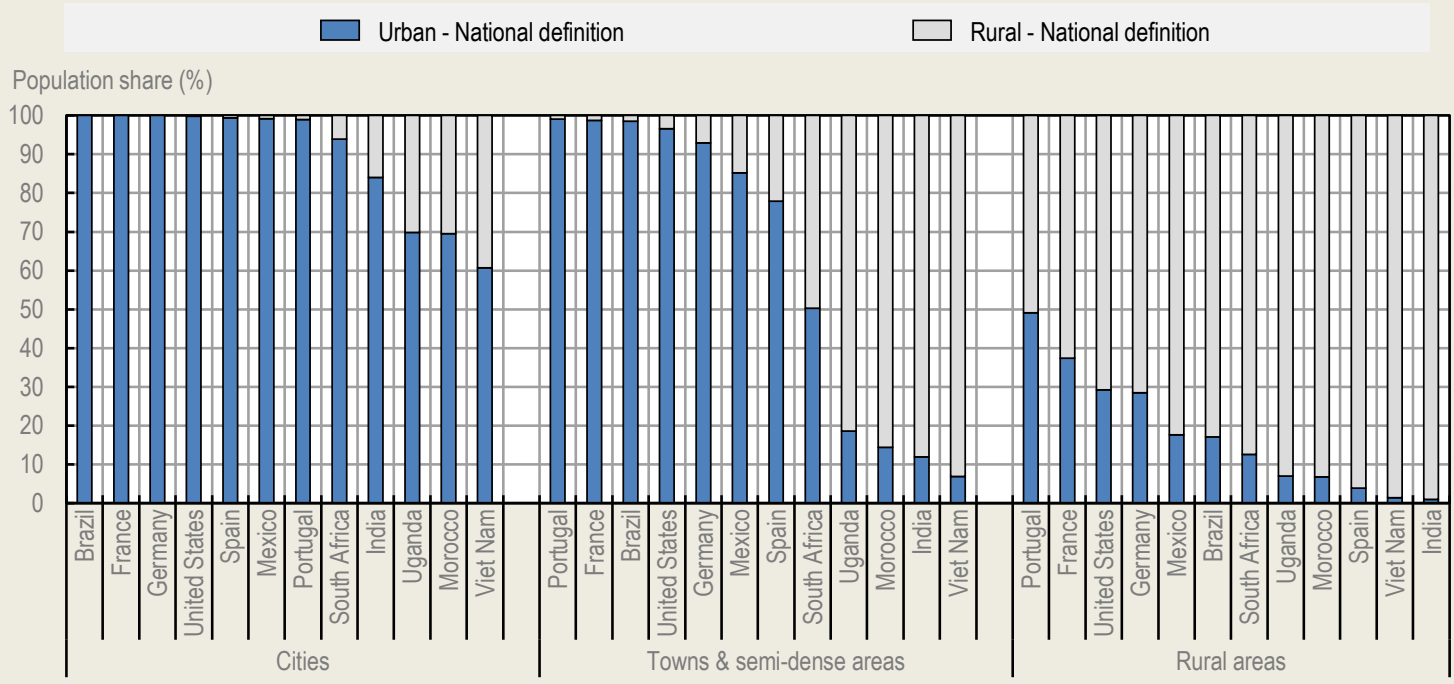

Source: EC Calculations based on data from National offices of Statistics and GHSL Data Package 2019, Florczyk, A. et al. (2019[1]), GHSL Data Package 2019 (database), http://dx.doi.org/10.2760/06297.

\section{Advantages of the new definitions}

The two new global definitions presented here have four key benefits: i) they rely on a population grid and not on administrative boundaries; ii) they are designed to monitor access to services and capture agglomeration economies; iii) they measure the spatial concentration of population directly; and iv) they classify settlements of the same size in the same way.

- The biggest innovation is that both definitions start from the population grid. Because each grid cell has the same size and shape ( 1 by $1 \mathrm{~km}$ ), it overcomes many of the distortions created by using administrative or statistical units that vary in size and shape, known by geographers as the modifiable areal unit problem or MAUP. For example, using a minimum population size threshold with administrative units would classify some rural areas with a very large area as urban because it contains a large but dispersed population. Using a population density threshold with administrative units would classify some cities with a large area as rural because of its low density.

- These definitions were developed to monitor and improve access to services and infrastructure. The SDGs include indicators measuring access to public transport, electricity, a mobile phone network, safe drinking water, waste management, an all-weather road, healthcare services or financial services. The costs of providing such services and infrastructure depend to a large degree 
on the number of people who live nearby. The concept of agglomeration economies is exactly what underpins these people-based definitions. This is also why such services are not included in the definitions. If the definition of a city included the presence of hospital, then by definition all cities would have a hospital. This would make it impossible to identify which cities lacked a hospital. Similarly, if the definition of rural areas included low access to electricity, it would become impossible to monitor access to electricity in rural areas.

- This people-based definition measures the concentration of people in space directly. Using indirect measures of population concentration, such as built-up areas, reduces the population share in urban areas in low-income countries and increases it in high-income countries. That is why a people-based definition is more suitable for international comparisons than one based on land use.

- These definitions consistently classify settlements of the same population size in the same way. The population size criteria are not combined with other criteria such as the share of agricultural employment. Including the share of agricultural employment would mean that settlements of the same size would no longer be consistently classified, as those with more agricultural jobs would be rural and those with less urban. Because agricultural employment is much lower in high-income countries, including it in the definition of urban and rural areas would also make high-income countries far more urban, making it less suitable for international comparisons.

\section{References}

Dijkstra, L., H. Poelman and P. Veneri (2019), "The EU-OECD definition of a functional urban area", OECD Regional Development Working Papers, No. 2019/11, OECD Publishing, Paris, https://doi.org/10.1787/d58cb34d-en (accessed on 21 October 2019).

Ehrlich, D. et al. (2018), "Remote sensing derived built-up area and population density to quantify global exposure to five natural hazards over time", Remote Sensing, Vol. 10/9, p. 1378, https://doi.org/10.3390/rs10091378.

Florczyk, A. et al. (2019), GHSL Data Package 2019 (database), http://dx.doi.org/10.2760/062975.

Florczyk, A. et al. (2019), GHS Urban Centre Database 2015, Multitemporal and Multidimensional Attributes, R2019A (dataset), Joint Research Centre (JRC), European Commission, https://data.jrc.ec.europa.eu/dataset/53473144-b88c-44bc-b4a3-4583ed1f547e.

Freire, S. et al. (2018), "Enhanced data and methods for improving open and free global population grids: Putting 'leaving no one behind' into practice.", International Journal of Digital Earth, https://doi.org/10.1080/17538947.2018.1548656.

Jones, B. et al. (forthcoming), Projecting Global Population Grids to 2100, Publications Office of the European Union.

Melchiorri, M. et al. (2019), "Principles and applications of the global human settlement layer as baseline for the land use efficiency indicator - SDG 11.3.1", International Journal of GeoInformation, Vol. 8/2, https://doi.org/10.3390/ijgi8020096.

Moreno-Monroy, A., M. Schiavina and P. Veneri (2020), "Metropolitan areas in the world. Delineation and population trends", Journal of Urban Economics, http://dx.doi.org/10.1016/.jue.2020.103242. 
Pesaresi, M. et al. (2016), Operating Procedure for the Production of the Global Human Settlement Layer from Landsat Data of the Epochs 1975, 1990, 2000, and 2014, EU Scientific and Technical Research Reports, http://dx.doi.org/10.2788/253582.

Pesaresi, M. et al. (2013), "A global human settlement layer from optical HR/VHR RS data: Concept and first results", IEEE Journal of Selected Topics in Applied Earth Observations and Remote Sensing, Vol. 6/5, pp. 2102-2131, http://dx.doi.org/10.1109/JSTARS.2013.2271445.

UN (2018), World Urbanization Prospects, United Nations, https://population.un.org/wup/Publications/Files/WUP2018-Report.pdf.

\section{Note}

${ }^{1}$ New cities almost exclusively consisted of towns as defined by the degree of urbanisation level 2 , presented in Annex 1.A. 


\section{Annex 1.A. The degree of urbanisation level 1 and 2}

\section{A detailed description of the degree of urbanisation}

The degree of urbanisation was designed to create a simple and neutral method that could be applied in every country in the world. It relies primarily on population size and density thresholds applied to a population grid with cells of 1 by $1 \mathrm{~km}$.

The three types of grid cells are classified as follows.

1. Cities consist of contiguous grid cells that have a density of at least 1500 inhabitants per $\mathrm{km}^{2}$ or are at least $50 \%$ built up. The cluster of contiguous cells must have a population of at least 50000 . Gaps in this cluster are filled and its edges are smoothed.

2. Towns and semi-dense areas consist of contiguous grid cells with a density of at least 300 inhabitants per $\mathrm{km}^{2}$ and are at least $3 \%$ built up. This cluster of contiguous cells must have a total population of at least 5000 . Once the minimum population has been verified, city cells that are part of this cluster are removed.

3. Rural areas are cells that do not belong to a city or a town and semi-dense area. Most of these have a density below 300 inhabitants per $\mathrm{km}^{2}$.

Annex Figure 1.A.1. City, towns and semi-dense areas, and rural areas around Cape Town, South Africa

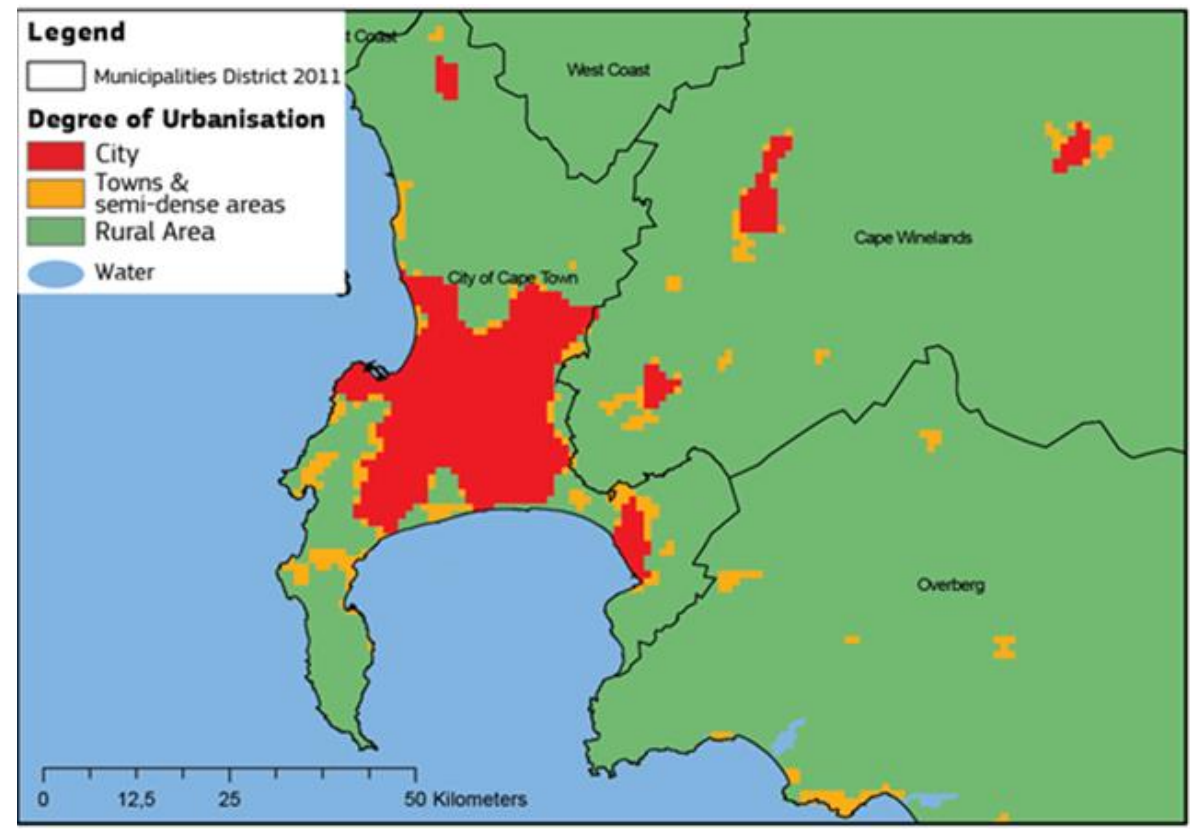

Source: GHSL Data Package 2019, Florczyk, A. et al. (2019[1]], GHSL Data Package 2019 (database), http://dx.doi.org/10.2760/06297. 
The degree of urbanisation as approved by the UN Statistical Commission includes first classification of grid cells and subsequent classification of local spatial units. As the boundaries of local administrative or statistical units are not globally available, this report only uses the grid cell classification. For ease of reading, it uses the terminology of the local units. For example, we refer to cities, not urban centres.

One small modification has been applied as a correction to GHS-POP, the population grid used in this report: a cell must be at least $3 \%$ built up to be considered part of towns and semi-dense areas. GHS-POP may overestimate the concentration of population in countries where population data has a coarse spatial resolution and a significant share of built-up areas are not detected. This $3 \%$ rule is not part of the definition and should not be applied to other population grids.

\section{How to identify towns and villages: Degree of urbanisation level 2}

Towns and villages can play an important role in providing access to services, such as education, healthcare and shops, for the surrounding areas. To identify these, a sub-classification of the degree of urbanisation was created as follows:

- Towns and semi-dense areas were split into three categories.

- Dense towns consist of contiguous cells with a density of at least 1500 inhabitants per km². The total population in the cluster has to be between 5000 and 50000 .

- Semi-dense towns consist of contiguous cells with a density of at least 300 inhabitants per $\mathrm{km}^{2}$, with a population of at least 5000 that is neither contiguous with nor within $2 \mathrm{~km}$ of a dense town or a city.

- Suburban or peri-urban areas consist of the remaining towns and semi-dense area cells. These cells are part of a cluster that is contiguous with or within $2 \mathrm{~km}$ of a city or a dense town.

- Rural areas were also split into three categories.

- Villages consist of contiguous cells with a density of at least 300 inhabitants per $\mathrm{km}^{2}$. The total population in that cluster has to be between 500 and 5000 .

- Dispersed rural areas consist of rural area cells with a density between 50 and 300 inhabitants per $\mathrm{km}^{2}$.

- Mostly uninhabited areas are defined by rural area cells with a density of 50 inhabitants per $\mathrm{km}^{2}$ or less.

As with the degree of urbanisation level 1 , this report uses the local unit terminology instead of the grid level terminology.

The income level of a country has a significant impact on the population distribution by degree of urbanisation level 2. In low-income countries, the population share in cities is relatively low, while a larger share of the population lives in towns and villages. In high-income countries, the population share in suburban areas is much higher, while the share of population living in villages and towns is much lower than in the other income groups. 
Annex Figure 1.A.2. Degree of urbanisation level 2 classification around Toulouse, France

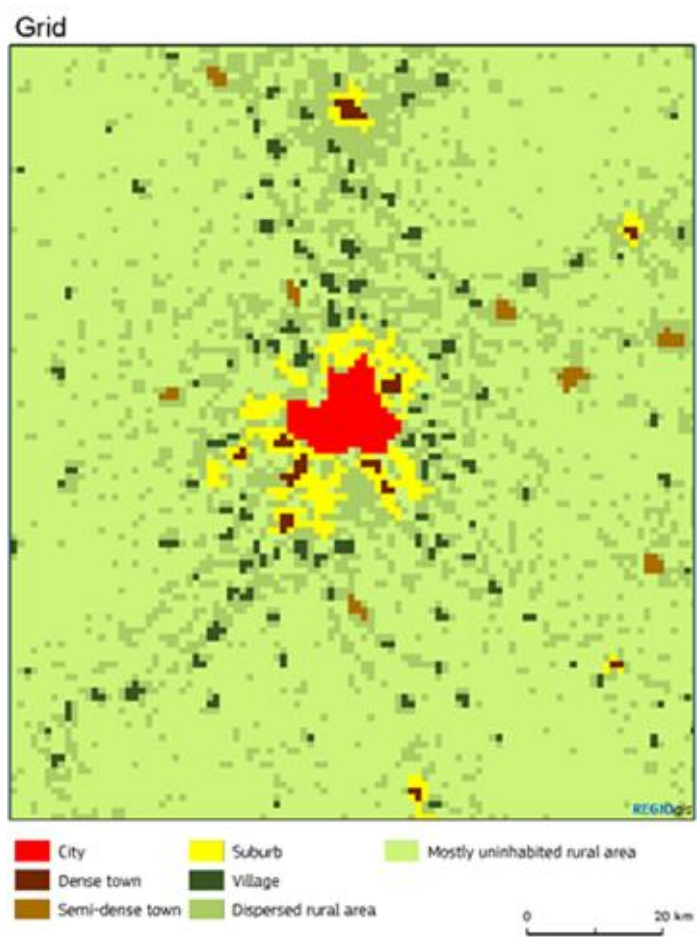

Source: GHSL Data Package 2019, Florczyk, A. et al. (2019[1]), GHSL Data Package 2019 (database), http://dx.doi.org/10.2760/06297.

Annex Figure 1.A.3. Population by degree of urbanisation level 2 and income group, 2015

Countries by income level

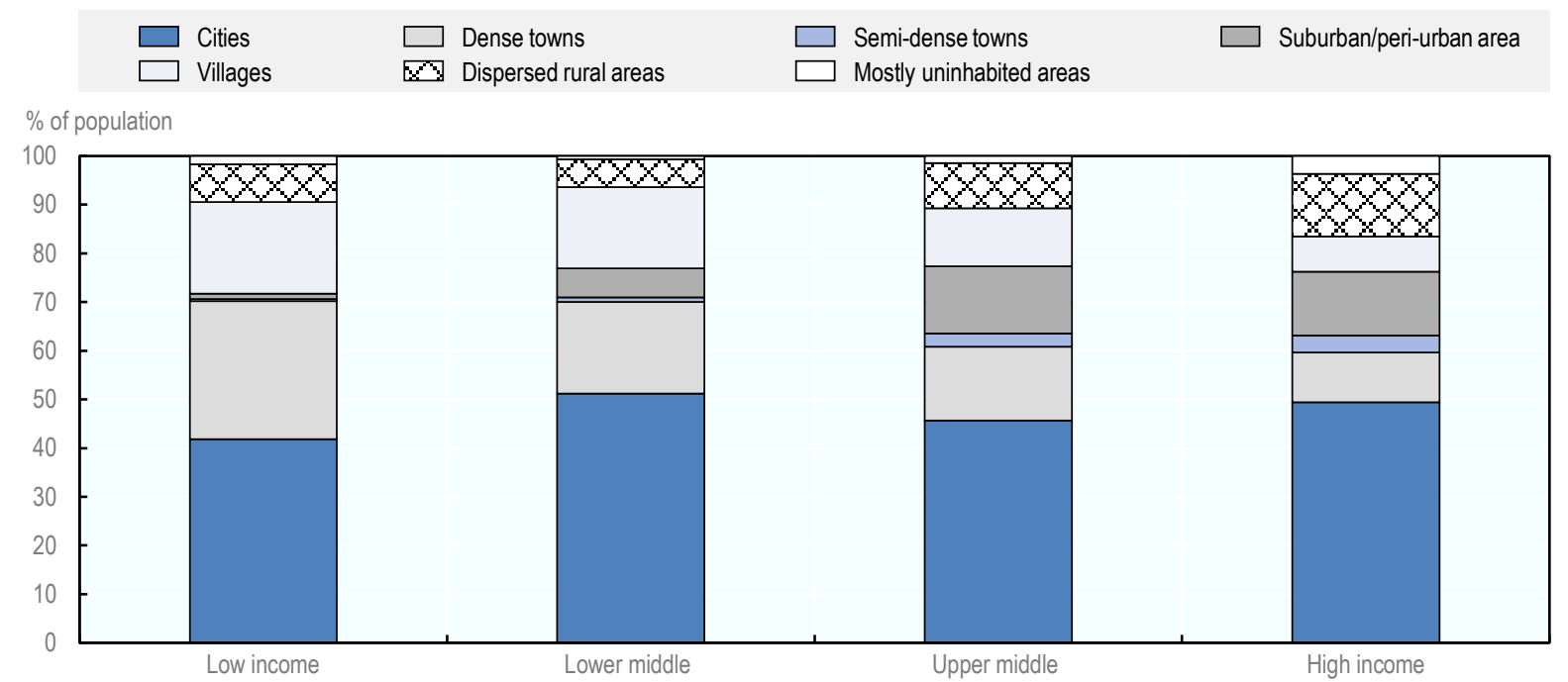

Source: Florczyk, A. et al. (2019[1] $)$, GHSL Data Package 2019 (database), http://dx.doi.org/10.2760/06297. 


\section{Annex 1.B. Functional urban areas}

\section{Delineating metropolitan areas (aka functional urban areas, FUAs) in the world}

The metropolitan areas used in this report are approximations at the grid level of the functional urban areas (FUAs) definition developed by the European Union and the OECD (Dijkstra, Poelman and Veneri, $2019_{[5]}$ ). This definition specifies that an FUA consists of a cluster of local administrative units that are either part of a city or the commuting zones of that city. Local units in the commuting zones have at least $15 \%$ of their working population commuting to the city for work.

Because commuting data and local administrative unit boundaries were not available for most countries, this report relies on estimated metropolitan areas using globally available gridded data. The delineation of these metropolitan areas is done in two steps (Moreno-Monroy, Schiavina and Veneri, 2020[6]):

- Delineation of cities (or urban centres). Consistently with the degree of urbanisation, cities are clusters of densely populated cells, with at least 1500 inhabitants per $\mathrm{km}^{2}$ and 50000 inhabitants overall. They are defined using the GHSL population grid.

- Commuting zones. They are defined through a probabilistic approach performed through a logistic regression model - which is trained using information on actual FUA boundaries in OECD countries where the EU-OECD definition was already available.

The logit model uses about 0.5 million one- $\mathrm{km}^{2}$ cells with at least 300 inhabitants in OECD countries. The predictors of whether a cell is part of a commuting zone are: i) the travel time of the cell to the closest urban centre; ii) the size of the urban centre; iii) population of the cell; and iv) the gross domestic product (GDP) per capita of the country. The logit model parameters are then used to obtain estimated probabilities for around 2.5 million cells in and outside baseline countries, which are then compared to appropriate optimal thresholds calculated by world region to define which cells belong to FUAs and which do not.

\section{Annex Figure 1.B.1. The metropolitan area of Medellin, Colombia}

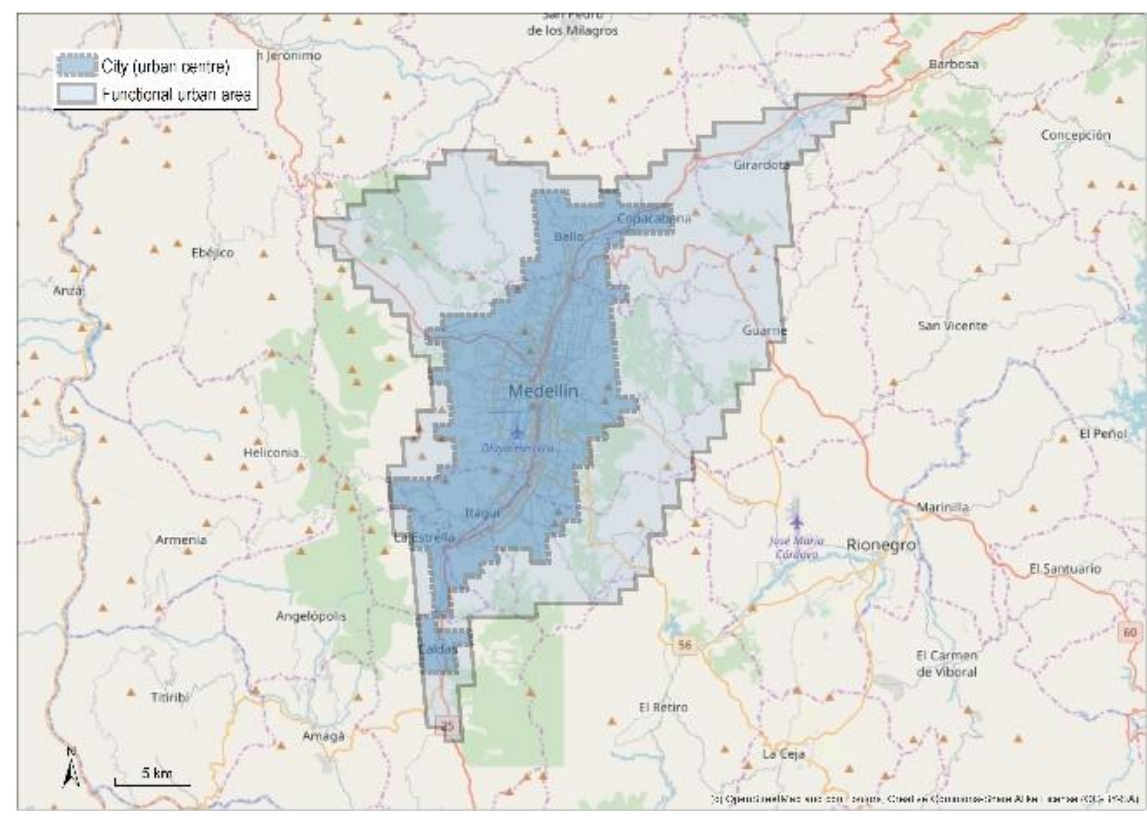

Source: GHSL Data Package 2019, Florczyk, A. et al. (2019[1]), GHSL Data Package 2019 (database), http://dx.doi.org/10.2760/06297. 
The method delineates about 9000 estimated FUAs of at least 50000 inhabitants worldwide (MorenoMonroy, Schiavina and Veneri, 2020[6]). Only cities that have been validated were used to create metropolitan areas. As a result, the population in the cities used for metropolitan areas is slightly lower $(44 \%)$ than the total population in cities (48\%) according to the degree of urbanisation. 


\section{Annex 1.C. The Global Human Settlement Population Grid (GHS-POP)}

The Global Human Settlement Population Grid (GHS-POP) estimates the population in each grid cell of 250 by $250 \mathrm{~m}$ in the world for the years 1975, 1990, 2000 and 2015. It disaggregates residential population estimates for smallest census unit provided by CIESIN (Columbia University, United States) for the years of interest. Disaggregation is based on built-up areas as mapped by GHSL for the same years (Freire et al., 2018[7]). The disaggregation is within each census unit and proportional to the share of built-up area of the census unit in that cell. If a cell contains $2 \%$ of the total amount of built-up area within a census unit, it will be allocated $2 \%$ of the total population.

The Global Human Settlement Layer (GHSL) project mapped built-up areas using Landsat imagery collections for the years 1975, 1990, 2000 and 2014 (Pesaresi et al., 2013[8]; 2016[9]). The GHSL approach is grounded on the concept that buildings and their agglomerations (i.e. settlements) are the main visible and direct manifestation of human presence on the Earth's surface.

At the time of the first public release (2016), GHS-POP was the highest resolution gridded global population time series. It remains the only detailed grid spanning 40 years. GHS-POP is produced in an equal-area projection (World Mollweide), which makes it easy to calculate population densities. It is the only disaggregated global dataset relying on a single, time-specific and consistent proxy (built-up areas). For the latest release (R2019), areas declared as unpopulated were revised critically and the representation of population along coastlines was improved (Freire et al., 2018 $\left.{ }_{[7]}\right)$. These grids can be downloaded as bulk or in regular tilesin World Mollweide (WGS84) for free from https://ghsl.jrc.ec.europa.eu/ghs pop2019.php.

GHS-POP is part of an integrated suite of geospatial products, aiming to constitute a detailed and consistent time series of lightly modelled population distributions that is based on reproducible methods for sustainable data production (Melchiorri et al., 2019 $9_{[10]}$ ). It can be used in policy support in numerous domains including monitoring exposure trends (Ehrlich et al., $\left.2018_{[11]}\right)$. These grids are created using consistent, open and free input data integrated using a clear and transparent approach. 


\section{Annex 1.D. Population projections for the world}

The projections used in this report rely on two models, one that produces spatial explicit projections of the population and one that produces the corresponding spatial projection of built-up land. They are independent models but each informs the other. Both models require aggregate (national level) projections of population and built-up land change, which are then downscaled to produce spatially explicit gridded outcomes. The models produce population and built-up land from 2020 to 2100 in 10-year intervals over a global $1-\mathrm{km}^{2}$ grid. Base-year data were the 2015 GHS-POP distribution (Florczyk et al., 2019 ${ }_{[1]}$ ) and the 2014 GHSL layer (built-up).

The model is a form of gravity-based spatial allocation (downscaling) approach applied over all the $1-\mathrm{km}^{2}$ grid cells in a country. The relative attractiveness of each location is modelled as a function of its population, characteristics of the local built environment and the agglomeration effect. The agglomeration or neighbourhood effect is based on potential accessibility to population calculated using a calibrated exponential distance decay function within a 50-km window. In past research, the agglomeration effect has been shown to correlate with the various socio-economic factors that make a place attractive to human populations (e.g. jobs, social opportunities, etc.).

National population totals (2020-2100) were taken from the IIASA population projections up to 2100 developed for the Shared Socioeconomic Pathway 2 (SSP2) and the UN World Population Prospects 2019 medium variant for countries or territories not included in the SSPs. National changes in built-up land are based on the historic relationship between population change and change in built-up land at the national level between 1990 to 2015. Changes in built-up land were then estimated (2020-2100) as a function of total population change. In the case of projected population decline, the relationship between population and built-up land change of a different country, one that lost population in the historic period, in the same world region was used. The models were calibrated using GHS-POP and GHS-BUILT for 1990, 2000 and 2015. For each of the 20 world regions used, parameters were estimated for 1 or more marker countries for which good historic data were available. For countries with insufficient historic data, parameters are estimated from the regional marker country were used. 



\section{Life in cities, towns and semi-dense} areas, and rural areas

This chapter sheds light on the quality of life in cities, towns and semi-dense areas, and rural areas around the world. It examines various dimensions of how quality of life differs between cities and other areas by examining both objective outcomes as well as subjective perceptions. First, it scrutinises geographic differences in life satisfaction. Second, the chapter analyses to what extent key well-being dimensions, which shape life satisfaction and quality of life, differ across cities, towns and semi-dense areas, and rural areas. Specifically, it examines income and employment opportunities, educational attainment, health outcomes, access to services and utilities, and crime and violence. 


\section{Rural-city differences in quality of life}

Differences in quality of life between urban and rural residents have been the subject of many economic studies. On average, urban residents appear to enjoy a higher quality of life than their counterparts in rural areas, particularly in developing countries (Gollin, Lagakos and Waugh, 2013[1]; Chauvin et al., 2017[2]; Gollin, Kirchberger and Lagakos, 2019 $9_{[3]}$. Economists have long argued that much higher per capita incomes in cities reflect the production benefits from agglomeration in rich countries. Recent work has demonstrated this differential exists in developing countries in terms of income (e.g. (Combes, Démurger and Wang $\left(2019_{[4]}\right)$ and Henderson, Kriticos and Nigmatulina $\left.\left(2019_{[5]}\right)\right)$ and poverty rates (Ferré, Ferreira and Lanjouw, 2012[6]), too. Similarly, more diverse consumption opportunities in cities that arise due to agglomeration economies may also enhance the well-being of local residents (Tabuchi and Yoshida, $\left.2000_{[7]}\right)$.

Within-country differences of quality of life are not only highly relevant per se but are also essential for assessing drivers of internal migration flows from rural areas to more densely populated places such as cities. Thus, such differences can help to shed light on urbanisation across the globe. This is particularly important for developing or middle-income countries where spatial disparities in amenities, services, real incomes or economic opportunities tend to be very large (Henderson, Kriticos and Nigmatulina, 2019[5]).

However, a number of factors complicate quantifying rural-city differences in quality of life. Foremost are the challenges inherent to defining and measuring urban residence (Dorélien, Balk and Todd, 2013 [8]; Balk et al., 2004[9]; Gollin, Kirchberger and Lagakos, 2019[3]). This adds considerable uncertainty to the magnitudes of these differentials. Surveys containing rich socio-economic outcomes typically report urban residence based on a binary administrative definition, which varies significantly across countries and thus makes cross-country comparisons difficult and biased.

This chapter sheds light on geographic differences in quality of life by using the novel, globally consistent definition of degree of urbanisation (see Florczyk et al. $\left(2019_{[10]}\right)$ and Chapter 1, which divides countries' national territory into three categories, cities [or densely populated areas], towns and semi-dense areas [or intermediate-density areas], and rural areas [or thinly populated areas]). By using this harmonised definition, the chapter reduces the bias in results that arises due to the diverse nature of definitions of urban areas along several dimensions (Corker, 2017 [11]; Ferré, Ferreira and Lanjouw, 2012[6]). For example, some countries define urban areas by making use of explicit ad hoc or subjective criteria such as the nature of a settlement, its centricity or its infrastructure. In contrast, the degree of urbanisation uses the same conditions across the globe in terms of population size and density to identify whether an area is a city, a town and semi-dense area (TSA), or a rural area.

In the following, this chapter presents differences in quality of life across types of human settlements. First, it examines differences in life satisfaction and well-being factors across the degree of urbanisation across the world. It then examines differences across the degree of urbanisation in important well-being dimensions that shape local quality of life of residents. Specifically, it explores differences across the degree of urbanisation in: i) income and employment opportunities; ii) educational attainment; iii) health outcomes; iv) access to services, utilities, and technology; and v) exposure to violence and crime.

\section{Life satisfaction by degree of urbanisation}

Over the past decade, economists and policymakers alike have engaged in a debate on broadening the measurement of the welfare and progress of societies. Increasingly, this public discourse has emphasised the importance of going beyond gross domestic product (GDP) as the single measure of development. Instead, initiatives such as the OECD How's Life project propose to look at a multitude of sound well-being indicators, accounting for the different dimensions of people's lives, from those related to material conditions, such as income, jobs and housing, to those related to quality of life (OECD, 2017[12]). Most 
factors that directly or indirectly determine people's well-being vary considerably across different regions or cities within the same country, which highlights the importance of assessing well-being and perceptions at the subnational level (OECD, 2014[13]). In assessing subnational differences in well-being, self-reported life satisfaction and perception-based measures are an important complement to objective indicators on well-being as they might capture geographic disparities in specific life domains that objective indicators do not reveal.

\section{Life satisfaction and living standards are highest in cities}

Satisfaction with one's standard of living and with life in general differ significantly between cities, towns and semi-dense areas, and rural areas in 111 countries across the world. ${ }^{1}$ On average, $18.6 \%$ of residents in cities are satisfied with their lives, compared to $16.5 \%$ of residents in rural areas, a statistically significant difference. ${ }^{2}$ Life satisfaction in towns and semi-dense areas $(17 \%)$ is lower than in cities but higher than in rural areas. For a limited sample of 13 OECD countries, the discrepancy in life satisfaction between cities (28.7\% satisfied with their lives) and rural areas (24.4\% satisfied with their lives) amounts to more than 4 percentage points. ${ }^{3}$ This rural-city life satisfaction gap is not limited to any specific world region. In all regions except for East Asia and the Pacific (and North America, which is only represented by the United States), city dwellers appear to be happier with their living condition than rural residents.

In the large majority of areas, women report a higher level of life satisfaction than men. Except for highincome OECD countries, the share of women satisfied with life consistently and, of statistical significance, exceeds the equivalent share of men across all levels of development and all degrees of urbanisation (Figure 2.1). This gender life satisfaction differential is largest in upper-middle-income countries and most striking in towns and semi-dense areas (TSAs). For example, life satisfaction of women in TSAs' is around 3 percentage points higher than men's in lower-middle-income and upper-middle-income countries respectively. In contrast, in OECD countries, men report higher life satisfaction in both cities (3 percentage points) and TSAs (1.8 percentage points) but similar life satisfaction to women in rural areas.

Figure 2.1. Life satisfaction by degree of urbanisation, income group and gender

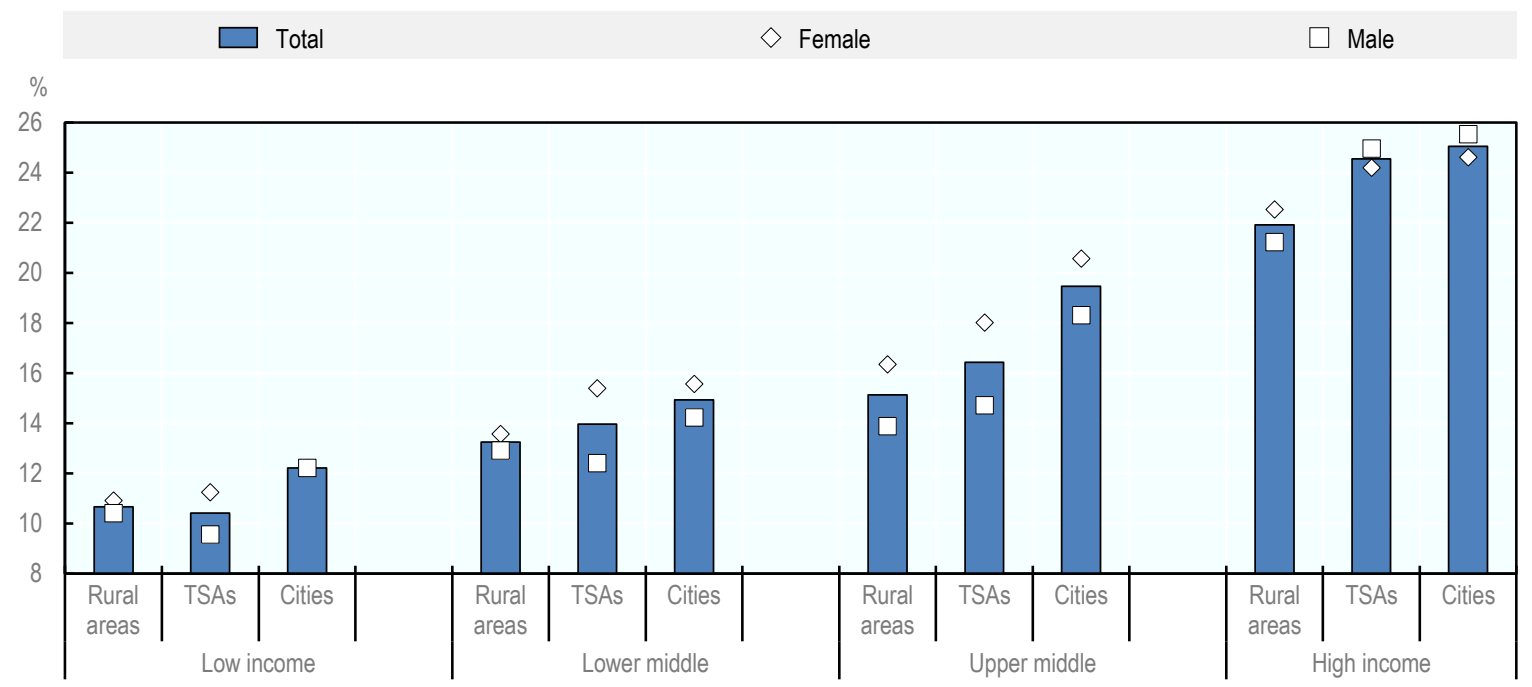

Note: The income groups follow the World Bank classification of countries.

Source: Based on Gallup (2017[14]), Gallup World Poll, 2016-17, https://www.gallup.com/analytics/232838/world-poll.aspx; elaborated by EC and OECD, 2019. 
In individual countries, geographic differences in life satisfaction can be enormous. In 12 countries, life satisfaction is more than twice as high in cities as it is in rural areas. ${ }^{4}$ This gap is largest in Azerbaijan, Egypt and the Gambia, where life satisfaction in cities is almost three times the level documented in rural areas. At the other end of the spectrum, 8 countries record $30 \%$ higher life satisfaction in rural areas. Common to most countries is that life satisfaction in TSAs usually lies in between life satisfaction in cities and rural areas.

Cities not only have higher life satisfaction but this difference to rural areas and TSAs also increases with future expectations. Compared to their current situation, citizens in all three degrees of urbanisation appear more optimistic about their future; however, residents in cities tend to be the most optimistic about their living standard five years from now (Figure 2.2). The share of city residents expecting to have a satisfying life in 5 years averages $44 \%, 25$ percentage points higher than current life satisfaction. In comparison, the increase between current and future life satisfaction is below 23 and 20 percentage points in TSAs and rural areas respectively. Even though current and future life satisfaction are linked, there are notable exceptions such as Bulgaria where more city dwellers are positive about their future $(30 \%)$ than rural residents $(13 \%)$, even though city dwellers are less satisfied with their current life than rural residents.

The happiness gap and optimism gap between cities and rural areas are most prominent in the poorest countries. In low-income countries, the share of people satisfied with their lives now and the share of those optimistic about their future are 4 and 8 percentage points lower in rural areas than in cities (which corresponds to $16 \%$ and $20 \%$ relatively lower happiness) (Figure 2.2). In contrast, life satisfaction and future life satisfaction are similar in cities and TSAs in rich countries, with only rural areas falling markedly behind. While the level of economic development, as measured by GDP per capita, is strongly associated with higher life satisfaction, it does not fully explain the discrepancy between cities and rural areas. ${ }^{5}$ Overall, the gradient in optimism about one's life across the three degrees of urbanisation is apparent in almost all parts of the world, except for North America (United States). Generally, city dwellers appear to be most optimistic, followed by residents of TSAs, with rural residents lagging behind.

\section{Figure 2.2. Difference between future and current life satisfaction}

Expected increase in life satisfaction across income groups and degrees of urbanisation, in percentage points

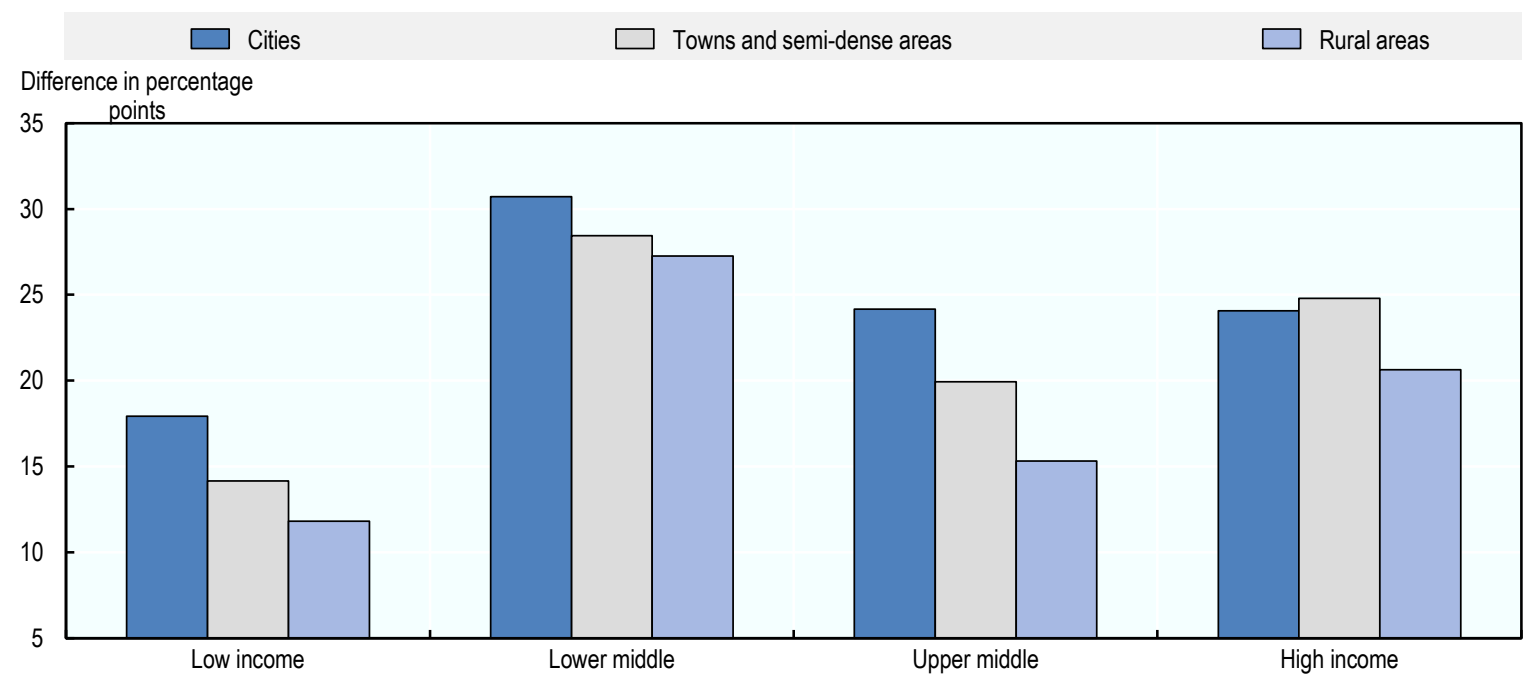

Note: The figure presents the percentage points difference between current and future life satisfaction by country income class across the degree of urbanisation. The question on expected future life satisfaction asks respondents to state their anticipated life satisfaction in five years. Source: Based on Gallup (2017[14]), Gallup World Poll, 2016-17, https://www.gallup.com/analytics/232838/world-poll.aspx; elaborated by OECD, 2019. 
Higher satisfaction with the quality of life in cities could partly explain the growth of cities (especially large ones) across the globe. The population growth of cities can occur both due to natural population growth in cities as well as due to migration, i.e. population movements towards urban settlements. Fertility rates tend to decline in cities, relative to rural areas. In all world regions, apart from Sub-Saharan Africa, fertility rates in cities converge towards the natural replacement rate (see Chapter 4). Therefore, migration appears to explain a considerable part of cities' growth, in particular outside of the developing world (International Organization for Migration, 2015 $[15])$.

Geographic differences in both current and anticipated life satisfaction appear to be associated with urbanisation patterns across countries between 2000 and 2015. Lower levels of optimism about future life satisfaction in rural areas are significantly correlated with population growth of cities, even when countries' level of development is taken into account. Countries that recorded significantly larger population growth of cities between 2000 and 2015 also reported rural-city gaps in anticipated life satisfaction. ${ }^{6}$ Furthermore, the population of towns and semi-dense areas grew more rapidly during that same period in countries where life satisfaction in TSAs was high relative to cities or rural areas. ${ }^{7}$

Life satisfaction does not only vary across the degree of urbanisation but also metropolitan areas of different sizes. The larger a metropolitan area, the more satisfied with their life and standard of living the residents appear to be. Figure 2.3 shows the different levels of life satisfaction and standard of living for different size classes of metropolitan areas. For standard of living, size matters: the percentage of people satisfied with their standard of living increases with metropolitan size. Around $58 \%$ of residents report being satisfied with the standard of living in metropolitan areas with less than 250000 inhabitants, compared to $74 \%$ of resident in metropolitan areas larger than 5 million inhabitants (left panel of Figure 2.3). When country-specific characteristics that might affect both life satisfaction and metropolitan area size are taken into account, the pattern becomes clearer (right panel of Figure 2.3). With increasing size, life satisfaction and satisfaction with living standards rise. ${ }^{8}$

\section{Figure 2.3. Life satisfaction and living standards by the size of metropolitan areas}

Average differences in percentage across the size of metropolitan areas and residuals after controlling for country fixed effects

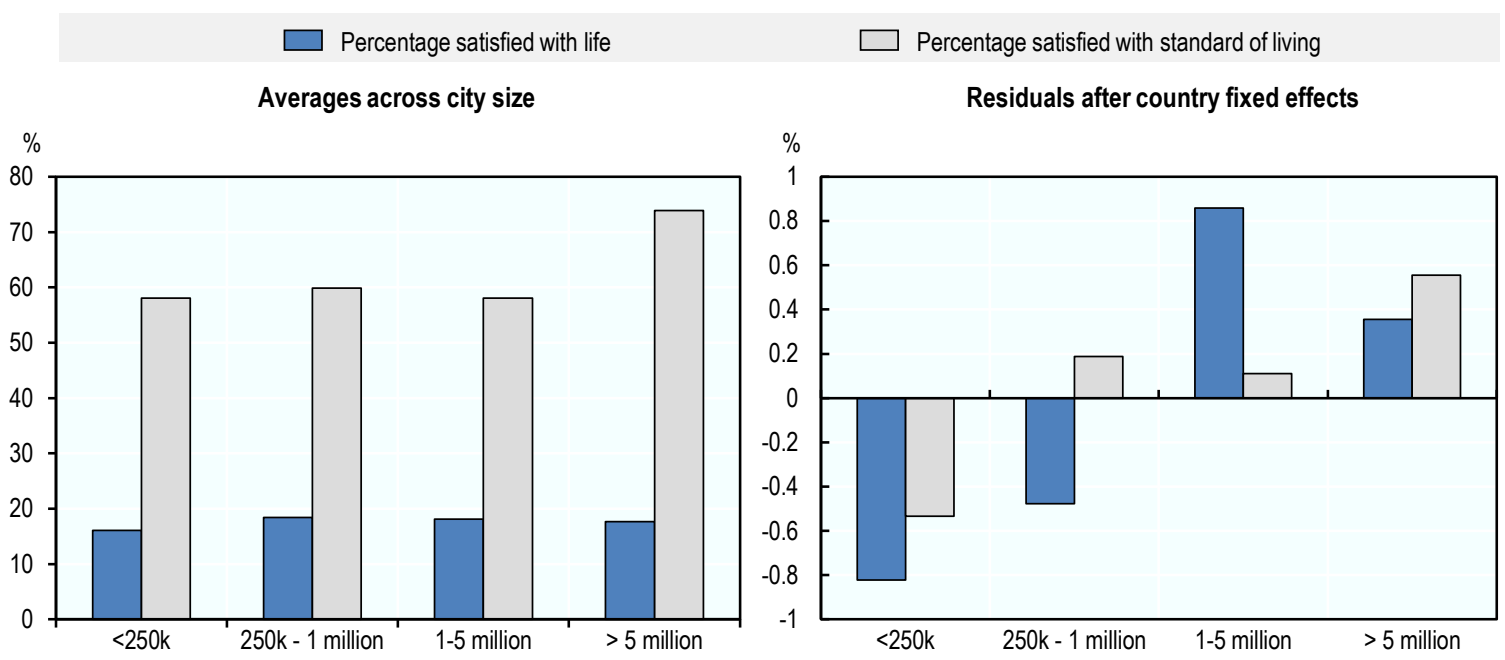

Note: The left figure displays the averages in life satisfaction and satisfaction with living standards by size class of metropolitan areas. The right figure presents residuals in life satisfaction and living standards after controlling for country fixed effects. Standard of living reports the expressed satisfaction with the standard of living conditions.

Source: Based on Gallup (2017[14]), Gallup World Poll, 2016-17, https://www.gallup.com/analytics/232838/world-poll.aspx; elaborated by OECD, 2019. 


\section{What explains differences in quality of life?}

In the following sections, this chapter analyses various dimensions of well-being that might explain the differences in life satisfaction across the degree of urbanisation. Until recently, data limitations inhibited an international assessment of differences in life satisfaction, well-being measures and perception between residents of different types of settlements. Two novel sources analysed in this chapter help fill this void, the Gallup World Poll and Demographic and Health Surveys (DHS) (see Box 2.1).

\section{Box 2.1. Data for differences in quality of life by degree of urbanisation}

The newly available classification of Gallup World Poll data by degree of urbanisation offers unprecedented opportunities for analysing differences in well-being between cities and other areas around the world. Based on geo-coded information of respondents' location, the classification provides aggregate statistics for the 3 degrees of urbanisation for more than 100 countries from different regions around the world. Due to the nature of the data, relatively few Western high-income countries are part of the sample. ${ }^{9}$ Instead, a majority of the sample consists of middle-income countries. The final sample consists of 111 countries. ${ }^{10}$

To gauge and quantify spatial differences in socio-economic outcomes in more detail, this chapter also studies highly policy-relevant indicators related to access to services, health, educational attainment, and domestic violence for 41 developing countries based on the Demographic and Health Surveys (DHS). ${ }^{11,12}$ The DHS offer granular geographic cross-country information on health and population, which is not available in developed countries. The countries included in the analysis span across four regions: Sub-Saharan Africa, Latin America and the Caribbean, Southeast Asia and South Asia. ${ }^{13}$

Using these data sources, the analysis in the rest of this chapter focuses on five broad topics that constitute important aspects of quality of life. First, it examines income, economic opportunities and employment across the degree of urbanisation. Second, it analyses educational attainment and schooling. Third, it assesses differences in health outcomes and access to healthcare. Fourth, it sheds light on people's access to services and utilities in each degree of urbanisation. Finally, the chapter presents evidence on residents' exposure to crime and violence.

In analysing these well-being dimensions across the degree of urbanisation, the chapter explores the role of individuals' expectations in shaping their satisfaction and reported quality of life by juxtaposing perception-based outcomes with objective socio-economic outcomes. While differentials across space in socio-economic outcomes might reflect local conditions, some differentials might arise due to sorting, i.e. inherent differences between the population of cities and other areas. To account for sorting, the analysis presented in this chapter includes results from regressions that take into account individual and household characteristics.

\section{Income, economic opportunities and employment}

While living in a city can come with many benefits such as better employment opportunities or higher wages, residents in cities also face higher costs such as living expenses or higher rent. Consequently, the agglomeration benefits which residents of larger cities enjoy can be, at least partly, offset by those higher costs (Ahrend and Lembcke, 2016 $\left[{ }_{[16]}\right)$. However, the overwhelming evidence from middle-income and especially developing countries suggests that cities offer higher real incomes than rural areas (Gollin, Kirchberger and Lagakos, 2019 $\left.{ }_{[3]}\right]$. Due to these real income differences, rural residents in developing countries might stand to benefit from migrating to cities but very large moving costs prevent many from 
doing so and also explain why the gap for real incomes has not been closed (Bryan and Morten, 2019 [17]; Tombe and Zhu, 2019 $[18])$. Those moving costs include financial considerations but also uncertainty as well as the loss of social networks.

\section{Cities and towns and semi-dense areas offer large income premiums}

An analysis of 6 African countries, home to more than 430 million people, based on the definition of degree of urbanisation, highlights that nominal wage and income premiums seem to be substantial in more densely populated areas. Residents and households in cities and towns and semi-dense areas benefit from significantly higher wages and much higher income levels compared to rural areas (Figure 2.4). Individual wages are $26 \%$ higher in towns and semi-dense areas (TSAs) and $35 \%$ higher in cities relative to rural areas. Most people in rural areas in developing countries do not work for wages or are self-employed (see next section) but those who do earn less than their peers in cities or TSAs. Since living costs are likely to be higher in cities and TSAs than rural areas, the real wage differences will be lower than the differences reported here. ${ }^{14}$

The economic benefits of living in densely populated places are even more striking for total household income, which combines income from self-employment, labour, capital and land. In cities, households have income levels more than two and a half times higher than households in rural areas do. Moving down the degree of urbanisation, the income premium falls markedly but remains very high. In TSAs, household incomes are almost $80 \%$ higher than in rural areas. The large premiums in nominal household incomes in cities is likely to derive from four factors. First, household income includes earnings from capital and land and thus extends beyond wage income. Second, in cities, it is more likely that both partners in a household find paid work. Third, if they find paid work, it is better paid and likely to consist of more working hours. Fourth, the cost of living is higher in cities, which requires higher nominal incomes but reduces the overall city premium in real terms.

\section{Figure 2.4. Wage and income differences across the degree of urbanisation in Africa}

Relative differences between cities and towns and semi-dense areas to rural areas
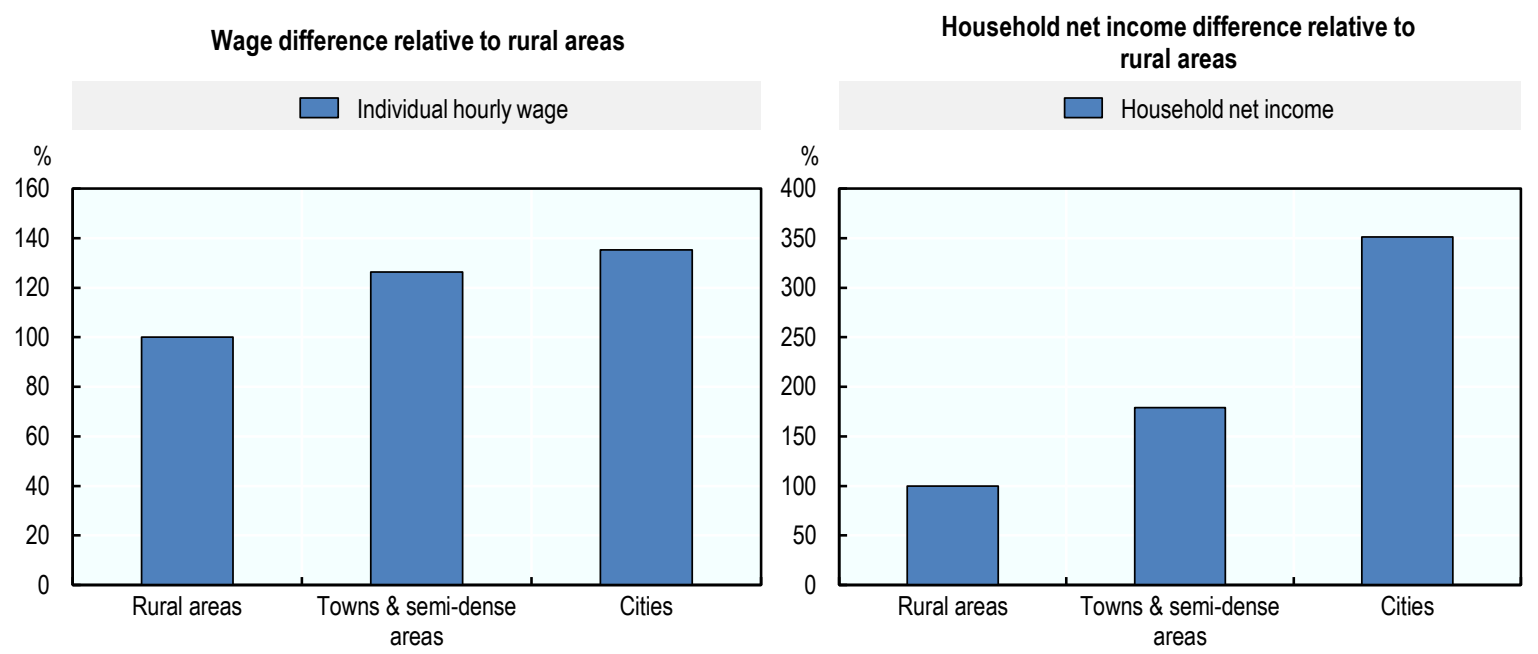

Note: Wages and income in rural areas are the baseline and are set to $100 \%$. The wage differences are based on regression results and control for country and survey year fixed effects. The six countries included are Ethiopia, Ghana, Malawi, Nigeria, Tanzania and Uganda. Wage data include wages from paid labour.

Source: Calculations following the work of Henderson, J., S. Kriticos and D. Nigmatulina (2019 $\left.{ }_{[5]}\right)$, "Measuring urban economic density", CEP Discussion Papers, extending it to the degree of urbanisation based on the GHSL and the Living Standards Measurement Study data of the World Bank. 
The large differences across the degree of urbanisation provide strong economic pull factors of cities, and towns and semi-dense areas in Africa, which might help explain rapid urbanisation in the region. Furthermore, such significant income premiums could directly enhance life satisfaction. Differences in the locally present industries and the types of jobs available to residents are likely to be factors that cause higher wages and income in cities and towns and semi-dense areas. However, even after taking into account such differences, wages and incomes remain substantially higher in more densely populated places (Henderson, Kriticos and Nigmatulina, 2019 $\left.9_{[5]}\right)$.

\section{Employment opportunities follow a clear urban gradient}

Regular employment opportunities are significantly more common in cities than elsewhere. Residents in cities more often work for employers, while self-employment is more frequent in rural areas (Figure 2.5). In general, both the share of employees and the share of self-employed follow clear gradients along the degree of urbanisation. While those patterns are apparent in all country income classes, the shares of employment and self-employment vary substantially by income level. For example, self-employment in rural areas reaches more than $55 \%$ in low-income countries compared to only $20 \%$ in high-income countries. The reliance on self-employment is particularly high in rural areas of Sub-Saharan Africa, Asia and the East Pacific. To some degree, the high rate of self-employment reflects the dominance of agriculture in many rural areas of the world, and especially in low-income countries with reliance on agriculture. ${ }^{15}$ However, self-employment remains significantly higher in rural areas than in cities even when the contribution of agriculture to national GDP is taken into account, which reveals a lack of alternative economic opportunities in modern manufacturing, for example, in rural areas compared to TSAs or cities.

Figure 2.5. Employment and self-employment by the degree of urbanisation and income level

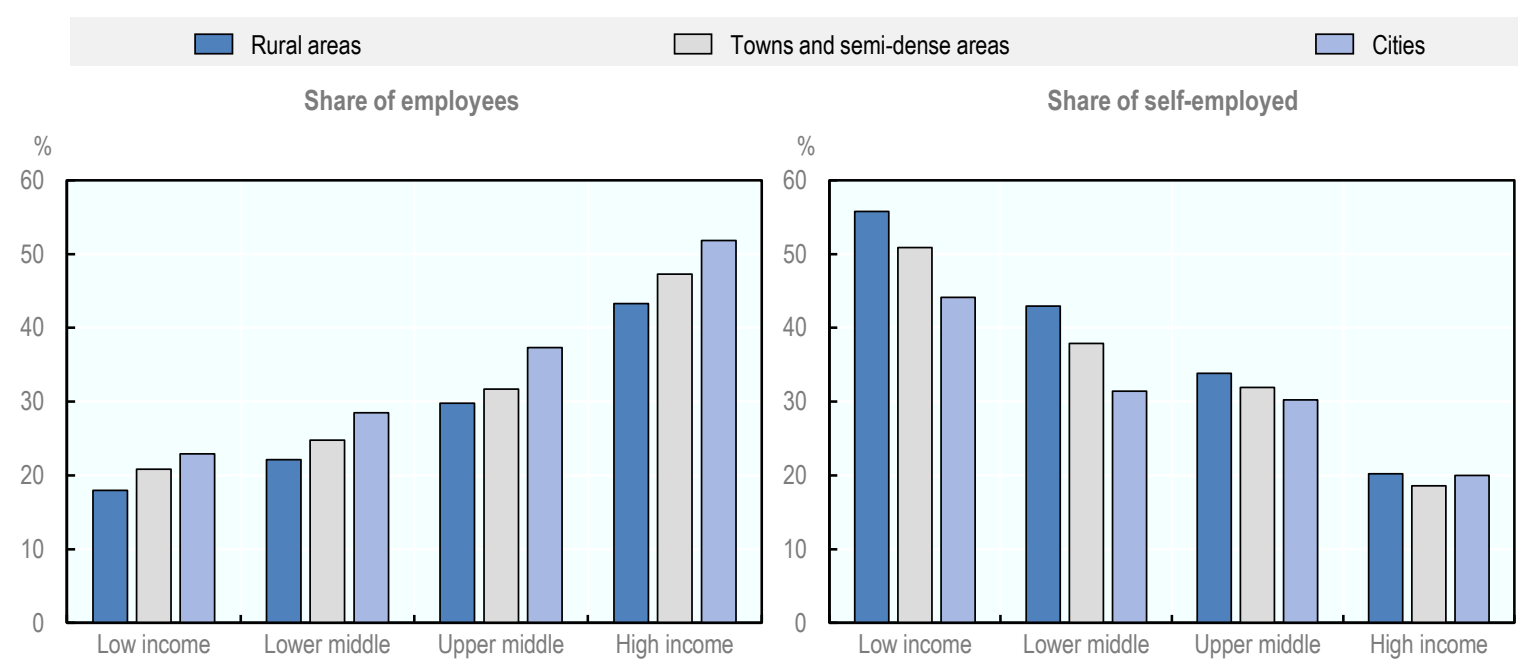

Note: The figure presents simple averages by degree of urbanisation and income group.

Source: Based on Gallup (2017[14]), Gallup World Poll, 2016-17, https://www.gallup.com/analytics/232838/world-poll.aspx; elaborated by OECD, 2019.

\section{More densely populated places offer better economic mobility}

A common assumption explaining the surge of domestic migration towards cities is the greater availability of economic opportunities in densely populated places. Cities benefit from economies of agglomeration that arise from a concentration of physical capital, firms, consumers and workers and make cities more productive with greater job opportunities for residents (Ahrend et al., 2017 $[19]$ ). The lure of more and 
different kinds of jobs, as well as higher wages, underpins the attractiveness of cities, which promise to offer higher economic and thus social mobility. The Gallup World Poll data by the degree of urbanisation for 111 countries appear to confirm this assumption; cities appear to offer their residents the conditions to improve their living standards. The share of the population feeling that their standard of living is getting better is largest in cities and, at $48.0 \%$, is 2.8 percentage points higher than in rural areas.

The gap between rural areas and cities is most pronounced in Sub-Saharan Africa and South Asia, particularly in very poor countries such as the Republic of the Congo, the Democratic Republic of the Congo or South Sudan. In contrast, TSAs perform best in Latin America and the Middle East and North Africa when it comes to improving living conditions. In those regions, countries such as Argentina, Brazil and Lebanon, with significantly lower housing affordability and availability in cities, also fare the worst in terms of improved living standards in cities, with $24 \%-42 \%$ lower values than in rural areas or TSAs.

Local conditions for starting a business offer a pathway for economic mobility. On average, they mostly do not differ significantly between the degrees of urbanisation (Figure 2.6). However, some countries display very high differences in entrepreneurship-friendly local conditions. Especially, rural areas in countries in Eastern Europe and Central Asia struggle to provide adequate conditions for business creations. Compared to rural areas, the share of residents in cities believing that their area is a good place to start a business is 20-30 percentage points higher in Bulgaria, Lithuania, Poland or Russia. In contrast, in Argentina and Bosnia-Herzegovina, rural residents perceive entrepreneurship conditions more favourably.

\section{Figure 2.6. Local conditions for starting a business}

Share of respondents who state the local conditions for starting a business are good

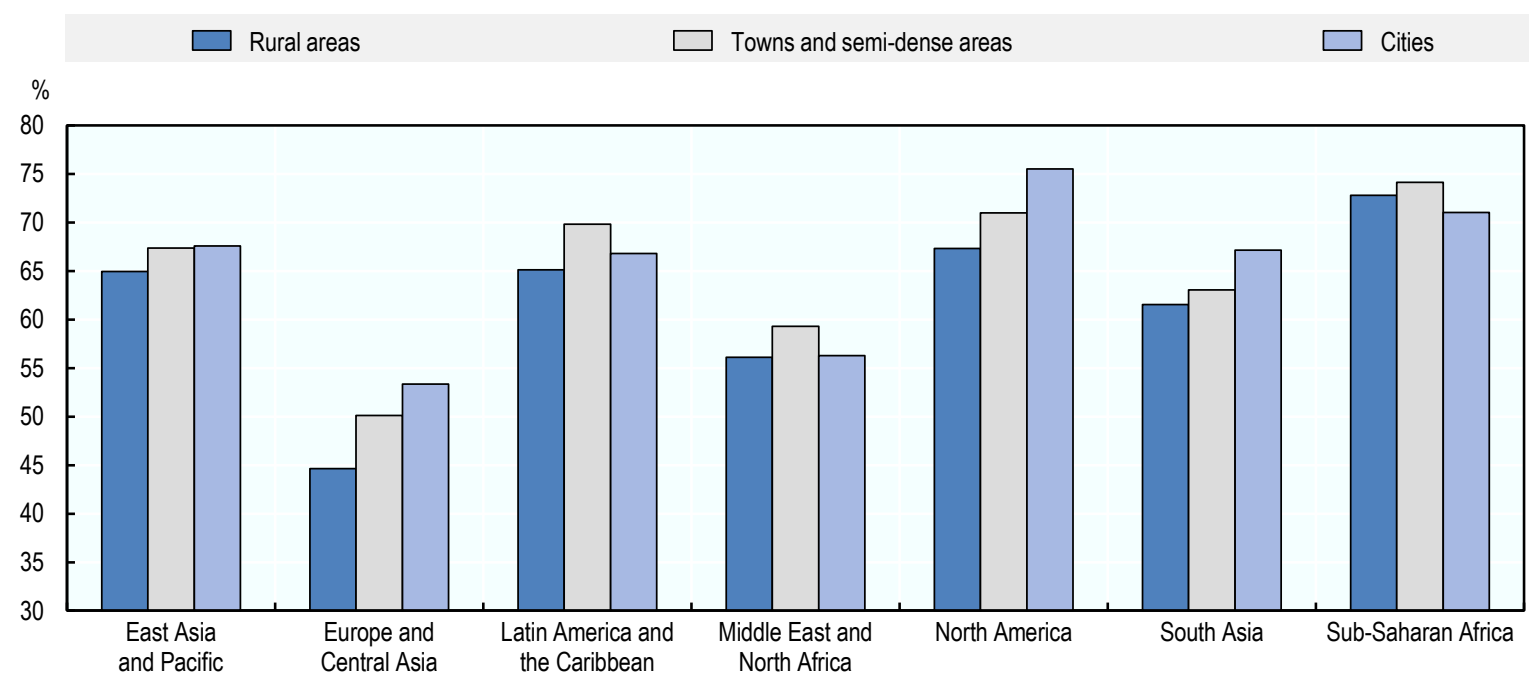

Note: Individuals are asked whether the city or area where they live is a good place or not a good place to live for people starting new businesses. Source: Based on Gallup (2017[14]), Gallup World Poll, 2016-17, https://www.gallup.com/analytics/232838/world-poll.aspx; elaborated by OECD, 2019.

\section{Educational attainment and schooling}

Higher income levels and better economic opportunities are not the only aspects that could explain higher life satisfaction in cities and towns and semi-dense areas compared to rural areas. Education is an important determinant for socio-economic mobility (Card, 1999[20]), as it is a decisive factor in enabling people to find employment, contribute to the economy and move up the socio-economic ladder in one's society. A lack of access to (quality) education in early lives can have a lasting impact on individuals' 
welfare (Heckman, 2006[21]). Educational opportunities can be an even greater policy issue if they vary spatially with some children growing up in a disadvantaged area, city or region. The data from the Gallup World Poll and DHS can shed light on differences in educational opportunities along the degree of urbanisation.

\section{Educational attainment follows a clear urban gradient}

Across the world, educational attainment is significantly higher in cities than in towns and semi-dense areas, which in turn is higher than in rural areas. In rural areas, $52 \%$ of individuals have 8 or fewer years of schooling compared to $34 \%$ in towns and semi-dense areas and $28 \%$ in cities. In contrast, tertiary degrees are more common in more densely populated areas. While less than $7 \%$ of rural residents have university degrees (or 4-year post-secondary education), $13 \%$ of residents in TSAs do. In cities, the share of residents with tertiary education reaches $17 \%$.

For the subsample of 40 developing countries, the differences in educational attainment are even more striking. On average, the share of 16 -year-olds who have completed at least 8 years of schooling is around 20 percentage points higher in cities than in rural areas (Figure 2.7). This pattern is apparent in all regions except for South Asia, where there is virtually no difference between educational attainment in cities and rural areas, and where educational attainment of residents is actually higher in rural areas than in TSAs. Sorting - differences in observable characteristics of individuals and households across the degree of urbanisation - matters but does not explain most of the observed geographic disparities. Consequently, public policies that affect the supply of educational opportunities are likely to be important drivers of geographic differences in educational attainment.

Figure 2.7. Share of 16 -year-olds with at least 8 years of schooling

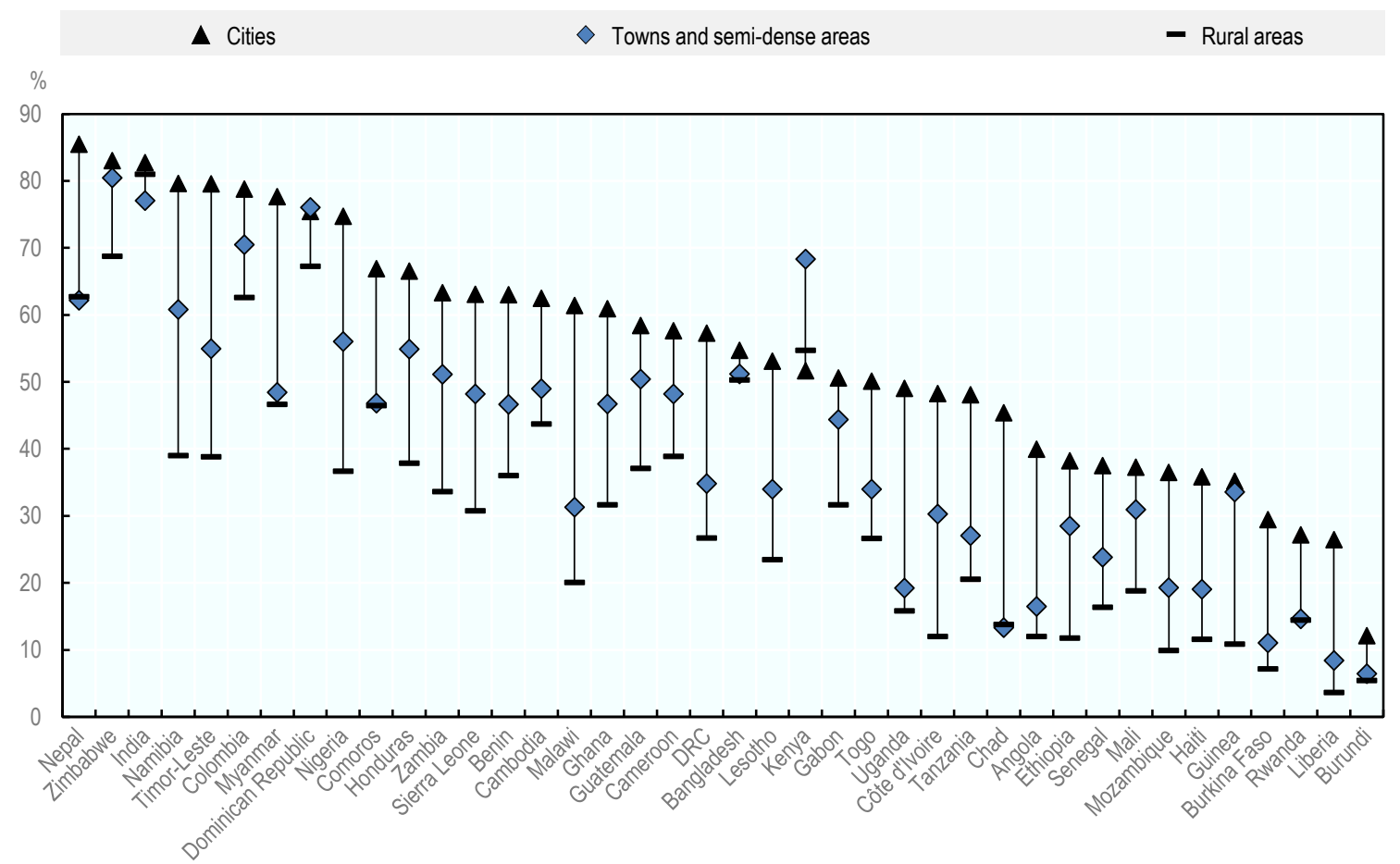

Source: DHS (2016[22]); Henderson, V. et al. (2019 $\left.{ }_{[23]}\right)$, "Urbanisation and demographic and health outcomes: Perspectives from a new classification of urban areas". 
Cities clearly seem to offer much better educational opportunities than other areas. Especially in Sub-Saharan Africa, educational attainment is significantly higher in cities, as rural areas record 8-year completion rates below 30\% whereas cities surpass 50\%. Even in Latin America and Southeast Asia, where 8-year completion rates exceed $70 \%$ in cities, less than half of the 16 -year-olds in rural areas have completed 8 years of schooling. In Sub-Saharan Africa, part of the reason children do not complete Grade 8 by age 16 is that many 12- and 13-year-old children have still not completed even Grade 4. This suggests two things: earlier years in school were marked by lack of completion of the grade, and likely by low attendance; they attend but do not finish grades.

Over the last 15 years, educational attainment has improved significantly. The fraction of 16 -year-old children who have completed 8 years of schooling increased in all degrees of urbanisation by 10 to 20 percentage points in Sub-Saharan Africa and by 20-30 percentage points in our South Asian sample. Within regions, however, the rural-city differential in Sub-Saharan Africa of 20 points in 2000 increased to over 25 percentage points in 2015. In contrast, in South Asia, that rural-city gap fell remarkably from almost 30 points, such that today rural and city rates of education are almost the same. Bangladesh and Nepal have made great strides in increasing especially rural education.

\section{Perception of quality of schools in rural areas is more positive than actual outcomes}

Perceptions of educational opportunities of children are more positive in rural areas but this stands in contrast to actual educational attainment and likely reflects lower expectations. Overall, residents in rural areas in East Asia and the Pacific have the highest faith in educational opportunities of children in their country. $87.5 \%$ believe that most children in their country have the opportunity to learn and grow every day. At the other side of the spectrum, only $54.3 \%$ of people in cities in the Middle East and North Africa have a favourable opinion about children's educational opportunities. Globally, negative views about children's educational opportunities are most common in cities, with towns and semi-dense areas and rural areas performing comparably in this regard.

Rather than disclosing better educational opportunities in rural areas, the observed pattern might indicate higher expectations of city residents with respect to the education system. For example, large withincountry differences are most striking in Latin America and the Caribbean, where positive views about children's opportunities to learn and grow are 8 to 9 percentage points lower in cities than in the rest of the country even though rural areas are unlikely to benefit from better schools or funding for education. As documented in Figure 2.7, rural areas, in fact, record significantly lower educational attainment than cities in Latin America and the Caribbean. The share of 16 -year-olds with at least 8 years of education is almost twice as high in cities (54\%) than in rural areas (28\%). A similar rural-city discrepancy is observable in Sub-Saharan Africa and Southeast Asia, suggesting that more favourable subjective assessment in rural areas might be due to a lack of experience with or missing exposure to educational opportunities.

\section{Health outcomes}

\section{Health outcomes vary substantially by gender across the degrees of urbanisation}

Outcomes on health, a key element of individual well-being (Boarini, Murtin and Schreyer, 2015[24]), reveal strong city-rural discrepancies. In terms of self-reported health outcomes, there is a clear gradient across the degrees of urbanisation (Figure 2.8). On average, more than $31 \%$ of residents of rural areas reported suffering from health problems that prevent them from doing things people their age normally do. Around $28 \%$ of residents in towns and semi-dense areas reported such health issues. In comparison, city residents appear to be significantly less likely to have health problems, with less than a quarter $(24.6 \%)$ reporting significant health issues. 
Across all degrees of urbanisation, there is a clear distinction in terms of gender: women report suffering significantly more from health problems than men (Figure 2.8). This gender health difference appears highest in Europe and Central Asia as well as the United States (US), where women in rural areas and TSAs state to fare considerably worse than men. Overall, the gap between rural areas on the one hand and cities on the other is especially large in the US and Sub-Saharan Africa, where the likelihood to report health problem is 15 and 11 percentage points respectively, higher in rural areas than in cities. These spatial differences cannot simply be explained by different age profiles or educational attainment of residents across the degree of urbanisation.

Figure 2.8. Health problems by gender in cities, TSAs and rural areas

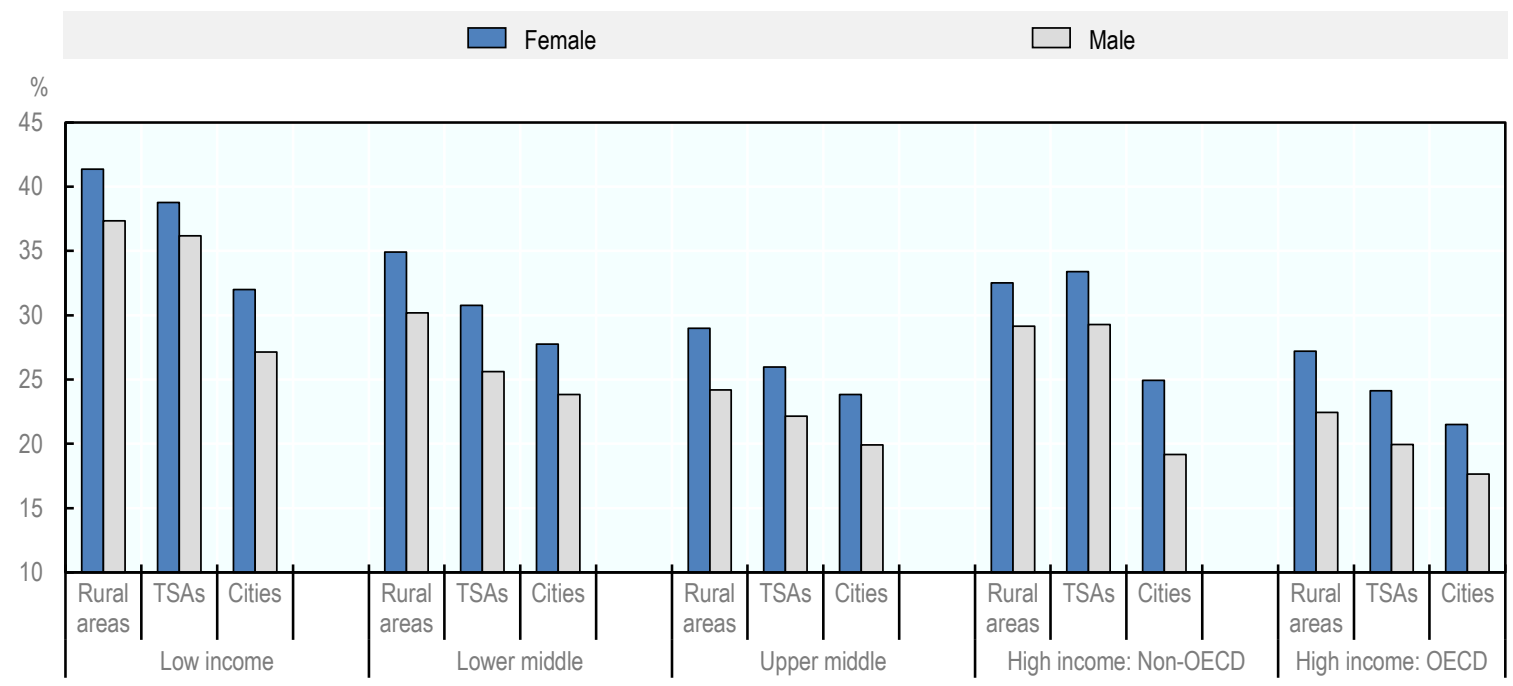

Note: Share of residents who report having significant health problems. TSAs denote towns and semi-dense areas.

Source: Based on Gallup (2017[14]), Gallup World Poll, 2016-17, https://www.gallup.com/analytics/232838/world-poll.aspx; elaborated by EC and OECD, 2019.

StatLink 젬 https://doi.org/10.1787/888934130284

Among cities, health problems tend to be worse in those countries that have a very large as well as rising urban population and that have experienced rapid economic growth. For example, in Bangladesh, China or Indonesia, health problems are $41 \%, 36 \%$, and $31 \%$ more likely in cities than in rural areas. The share of people living in cities (or urban centres) has reached $41 \%$ in China (compared to $29 \%$ in 1975 ), $54 \%$ in Bangladesh (compared to $18 \%$ in 1975) and even $57 \%$ in Indonesia (compared to $47 \%$ in 1975). At the same time, the GDP per capita in those 3 countries multiplied by a factor of 28 (China), 5 (Indonesia) and 4 (Bangladesh) between 1975 and 2018.

Despite a greater propensity of rural residents to have health problems, satisfaction with health services does not substantially differ across the degrees of urbanisation, highlighting the role of expectations in shaping perception measures. There are only marginal differences between cities and rural areas across all regions of the world, apart from South Asia where city residents are $30 \%$ more likely to be satisfied with the availability of healthcare in their area. Overall, residents of towns and semi-dense areas express the highest level of satisfaction (52\%) with the availability of quality health services. However, measures of actual access to health services vary enormously (see below section on women's access to health services), with much lower levels in rural areas, indicating that local satisfaction is strongly shaped by expectations. 


\section{In developing countries, rural areas are catching up on health outcomes}

Health outcomes such as infant mortality, diarrhoea among children and vaccinations are better in cities than in the countryside in developing countries. However, the discrepancies by the degree of urbanisation in all four regions considered (Sub-Saharan Africa, Latin America and the Caribbean, South Asia and Southeast Asia) are more modest when differences in the characteristics of the local population are taken into account. A second set of health outcomes shows a consistent urban penalty, demonstrating that some health aspects in developing countries deteriorate in cities compared to rural areas.

Health outcomes offer a good indication of living conditions, including access to health services and other public services. Thus, they help to highlight and quantify to what extent living conditions differ across the degree of urbanisation in the developing world. However, sorting, inherent differences in the composition of the population of different areas in terms of education etc. can cause spatial differences in health outcomes by affecting the information on and use of health services. This section additionally examines how such sorting influences geographic differences in health outcomes.

\section{Core child health outcomes}

Infant mortality and diarrhoea rates display the expected urban gradient, with better outcomes in cities, followed by towns \& semi-dense areas (TSAs), and worst outcomes in rural areas. However, the differentials across rural areas, TSAs and cities are generally not large. Per thousand live births, infant mortality is 5-10 deaths higher in rural areas than in cities (Figure 2.9). The rural-city gap is largest in lowermiddle-income countries, where less than 38 children per 1000 live births do not survive to age 1 in cities, compared to 47 deaths per 1000 live births in rural areas. Overall child mortality rates range from 25 to 50 per 1000 live birth by world region, with Sub-Saharan Africa recording the largest mortality rates.

Compared to child mortality, geographic differences in diarrhoea rates and DPT (diphtheria, pertussis and tetanus) vaccination rates are relatively small, never exceeding a few percentage points (Figure 2.9). Both diarrhoea and DPT vaccination rates are health dimensions with noticeable inter-regional differentials, especially between Latin America and the Caribbean and Sub-Saharan Africa, but minuscule within-region differences between rural areas, TSAs and cities. The largest rural-city differences in diarrhoea rates exist in Latin America and Southeast Asia with around 3 percentage points higher rates in rural areas. In all four regions, national average DPT vaccination rates are high and geographic differences appear small, which might perhaps be due to large international vaccination campaigns.

Overall, diarrhoea rates mirror the patterns observed in access to utilities, especially improved sanitation, highlighting the fact that they are directly linked to water and sanitation infrastructure. Consequently, geographic disparities in terms of such infrastructure appear to lead to differences in the health outcomes of children. For example, in Sub-Saharan Africa and South Asia, improved sanitation is significantly associated with lower diarrhoea rates of children. ${ }^{16}$ Consequently, children in cities who benefit from better provision of utilities are less at risk of health problems such as diarrhoea.

Even though geographic disparities persist, health outcomes have improved vastly and broadly along the degrees of urbanisation. Over the past 15 years, infant mortality as well as diarrhoea rates fell markedly while DPT vaccination increased further. For example, infant mortality fell in South Asian countries by about $50 \%$ in each type of area. Sub-Saharan Africa saw a similar drop close to $50 \%$ in rural areas and smaller but substantial decreases in cities and TSAs as well (Figure 2.10). Rates of diarrhoea fell less dramatically but still substantially, by about 5 percentage points across the degrees of urbanisation from previous rates of $8 \%-20 \%$. DPT vaccinations rose by more than 15 percentage points in all areas from a starting point of about $50 \%-65 \%$, with the largest gains occurring in urban areas. All of these developments demonstrate significantly improved healthcare and more information and awareness of available services even in less densely populated areas in the developing world. 
Figure 2.9. Infant mortality, diarrhoea and DPT vaccination rates, by world regions and income classes

Differences by the degree of urbanisation

$\square$ Rural areas $\square$ Towns and semi-dense areas $\quad \square$ Cities
Child mortality rates
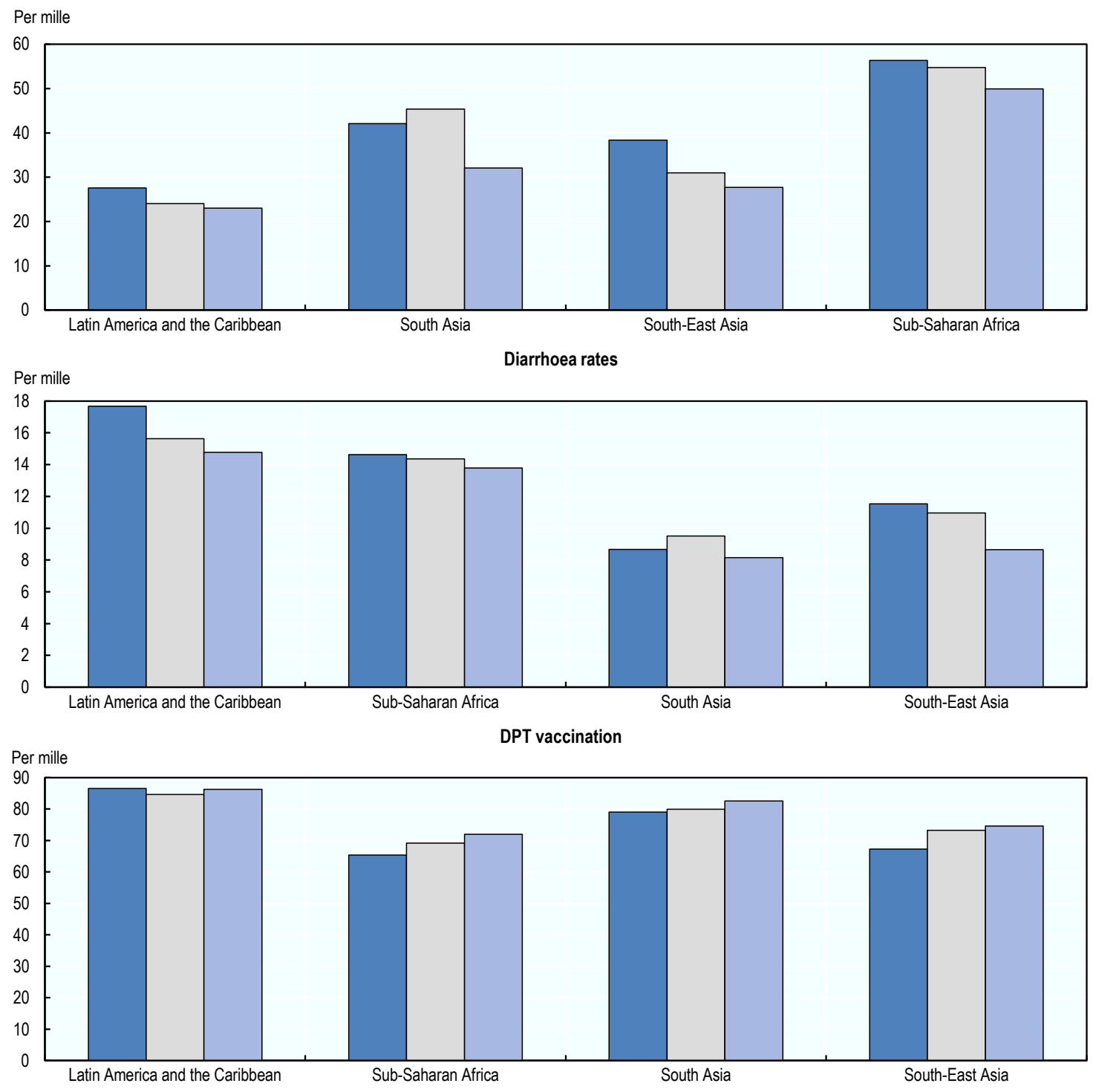

Note: Infant mortality rate is the share of children born in the 5 years before the survey that did not survive to age 1 . The diarrhoea rate is the share of children under 5 experiencing diarrhoea in the past 2 weeks. DPT vaccination shows the share of children that received the third dose of DPT vaccine.

Source: DHS (2016[22]); Henderson, V. et al. (2019[23]), "Urbanisation and demographic and health outcomes: Perspectives from a new classification of urban areas". 
Figure 2.10. Relative changes (in percentage) in health outcomes, 2000-15, Sub-Saharan Africa and South Asia

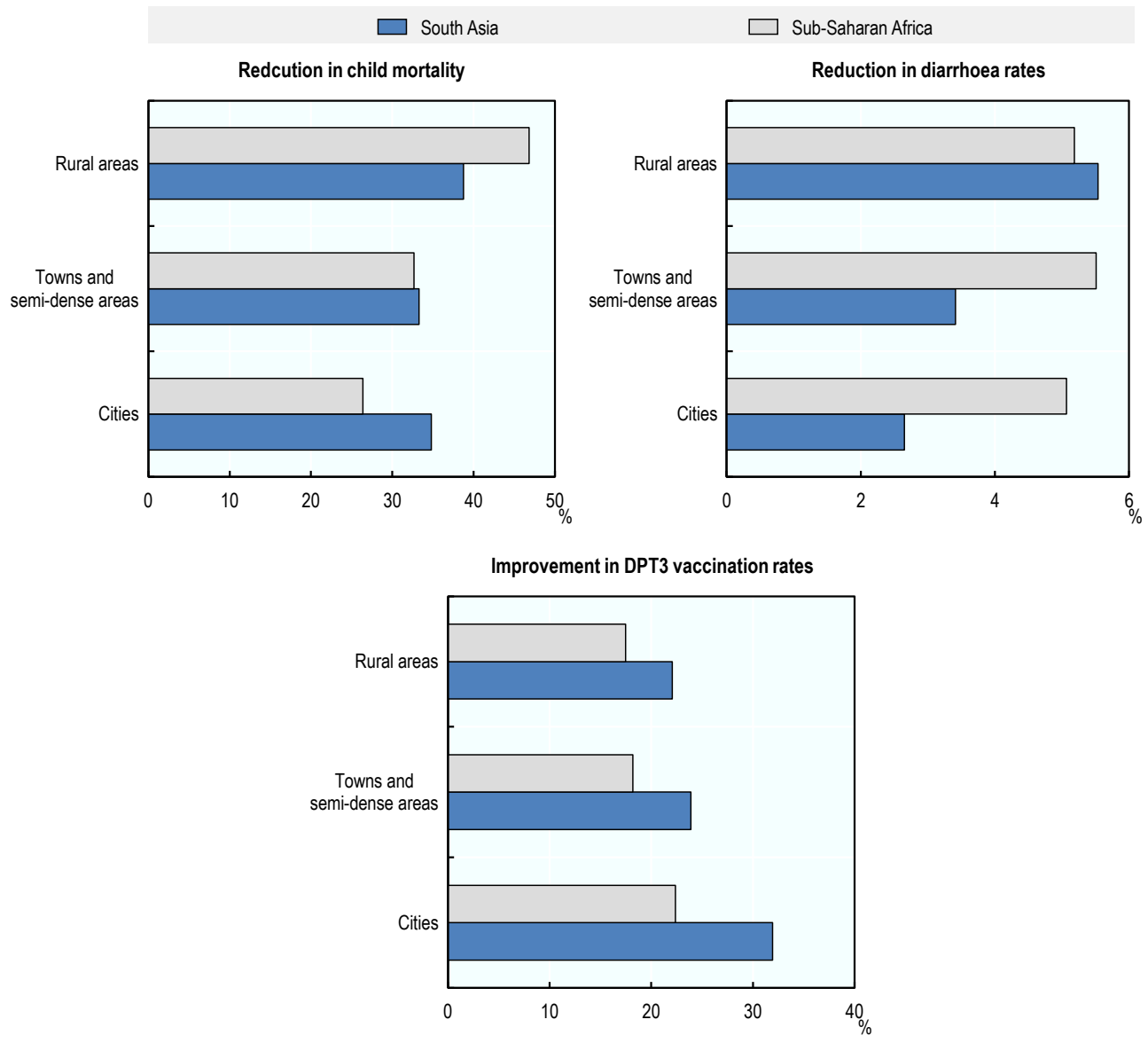

Note: All changes present percentage reductions (child mortality, diarrhoea) or increases (DPT3 vaccination) between 2000 and 2015 , with the averages in 2000 as the base rates. The infant mortality rate is the share of children born in the 5 years before the survey that did not survive to age 1. The diarrhoea rate is the share of children under 5 experiencing diarrhoea in the past 2 weeks. DPT vaccination shows the share of children that received the third dose of DPT vaccine.

Source: DHS (2016[22]); Henderson, V. et al. (2019 $\left.{ }_{[23]}\right)$, "Urbanisation and demographic and health outcomes: Perspectives from a new classification of urban areas".

\section{Women's access to health services}

Access to medical services is a major impediment to better health outcomes in rural areas in developing countries, in particular for women. Two key factors prevent female residents, especially in rural areas, from using and benefitting from medical services. First, supply, i.e. the availability, of medical facilities is geographically concentrated in specific areas. Therefore, residents in many areas need to travel large distances to even reach such facilities. Second, women's permission to seek and exploit medical services at their disposal is often limited in developing countries.

In most developing countries, distance to medical facilities prevents better access to medical services. Consistent with cost minimisation in care provision, the share of women who report not using medical services due to distance is much lower in cities (Figure 2.11). On average, women in rural areas are twice as likely to report distance as an obstacle for seeking medical help as women in cities. In Cambodia, Liberia, Sierra Leone, Zambia and Zimbabwe, distance is three to four times more likely to be an impediment in rural areas than in cities. Requiring the permission of their partner or family is a second reported barrier to healthcare for women but its impact appears to be lower than geographic distance. On 
average, $16 \%$ (in cities) to $21 \%$ (in rural areas) of women cite a lack of permission as a reason for not receiving medical services. In general, differences across the degree of urbanisation are relatively small, in particular in Africa and Latin America, where there are no distinguishable differences between women in cities, TSAs or rural areas.

\section{Figure 2.11. Distance as an impediment to medical services}

Women citing distance as a reason to not seek medical help

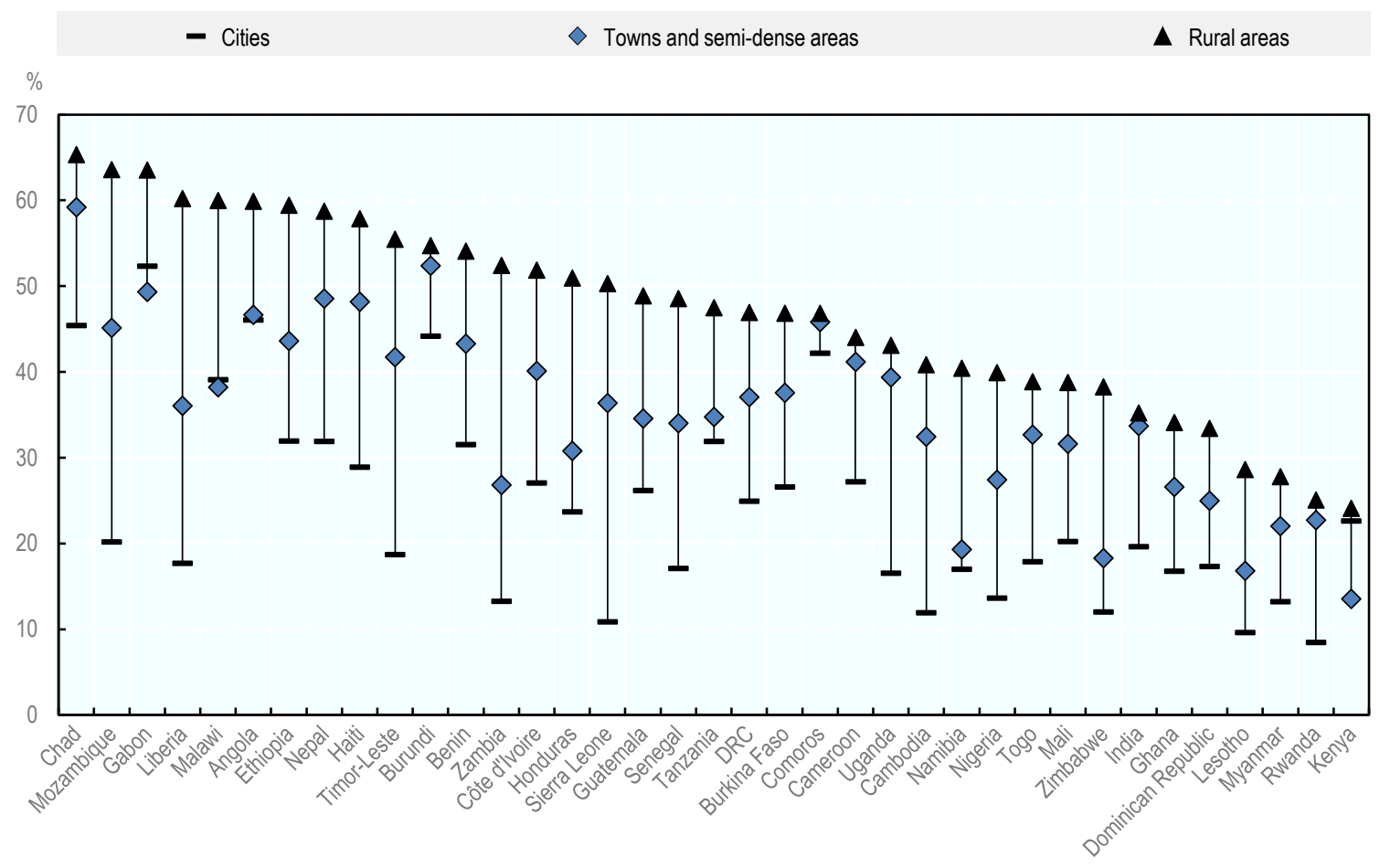

Note: Percentage of respondents, women aged 15-49, who did not go to a medical facility when sick. The indicator records the fraction of respondents reporting that distance was a big problem versus no problem or a small problem.

Source: DHS (2016[22]); Henderson, V. et al. (2019[23]), "Urbanisation and demographic and health outcomes: Perspectives from a new classification of urban areas".

\section{Health risks in cities}

While cities afford their residents plenty of opportunities in terms of jobs and services, they are also prone to specific health risks and hazards that concentrate in urban environments. Air pollution, a lack of exercise or the abundance of unhealthy food are often associated with cities and lead to adverse health outcomes in various dimensions. Therefore, city residents are also likely to face "urban ills" that result from those health-deteriorating factors.

Among those urban ills, obesity especially shows more negative health outcomes in cities. Obesity rates are strikingly higher in cities than in both towns \& semi-dense areas, and rural areas. In Sub-Saharan African and South Asian cities, residents are 2.3 times more likely to be obese than in rural areas (Figure 2.12). Across all four world regions, obesity increases with population density. Cities also report slightly higher rates of children's cough than rural areas in all regions. Even though these differences appear small, they are statistically significant in a regression framework even when controlling for sorting. ${ }^{17}$ 
Figure 2.12. Obesity and cough by region and degree of urbanisation

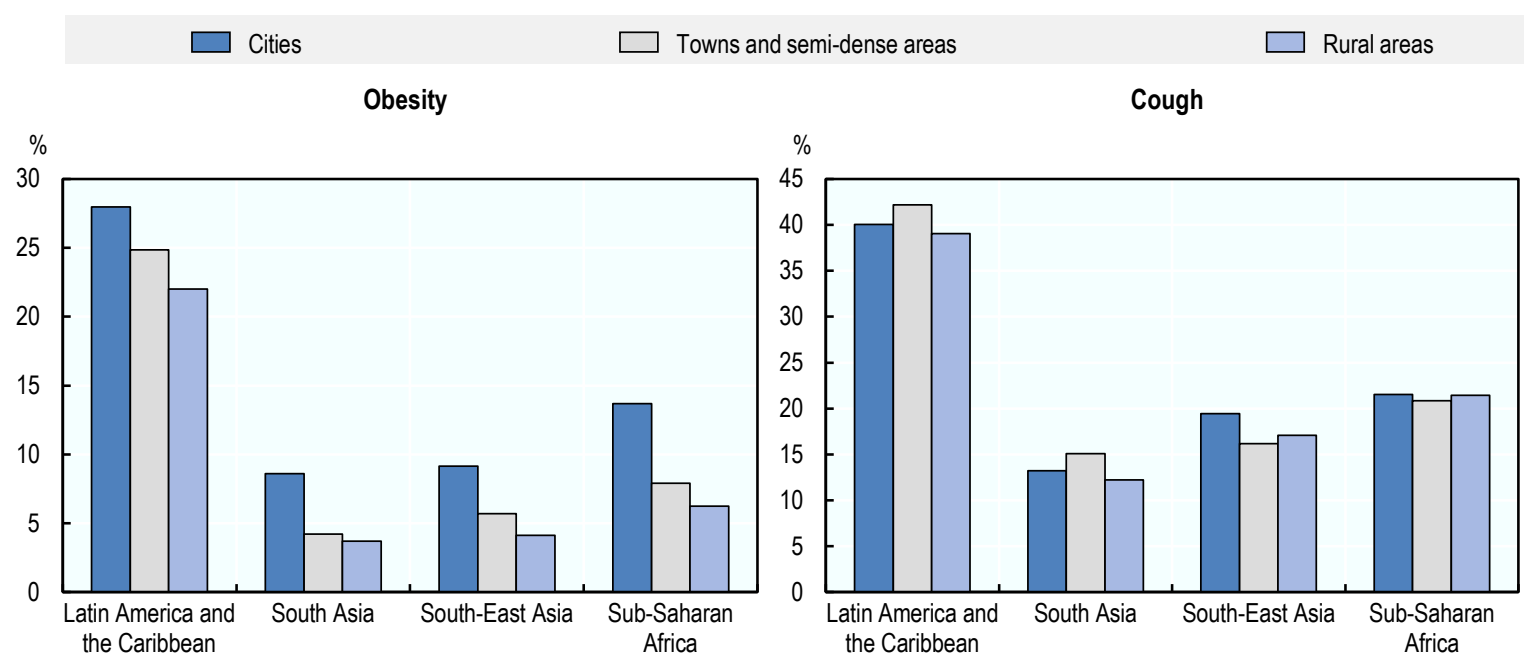

Note: The left panel displays the percentage of obese respondents, where obesity was defined as having a body mass index $\geq 30$. The sample consists of household members that were 20-49 years old, eligible for the individual male and female surveys, and not pregnant. Data on obesity for the Angola 2015-16 survey was unavailable. The right panel shows the percentage of children aged 5 and under who have had a cough in the last 2 weeks.

Source: DHS (2016[22]); Henderson, V. et al. $\left(2019_{[23]}\right)$, "Urbanisation and demographic and health outcomes: Perspectives from a new classification of urban areas".

\section{Access to services and utilities}

\section{Location matters enormously for access to public infrastructure and modern technology}

Across the world, the geographic concentration of satisfactory public infrastructure is highest in SubSaharan Africa and South Asia where the satisfaction with roads and highways ranges from $66 \%$ to $54 \%$ and $42 \%$ to $35 \%$. Expectedly, highest satisfaction recorded in cities and lowest in rural areas. The geographic disparity in actual access to roads and highways is likely to be higher than suggested by satisfaction levels, again highlighting the role of expectations in shaping individuals' perceptions of local conditions.

Disparities in accessibility are even more striking in terms of digital infrastructure and modern technology (Figure 2.13). Across all four country income groups, Internet access follows a clear gradient. More residents in cities and TSAs have Internet access than in rural areas. Globally, the share of residents in cities with regular Internet access is almost $50 \%$ above that of rural residents. Unsurprisingly, the largest disparities exist in low-income and lower-middle-income countries. Recent use of the Internet, which is linked to SDG 17.8.1, is more common than regular Internet access and displays less geographic differences. Nonetheless, residents' Internet use still differs significantly by location in lower-middle- and low-income countries. For example, only $56 \%$ of rural residents had used the Internet over the past 7 days, compared to $67 \%$ and $74 \%$ of residents in TSAs and cities respectively. 
Figure 2.13. Use and regular access to the Internet

Shares of respondents who have used the Internet in the past seven days and who have regular Internet access

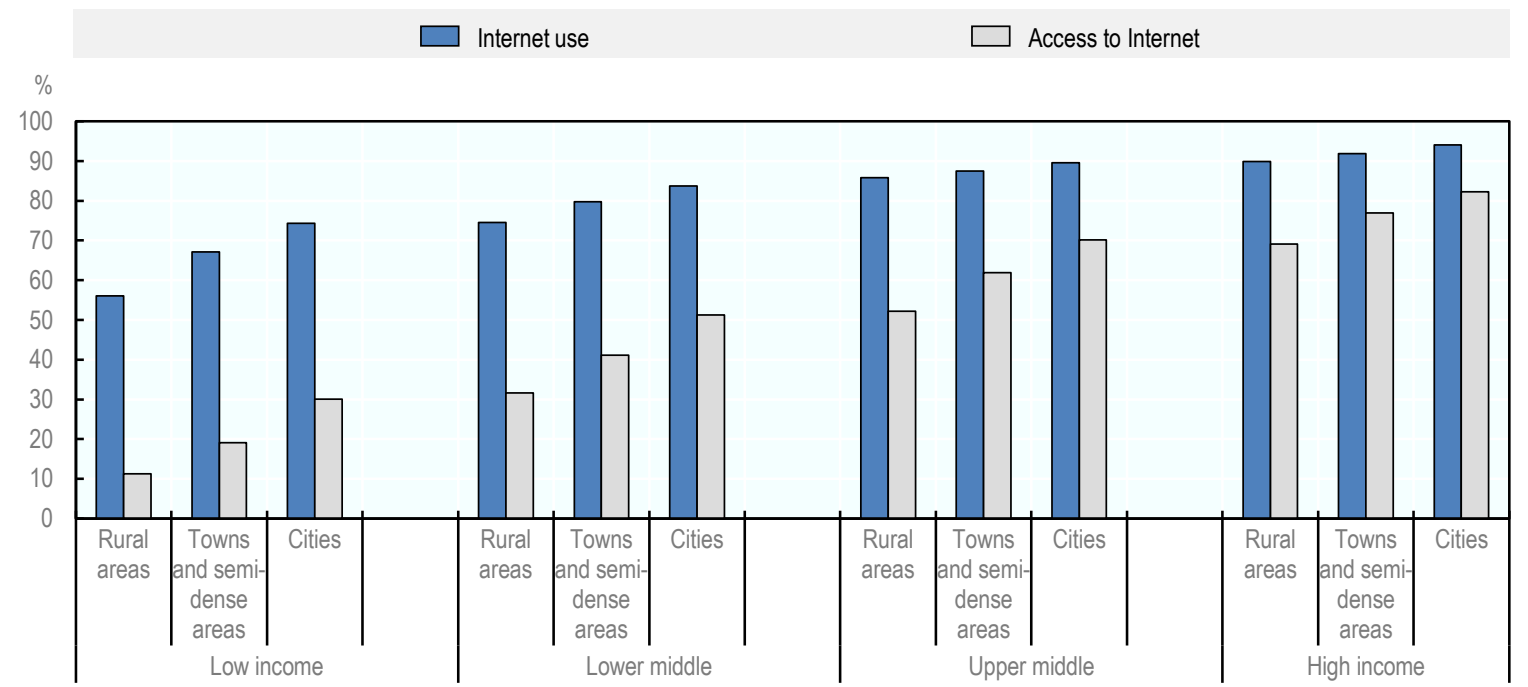

Source: Based on Gallup (2017[14]), Gallup World Poll, 2016-17, https://www.gallup.com/analytics/232838/world-poll.aspx; elaborated by OECD, 2019.

Disparities by degree of urbanisation in low-income countries also exist with respect to mobile phones (SDG 5.b.1). Only around half of rural residents in low-income countries own a mobile phone compared to more than $60 \%$ of residents in TSAs and more than $70 \%$ of residents in cities (Figure 2.14). In more economically developed countries, the pervasive spread and low cost of mobile phones have led to almost full coverage of mobile phones among residents in all degrees of urbanisation.

\section{Figure 2.14. Share of individuals that have a mobile phone}

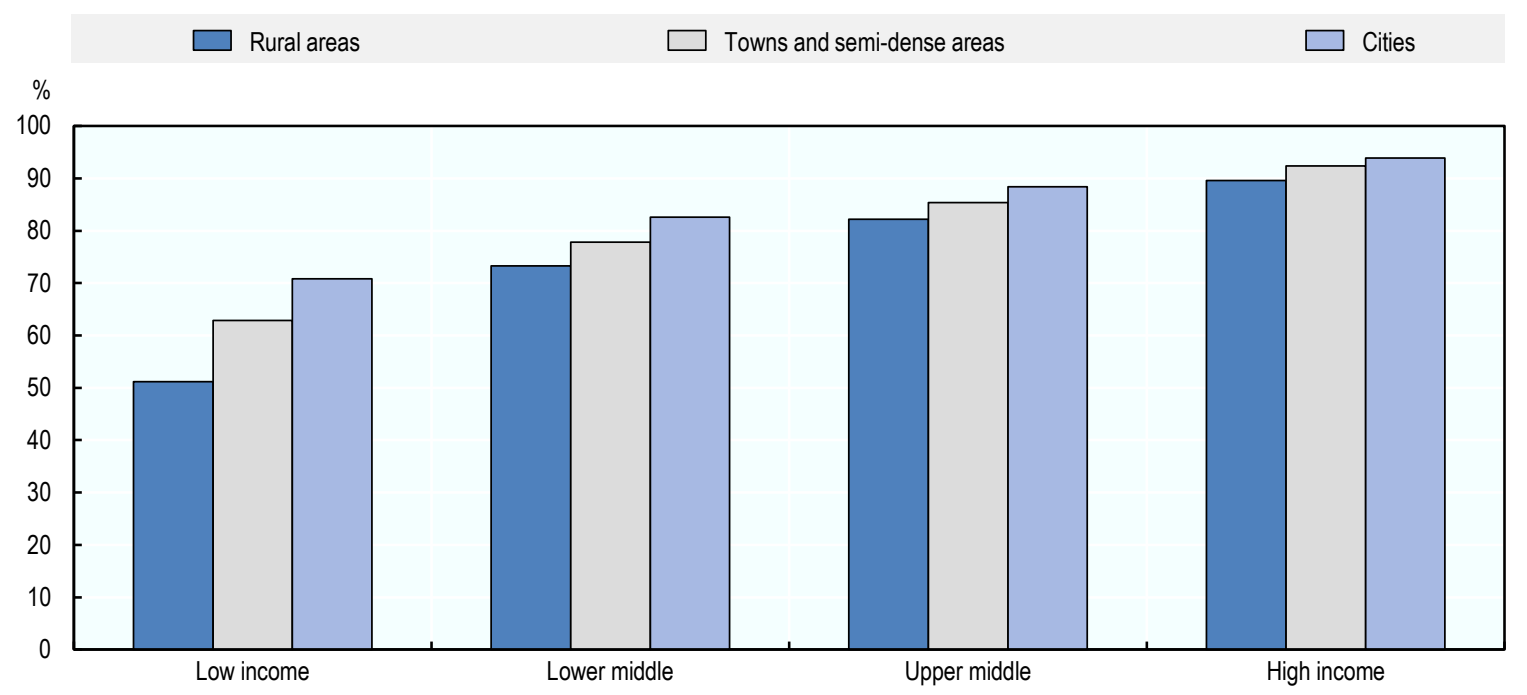

Source: Based on Gallup (2017[14]), Gallup World Poll, 2016-17, https://www.gallup.com/analytics/232838/world-poll.aspx; elaborated by OECD, 2019. 
Lower access to infrastructure and modern technology in rural areas is a pressing issue due to its relevance for existing as well as emerging policy challenges. Demographic and environmental changes create new obstacles to providing public services and infrastructure in all territories. In many OECD countries, for instance, ageing fundamentally alters the demographic and social fabric of regions and cities (OECD, $2019_{[25]}$ ). Consequently, providing access to services will become a formidable challenge for policymakers, especially in sparsely populated areas that already experience lower levels of service provision. Leveraging the opportunities that digitalisation offers can mitigate such problems, especially in remote areas (OECD, 2018[26]). Furthermore, quality digital infrastructure promises to create new job opportunities and might increase productivity. However, taking advantage of those opportunities requires adequate infrastructure in terms of modern technology such as high-speed Internet connections.

Accessibility is a policy challenge that extends beyond OECD countries. Geographic discrepancies in accessibility appear exacerbated in countries with even larger economic differences between cities and the rest of the respective country. The next section examines in more detail these differences by the degree of urbanisation, shedding light on access to utilities in 40 developing countries.

\section{In developing countries, city residents benefit from substantially better provision of public services}

Across all four world regions (Sub-Saharan Africa, Latin America and the Caribbean, South Asia and Southeast Asia), the provision of utilities is consistently and significantly better in cities than in rural areas. Overall, there is clear gradient in utilities along the degree of urbanisation, with residents in towns \& semidense areas having lower access to utilities than city residents but better access than rural residents. Cityrural differences are particularly large for electrification rates, piped water and access to safely managed drinking water. However, most areas but especially rural areas have documented significant improvements in core utilities over the past 15 years that have a direct link to health outcomes.

While access to electricity is a requirement for many home-based amenities, electrification remains an area with very large rural-city differences in developing countries. Unsurprisingly, electrification is much more common in cities than in both towns \& semi-dense areas (TSAs) as well as rural areas. On average, almost $75 \%$ of homes in cities have access to electricity, compared to $45 \%$ in TSAs and less than $31 \%$ in rural areas (Figure 2.15). The city-rural differentials in electrification are especially large in Sub-Saharan Africa and Southeast Asia, which also have the lowest average national rates. One exception to the observed gradient along the degree of urbanisation is South Asia, where electrification rates are almost 10 percentage points lower in TSAs than in rural areas. Similar to electrification, piped water is more common in cities everywhere but differences between rural areas and TSAs are generally small. The higher population density in cities reduces the per capita cost of providing the necessary infrastructure for utilities and might thus explain the observable geographic differences. While general availability of piped water is low in Sub-Saharan Africa and Southeast Asia, settlements in Latin America have a much higher uptake of piped water and also report a clear urban gradient. Households in Latin American cities are most likely to have piped water but households in TSAs also report a sizeable advantage over households in rural areas.

Broader categories of water-related utilities reveal a clearer picture of geographic disparities. Safely managed water, which includes protected wells or springs, boreholes, packaged water and rainwater, is not only more widely available in all four regions but differences across the degrees of urbanisation are also larger. On average, TSAs report more than 5 percentage points higher access to safely managed water than rural areas but still fall 10 percentage points short of the level of cities. Some of the largest within-country differences exist in Sub-Saharan African countries. For example, in the Ivory Coast, Malawi and Nigeria, rural areas display approximately 35 to 40 percentage points lower access to safe drinking water (Figure 2.16). Improved sanitation also follows the expected urban gradient, with large city-rural differences of at least 20 percentage points, and levels in TSAs levels slightly above those in rural areas. ${ }^{18}$ 
For Sub-Saharan Africa specifically, overall rates are lower than in other regions; and there are very large rural-city differentials. In particular, $40 \%$ and $70 \%$ of city households have respectively safe water or improved sanitation, while in rural areas the respective numbers are about $12 \%$ and $36 \%$, under half of city rates.

Figure 2.15. Electricity and piped water across the degree of urbanisation

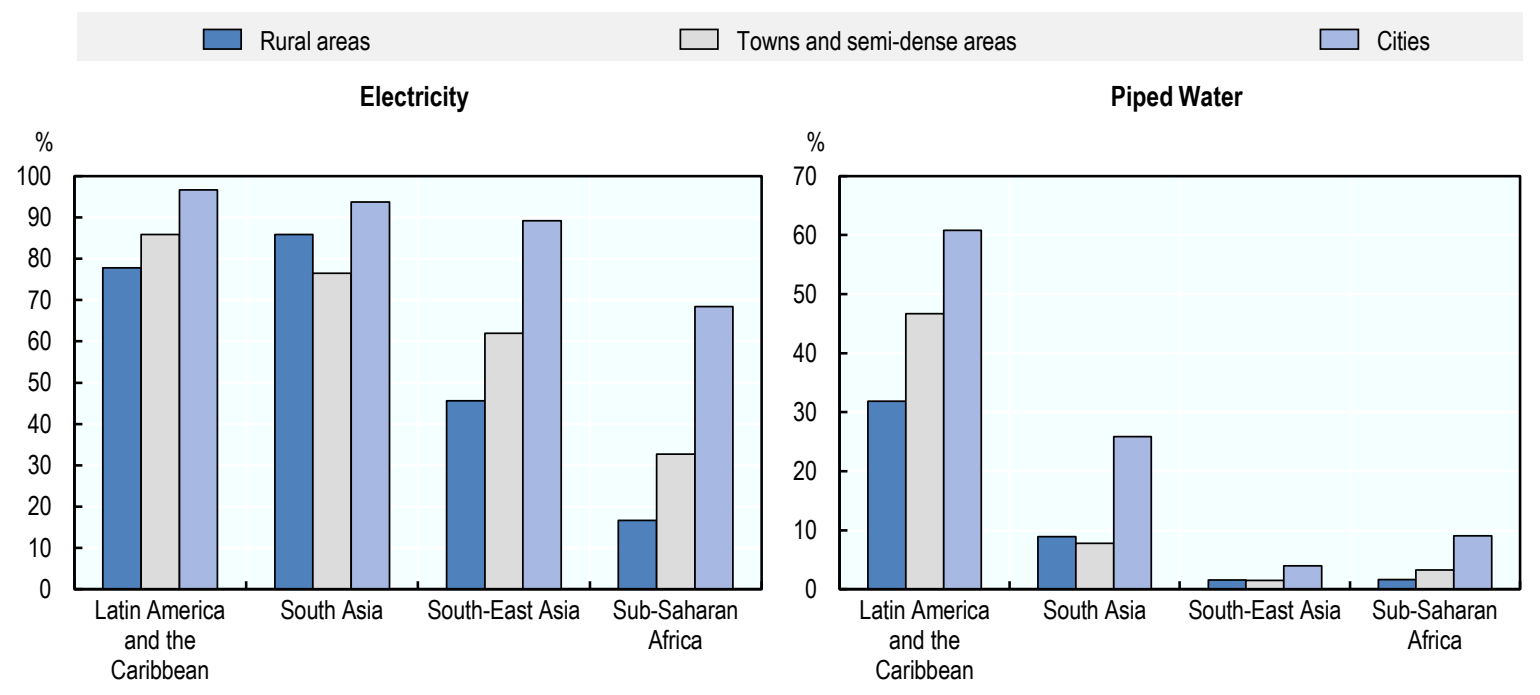

Note: Electricity refers to electricity in the household. Piped water refers to water piped into the respondent's house.

Source: DHS (2016[22]); Henderson, V. et al. (2019[23]), "Urbanisation and demographic and health outcomes: Perspectives from a new classification of urban areas".

Over the past 15 years, the provision of utilities has improved dramatically in some countries but stagnated in others. ${ }^{19}$ While residents in all degrees of urbanisation in South Asia enjoyed both improvements in electrification rates and piped water, the picture is more mixed in Sub-Saharan Africa. Electricity connections increased significantly in all degrees of urbanisation but most strikingly in rural areas. Rural electrification nearly doubled in Sub-Saharan Africa from initial rates of around $10 \%$ and almost quadrupled in South Asia, reaching nearly $60 \%$ in 2015 . Interestingly, rural electrification even surpassed electrification in TSAs, suggesting that infrastructure investments in rural areas were significantly higher during that period.

In contrast to electrification, piped water penetration actually fell in cities in Sub-Saharan Africa and remained essentially unchanged in rural Africa. A potential explanation for the observed differences in changes over time in Sub-Saharan Africa is that new city residents moved to sites on the edge of cities that had been rural, with no infrastructure in 2000. In South Asia, all areas recorded improvements in piped water access. While the largest expansion took place in South Asian cities, rural areas recorded larger improvements than TSAs and now display a greater level of access to piped water. Consequently, Sub-Saharan African cities have faced a challenge of providing services to meet the needs of a rapidly growing population. Since piped water, which requires laying down water mains and often retrofitting, is more expensive to provide than extending electricity lines, electrification improved while access to piped water deteriorated. 
Figure 2.16. Access to safely managed drinking water across the degree of urbanisation

Selected countries, 2010-16

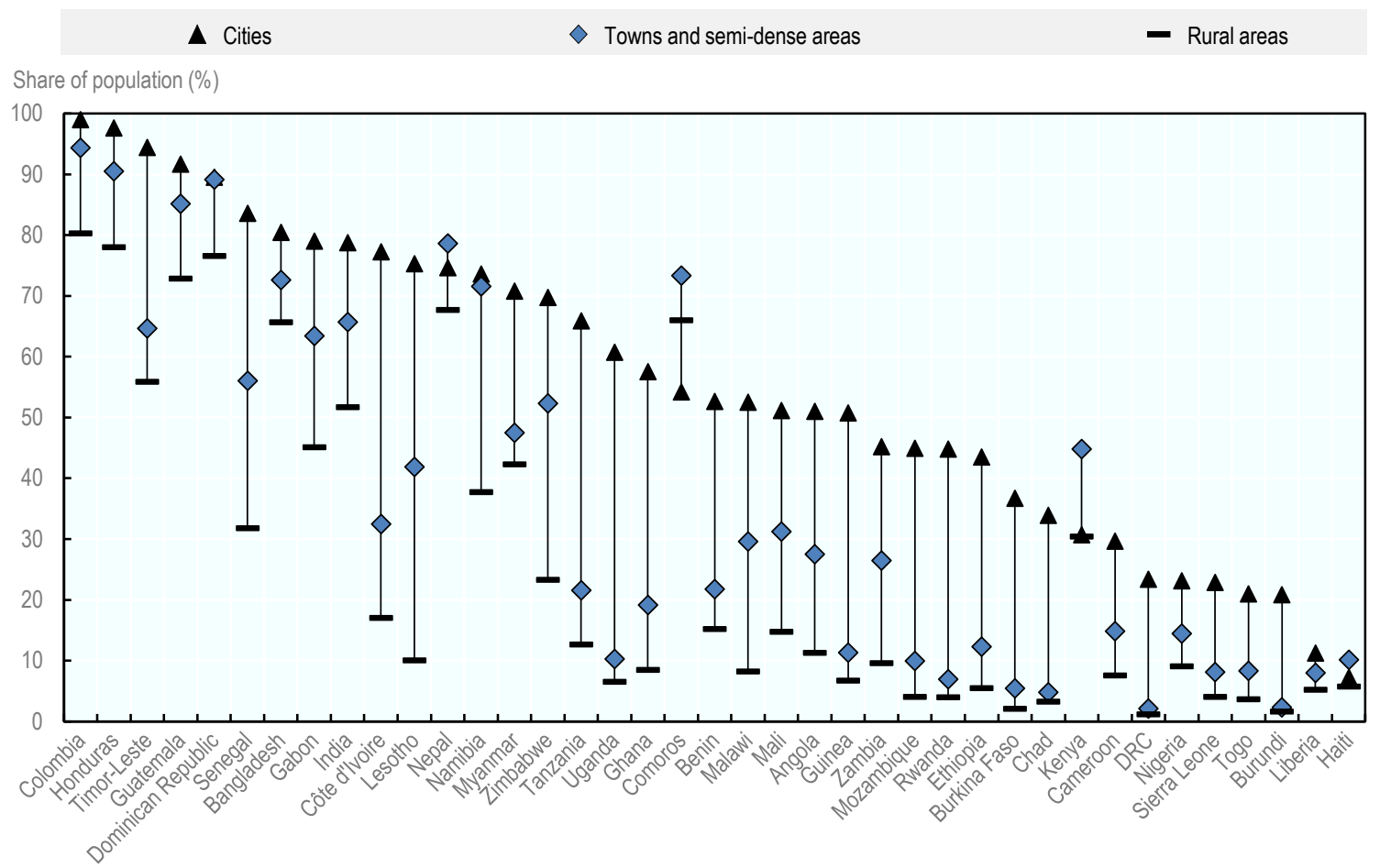

Source: DHS (2016[22]); Henderson, V. et al. $\left(2019_{[23]}\right)$, "Urbanisation and demographic and health outcomes: Perspectives from a new classification of urban areas".

Rural-city differences in public services are likely to have a significant impact on urbanisation. City residents often enjoy better public services because the provision of those services benefits from population density, which drastically lowers per capita costs. For example, in Sub-Saharan Africa many public-service-related outcomes appear to improve with density (Gollin, Kirchberger and Lagakos, 2019[3]). Furthermore, some cities enjoy a political advantage due to their status as national or regional capitals and thus receive more support for the provision of public services (Box 2.2). These advantages that lead to significant geographic differences in utilities or amenities can motivate rural-urban migration and thus lead to further growth of cities (Brueckner and Lall, 2015[27]). Previous work has documented that public services attract rural migrants to cities. For example, in Brazil, better public services such as water and sanitation are an important factor that, in addition to higher wages, draws people into bigger cities (Lall, Timmins and $\left.\mathrm{Yu}, 2009_{[28]}\right)$. The poorest might benefit the most from better public services and could thus be particularly attracted by cities despite higher living costs.

\section{Box 2.2. The effect of city status on the provision of utilities}

The administrative or political status of settlements influences the local provision of utilities. Across the world, the political status of a settlement, i.e. being a national or regional capital, affects socio-economic outcomes and explains a substantial portion of the differences between cities and intermediate-density areas (towns and semi-dense areas). In particular, being a national capital comes with advantages in terms of better sanitation, electricity and drinking water infrastructure. 
Besides the importance of political status, the data also reveal that the administrative status of an area matters. Even when accounting for population density, whether a settlement is defined as urban in the national census matters. Areas with urban status benefit from significantly higher provision of utilities. Residents in areas that are considered urban according to national definitions have significantly higher access to improved sanitation, electricity and safely managed drinking water. One of the reasons why nationally defined urban places record higher access to services is that in some countries access to services is in fact part of the national definition of urban.

Note: The findings are based on regression results, included in Henderson et al. (2019[23]).

Source: DHS (2016[22]); Henderson, V. et al. (2019[23]), "Urbanisation and demographic and health outcomes: Perspectives from a new classification of urban areas".

\section{Crime, gender, violence, safety}

\section{Crime is a more pressing concern in cities than elsewhere}

Crime, violence and attitudes towards women directly influence people's daily lives and thus affect their quality of life. Similar to health outcomes, those important well-being dimensions vary a lot along the degrees of urbanisation, gender and countries' level of development.

Overall, residents in cities are most exposed to crime and violence. Across all income levels, the share of individuals whose property or money was stolen in the 12 months preceding the survey is at $19.9 \%$ highest in cities, followed by TSAs (16.3\%) (left panel, Figure 2.17). Such crime occurs less often in rural areas $(14.9 \%)$. Theft in cities is particularly high, relative to rural areas and TSAs, in upper-middle- and highincome countries. Similar to theft, city residents are also the ones most likely to get mugged or assaulted. While differences in mugging across the degree of urbanisation are negligible in low-income countries, they are significant in both middle- and high-income countries (right panel, Figure 2.17). Generally, the pattern again indicates the lowest assault levels in rural areas and intermediate levels in TSAs.

\section{Figure 2.17. Theft and assault across the degree of urbanisation}

Shares of individuals who were victims of theft or mugging over the past 12 months

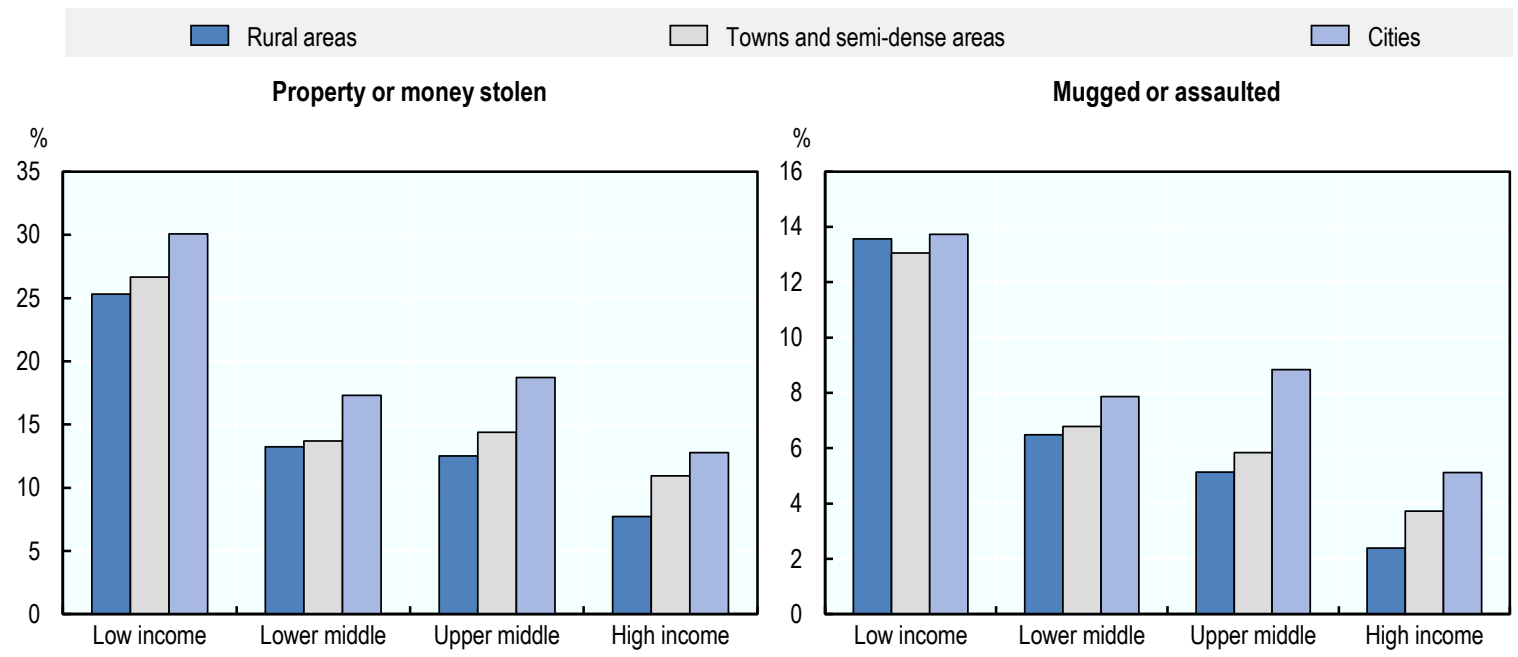

Source: Based on Gallup (2017[14]], Gallup World Poll, 2016-17, https://www.gallup.com/analytics/232838/world-poll.aspx; elaborated by OECD, 2019. 
When it comes to walking alone at night in one's local areas, which corresponds to SDG 16.1.4, however, city residents and especially women report the lowest safety levels. On average, $63.5 \%$ of rural residents, $59.7 \%$ of residents in TSAs and $52 \%$ of residents in cities feel safe walking alone at night. In all country income groups and degrees of urbanisation, women are significantly less likely to feel safe at night than men (Figure 2.18). The gender difference is highest in upper-middle-income and high-income countries, where the share of respondents reporting to feel safe walking alone at night is 10 to 20 percentage points lower for women than for men. The gender disparity in SDG 16.1.4 is also reflected in other aspects that have a direct negative impact on women's quality of life. On average, a lack of respectful treatment of women remains an important concern of residents across the degree of urbanisation in the world. Only $50 \%-70 \%$ of women believe that women are treated with respect in their local environment, and this share is lower in cities than in rural areas. This highlights that more needs to be done to achieve gender equality and empower all women and girls (SDG 5).

Figure 2.18. Share of men and women feeling safe walking alone at night

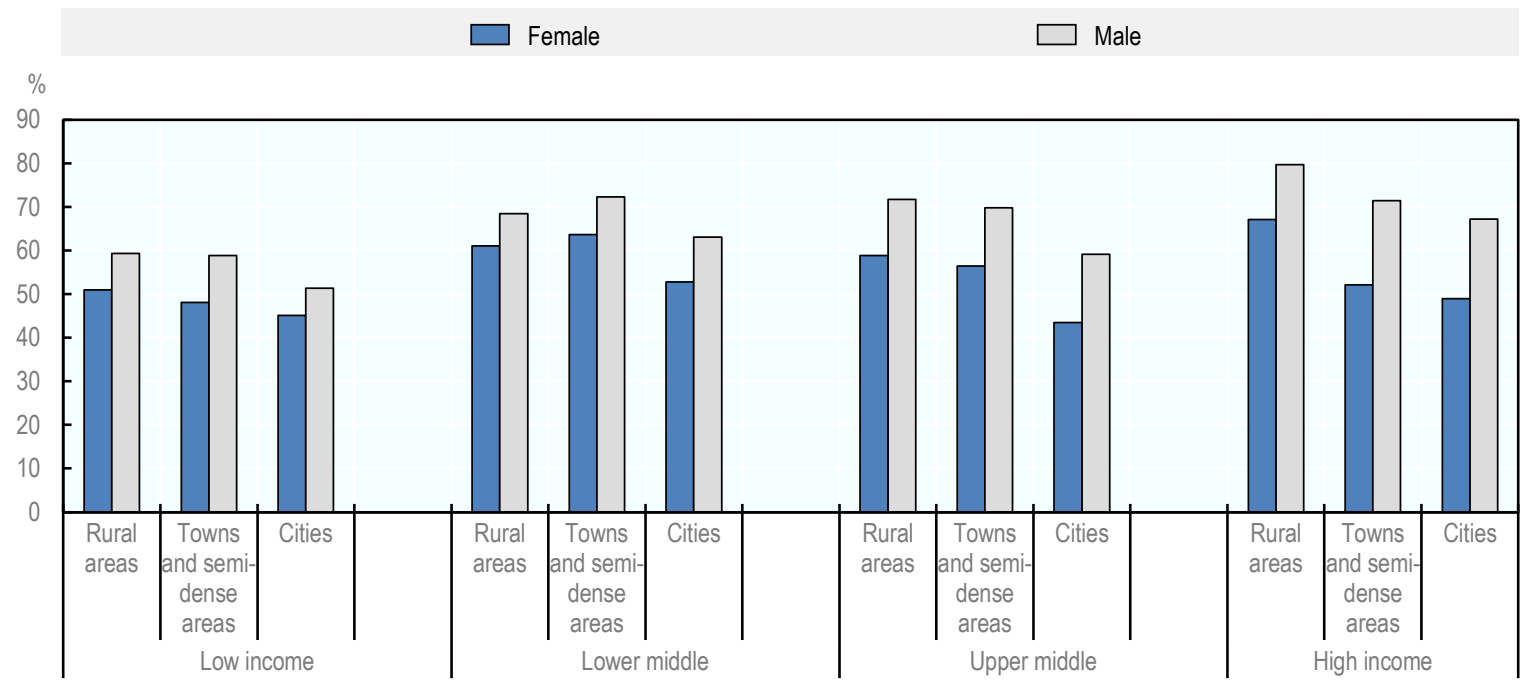

Source: Based on Gallup (2017[14]), Gallup World Poll, 2016-17, https://www.gallup.com/analytics/232838/world-poll.aspx; elaborated by EC and OECD, 2019.

\section{Acceptance of domestic violence against women is falling but geographic differences remain substantial}

In developing countries, approximately $27 \%$ to $30 \%$ of married women have experienced spousal violence (Figure 2.19). While there are no discernible differences by the degree of urbanisation across country income groups, the regional experience of women differs. In Sub-Saharan Africa, South Asia and Southeast Asia, the share of women who experienced domestic violence is higher in rural areas than in cities. In Latin America, however, women in cities are much more likely to have experienced domestic violence than women in rural areas.

In contrast to reported domestic violence, acceptance of domestic violence remains substantially more common in rural areas than elsewhere. Compared to cities and towns and semi-dense areas, both women and men in rural areas are more likely to justify wife-beating (Figure 2.19). Surprisingly, more women than men think wife-beating is justified for at least one reason, which is particularly striking in rural areas and towns \& semi-dense areas. Although Southeast Asia has the highest rates for beating being justified, it records the lowest reported actual domestic violence. In contrast, relatively more progressive attitudes towards domestic violence in Latin America do not translate into better outcomes. 
Encouragingly, attitudes towards domestic violence appear to be changing in all degrees of urbanisation. In Sub-Saharan Africa, the only region with sufficient data availability to observe changes over time, acceptance of wife-beating fell substantially between 2000 and 2015. On average, acceptance of wifebeating dropped by over 20 percentage points for both men and women, from about $50 \%$ (men) and $70 \%$ (women) respectively in 2000 . The remaining difference in attitudes towards domestic violence across the degree of urbanisation is in part driven by structural differences of rural and city populations. For example, the Sub-Saharan African city-rural and town-rural differentials in the share of women who think wife-beating is justified for any reason fall by $35 \%-50 \%$ when household characteristics such as age and education are accounted for. Similarly, in South Asia, the lower rates in cities compared to the countryside for both attitudes towards violence and experience of violence are both eliminated by sorting (see Henderson et al. (2019[23]) for more information).

Figure 2.19. Domestic violence by the degree of urbanisation

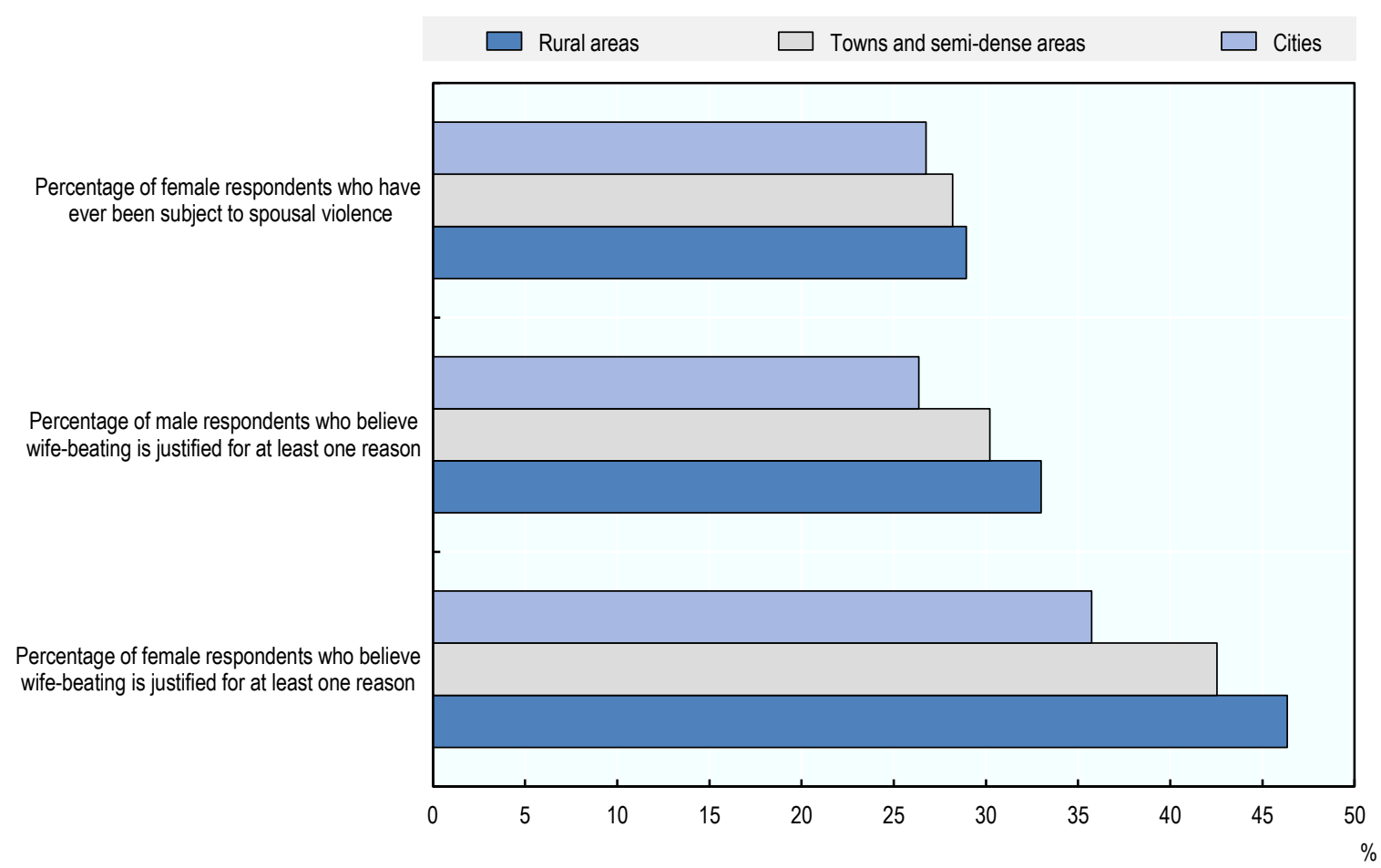

Source: DHS (2016[22]); Henderson, V. et al. (2019[23]), "Urbanisation and demographic and health outcomes: Perspectives from a new classification of urban areas".

\section{Explaining differences in life satisfaction}

As documented in the preceding sections, differences in key well-being dimensions across the degree of urbanisation can be considerable. The results suggest more favourable outcomes in key well-being dimensions in cities, albeit with notable exceptions. On average, quality of life appears to be best in cities and lowest in rural areas. Towns and semi-dense areas mostly fall in between cities and rural areas. However, the results are more nuanced when considering individual well-being dimensions.

Residents in cities have higher incomes and enjoy more economic opportunities. Even though not all benefit equally from this due to higher inequality and higher living costs in cities, on average city residents are better off economically. City residents also achieve the highest educational attainment, followed by residents in towns and semi-dense areas, with educational attainment in rural areas lagging behind. In 
health, the picture is more mixed. In some health dimensions, cities and towns and semi-dense areas fare better than rural areas. However, cities are also prone to urban ills such as obesity, stress or air pollution. Access to public infrastructure, modern technology and public utilities all follow a clear urban gradient; the more densely populated the area, the better such access tends to be. In contrast, crime and security are greater issues in cities, except for domestic violence, which remains highest in rural areas.

The evidence on those key well-being dimensions might offer an explanation of why quality of life differs across the degree of urbanisation and why cities offer the highest quality of life for their residents. While many of those factors such as access to public infrastructure, healthcare or employment opportunities are local determinants of quality of life, other factors can lead to directly observable systematic differences between residents of different areas. Systematic differences between residents of cities and other areas in aspects such as educational attainment, age or motivation, referred to as sorting, could also partly explain geographic differences in life satisfaction, and thus quality of life more generally. For example, previous studies have shown that age affects life satisfaction differently over the life cycle. ${ }^{20}$ Similarly, previous work highlights the importance of educational attainment (Witter et al., 1984[29]; Chen, 2012[30]) and employment outcomes (Di Tella, MaCulloch and Oswald, 2001 [31]) for life satisfaction and well-being. ${ }^{21}$

Residents across the degree of urbanisation differ substantially in key characteristics such as educational attainment, age and per capita income (Annex Table 2.B.1). Taking into account such differences is important for examining life satisfaction across the degree of urbanisation as the observed differences in life satisfaction might reflect differences in the composition of population across settlements. ${ }^{22}$ Cities or towns and semi-dense areas often attract skilled individuals, with higher educational attainment, better health and greater economic opportunities, all of which can directly influence quality of life.

Across the world, individual and household characteristics, as well as country-specific factors, explain a considerable proportion of the happiness gap between cities and rural areas. City residents are more than $13 \%$ more likely to be satisfied with their lives than rural residents, a difference that falls $7.6 \%$ when country-specific characteristics (fixed effects) are included and further to $1.8 \%$ when the analysis controls for observable characteristics (Figure 2.20). After controlling for the level of education, age, household size, gender and per capita income, the effect of living in a city on life satisfaction remains statistically significant but is strongly reduced. However, the true effect of living in a city on life satisfaction might be larger than suggested by the estimates in Figure 2.20. Living in a city can directly affect income levels and educational attainment due to, on average, more and better schooling and job opportunities as well as the presence of different types of industries and service sectors (as documented in the sections above). Thus, controlling for observable characteristics such as age, education or income, some of which are influenced by living in a city, provides a lower-bound estimate for the actual effect of living in a city (or town or semidense area) on life satisfaction.

In summary, the analysis in this chapter provides novel and important insights into the subnational dimension of quality of life. First, it documents that quality of life differs substantially across the degree of urbanisation around the world. Second, it explains why quality of life is highest in cities and lowest in rural areas. Along many key well-being dimensions, residents in cities or towns \& semi-dense areas benefit from better local conditions such as employment opportunities, healthcare, educational opportunities, access to services or modern infrastructure. Additionally, systematic differences in terms of age, educational attainment or income of residents help explain higher quality of life in cities and towns \& semidense areas. Therefore, this chapter does not only shed light on the importance of place-based factors for quality of life but also offer evidence on the reasons why quality of life differs within countries. Hereby, the report contributes to a place-based understanding of SDGs related to quality of life. 
Figure 2.20. Regression analysis: Life satisfaction by degree of urbanisation

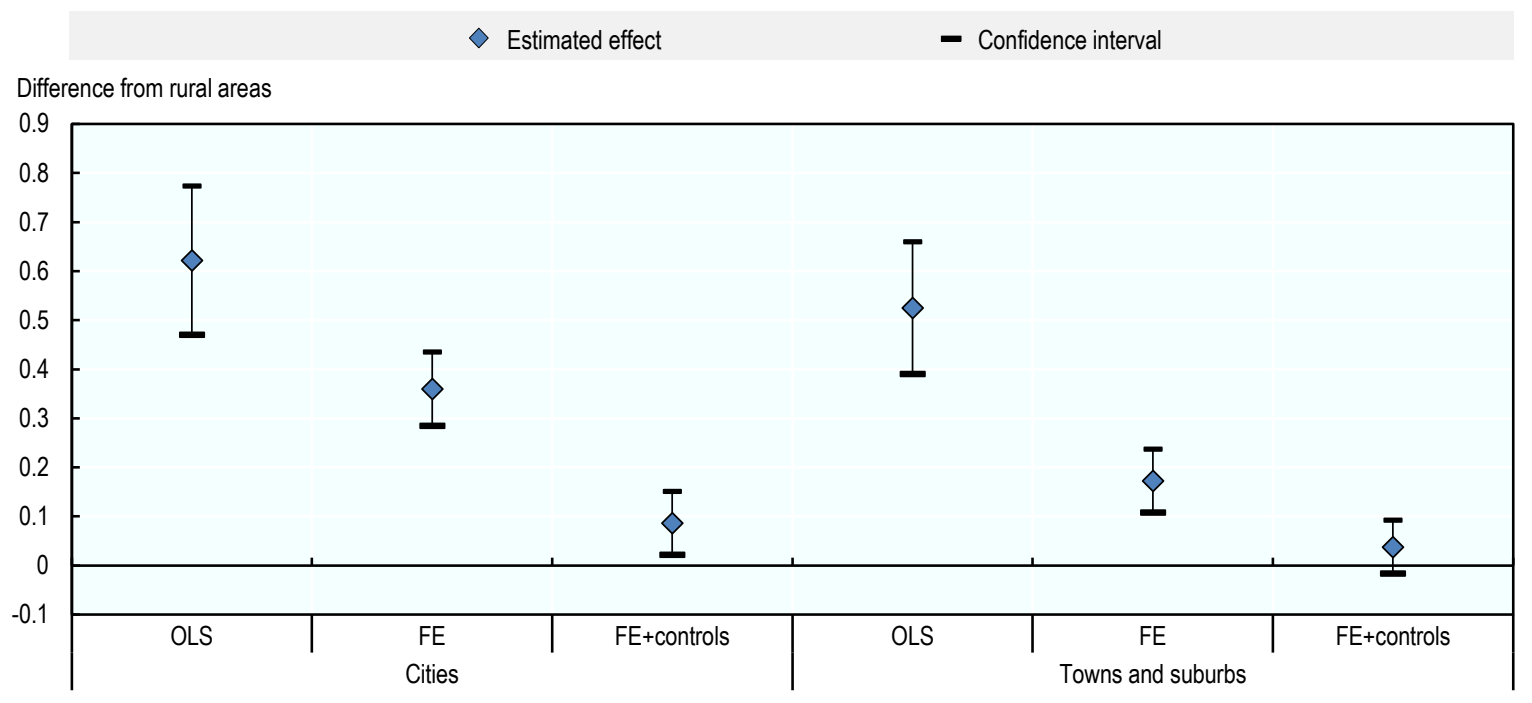

Note: Annex 2.C explains the underlying regression in detail. Life satisfaction in rural areas is the baseline result. The figure presents the effects relative to the baseline and the confidence intervals. Observations are weighted with the individual weights provided by Gallup. Standard errors are robust and clustered at the country level.

OLS denotes ordinary least squares regressions.

FE demarks regressions that include country fixed effects. For results presented by the columns "FE+controls", household and respondents' characteristics are additionally controlled for.

Source: All data from Gallup (2017[14]), Gallup World Poll, 2016-17, https://www.gallup.com/analytics/232838/world-poll.aspx; elaborated by OECD, 2019.

Finally, this chapter demonstrates that towns \& semi-dense areas have idiosyncratic properties and offer an insightful view on the rural-urban continuum in policy areas. In many dimensions of quality of life, in particular, in economic opportunities and the provision of services such as healthcare and utilities, towns $\&$ semi-dense areas are halfway between cities and rural areas. This position, in between the traditional rural-urban dichotomy, also means that towns and semi-dense areas can play an important role of fostering urban linkages that can help enhance economic growth and quality of life in all areas (OECD, 2019[32]; forthcoming[33]). Towns \& semi-dense areas can facilitate rural-urban linkages, in particular in developing countries, by providing a bridge between rural areas on the one hand and cities on the other (OECD/PSI, 2020[34]).

\section{References}

Ahrend, R. et al. (2017), "What Makes Cities More Productive?: Agglomeration economies and the role of urban governance: Evidence from 5 OECD Countries", OECD Productivity Working Papers, No. 6, OECD Publishing, Paris, https://dx.doi.org/10.1787/2ce4b893-en.

Ahrend, R. and A. Lembcke (2016), "Does It Pay to Live in Big(ger) Cities? : The Role of Agglomeration Benefits, Local Amenities, and Costs of Living", OECD Regional Development Working Papers, No. 2016/9, OECD Publishing, Paris, https://dx.doi.org/10.1787/e0490ba8en.

Balk, D. et al. (2004), "A spatial analysis of childhood mortality in West Africa", Population, Space and Place, Vol. 10/3, pp. 175-216, https://doi.org/10.1002/psp.328. 
Bjornskov, C., A. Dreher and J. Fisher (2008), "Cross country determinants of life satisfaction: Exploring different determinants", Social Choice and Welfare, Vol. 30, pp. 119-173, https://doi.org/10.1007/s00355-007-0225-4.

Blanchflower, D. and A. Oswald (2011), "International happiness: A new view on the measure of performance", The Academy of Management Perspectives, Vol. 25/1, pp. 6-22, https://doi.org/10.5465/amp.25.1.6.

Boarini, R., F. Murtin and P. Schreyer (2015), "Inclusive Growth: The OECD Measurement Framework", OECD Statistics Working Papers, No. 2015/6, OECD Publishing, Paris, https://dx.doi.org/10.1787/5jrqppxighg4-en.

Brueckner, J. and S. Lall (2015), "Cities in developing countries: Fueled by rural-urban migration, lacking in tenure security, and short of affordable housing", Handbook of Regional and Urban Economics, No. 5, Elsevier, https://doi.org/10.1016/B978-0-444-59531-7.00021-1.

Bryan, G. and M. Morten (2019), "The aggregate productivity effects of internal migration: Evidence from Indonesia", Journal of Political Economy, Vol. 127/5, pp. 2229-2268, https://doi.org/10.1086/701810.

Card, D. (1999), "The causal effect of education on earnings", Handbook of Labor Economics, No. 30, Elsevier, http://davidcard.berkeley.edu/papers/causal educ earnings.pdf.

Chauvin, J. et al. (2017), "What is different about urbanization in rich and poor countries? Cities in Brazil, China, India and the United States", Journal of Urban Economics, Vol. 98, pp. 1749, https://doi.org/10.1016/j.jue.2016.05.003.

Chen, W. (2012), "How education enhances happiness: Comparison of mediating factors in four East Asian countries", Social Indicators Research, Vol. 106/1, pp. 117-131, https://doi.org/10.1007/s11205-011-9798-5.

Combes, P. et al. (2019), "Unequal migration and urbanisation gains in China”, Journal of Development Economics, https://doi.org/10.1016/j.jdeveco.2019.01.009.

Corker, J. (2017), "Fertility and child mortality in urban west africa: Leveraging geo-referenced data to move beyond the urban/rural dichotomy", Population, Space and Place, Vol. 23, http://dx.doi.org/10.1002/psp.2009.

Di Tella, R. and R. MacCulloch (2006), "Some uses of happiness data in economics", The Journal of Economic Perspectives, Vol. 20, pp. 25-46, http://dx.doi.org/10.1257/089533006776526111.

Di Tella, R., R. MaCulloch and A. Oswald (2001), "Preferences over inflation and unemployment: Evidence from surveys of happiness", American Economic Review, Vol. 91/1, pp. 335-341, http://dx.doi.org/10.1257/aer.91.1.335.

Dorélien, A., D. Balk and M. Todd (2013), "What is urban? Comparing a satellite view with the demographic and health surveys", Population and Development Review, Vol. 39/3, pp. 413439, https://doi.org/10.1111/j.1728-4457.2013.00610.x.

Easterlin, R. (1995), "Will raising the incomes of all increase the happiness of all?", Journal of Economic Behavior and Organization, Vol. 27, pp. 25-47, https://doi.org/10.1016/01672681(95)00003-B. 
Ferré, C., F. Ferreira and P. Lanjouw (2012), "Is there a metropolitan bias? The relationship between poverty and city size in a selection of developing countries", World Bank Economic Review, Vol. 26/3, pp. 351-382, https://www.jstor.org/stable/41679566?seq=1\#metadata info tab contents.

Florczyk, A. et al. (2019), GHSL Data Package 2019, https://ec.europa.eu/jrc/en/publication/ghsldata-package-2019.

Gallup (2018), Gallup Word Poll 2018, https://www.gallup.com/analytics/232838/world-poll.aspx.

Gallup (2017), Gallup World Poll, 2016-17, https://www.gallup.com/analytics/232838/worldpoll.aspx.

Gollin, D., M. Kirchberger and D. Lagakos (2019), "In search of a spatial equilibrium in the developing world", NBER Working Paper 23916, http://dx.doi.org/10.3386/w23916.

Gollin, D., D. Lagakos and M. Waugh (2013), "The agricultural productivity gap", The Quarterly Journal of Economics, Vol. 129/2, pp. 939-993, https://doi.org/10.1093/qje/qjt056.

Heckman, J. (2006), "Skill formation and the economics of investing in disadvantaged children", Science, Vol. 312/5782, pp. 1900-1902, http://dx.doi.org/10.1126/science.1128898.

Henderson, J., S. Kriticos and D. Nigmatulina (2019), "Measuring urban economic density", Journal of Urban Economics, https://doi.org/10.1016/j.jue.2019.103188 (accessed on 18 September 2019).

Henderson, V. et al. (2019), "Urbanisation and demographic and health outcomes: Perspectives from a new classification of urban areas".

ICF (2016), Demographic and Health Surveys (various).

International Organization for Migration (2015), World Migration Report 2015 - Urbanization, Rural-urban Migration and Urban Poverty, https://www.iom.int/world-migration-report-2015.

Lall, S., C. Timmins and S. Yu (2009), Connecting Lagging and Leading Regions: The Role of Labour Mobility, World Bank, https://doi.org/10.1596/1813-9450-4843.

Nikolaev, B. and P. Rusakov (2016), "Eudcation and happiness: An alternative hypothesis", Applied Economics Letters, Vol. 23/12, pp. 827-830, https://doi.org/10.1080/13504851.2015.1111982.

OECD (2019), OECD Regional Outlook 2019: Leveraging Megatrends for Cities and Rural Areas, OECD Publishing, Paris, https://dx.doi.org/10.1787/9789264312838-en.

OECD (2019), Principles on Urban Policy and on Rural Policy, OECD, Paris.

OECD (2018), "RURAL 3.0. A framework for rural development”, OECD, Paris.

OECD (2017), How's Life? 2017: Measuring Well-being, OECD Publishing, Paris, https://dx.doi.org/10.1787/how life-2017-en.

OECD (2014), How's Life in Your Region?: Measuring Regional and Local Well-being for Policy Making, OECD Publishing, Paris, https://dx.doi.org/10.1787/9789264217416-en.

OECD (forthcoming), Rural Wellbeing: Geography of Opportunities, OECD Publishing, Paris. 
OECD/PSI (2020), Rural Development Strategy Review of Ethiopia: Reaping the Benefits of Urbanisation, OECD Development Pathways, OECD Publishing, Paris, https://dx.doi.org/10.1787/a325a658-en.

Peiró, A. (2006), "Happiness, satisfaction and socio-economic conditions: some international evidence", Journal of Socio-Economics, Vol. 35, https://doi.org/10.1016/j.socec.2005.11.042.

Tabuchi, T. and A. Yoshida (2000), "Separating urban agglomeration economies in consumption and production", Journal of Urban Economics, Vol. 48/1, pp. 70-84, https://doi.org/10.1006/juec.1999.2157.

Tombe, T. and X. Zhu (2019), "Trade, migration, and productivity: A quantitative analysis of China", American Economic Review, Vol. 109/5, pp. 1843-72, http://dx.doi.org/10.1257/aer.20150811.

Witter, R. et al. (1984), "Education and subjective well-being: A meta-analysis", Educational Evaluation and Policy Analysis, Vol. 6/2, pp. 165-173, https://journals.sagepub.com/doi/pdf/10.3102/01623737006002165.

\section{Notes}

${ }^{1}$ Data come from the Gallup World Poll and consist of countries from all world regions and all country income groups. In total, $13 \%$ are high-income countries, $65 \%$ middle-income countries $(32 \%$ upper- and $33 \%$ lower-middle income) and $22 \%$ low-income countries.

2 The question asks respondents to rate their current living conditions on a scale from 0 , the worst possible life, to 10 , the best possible life. Respondents are considered to be satisfied with their life if they give a score of 8 or higher.

${ }^{3}$ All reported averages for the Gallup data by income group or world region are unweighted country averages.

${ }^{4}$ The twelve countries, in order of largest relative difference, are the Gambia, Egypt, Azerbaijan, Senegal, Venezuela, Bulgaria, Mauritania, Central African Republic, Tunisia, South Sudan, Tajikistan and Afghanistan.

${ }^{5}$ In fact, these differences remain significant in a regression framework even after controlling for GDP (log GDP per capita) and income level group (high, upper-middle, lower-middle, low), and clustering standard errors by either region or income group.

${ }^{6}$ These findings are based on country cross-sectional linear regressions. City growth is defined as the annualised population growth rate between 2000 and 2015. The underlying regression controls for the log of countries' GDP per capita in purchasing power parity (PPP) and is robust to clustering standard errors at the regional as well as income group level. 
7 The regressions control for the log of countries' GDP per capita in PPP and the levels of life satisfaction in both cities and rural areas.

${ }^{8}$ The results are robust to controlling for sorting, i.e. controlling for individual and household characteristics.

${ }^{9}$ Geo-coding of Gallup differs by country, based on the availability of land phone lines. Gallup uses telephone surveys in countries where telephone coverage represents at least $80 \%$ of the population or is the customary survey methodology. In all other countries, Gallup uses face-to-face interviews, which yield the necessary information geo-code and classify responses into the degree of urbanisation.

10 The sample covers countries from around the world. In total, it includes 35 countries from Sub-Saharan Africa, 30 from Central Asia and Europe, 21 from Latin America and the Caribbean, 10 from East Asia and the Pacific, 8 from the Middle East and North Africa, 6 from South Asia, and 1 from North America. Among the 111 countries referred to in this section, 14 are OECD members. The included OECD countries are Chile, Colombia, the Czech Republic, Estonia, Greece, Hungary, Israel, Latvia, Lithuania, Mexico, Poland, the Slovak Republic, Turkey and the United States.

11 The analysis of DHS work builds on the work by Henderson et al. $\left(2019_{[23]}\right)$.

12 The Demographic and Health Surveys (DHS) program collects and disseminates accurate, nationally representative data on health and population in developing countries: https://dhsprogram.com/.

13 The country breakdown is as follows: 29 countries from Sub-Saharan Africa (Angola, Benin, Burkina Faso, Burundi, Cameroon, Chad, CDR, Comoros, Côte d'Ivoire, Ethiopia, Gabon, Ghana, Guinea, Kenya, Liberia, Lesotho, Malawi, Mali, Mozambique, Namibia, Nigeria, Rwanda, Senegal, Sierra Leone, Tanzania, Togo, Uganda, Zambia and Zimbabwe), three from South Asia (Bangladesh, India, Nepal), four from Southeast Asia (Cambodia, Myanmar, Philippines, Timor-Leste) and five from Latin America and the Caribbean (Colombia, Dominican Republic, Guatemala, Haiti, Honduras). For a subset of these countries, earlier geo-coded surveys are available so that changes over time can be observed.

${ }^{14}$ Due to limited data availability on the cost of living, this section only presents findings on nominal wages and income.

${ }^{15}$ Gallup data do not include information on the specific occupation of respondents.

${ }^{16}$ The findings are based on regression evidence that points out a significant correlation between improved sanitation and lower diarrhoea rates, accounting for household characteristics.

17 Due to data limitations, other health outcomes are limited to India. Henderson et al. (2019[23]) report statistics on high blood pressure, asthma and diabetes among adults. In India, high blood pressure, asthma and diabetes are all higher in cities than in towns and semi-dense areas, which in turn have higher rates than rural areas.

18 Improved sanitation is defined by the DHS-WHO Joint Monitory Program to include the following: all shared and non-shared facilities that flush/pour flush to piped sewer system, septic tank, pit latrine; ventilated improved pit latrine, pit latrine with slab, and composting toilet. Additionally, facilities that flush to unknown locations are considered improved, whereas facilities that flush to a known location but not to a sewer system, septic tank, or pit latrine are classified as unimproved.

19 The analysis of changes over time is limited to Sub-Saharan Africa and South Asia because countries in Latin America and Southeast Asia generally do not have usable DHS surveys for the years around 2000. 
Since Indian DHS data in 2000 were not georeferenced, the South Asia sample consists of Bangladesh and Nepal.

${ }^{20}$ Recent work has shown that age exhibits a U-shape relationship with happiness. Younger (below 20) and older (above 50) individuals have a higher life satisfaction than individuals in between (Blanchflower and Oswald, 2011[37]). Nikolaev and Rusakov (2016[40] $)$ argue that pursuing education might result in shortterm costs in terms of sacrificing satisfaction but results in higher levels of happiness for educated individuals from their mid-30s.

${ }^{21}$ In addition to age, empirical research has highlighted a number of objective socio-economic factors correlated to subjective well-being. Income boosts individual well-being (Easterlin, 1995[39]; Peiró, 2006[41]) and unemployment depresses it (Di Tella and MacCulloch, 2006 ${ }_{[38]}$ ). Being married or in a relationship (Bjornskov, Dreher and Fisher, 2008[36]) is positively correlated with subjective measures of life satisfaction.

22 Annex 2.B provides a thorough explanation of and motivation for why sorting matters and how using microdata can mitigate the sorting problem through econometric regressions. 


\section{Annex 2.A. Description of main variables}

The table below summarises and describes the key outcome and control variables derived from the Gallup World Poll.

\section{Annex Table 2.A.1. Main variables from Gallup World Poll}

\begin{tabular}{|c|c|c|}
\hline Variable & Survey question & Values \\
\hline Life satisfaction & $\begin{array}{l}\text { Please imagine a ladder with steps numbered from } 0 \text { at the bottom to } 10 \text { at the top. Suppose we } \\
\text { say that the top of the ladder represents the best possible life for you, and the bottom of the ladder } \\
\text { represents the worst possible life for you. On which step of the ladder would you say you personally } \\
\text { feel you stand at this time, assuming that the higher the step the better you feel about your life, and } \\
\text { the lower the step the worse you feel about it? Which step comes closest to the way you feel? }\end{array}$ & $\begin{array}{l}0 \text {-worst; } \\
\text { 10-best }\end{array}$ \\
\hline $\begin{array}{l}\text { Binary life } \\
\text { satisfaction }\end{array}$ & Recoded variable: 0-6 dissatisfied; 7-10 satisfied. & $\begin{array}{l}\text { 0-dissatisfied; } \\
\text { 1-satisfied }\end{array}$ \\
\hline $\begin{array}{l}\text { Future life } \\
\text { satisfaction }\end{array}$ & $\begin{array}{l}\text { Please imagine a ladder with steps numbered from } 0 \text { at the bottom to } 10 \text { at the top. Suppose we } \\
\text { say that the top of the ladder represents the best possible life for you, and the bottom of the ladder } \\
\text { represents the worst possible life for you. Just your best guess, on which step do you think you will } \\
\text { stand on in the future, say about five years from now? }\end{array}$ & $\begin{array}{l}\text { 0-worst; } \\
\text { 10-best }\end{array}$ \\
\hline $\begin{array}{l}\text { Standard of living } \\
\text { satisfaction }\end{array}$ & Are you satisfied or dissatisfied with your standard of living, all the things you can buy and do? & $\begin{array}{l}\text { 0-dissatisfied; } \\
\text { 1-satisfied }\end{array}$ \\
\hline $\begin{array}{l}\text { Future standard of } \\
\text { living satisfaction }\end{array}$ & Right now, do you feel your standard of living is getting better or getting worse? & $\begin{array}{l}\text { 1-worse; } \\
\text { 3-better }\end{array}$ \\
\hline $\begin{array}{l}\text { Satisfaction for area } \\
\text { of residence }\end{array}$ & Are you satisfied or dissatisfied with the city or area where you live? & $\begin{array}{l}\text { 0-dissatisfied; } \\
\text { 1-satisfied }\end{array}$ \\
\hline $\begin{array}{l}\text { Recommendation } \\
\text { area of residence }\end{array}$ & $\begin{array}{l}\text { Would you recommend the city or area where you live to a friend or associate as a place to live, or } \\
\text { not? }\end{array}$ & $\begin{array}{l}0 \text {-no; } \\
1-\text { yes }\end{array}$ \\
\hline $\begin{array}{l}\text { Economic conditions } \\
\text { area of residence }\end{array}$ & $\begin{array}{l}\text { How would you rate economic conditions in this city or area today - as excellent, good, only fair or } \\
\text { poor? }\end{array}$ & $\begin{array}{l}\text { 1-poor; } \\
\text { 4-excellent }\end{array}$ \\
\hline $\begin{array}{l}\text { Future economic } \\
\text { conditions area }\end{array}$ & $\begin{array}{l}\text { Right now, do you think that economic conditions in the city or area where you live, as a whole, are } \\
\text { getting better or getting worse? }\end{array}$ & $\begin{array}{l}\text { 1-worse; } \\
\text { 3-better }\end{array}$ \\
\hline $\begin{array}{l}\text { Work mobility in } \\
\text { country }\end{array}$ & Can people in this country get ahead by working hard, or not? & $\begin{array}{l}0 \text {-no; } \\
1-\text { yes }\end{array}$ \\
\hline $\begin{array}{l}\text { Good area for new } \\
\text { businesses }\end{array}$ & $\begin{array}{l}\text { Is the city or area where you live a good place or not a good place to live for: People starting new } \\
\text { businesses? }\end{array}$ & $\begin{array}{l}0 \text {-no; } \\
1 \text {-yes }\end{array}$ \\
\hline $\begin{array}{l}\text { Educational } \\
\text { opportunities in } \\
\text { country }\end{array}$ & Do most children in this country have the opportunity to learn and grow every day? & $\begin{array}{l}0 \text {-no; } \\
1 \text {-yes }\end{array}$ \\
\hline Health & $\begin{array}{l}\text { Do you have any health problems that prevent you from doing any of the things people your age } \\
\text { normally can do? }\end{array}$ & $\begin{array}{l}0 \text {-no; } \\
1-\text { yes }\end{array}$ \\
\hline Housing affordability & $\begin{array}{l}\text { In the city or area where you live, are you satisfied or dissatisfied with the availability of good, } \\
\text { affordable housing? }\end{array}$ & $\begin{array}{l}\text { 0-dissatisfied; } \\
\text { 1-satisfied }\end{array}$ \\
\hline $\begin{array}{l}\text { Public transport } \\
\text { system satisfaction }\end{array}$ & $\begin{array}{l}\text { In the city or area where you live, are you satisfied or dissatisfied with the public transportation } \\
\text { systems? }\end{array}$ & $\begin{array}{l}\text { 0-dissatisfied; } \\
\text { 1-satisfied }\end{array}$ \\
\hline $\begin{array}{l}\text { Roads and highways } \\
\text { satisfaction }\end{array}$ & In the city or area where you live, are you satisfied or dissatisfied with the roads and highways? & $\begin{array}{l}\text { 0-dissatisfied; } \\
\text { 1-satisfied }\end{array}$ \\
\hline
\end{tabular}

Source: Based on Gallup (2017[14]), Gallup World Poll, 2016-17, https://www.gallup.com/analytics/232838/world-poll.aspx. 


\section{Annex 2.B. The advantage of microdata: Addressing the sorting problem}

Using information on more than 163000 geo-localised individuals living in 111 countries, an analysis of the Gallup World Poll microdata can mitigate the sorting problem by controlling for observable individual and households characteristics in a regression framework. The data are from the 2016 and 2017 waves of Gallup World Poll. The regressions presented in the section explaining the differences in life satisfaction additionally include country fixed effects to control for any country-specific characteristics that might affect the results. Controlling for these factors is necessary because city residents differ markedly in many characteristics from residents in TSAs or rural areas (Annex Table 2.B.1). City residents are, on average, significantly more educated. While more than $71 \%$ of city residents have completed more schooling than primary education, less than half of residents in rural areas have done so. Additionally, household size varies significantly across the degrees of urbanisation. Average household size in rural areas amounts to more than 4.5, compared to 3.8 in TSAs and 3.9 in cities. Financial means also differ strongly across the degree of urbanisation. Average per capita income is highest for residents in TSAs, followed by city residents, with $82 \%$ and $56 \%$ higher income levels than in rural areas respectively. Finally, employment patterns differ strongly, with higher employment rate in cities, TSAs and more self-employment in rural areas.

Annex Table 2.B.1. Differences in individual characteristics across the degree of urbanisation Average education, household size and per capita income by degree of urbanisation

\begin{tabular}{|c|c|c|c|c|c|}
\hline Variable & & Rural areas & $\begin{array}{c}\text { Towns and semi- } \\
\text { dense areas }\end{array}$ & Cities & Total \\
\hline Education level & $\mathrm{N}$ & 69041 & 35264 & 58486 & 162791 \\
\hline $\begin{array}{l}\text { Elementary education or less } \\
\text { (up to } 8 \text { years of education) }\end{array}$ & \multirow{3}{*}{$\begin{array}{l}\text { Share } \\
(\%)\end{array}$} & 51.9 & 33.6 & 28.4 & 39.5 \\
\hline $\begin{array}{l}\text { At least secondary education } \\
\text { (9-15 years of education) }\end{array}$ & & 41.3 & 53.3 & 54.7 & 48.7 \\
\hline $\begin{array}{l}4 \text { year of post-secondary } \\
\text { education and/or } 4 \text {-year college } \\
\text { degree }\end{array}$ & & 6.8 & 13.1 & 16.9 & 11.8 \\
\hline \multirow[t]{2}{*}{ Household size } & $\mathrm{N}$ & 68964 & 35277 & 58285 & 162526 \\
\hline & Average & 4.5 & 3.8 & 3.9 & 4.1 \\
\hline \multirow[t]{2}{*}{$\begin{array}{l}\text { Per capita annual income in } \\
\text { International Dollars }\end{array}$} & $\mathrm{N}$ & 68964 & 35277 & 58285 & 162526 \\
\hline & Average & 3294 & 5318 & 5948 & 4685 \\
\hline
\end{tabular}

Note: The presented statistics are based on simple averages of all respondents across all 111 countries included in the Gallup World Poll. Source: All data from Gallup (2017[14]), Gallup World Poll, 2016-17, https://www.gallup.com/analytics/232838/world-poll.aspx; elaborated by OECD, 2019. 


\section{Annex 2.C. Regression framework for micro data analysis}

The regression analysis presented in this chapter is based on linear regressions as described by the following equation:

$Y_{i}=\alpha+\beta_{1} D E G U R B A_{i}+\beta_{2} X_{i}+\mu_{c}+\varepsilon_{i}$

where: $Y_{i}$ is the outcome of interest for individual $i$;DEGURBA $A_{i}$ is a categorical variable indicating if the individual $i$ is living in an urban area, town and semi-dense area or a rural one; $X_{i}$ is the list of individual observable controls previously mentioned ( 6 dummies for employment status; 10 age brackets dummies; gender; 3 dummies for education; 6 dummies for marital status; household size; log of per capita annual income); $\mu_{c}$ is the country fixed effect which should capture the unobservable characteristics common to country $c$; and $\varepsilon_{i}$ is the error term. $\beta_{1}$ is the coefficient of interest that captures eventual differences in life satisfaction or the other outcome variables between the different degrees of urbanisation. The observations are weighted with the weights provided by the designers of the survey and the standard errors are robust and clustered at the country level. In a second phase of the analysis, a dummy variable indicating whether an individual lives in an urban areas, cities or town and suburbs, or in a rural one replaces the degree of urbanisation indicator.

Annex Table 2.C.1. Regression analysis: Life satisfaction by degree of urbanisation

\begin{tabular}{|c|c|c|c|c|c|c|}
\hline \multirow{2}{*}{$\begin{array}{l}\text { Life satisfaction } \\
\text { (WP16) }\end{array}$} & \multicolumn{3}{|c|}{ DEGURBA } & \multicolumn{3}{|c|}{ Urban areas vs. rural areas } \\
\hline & OLS & FE & FE-Controls & OLS & $\mathrm{FE}$ & FE-Controls \\
\hline Rural areas & 0 & 0 & 0 & 0 & 0 & 0 \\
\hline \multirow{2}{*}{$\begin{array}{l}\text { Towns and semi-dense } \\
\text { area }\end{array}$} & $0.525^{\star \star \star}$ & $0.172^{\star \star \star}$ & 0.037 & & & \\
\hline & 0.068 & 0.032 & 0.028 & & & \\
\hline \multirow[t]{2}{*}{ Cities } & $0.0622^{* * *}$ & $0.359^{* \star *}$ & $0.086^{\star \star *}$ & & & \\
\hline & 0.077 & 0.038 & 0.033 & & & \\
\hline \multirow[t]{2}{*}{ Urban areas } & & & & $0.585^{\star \star \star}$ & $0.285^{\star \star \star}$ & $0.066^{* * *}$ \\
\hline & & & & 0.067 & 0.03 & 0.025 \\
\hline \multirow[t]{2}{*}{ Constant } & $4.719^{\star * *}$ & $6.739^{* * *}$ & $3.389^{* * *}$ & $4.719^{* * *}$ & $6.743^{\star * *}$ & $3.375^{\star * *}$ \\
\hline & 0.102 & 0.023 & 0.233 & 0.102 & 0.022 & 0.232 \\
\hline N_tot & 160314 & 160314 & 153503 & 160314 & 160314 & 153503 \\
\hline Cluster & 111 & 111 & 110 & 111 & 111 & 110 \\
\hline R2 & 0.014 & 0.136 & 0.185 & 0.014 & 0.136 & 0.185 \\
\hline Country FE & No & Yes & Yes & No & Yes & Yes \\
\hline Individual controls & No & No & Yes & No & No & Yes \\
\hline Y_mean & 5.048 & 5.048 & 5.075 & 5.048 & 5.048 & 5.075 \\
\hline Y_sd & 2.448 & 2.448 & 2.433 & 2.448 & 2.448 & 2.433 \\
\hline
\end{tabular}

Note: Confidence levels: ${ }^{*} p<0.10,{ }^{* *} p<0.01$. OLS refers to ordinary least squares regressions. FE refers to regressions that include country fixed effects. FE-Controls refers to regressions with fixed effects and additional controls. Clustered standard errors below the coefficients. Controls: 6 dummies for employment status; 10 age brackets dummies; Gender; 3 dummies for education; 6 dummies for marital status; household size; log of per capital annual income.

Observations are weighted with the individual weights provided by Gallup. Standard errors are robust and clustered at the country level.

Source: Based on Gallup (2018[35]), Gallup World Poll 2018, https://www.gallup.com/analytics/232838/world-poll.aspx; estimation by OECD, 2019. 


\section{Economic development and the metropolitan system}

This chapter presents evidence on the relationship between economic development and the growth of metropolitan areas. It examines how the share of people living in metropolitan areas differs by countries' economic development, with a focus on the role of structural transformation for explaining such differences. It analyses how the proportion of people living in metropolitan areas is associated with both economic development and regional income disparities. Finally, it examines the relevance of human capital and migration in metropolitan areas as drivers of regional disparities. 


\section{Key messages}

- Urbanisation and economic development go hand in hand. Overall, countries with higher per capita gross domestic product (GDP) tend to be more urbanised, especially in terms of the metropolitan population. The population share living in metropolitan areas above 1 million is roughly 4 times higher in high-income $(47 \%)$ than in low-income countries $(12 \%)$. This confirms the notion that while urbanisation does not necessarily lead to economic development, economic development does not happen without urbanisation.

- In advanced economies, urbanisation historically occurred at the same time as a structural shift from agriculture to manufacturing and, more recently, as a transition to the service sector. Thus, the distribution of population across space is linked to countries' economic structure. For example, a large service sector and a high proportion of people living in metropolitan areas go together in European and OECD countries.

- However, the link between urbanisation and structural transformation is less clear in less advanced economies. While Asia mainly urbanised through a process of industrialisation, many countries in Africa, Latin America and the Middle East have taken a different path to urbanisation, backed by large natural resource rents.

- Within countries, the distribution of the metropolitan population across metropolitan areas differs by countries' economic development. In middle-income countries, the dominance of a few large metropolitan areas creates a higher concentration of metropolitan population. In high-income countries, the metropolitan system is spatially more balanced as a larger number of large metropolitan areas are more spread out across the territory. Therefore, regional economic disparities differ by level of economic development. They are largest in middle-income countries, where the GDP per capita in the most metropolitan regions is twice as large as the per capita income in the least metropolitan regions.

- Different patterns of migration and human capital accumulation within countries appear to drive spatial disparities. Regions with larger shares of metropolitan population record higher net migration than regions with a lower metropolitan population. Human capital accumulation, as measured by the year of schooling of the population, is also higher in metropolitan regions, although to a much larger extent outside European and OECD countries. There, people living in the most metropolitan regions are on average almost 2.6 years more educated than inhabitants of the least metropolitan regions.

\section{Economic development and the distribution of people over space}

\section{Urbanisation and economic development go hand in hand}

Many countries have experienced sizeable shifts in the geographic distribution of their population over the past decades, in particular developing countries. Population growth paired with gradually increasing urbanisation rates have resulted in an expansion in the size of some cities, a shrinking population in others, and the emergence of entirely new cities. Population growth in Africa and Asia has been especially rapid in the previous two decades. Between 1990 and 2015, the population living in cities with more than 10 million people more than doubled, and 10 of these cities emerged, including 7 in Asia, as well as Istanbul, Lagos and Teheran (see Chapter 4 for more details). 
Despite the sharp increase in urbanisation in developing countries, countries with higher per capita GDP (purchasing power parity [PPP], 2011 USD) still tend to be more urbanised. This finding is visible at different points in time between 1975 and 2015. More specifically, building on data covering 168 countries in 2015 , a positive and statistically significant correlation is consistently observed between national GDP per capita and measures of urbanisation. The latter include the share of people living in metropolitan areas, in cities only or cities, towns and semi-dense areas. The term "metropolitan areas" in this publication is used as a shorthand for functional urban areas (FUAs), i.e. cities plus their commuting zones. ${ }^{1}$ While national GDP per capita is positively correlated with all three measures of urbanisation, the correlation is strongest when the share of the population in metropolitan areas is considered (see Annex 3.A for a detailed description). Also, from a theoretical point of view, it would seem most appropriate to look at the connection of urban development with the share of people that are part of cities' labour markets, i.e. live in metropolitan areas.

Consequently, this chapter aims to describe the relationship between economic development and the spatial distribution of the population across metropolitan areas (with more than 50000 inhabitants). ${ }^{2}$ This relationship is examined at different spatial scales and through different lenses, depending on the question of interest. The fact that urbanisation and economic development often tend to go hand in hand raises the question of which one drives which. There are good reasons to believe that causality runs both ways. It is generally argued that while the fact that countries urbanise does not necessarily imply that they will develop (Henderson, 2010[1]), sustainable economic growth does not occur without urbanisation.

\section{Higher levels of development correspond to larger metropolitan areas}

As countries develop, the share of people living in metropolitan areas increases and does so relatively more in the largest ones. The average share of a country's total population living in metropolitan areas is only $34 \%$ in low-income countries, but $71 \%$ in high-income countries (Figure 3.1). Between low- and highincome countries, the relative difference in the population share in metropolitan areas increases with the size of the metropolitan area. While the share of the population living in metropolitan areas with up to 1 million inhabitants is roughly the same across the different income classes, the population share living in metropolitan areas with more than 1 million is roughly 4 times higher in high-income countries than in lowincome countries. Even more striking, the share of inhabitants of metropolitan areas with more than 5 million inhabitants is roughly 13 times as high in high-income than in low-income countries. More precisely, when moving from low- to high-income countries (i.e. from the left to the right of Figure 3.1), the average share of people living in metropolitan areas with more than 5 million people increases from $2 \%$ to $22 \%$. By contrast, the average share of population living in metropolitan areas with less than 250000 people shrinks with economic development: it halves from $14 \%$ in low-income countries to $7 \%$ in high-income economies. This pattern is robust to controlling for potentially different average country sizes in the four income groups (see Annex 3.B).

Overall, larger metropolitan areas tend to be relatively more related to national economic development. To some extent, this might be the result of a structural transformation process happening at a higher pace in these areas.

The positive relationship between economic development and the share of the metropolitan population holds also over time. A panel analysis based on GDP and population data in 1990, 2000 and 2015 confirms that, over time, higher economic growth and a larger share of the metropolitan population are correlated (see below). This correlation between economic development and share of the metropolitan population is particularly strong in countries at low and middle stages of development relation. 
Figure 3.1. Economic development and population in metropolitan areas, 2015

Share of population in metropolitan areas of different sizes by income group

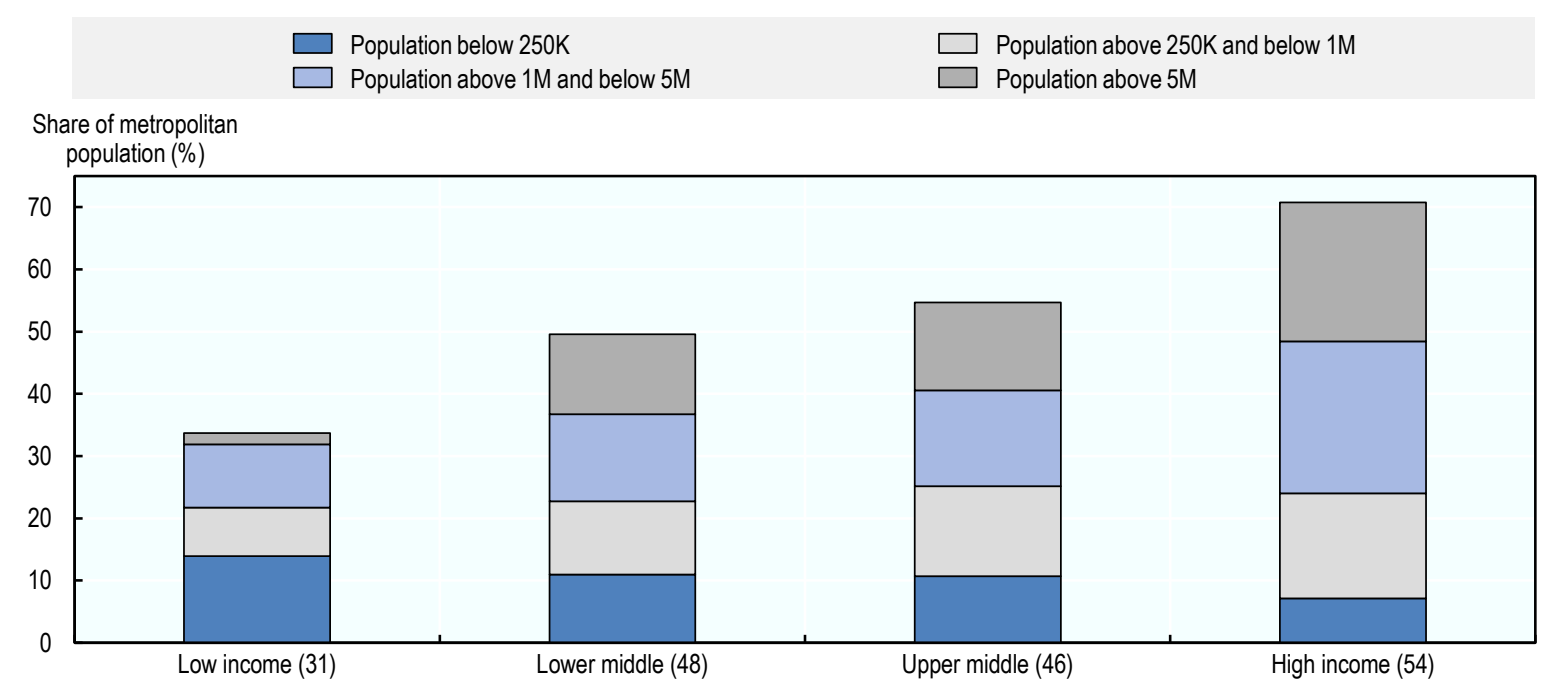

Note: Metropolitan areas refer to functional urban areas (FUAs), which are composed of cities of at least 50000 inhabitants plus their respective commuting zones. The number of countries in each income group is reported in parentheses. This figure shows the total population in each metropolitan area size class divided by the total population in each income group (as defined by the World Bank income categories in 2015). Similar patterns hold when restricting the attention to the share of population living in cities, as well as when looking at the share of the metropolitan population in 1990 and 2000.

Source: OECD calculations based on GDP data from the World Bank and population data from the GHSL Data Package 2019, Florczyk, A. et al. (2019[2]), GHSL Data Package 2019 (database), http://dx.doi.org/10.2760/06297.

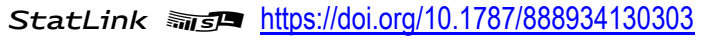

\section{Economic theories on why urbanisation is connected to economic development}

Traditional economics has long viewed the process of urbanisation through the lens of structural transformation. When countries develop, they experience structural changes in their economic sectors and therefore urbanise. In particular, the spatial distribution of the population, employment, and production changes with economic development (Desmet and Henderson, 2015[3]). Theories on structural transformation state that the transition to modern economic growth is intrinsically linked to rural-urban migration through a declining share of employment in rural agriculture and a shift toward manufacturing and service industries in cities (Rostow, 1960[4]). Thus, urbanisation occurs for two concurrent reasons when economies develop. First, productivity gains in agriculture release rural labour and push employment toward cities. Second, the rise of industrial sectors (for example those driven by enhanced international trade), pull resources towards cities (Gollin, Parente and Rogerson, 2002[5]; Michaels, Rauch and Redding, 2012[6]; Jedwab, Christiaensen and Gindelsky, 2017[7]).

Other views stress the importance of technological progress in allowing for urbanisation, citing, for example, the role of sewage, surges in agricultural productivity, high-rise buildings or urban transport as factors allowing for increasing levels of urbanisation. Agglomeration benefits (see Box 3.1) and increased innovation arising in decently-functioning cities would then drive economic development. This would be accompanied by a sectoral transformation as when people move out of rural areas into urban centres, they typically shift from agricultural to manufacturing and service activities (Henderson, 2010[1]; Duranton, 2015[8]; Glaeser, 2014[9]; Jedwab and Vollrath, 2015 $5_{[10]}$. These non-agricultural sectors have high rates of productivity growth and agglomeration effects in urban areas also promote further economic growth. 
Causality likely runs both from economic development to urbanisation, and from urbanisation to economic development. That is, as countries develop, they become more urbanised, which in turn drives economic development. Examples of such a virtuous circle encompass countries in Europe and the United States since the $18^{\text {th }}-19^{\text {th }}$ centuries, Japan and South Korea since the mid-20 th century, as well as China and India more recently (Glaeser et al., 1992[11]; Duranton, 2008[12]; Glaeser and Gottlieb, 2009[13]).

\section{Box 3.1. Agglomeration economies}

In cities, agglomeration economies arise because some economic factors make it beneficial for firms and households to be located close to each other (OECD, 2015[14]; Collier, Jones and Spijkerman, $\left.2018_{[15]}\right)$. The mechanisms that create agglomeration benefits can be broadly split into three groups: sharing, matching and learning (Duranton and Puga, 2004 [16]; de la Roca and Puga, $2017_{[17]}$ ).

Sharing of facilities or inputs by a large number of firms generates the critical mass that is needed for the provision of certain goods and services that involve high fixed costs (e.g. large infrastructure). Larger labour markets result in better matches between employers and employees, which raises productivity. Finally, technology spillovers allow businesses to learn from other nearby located businesses about the latest production methods. In larger cities, more businesses in similar sectors exist, yielding more opportunities to learn and adopt the most efficient production methods. Furthermore, access to finance and venture capital might be larger in locations with existing agglomerations of successful firms.

Overall, agglomeration economies can have large effects. OECD estimates suggest that productivity increases by $2 \%-5 \%$ for a doubling population size, which is in line with comparable studies for individual countries (Ahrend et al., 2014[18]; Combes, Duranton and Gobillon, 2011 [19]). Other recent studies find even larger estimates in African and other developing economies (Henderson, Nigmatulina and Kriticos, 2018[20]), which might be particularly relevant for today's rapidly urbanising countries. However, agglomerations also give rise to disadvantages and specific costs, which can discourage migration to cities. Higher prices of land, housing and cost of living can offset the benefits of being located in a city. Moreover, factors like air pollution or congestion increase when cities become larger, further reducing the benefits of agglomeration.

Source: OECD (2015[14]), The Metropolitan Century: Understanding Urbanisation and its Consequences, https://dx.doi.org/10.1787/9789264228733-en; Collier, P., P. Jones and D. Spijkerman (2018[15]), Cities as Engines of Growth: Evidence from a New Global Sample of Cities; Duranton, G. and D. Puga $\left(2004_{[16]}\right)$, "Micro-foundations of urban agglomeration economies", http://dx.doi.org/10.1016/S0169-7218(04)07048-0; Ahrend, R. et al. (2014[18]), "What Makes Cities More Productive? Evidence on the Role of Urban Governance from Five OECD Countries", https://dx.doi.org/10.1787/5jz432cf2d8p-en; Combes, P., G. Duranton and L. Gobillon $\left(2011_{[19]}\right)$, "The identification of agglomeration economies", http://dx.doi.org/10.1093/jeg//bq038; Henderson, J., D. Nigmatulina and S. Kriticos (2018[20]), Measuring Urban Economic Density, http://dx.doi.org/10.1596/1813-9450-8678.

Despite supporting evidence from developed countries, structural transformation is no longer the main explanation for urbanisation in many developing countries. Particularly in Sub-Saharan Africa, high levels of urbanisation are not accompanied by industrialisation. Here, urbanisation has proceeded without the development of significant and competitive manufacturing sectors (Henderson and Kriticos, $\left.2018_{[21]}\right) .{ }^{3} \mathrm{~A}$ stream of recent studies argues that the income effects of natural resource exploitation have driven urbanisation without industrialisation across many countries of the continent (Gollin, Jedwab and Vollrath, $\left.2016_{[22]}\right)$. Other studies suggest that rural deprivation has induced significant migration to African cities for reasons such as civil wars, deficient rural infrastructure and services, and climatic variability (Fay and Opal, 1999[23]; Collier et al., 2010[24]; Henderson, Storeygard and Deichmann, 2016[25]). Furthermore, a combination of high fertility rates in cities and declining urban mortality played a leading role in driving 
urbanisation (Jedwab and Vollrath, 2019[26]). Finally, structural change seems to have played out differently in many resource-rich countries in Africa and Latin America, where labour has moved into low-productivity sectors or informality rather than high productivity (Mcmillan, Rodrik and Verduzco-Gallo, 2014[27]). The following three sections provide evidence on the relevance of structural transformation for urbanisation and examine developing and developed countries separately, while further distinguishing between resource-exporting and non-resource-exporting developing countries.

\section{Evidence on structural transformation at play}

The structure of countries' economies differs with their economic development, as previously mentioned. Across the world, higher GDP per capita is associated with a lower share of agriculture, and higher shares in manufacturing and services in the economy (Figure 3.2). In fact, the macroeconomic literature documents that modern economic growth is intrinsically linked to the transition of the economy from agriculture to manufacturing and services (see Herrendorf, Rogerson and Valentinyi (2014[28]) for a review). While the decrease of agriculture and the increase in the service sector is steady with economic development, manufacturing behaves differently. Its share in the economy follows a hump shape. It increases for lower levels of development, peaks at some moment in time, and then starts to decrease for higher levels of development. This transition of the economy between different sectors implies that the spatial distribution of the population, employment and production processes change, and some of these shifts will favour urbanisation. Most of today's developed economies have undergone this path during the first wave of urbanisation that accompanied the Industrial Revolution. Improvements in agricultural productivity driven by innovation occurred in Great Britain before the $18^{\text {th }}$ century and spread to other parts of Europe, which coincided with a move of workers out of agriculture and into manufacturing. As a larger population could be sustained from farming the same amount of land, the number of people that could live in cities increased leading to fast urbanisation (Allen, 2012[29]). In this context, however, it is also important to note that urbanisation itself typically leads to shifts in sectoral activity, for example by resulting in an increasing weight of the service sector in the economy.

\section{Figure 3.2. As countries grow, the sectoral composition of the economy changes}

Average value-added per economic sector (as a share of total value-added in the three sectors) by income group

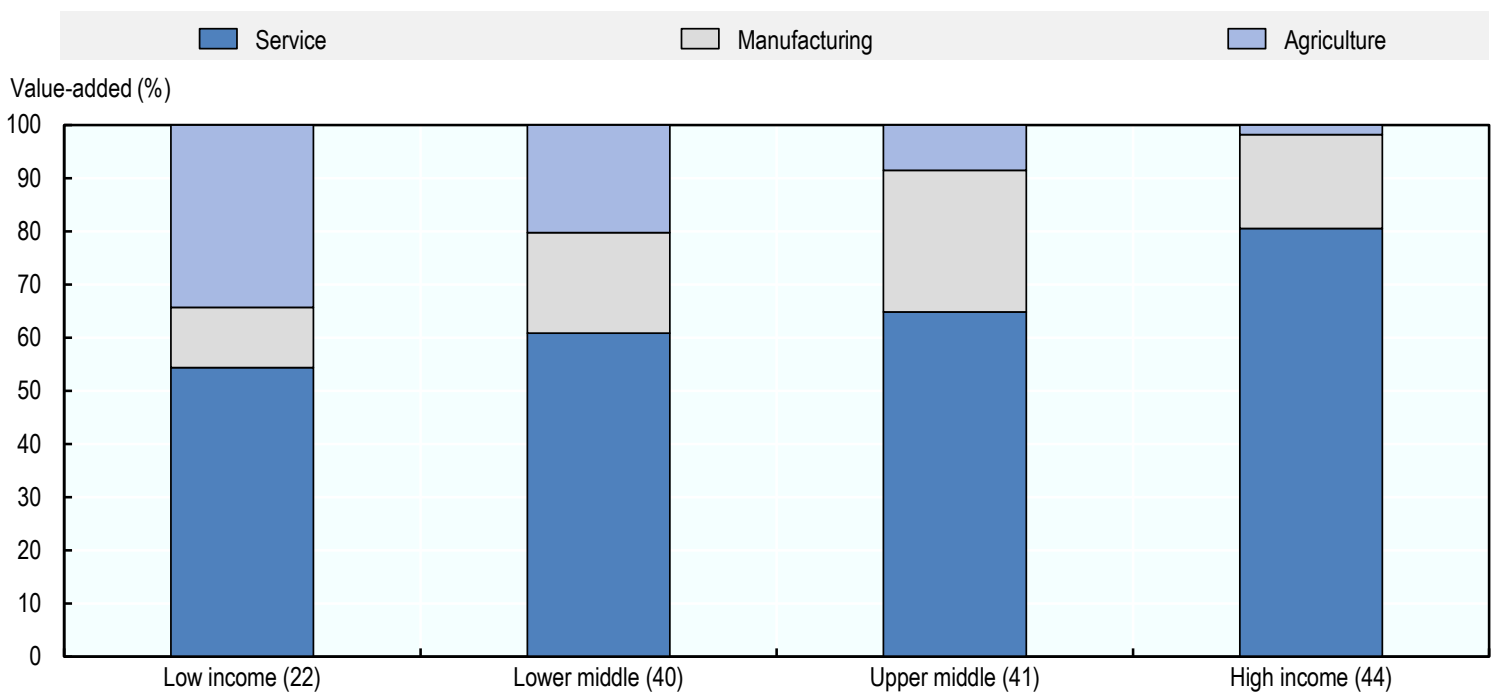

Note: Data refer to the year 2015. Only countries with available sectoral information are included. The number of countries in each category is reported in parentheses. First, for every country, the value-added shares in each sector are computed. Then, these values are considered when taking population-weighted averages by income group the country belongs to in 2015.

Source: OECD calculations based on sectoral composition data from the World Bank. 


\section{Manufacturing vs. services in the context of urbanisation}

The relative importance of the manufacturing and service sectors in the context of urbanisation depends on countries' economic development and the respective start of urbanisation. In countries that were at the forefront of industrialisation, the share of employment in manufacturing peaked as early as the first half of the $20^{\text {th }}$ century (OECD, 2015 $\left.{ }_{[14]}\right)$. Among advanced economies today, the share of the metropolitan population is positively correlated with the importance of the service sector and negatively correlated with the importance of manufacturing in the economy (Figure 3.3). ${ }^{4}$

Today's developed economies, which mostly experienced industrialisation in the past, now heavily rely on metropolitan areas as important locations for tertiary activities. This results from two factors. Urban dwellers typically consume more services than those in rural areas, implying a shift towards services with urbanisation. At the same time, as the service sector benefits from agglomeration economies, the availability of information technology (IT) and the large variety of amenities that cities and their commuting zones offer, a larger service sector may lead to an increase in population in metropolitan areas. ${ }^{5}$ This is consistent with the observation that developed countries that remain more manufacturing-intensive tend to have smaller metropolitan areas in relative terms, partly driven by the fact that manufacturing has become spatially more dispersed and services spatially more concentrated (Desmet and Henderson, $\left.2015_{[3]}\right)$.

\section{Figure 3.3. Structural transformation and the metropolitan system in European Union and OECD countries, 2015}

Rich countries with larger metropolitan areas have more service-based economies

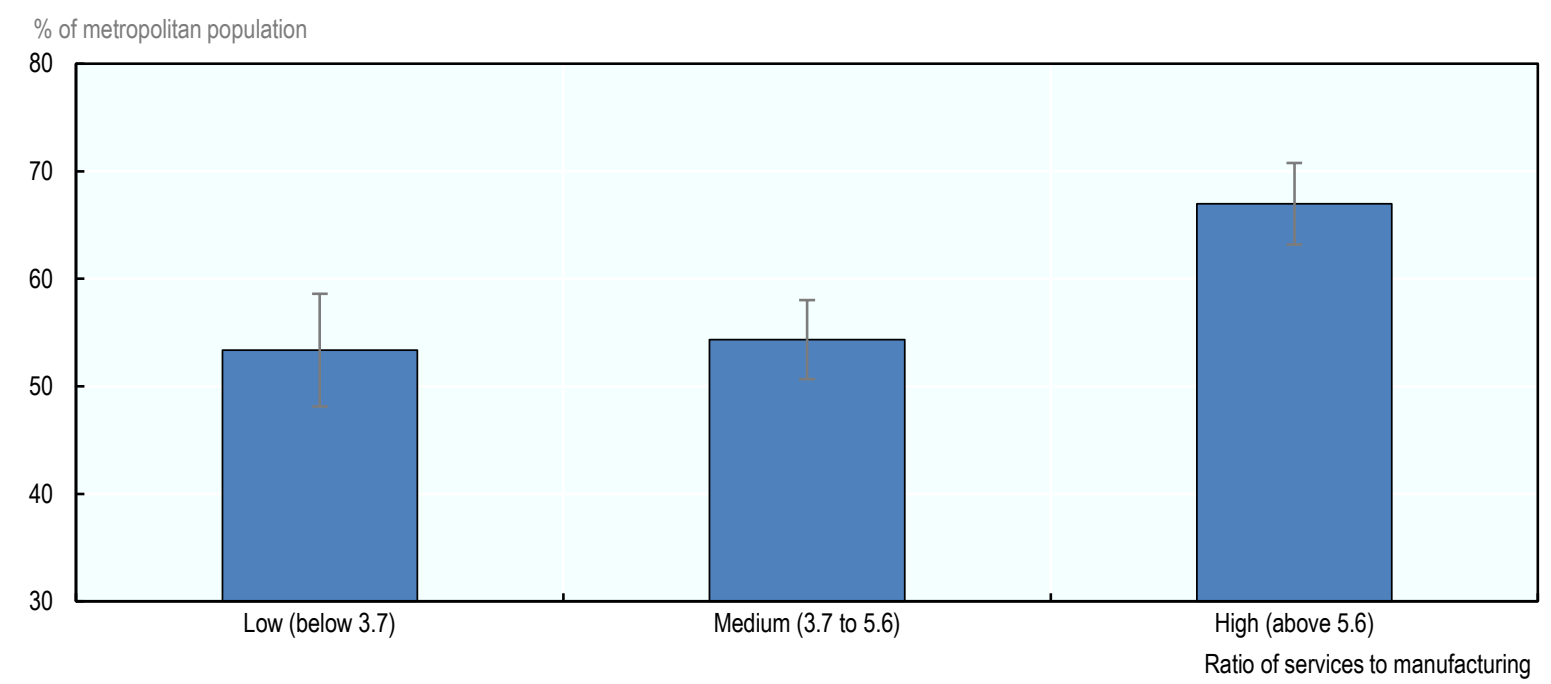

Note: Unweighted average of country values. Horizontal categories are defined using terciles of the ratio of value-added share in the service and the manufacturing sector. Only countries with available sectoral information are included. $90 \%$ confidence intervals are reported. Similar results are obtained with high-income countries as defined by the World Bank.

Source: OECD calculations based on sectoral composition data from the World Bank and population data from the GHSL Data Package 2019, Florczyk, A. et al. (2019[2]), GHSL Data Package 2019 (database), http://dx.doi.org/10.2760/06297.

The empirical pattern in developing countries contrasts with the experience of developed economies. For developing countries, there is no clear link between a more metropolitan population and a more servicebased economy (relative to manufacturing, see Annex 3.C). Two factors could explain the different experience compared to developed countries. First, for most of those developing countries that have been industrialising, industrialisation occurred later than in developed economies and thus manufacturing could 
still play an important role in driving urbanisation in those places. Second, the presence of natural resources in many developing countries, especially in Africa but also in Latin America, has attenuated the link between structural transformation and the shape of the metropolitan system. Among those resourcerich countries, many never fully experience industrialisation but transitioned directly from agriculture to services, mostly consisting of non-tradable, low-value-added services often in the informal economy (Mcmillan, Rodrik and Verduzco-Gallo, 2014[27]). The next section takes a closer look at those resourcerich developing countries that seem to have followed a different path to urbanisation with a markedly different structural change than both high-income countries that urbanised early and countries in Asia such as China.

\section{An alternative path: Urbanisation without industrialisation}

Industrialisation and urbanisation do not necessarily need to go hand in hand. A number of recent studies show that different urbanisation paths can occur, as in the case of many African and Middle Eastern countries with large natural resource endowments (Gollin, Jedwab and Vollrath, 2016[22]; Collier et al.,

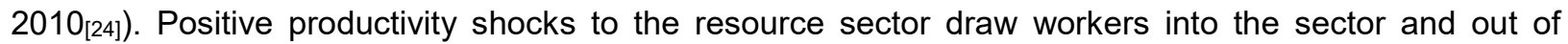
agriculture and other tradable sectors. Surplus income generated from natural resource extraction can, in turn, generate a strong rise in the demand for urban goods and services (relative to food), in particular, if the government transfers a larger than proportional share of the tax intake from natural resource extraction to the urban population, which frequently appears to be the case. This added demand is met largely through imports (except for urban services, which are produced locally). As a result, urbanisation is driven by consumption, not production, creating "consumption cities" (Lall, Henderson and Venables, 2017 [30]). In fact, evidence from the harmonised global definition of metropolitan areas confirms that among less advanced economies, countries with a higher share of natural resource exports have a larger proportion of people living in metropolitan areas (column 3 of Annex Table 3.C.1). In a sample of 82 countries, there is a positive and statistically significant association between the metropolitan population and resource exports (as a share of total merchandising exports). ${ }^{6}$

Although there is a positive association between economic development and the size of metropolitan areas across both resource exporting and non-resource exporting developing countries, the process that shaped the urban system differs substantially across these economies (column 4 of Annex Table 3.C.1). For those countries that rely relatively little on natural resource exports, industrialisation (measured by the share of manufacturing in the economy) and the size of the metropolitan system are strongly correlated. In contrast, for resource exporters, the share of the population living in metropolitan areas is relatively high, and this share is unrelated to the size of the manufacturing sector (see Annex Figure 3.C.2). Recent work supports this finding. In Africa and Latin America, where for many countries natural resources account for a large share of exports, the relatively productive sectors such as natural resource extraction or certain parts of manufacturing have not been able to absorb the surplus labour from agriculture (Mcmillan, Rodrik and Verduzco-Gallo, 2014[27]). Instead, workers have mostly moved into low-productivity services and informality.

Overall, these findings correspond to two widely discussed but distinct paths to urbanisation, namely the different experiences in Africa and Asia as well as parts of Latin America. In East Asia and South Asia, countries mainly urbanised via a process of industrialisation. More recently, those countries have increasingly transitioned to service-based economies. In contrast, many countries in Sub-Saharan Africa and Latin America did not experience a notable structural transformation. Resource-rich countries in Africa and Latin America often urbanised without developing a strong manufacturing sector, with increases in urbanisation instead of being driven by resource rents. In those countries, structural change may not have been growth-increasing as in Asia because labour did not move to high-productivity activities, but often ended up in low-productivity activities, in particular in the informal sector (Mcmillan, Rodrik and VerduzcoGallo, 2014[27]; OECD, 2016[31] $)$. Encouragingly, evidence suggests that, at least in Africa, the effect of 
structural change on productivity has passed a turning point, positively contributing to overall productivity growth in recent years (Mcmillan, Rodrik and Verduzco-Gallo, 2014 ${ }_{[27]}$ ).

\section{Regional economic development and the metropolitan system}

\section{The distribution of population across metropolitan areas differs with economic development}

A positive association between economic development and the share of metropolitan population leaves open the question of the spatial distribution of the metropolitan population at different stages of development. A growing metropolitan population might result in a homogenously-distributed and lowconcentrated metropolitan system, characterised by similarly medium-sized metropolitan areas. At the same time, it may also lead to an unbalanced and highly concentrated metropolitan system, with one or a few highly populated metropolitan areas and many smaller ones may arise.

Across the world, there is a non-linear relationship between the stage of development of a country and the concentration of the metropolitan population across different metropolitan areas. The dominance of a few large metropolitan areas over the remaining ones tends to increase from low to intermediate stages of development. For richer countries, the metropolitan system is more balanced, with a lower concentration of the metropolitan population in a few metropolitan areas. This non-linear pattern is shown in Figure 3.4, in which the Gini index is used to measure the spatial concentration of the metropolitan population. ${ }^{7}$ These results hold when using different measures of concentration, such as the coefficient of variation of the metropolitan population, the Herfindahl-Hirschman Index $(\mathrm{HHI})$, and the coefficients from Zipf's law between rank and population for the largest 10 metropolitan areas in the country. ${ }^{8}$

The presence of a few large metropolitan areas rather than the predominance of a single one best explains the higher concentration of metropolitan population in countries at intermediate stages of development. Regression analysis confirms that primacy, i.e. the share of the largest metropolitan area in the national metropolitan population, first increases and then decreases as income grows. However, the ratio between the largest and second-largest metropolitan areas does not. This suggests that it is not the difference between the largest metropolitan areas and the subsequent ones that drives the inverted U-shaped correlation between metropolitan concentration and development. Rather, it is more likely to be the existence of a few large metropolitan areas dominating over the remaining smaller ones. ${ }^{9}$

The non-linear relationship between economic development and the concentration of the metropolitan system, depicted in Figure 3.4, is often characterised as a regional development issue. As countries urbanise, the process of urbanisation proceeds at first in a small number of regions where a large share of the metropolitan population concentrates (more discussion in the next section). With further economic

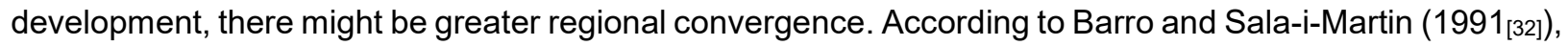
such regional convergence would be driven by a catching-up of backward regions.

To some extent, the relationship between growth and the concentration of metropolitan population might also reflect the transition from agriculture to manufacturing and, subsequently or directly without farreaching industrialisation, to the service economy that countries may experience as they develop. If the geographical use of space differs across sectors, then a country's overall spatial organisation will change as the relative importance of different sectors evolves. In particular, the shift from agriculture to manufacturing could create imbalances in the distribution of the metropolitan population. Locational advantages, together with agglomeration economies, could explain the formation and sustained growth of only a few large metropolitan areas experiencing fast industrialisation compared to others remaining behind. For instance, historical proximity to agricultural land, natural resources or navigable waterways have been important factors for the emergence of metropolitan areas in the first place. Later on, agglomeration economies make it convenient for businesses and workers to move to the existing high- 
density areas, thus creating a virtuous circle. This transition that accompanies countries from low- to middle-income levels helps to describe the initial positive relationship between the Gini index for the metropolitan population and GDP per capita (Figure 3.4, lighter part of the line).

\section{Figure 3.4. Economic development and the concentration of the metropolitan population}

Higher values of the Gini coefficient indicate a higher concentration of a country's total metropolitan population

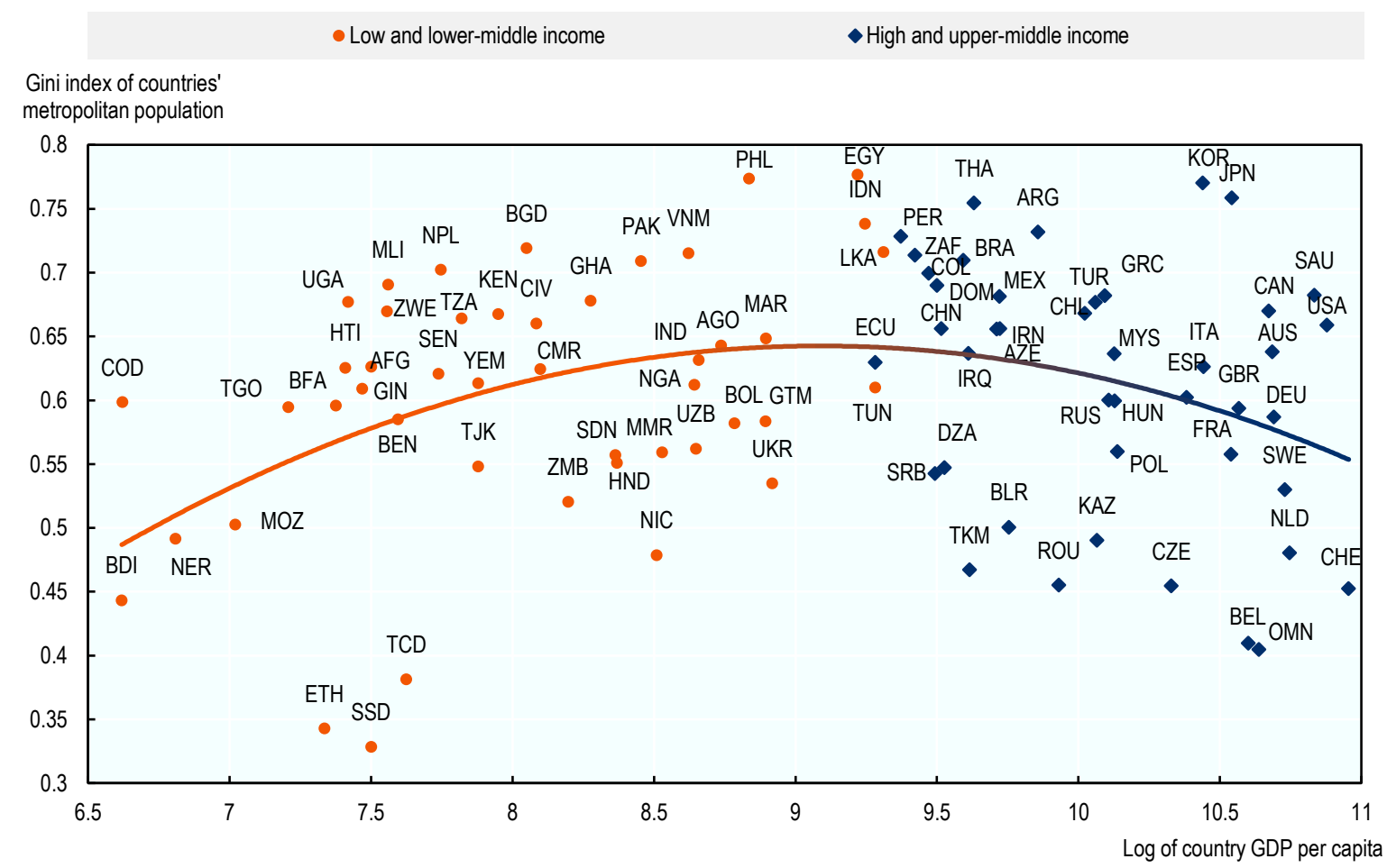

Note: Eighty-nine countries are included. For a meaningful interpretation of the Gini coefficient, countries with less than ten metropolitan areas are excluded from the computation. The R-squared of the regression that includes the log (country GDP per capita) and its quadratic value is 0.12. The estimated value of GDP per capita at which Gini reaches its maximum is almost USD 10000 . A similar pattern is obtained when using the coefficient of variation in the metropolitan population rather than the Gini index.

Source: OECD calculations based on data from the World Bank and population data from the GHSL Data Package 2019, Florczyk, A. et al. (2019[2]], GHSL Data Package 2019 (database), http://dx.doi.org/10.2760/06297.

StatLink त्ताजम https://doi.org/10.1787/888934130322

However, even within a given sector, the geographical use of the space may change over time, as sectors transition from being young to being mature. For instance, as mentioned above, European countries and the United States have experienced deconcentration in manufacturing and greater concentration in services in past decades. In part, this is explained by the fact that younger industries stand more to gain from knowledge spillovers, which are enhanced by the geographic concentration of economic activity (Desmet and Henderson, $2015_{[3]}$ ). As a result, with manufacturing becoming spatially more dispersed, the population in small- or medium-sized metropolitan areas could increase, compensating existing imbalances. This transition, which is more likely to occur at more advanced stages of development, is a possible explanation underlying the negative relationship between the Gini index and GDP per capita (Figure 3.4, darker part of the line). As pointed out in the previous section, many developing countries in Africa and certain countries in Latin America followed a different path to urbanisation than most of 
North America, Asia and Europe did beforehand. They urbanised without far-reaching industrialisation and without significant gains in productivity. This markedly different experience, especially in Africa, raises the question of whether today's low-income countries will follow the same trajectory of moving to a more balanced metropolitan system as they develop.

\section{Box 3.2. Income inequality and the concentration of the metropolitan population}

A large literature dating back to Williamson (1965[33]) has examined the link between regional development and spatial as well as overall interpersonal income inequality. In most OECD countries, income inequalities have been rising over the last three decades and the global financial crisis has further increased inequality and poverty rates (OECD, 2015 $[34]$ ). Rising inequality has not only been connected with other macro-level trends such as globalisation or skill-biased technical progress but also with the evolution of metropolitan areas (Hamnett, 1994[35]).

In developed economies, there is a positive and significant relationship between the spatial concentration of the metropolitan population within the country and the level of interpersonal income inequality among its citizens (Figure 3.5). Countries with a more unbalanced metropolitan system, as measured by the Gini coefficient of the metropolitan population, tend to have a higher Gini inequality index of personal income. The result is robust to the inclusion of controls such as the country per capita GDP and total population. Importantly, this positive association does not imply a causal relationship due to many omitted factors that could simultaneously influence both variables. Nevertheless, some hypotheses to explain this finding can be outlined.

In OECD countries, larger metropolitan areas display higher levels of income inequality (Boulant, Brezzi and Veneri, 2016[36] $)$. As a result, countries characterised by the dominance of a few big metropolitan areas over the remaining smaller ones could exhibit higher interpersonal income inequality overall. In fact, the gap between high- and low-skilled jobs tends to widen in metropolitan areas, where the effect of globalisation on workforce polarisation are stark (OECD, 2016[37]). Moreover, the high socioeconomic residential segregation of the rich and the poor that metropolitan areas exhibit is also closely connected to higher income inequality (OECD, 2018[38]).

High-productivity gains due to agglomeration economies in larger metropolitan areas could also imply that an unequal distribution of the metropolitan population might translate into economic disparities across subnational regions, which are a crucial component of the overall interpersonal income inequality (Milanović, 2005[39]). In this respect, recent studies have shown that variation in individuals' earnings in the United States (US) has an important spatial dimension. Much of the 1970s-2010s increase in earnings inequality resulted from increased dispersion of the earnings among the establishments where individuals work, rather than within-establishment differences (Barth et al., 2016 [40]).

Imbalances in the distribution of the metropolitan population might also be correlated with other socioeconomic factors, which can, in turn, explain interpersonal income inequality. Examples include the level of economic development or the degree of trade openness of a country, its fiscal and political decentralisation as well as the level of linguistic and ethnic segregation (Ezcurra and Rodriǵuez-Pose, 2017[41] $)$. Moreover, internal conflicts, which undermine trust, social and political stability, might be correlated with the distribution of both income and people over space (Kanbur and Venables, 2005[42]). 


\section{Figure 3.5. Income inequality and spatial concentration in developed countries}

Higher values of the Gini coefficients indicate higher interpersonal income inequality (vertical axis) or higher concentration of the country's total metropolitan population (horizontal axis)

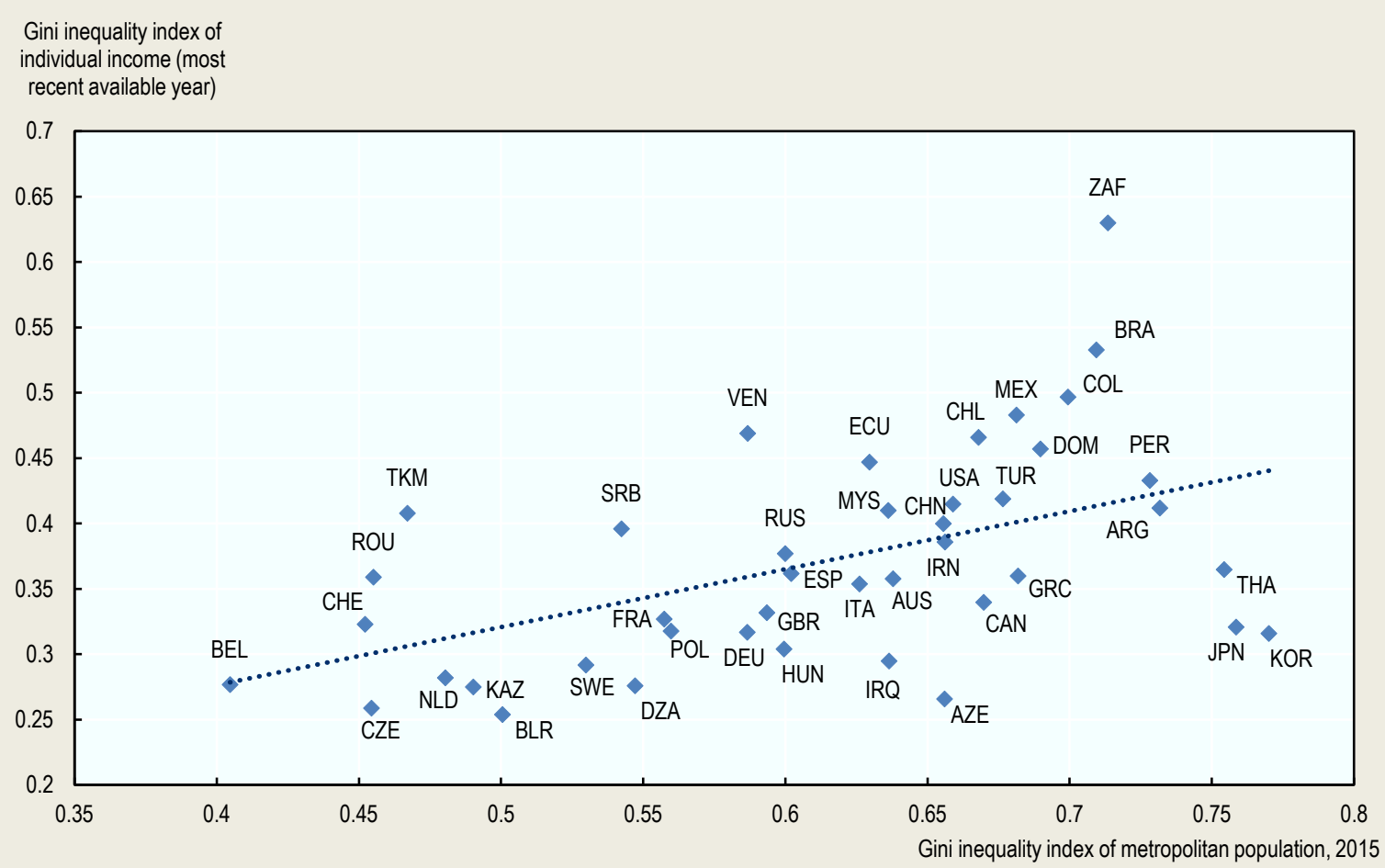

Note: Only high and upper-middle-income (42) countries are included. Moreover, countries with less than ten metropolitan areas are excluded from the computation of the Gini index of the metropolitan population. The coefficient of the underlying regression is 0.44 and the associated R-squared is 0.26 . Results are robust to the inclusion of (the log of) country GDP per capita and total population.

Source: OECD calculations based on disposable household income inequality data from the World Bank and population data from the GHSL Data Package 2019, Florczyk, A. et al. (2019[2]], GHSL Data Package 2019 (database), http://dx.doi.org/10.2760/06297.

Finally, another plausible explanation for the observed relationship is that the expected returns from moving to a metropolitan area are higher if there is greater interpersonal income inequality. A job at the upper end of the distribution is worth more if inequality is high and these jobs are predominantly found in metropolitan areas, especially in the largest ones. Therefore, in this view, the higher level of income inequality in a country might influence the distribution of people over space.

Source: Williamson, J. (1965[33]), "Regional inequality and the process of national development: A description of the patterns", Economic Development and Cultural Change, Vol.13/4, pp.1-84; OECD (2015[34]), In It Together: Why Less Inequality Benefits All, https://dx.doi.org/10.1787/9789264235120-en; Hamnett, C. (1994[35]), "Social polarisation in global cities: Theory and evidence", http://dx.doi.org/10.1080/00420989420080401; Boulant, J., M. Brezzi and P. Veneri $\left(2016{ }_{[36]}\right)$, "Income Levels And Inequality in Metropolitan Areas: A Comparative Approach in OECD Countries", https://dx.doi.org/10.1787/5j|wj02zz4mr-en; OECD (2016[37]), Making Cities Work for All: Data and Actions for Inclusive Growth, https://dx.doi.org/10.1787/9789264263260-en; OECD (OECD, 2018[38]), OECD (2018), Divided Cities: Understanding Intra-urban Inequalities, https://dx.doi.org/10.1787/9789264300385-en; Milanovic $\_$, B. (2005[39]), Worlds Apart: Measuring International and Global Inequality, Princeton University Press; Barth, E. et al. (2016 $[40])$, "It's where you work: Increases in the dispersion of earnings across establishments and individuals in the United States", http://dx.doi.org/10.1086/684045; Ezcurra, R. and A. Rodriǵuez-Pose (2017[41]), “Does ethnic segregation matter for spatial inequality?", http://dx.doi.org/10.1093/jeg//bx007; Kanbur, R. and A. Venables (2005[42]), Spatial Inequality and Development, http://dx.doi.org/10.1093/0199278636.001.0001. 


\section{The income gap between regions with the highest and lowest metropolitan population shares decreases with economic development}

Economic disparities across regions within a country are often relatively high. They typically go beyond simple income inequality and can be found in numerous dimensions such as productivity, housing prices, job opportunities and access to services (OECD, 2018[43]). Whether lagging regions are converging to economically more advanced ones is therefore of crucial importance when considering the persistence of regional inequality (see Box 3.3). Socio-economic disparities often emerge when comparing regions with a different share of the metropolitan population. A newly assembled dataset consisting of a sample of about 1500 subnational regions from 82 countries (described in Annex 3.D) allows examining to what extent regional disparities in various socio-economic dimensions change with the share of the regional population in metropolitan areas. Similarly, it allows to assess how such disparities are associated with country-wide economic development.

At higher stages of economic development, countries tend to have a more equal distribution of resources across the most and the least metropolitan regions. Thus, economic development has largely reduced regional disparities in terms of GDP per capita in today's industrial countries. Similar patterns hold for a range of well-being indicators other than GDP per capita, such as unemployment, consumption and human capital (World Bank, 2009[44]).

Structural transformation helps to explain the link between spatial inequality and regional development. In agrarian economies, regional differences are limited. Early industrialisation leads to clusters of manufacturing activity emerging in particular locations, leading to an increase in regional income disparities. As industrialisation spreads and agriculture loses importance across the economy, those income differences decline (Desmet and Henderson, 2015[3]).

The US economy provides an example for the rise of regional differences at earlier stages of development, and their subsequent decline later on. In fact, US income per capita across regions diverged during the $19^{\text {th }}$ century and early $20^{\text {th }}$ century and converged afterwards (yet at a much slower pace over the last 30 years (Ganong and Shoag, $\left.2017_{[45]}\right)$ ). Changes in the industrial structure across regions help to explain these patterns. During the industrialisation of the northeast and the formation of the manufacturing belt, regional differences in the share of manufacturing increased and with it, regional differences in income per capita. At the beginning of the $20^{\text {th }}$ century, this trend reversed. The states which had most agriculture initially were also the ones where agriculture declined the most and where income per capita growth was strongest. This led to a more equal redistribution of income gains across regions (Kim and Margo, 2004[46]).

\section{Box 3.3. Economic growth and income convergence across regions}

There is substantial inequality among regions of the same country that needs to be understood. For example, according to a data set based on the OECD regional database and Gennaioli et al. (2014[47]) (see Annex 3.D), the richest region in the average country is 4.7 times richer than the poorest one, a difference roughly similar to that between South Africa and the United States in 2010. Sometimes, these differences can be more extreme. Moreover, poor countries display a greater dispersion of regional GDP levels than rich countries. Because these income differences summarise past growth trajectories, understanding the speed of regional convergence can shed light on the persistence of regional inequality.

The work by Gennaioli et al. (2014[47]) systematically studies regional convergence by using a large sample of subnational regions. To compute GDP growth rates, the authors expand the dataset from Gennaioli et al. (2013[48]) by collecting time-series data on regional GDP as well as human capital. Using 
data on 1528 regions in 83 countries, they analyse the patterns of convergence among regions and compare them to convergence across countries.

According to their estimates, regions converge by around $2 \%$ per year within a country. The national convergence rate is around $1 \%$, not much slower than the regional rate. This result is puzzling. Barriers to the mobility of human and physical capital are arguably much less important within than between countries, implying that the difference between regional and national convergence should be higher than what is observed in reality.

The authors explore whether slow regional convergence is the product of institutional barriers to regional mobility of resources. They find that regional convergence is indeed faster in richer countries, consistent with the latter having lower regional inequality, and in countries with better-regulated capital markets and fewer trade barriers.

The research raises the puzzle of slow convergence between subnational regions but does not provide a resolution of this puzzle. Potentially critical factors accounting for regional growth such as structural transformation, technology diffusion and urbanisation should be taken into account. One potential explanation might be that regional convergence is mostly driven by technological catch-up rather than migration (Barro and Sala-I-Martin, 1992[49]).

Source: Gennaioli, N. et al. (2014[47]), "Growth in regions", http://dx.doi.org/10.1007/s10887-014-9105-9; Gennaioli, N. et al. (2013[48]), "Human capital and regional development", http://dx.doi.org/10.1093/qje/qjs050; Barro, R. and X. Sala-I-Martin (1992[49]), "Regional growth and migration: A Japan-United States comparison", Journal of the Japanese and International Economies, Vol. 6/4, pp. 312-346.

\section{Income disparities between more and less metropolitan regions are larger in countries at intermediate stages of development}

Over time, there is a common pattern of rising differences in income between more and less metropolitan regions, followed by a process of regional convergence. Consequently, the relation between national income per capita and regional dispersion in income per capita often exhibits an inverted-U-shaped pattern, a phenomenon called "spatial Kuznets curve" (Kim, 2008[50]; Combes et al., 2011 [51]). Consistent with the evidence on the spatial Kuznets curve, findings based on the globally consistent definition of metropolitan areas show that economies at intermediate stages of development tend to have larger regional income disparities between more and less metropolitan regions than the poorest and the richest countries (Box 3.4).10 In particular, in lower- and upper-middle-income countries, the GDP per capita in the most metropolitan regions is twice as large as in the least metropolitan regions. By contrast, in low and high-income economies, this gap more than halves, with income per capita around $40 \%$ higher in the most metropolitan region compared to the least metropolitan region (Figure 3.6).

\section{Box 3.4. Regional income according to share of the population in metropolitan areas}

The figure below reports the percentage difference in GDP per capita of regions compared to the least metropolitan region in their respective country. This difference in GDP per capita varies with the share of the metropolitan population in a region. Average differences are presented separately for two groups of countries. The lighter, dashed line presents the regional income disparities based on metropolitan population for middle-income countries. The darker, solid line shows those disparities for high- and lowincome countries.

The higher the metropolitan population share of regions in middle-income countries is, the richer they tend to be (dashed line, Figure 3.6). The y-axis shows the relative income difference to the least metropolitan region in the country. Regions in middle-income countries with $90 \%-100 \%$ of the 
population in metropolitan areas have twice the GDP per capita level of the least metropolitan region in the same country.

Figure 3.6. Income disparities between less and more metropolitan regions by stage of development

Countries at intermediate stages of development have larger regional income disparities

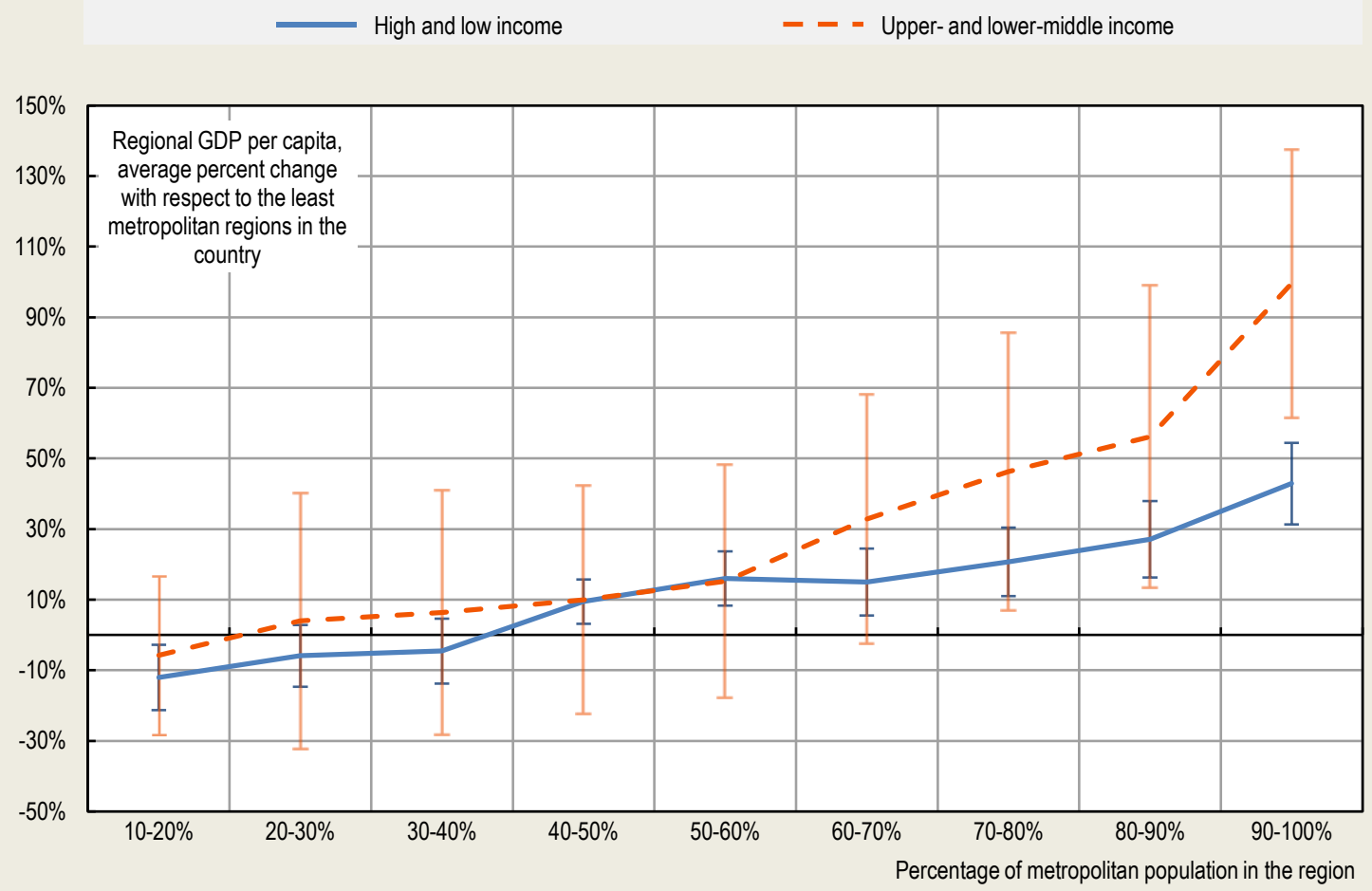

Note: Data refer to the year 2000. The solid line uses data on 567 regions in 36 countries. The dashed line uses data on 932 regions in 45 countries. The chart reports coefficients on a set of dummies, one for each category of metropolitan population share, and the respective $95 \%$ confidence intervals. The omitted dummy is the one referring to $0 \%-10 \%$ of the metropolitan population. Hence, each number needs to be interpreted with respect to the average regional GDP per capita in regions with less than $10 \%$ of their population living in metropolitan areas. Each number is statistically significant when the associated confidence interval does not overlap with the horizontal $(0 \%)$ line. Source: OECD calculations based on GDP data described in Annex 3.D, population data from the GHSL Data Package 2019, Florczyk, A. et al. (2019[2]), GHSL Data Package 2019 (database), http://dx.doi.org/10.2760/06297, and country's income group data from the World Bank.

The findings suggest that a part of the spatial Kuznets curve may be explained by the higher advantages of urbanisation in middle-income countries. With economic development, countries tend to follow a process of urbanisation, which is concentrated in a few regions. This increases spatial inequality. In countries at higher stages of development, urbanisation spreads more evenly across regions, potentially mitigating spatial income disparities. In countries with lower development, a rapidly increasing concentration of population and economic activity in a country's metropolitan areas takes place. As a result, significant disparities in productivity, wages and basic welfare may occur between regions with higher and lower shares of the metropolitan population. The concentration of capital, consumers and workers brings production advantages to metropolitan regions, which benefit from agglomeration economies. Larger local markets enable firms to spread the fixed costs of production across a wider number of consumers and lead to productivity advantages. This, in turn, is reflected in higher wages in metropolitan areas and greater availability of a more diversified range of goods and services (World Bank, 2009 ${ }_{[44]}$ ). 


\section{The metropolitan population is larger in regions with higher GDP growth rates}

Within countries, a larger share of the metropolitan population in 1990 is associated with faster regional economic growth over the last 25 years (Figure 3.7). This finding holds in both EU, OECD and other countries, yet the pattern seems to be clearer in the former. Figure 3.7 shows the average share of metropolitan population for different categories of regional GDP growth, in deviations from the country averages. Regions with very low relative GDP growth rates had 5 percentage point lower metropolitan population shares compared to the national average. In contrast, regions with very high GDP per capita growth had metropolitan population shares that were almost 8 percentage points higher than the country average.

\section{Figure 3.7. The share of metropolitan population and regional GDP per capita growth}

Within countries, regions with a relatively larger share of the metropolitan population grew faster

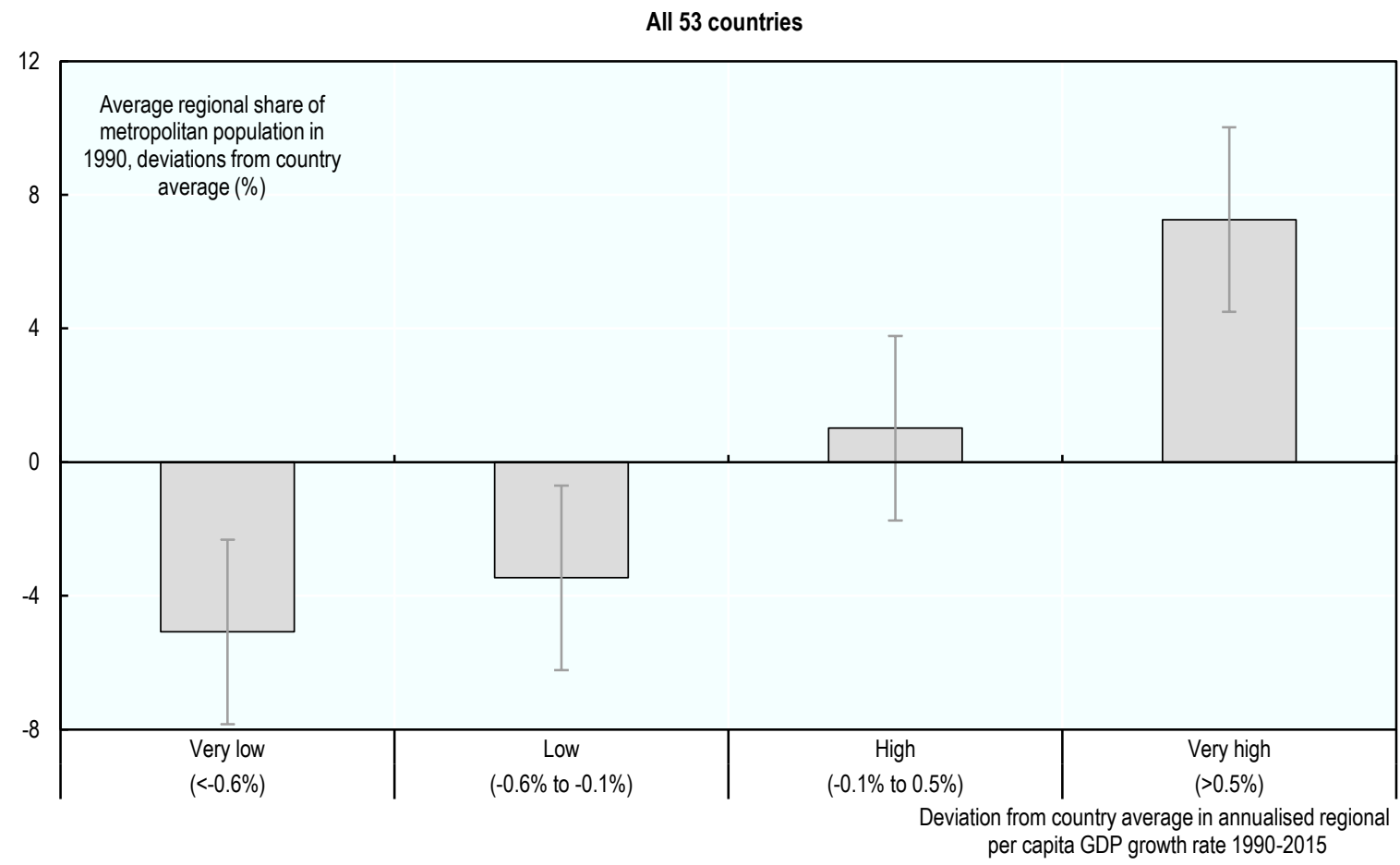

Note: Data on 641 regions in EU+OECD and 444 regions in other countries. 95\% confidence intervals are reported. Annualised GDP growth rates (1990-2015) controlling for country dummies and 1990 GDP levels are used to build categories on the horizontal axis. Each category contains the same number of regions (quartiles of GDP growth), ordered from the smallest to the highest value of growth rate. Growth is based on constant price GDP.

Source OECD calculations based on GDP data described in Annex 3.D and population data from the GHSL Data Package 2019, Florczyk, A. et al. (2019[2] $)$, GHSL Data Package 2019 (database), http://dx.doi.org/10.2760/06297.

Within the EU and the OECD, this pattern is even more striking. Regions, where per capita GDP grew much faster than their countries' average, have a share of the metropolitan population that is 10 percentage points larger than the respective country average in 1990. The corresponding number for countries outside of the EU and OECD is slightly above 6 percentage points. Regression analysis confirms these findings.

The positive association between regional economic development and the share of the metropolitan population holds also when GDP levels are considered. In fact, regions with a larger share of the metropolitan population have higher GDP per capita levels in 2015. Regression analysis on 1153 regions 
in 57 countries with available data for 2015 shows that, on average, a 1\% rise in GDP per capita relative to the country GDP per capita is associated with a 0.25 percentage point increase in the share of metropolitan population. ${ }^{11}$ The relationship is larger in EU and OECD countries, where the estimate is 0.43 , more than twice as large as the corresponding number for other economies.

Theories on structural transformation and agglomeration economies help explain the positive association between economic growth and the share of the metropolitan population across subnational regions. Similar to countries, regions' economic sectors transition from agriculture to manufacturing or from manufacturing to services when they develop.

In developing countries, agricultural productivity differentials across regions can be large, implying that industrialisation is unevenly spread over the territory. Adoption of new technologies yields productivity gains in agriculture in regions with high growth potential, releasing rural labour and promoting the development of the industrial sector, thus pushing workers towards metropolitan areas where industries tend to be located. As a consequence, the level of migration towards metropolitan areas may differ substantially across space.

In regions in developed countries, economic development goes hand in hand with technological progress and labour-saving innovations, which reduce employment in manufacturing and boost the transition to services and knowledge-intensive professions. While manufacturing becomes spatially more dispersed, services concentrate in high-density areas, where they benefit from knowledge spillovers and information technology (IT) infrastructure. As a result, metropolitan areas become the centres of innovation and creativity, home to IT-intensive industries with high growth potentials. While further growth of the service economy might benefit metropolitan areas and induce economic growth, the documented pattern does not offer any information on whether faster GDP per capita growth in more metropolitan regions will continue.

Regions with a high share of metropolitan population today were also denser in the past. They experienced productivity growth over time due to economic factors that, in the long run, make it beneficial for firms and households to be located close to each other such as lower transport costs, better employer-employee matches and knowledge spillovers. These factors create productivity advantages and higher wages, which in turn attract more workers and firms. As a result, metropolitan areas that already have many businesses and people attract even more and grow in this process.

\section{Box 3.5. The economic performance of OECD metropolitan areas}

Is per capita income higher in metropolitan areas? In the following, this box examines whether GDP per capita is higher in OECD metropolitan areas than the respective national average. Using data from the OECD Metropolitan Database on the 630 metropolitan areas in OECD countries allows for a comparison of GDP levels, both in absolute and per capita terms.

Cities and their commuting areas are key contributors to the national socio-economic performance. In 2015, the 563 metropolitan areas with available data accounted for almost $55 \%$ of the total population and more than $60 \%$ of the total GDP of the entire OECD area. The economic importance of metropolitan areas reflects their large potential for job creation, innovation and green growth, as well as the fact that these places are hubs and gateways in global trade and transport networks (OECD, 2015[14]).

Within OECD countries, metropolitan areas have around 10\% higher GDP per capita levels than their respective country (Figure 3.8). In contrast, areas outside metropolitan areas have an average GDP per capita equivalent to $92 \%$ of the country average. Moreover, the larger the metropolitan area is, the higher is its GDP per capita. To show this, the figure below reports the average ratio of GDP per capita in metropolitan areas (and non-metropolitan areas) with respect to that in their countries. While the largest metropolitan areas with more than 5 million people have more than $25 \%$ higher per capita income levels than their respective country, this is not true for smaller metropolitan areas. In fact, metropolitan areas 
below a population of 1 million inhabitants actually record lower GDP per capita than the national average. More specifically, regression analysis indicates that the population threshold at which the average GDP per capita in the metropolitan areas exceeds that of their countries is, on average, 700000 inhabitants.

\section{Figure 3.8. Per capita income in metropolitan areas and their countries, 2015}

Larger metropolitan areas have higher per capita income relative to their countries

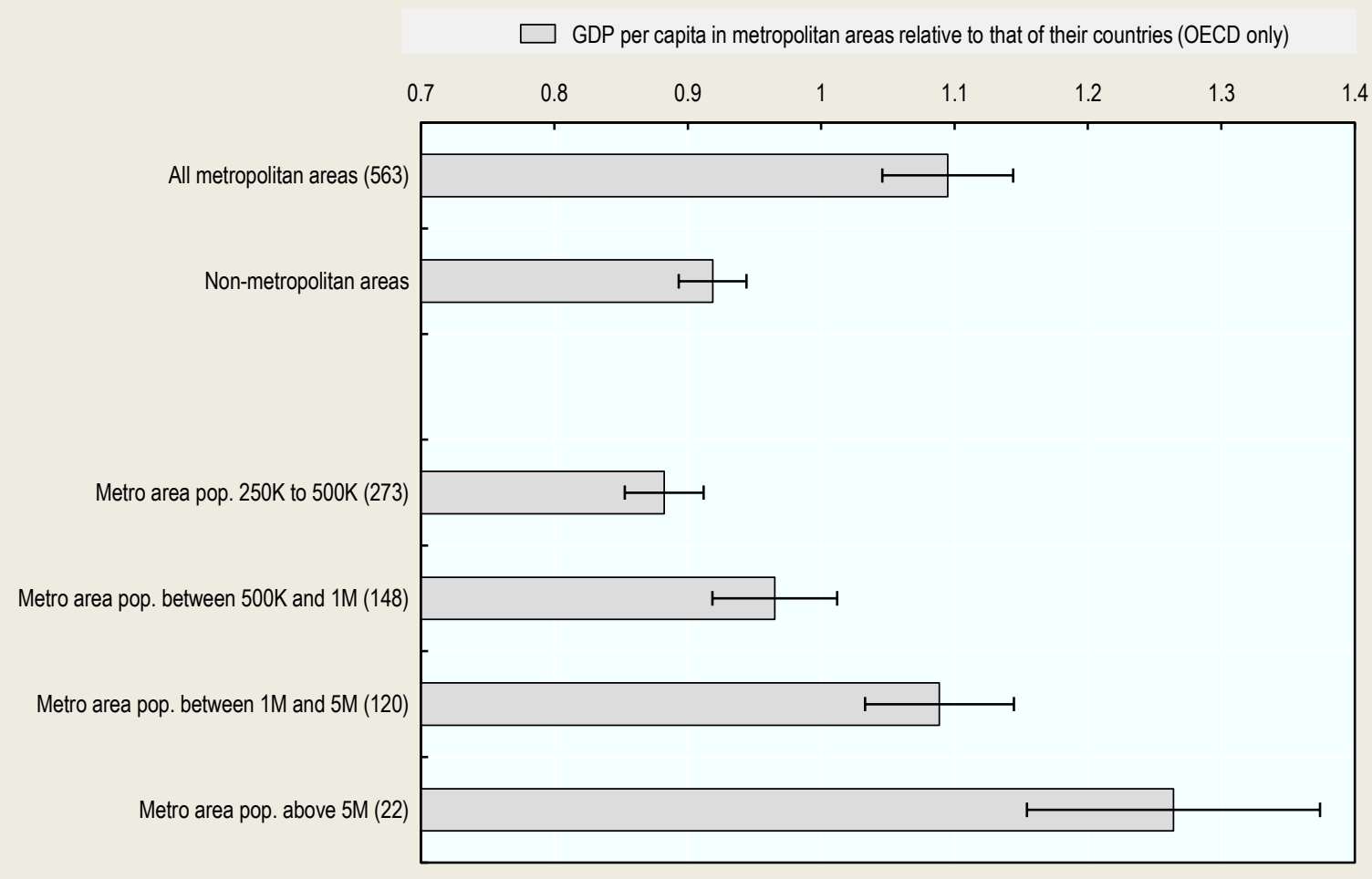

Note: Population-weighted averages of the ratio of GDP per capita in metropolitan areas relative to that of their countries are reported. Source: OECD (n.d.[52]), OECD Metropolitan Database, https://stats.oecd.org/Index.aspx?Datasetcode=CITIES.

StatLink :ना15 https://doi.org/10.1787/888934130341

Larger metropolitan areas are generally more productive, and hence have higher per capita GDP. However, although this is true on average, there are many differences across countries (see Annex Figure 3.D.1). Recent OECD studies suggest that for each doubling population size, the productivity level of a city increases by $2 \%-5 \%$ (Ahrend et al., $2014_{[18]}$ ). This is due to several factors, such as greater competition or deeper labour markets (and thus a better matching between workers and jobs) in larger cities, but also due to a faster spread of ideas, higher levels of human capital and a more diverse intellectual and entrepreneurial environment. Finally, it is important to mention that higher nominal GDP per capita levels do not necessarily imply that people are richer in real terms. In fact, prices of goods and services tend to be higher in larger metropolitan areas and this could offset the larger per capita income of their population (Ahrend and Lembcke, 2017[53]).

Source: OECD (n.d.[52]), OECD Metropolitan Database, https://stats.oecd.org/Index.aspx?Datasetcode=CITIES; OECD (2015[14]), The Metropolitan Century: Understanding Urbanisation and its Consequences, https://dx.doi.org/10.1787/9789264228733-en; Ahrend, R. et al. (2014[18]), "What Makes Cities More Productive? Evidence on the Role of Urban Governance from Five OECD Countries", https://dx.doi.org/10.1787/5jz432cf2d8p-en; Ahrend, R. and A. Lembcke (2017[53]), "Does it pay to live in big(ger) cities? The role of agglomeration benefits, local amenities, and costs of living", http://dx.doi.org/10.2139/ssrn.2925676. 


\section{Migration as a mechanism of regional disparities}

\section{Net migration towards metropolitan regions might partly explain regional income gaps within countries}

Higher availability of job opportunities makes metropolitan areas attractive for migrants. As a result, immigration and emigration flows differ across regions within a country. These flows have been rising over the past few decades, due to large demographic and economic imbalances, ongoing conflicts and consequences of climate change such as droughts and floods. Since migration has important economic implications, understanding regional differences in migration patterns is essential. Migration typically boosts the working-age population and migrants can contribute to long-term economic growth and technological progress provided their skills are well used (OECD, 2019[54]).

The share of the immigrant population (defined as the proportion of international and domestic population aged 15 years or older moving into a given region within 5 years of a given census) tends to be larger in metropolitan regions. ${ }^{12}$ Estimates indicate that a 10 percentage point higher share of metropolitan population is associated with an almost 2 percentage points higher share of immigrants. ${ }^{13}$ In other words, with respect to their resident population, regions with a larger proportion of their population living in metropolitan areas tend to host more immigrants than other regions. This is depicted by the grey dashed line in Figure 3.9, which shows the additional share of the immigrant population that metropolitan regions experience compared to the least metropolitan ones.

More metropolitan regions not only have a higher share of immigrants but also a lower share of emigrants, resulting in higher net migration than in less metropolitan regions. A 10 percentage point increase in the share of the metropolitan population is associated with a drop in the share of emigrants by almost 3.8 percentage points (solid line in Figure 3.9). ${ }^{14}$ Overall, more metropolitan regions record higher net migration gains (dash-dotted line in Figure 3.9). Although this analysis gives only a static picture, it may reconcile with the overwhelming evidence on the unprecedented growth of cities and their areas of influence in the $20^{\text {th }}$ century, and especially over the last 40 years.

Both economic and non-economic factors can entice migration to metropolitan regions. Non-economic considerations often include amenities, such as access to better healthcare, education facilities and specialised shopping opportunities, which make metropolitan areas attractive (see Chapter 2 for detailed evidence). Moreover, cities and their areas of influence offer larger networks that make it more likely for newcomers to find people who share similar cultural and ethnic backgrounds. Economic considerations relate to push and pull factors that determine people's movements from the least to the most metropolitan regions. Structural transformation or lower income in rural areas pushes migrants from agricultureintensive places towards metropolitan areas. At the same time, higher wages in metropolitan areas have a pull effect on workers. Similarly, thick labour markets in metropolitan regions result in more job opportunities and better matches between employers and employees. Finally, metropolitan areas offer migrants learning possibilities that accrue over time and bring them lasting benefits. ${ }^{15}$ 
Figure 3.9. Migration and the share of people in metropolitan areas

Net migration is larger in metropolitan regions due to higher immigration and lower emigration

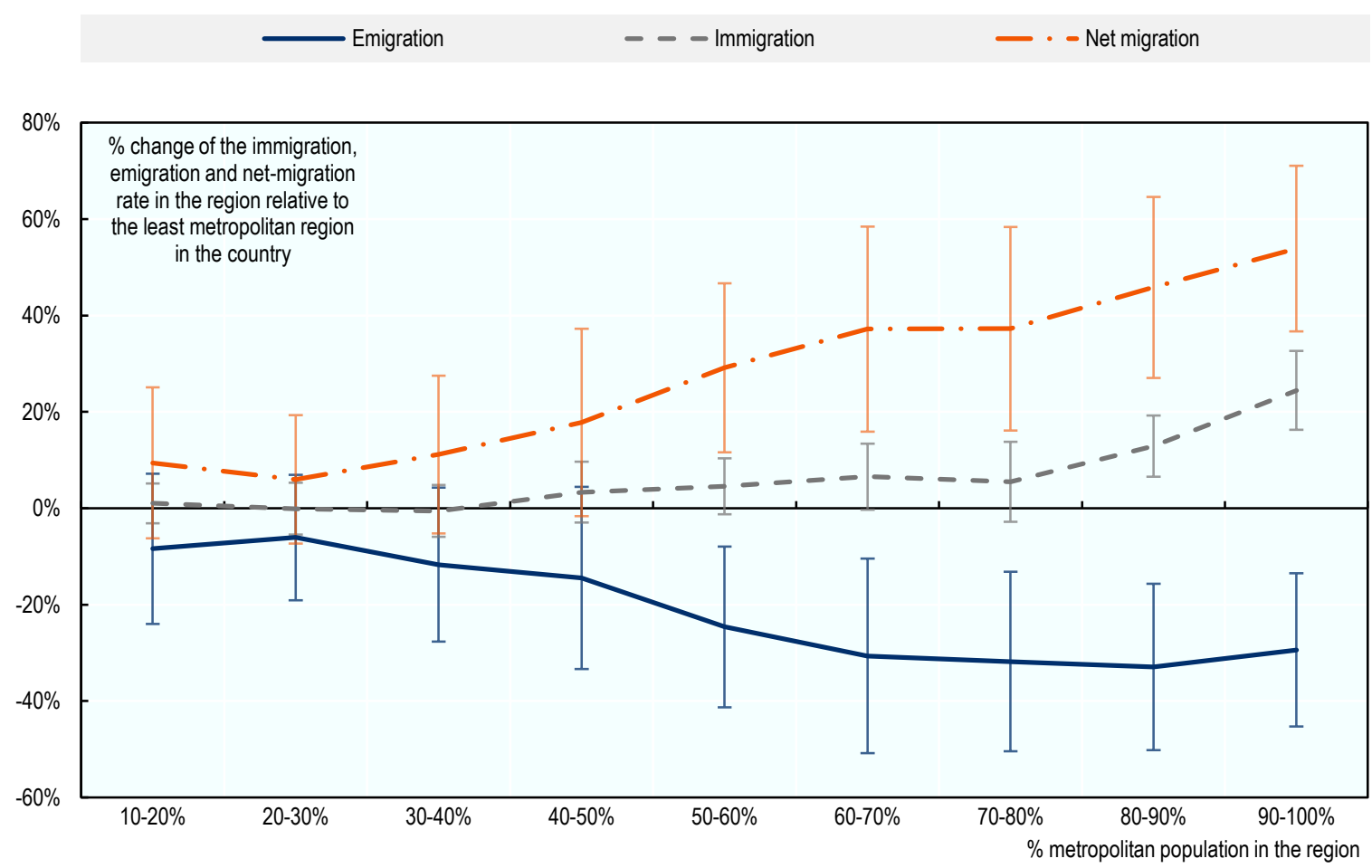

Note: Data on 683 regions in 32 countries, of which 2 are low-income, 9 are lower-middle, 13 are upper-middle and 8 are high-income, as defined by the World Bank. The share of migrants (emigrants) is defined as the proportion of international and domestic population aged 15 years or older moving into (from) a given region within 5 years of a given census. Data refer to the years between 1990 and 2010 . For each region, the most recent available year is considered. The chart reports coefficients on a set of dummies, one for each category of metropolitan population share, and the respective $95 \%$ confidence intervals. The omitted dummy is the one referring to $0 \%-10 \%$ metropolitan population. Each line corresponds to a separate regression, where the dependent variable is, alternatively, the share of emigrant and immigrant population, and their sum. Hence, each number needs to be interpreted with respect to the average shares in regions with less than $10 \%$ of their population living in metropolitan areas. Each number is statistically significant when the associated confidence interval does not overlap with the horizontal $(0 \%)$ line.

Source: OECD calculations based on migration data described in Annex 3.D and population data from the GHSL Data Package 2019, Florczyk, A. et al. (2019[2]), GHSL Data Package 2019 (database), http://dx.doi.org/10.2760/06297.

\section{Metropolitan regions attract more skilled workers}

Metropolitan regions attract and generate more educated residents. These regions are hubs for higher education institutions and manage to maintain high human capital levels as graduates often stay on after their studies to take advantage of better job opportunities. The complementarities between universities and thick labour markets create a virtuous circle: the higher the human capital of a region, the bigger the incentive for skill-intensive firms to locate in the region and, as a result, the larger the number of highly skilled individuals that will move there.

Overall, regions with a larger share of metropolitan population have higher human capital levels, as measured by the average years of schooling. Based on a dataset of human capital in more than 1500 regions in 110 countries (described in Box 3.6), regions with more than half of their population living in metropolitan areas have a population with 0.5 to 1 more year of schooling than regions where the share of metropolitan population is below $10 \% .{ }^{16}$ In EU+OECD countries, people living in the most metropolitan regions (above $90 \%$ of metropolitan population share) are on average almost 1 year more educated than 
inhabitants of the least metropolitan regions (below $10 \%$ of metropolitan population share). Overall, estimates indicate that a 10 percentage point higher share of metropolitan population is associated with average education levels being more than 1 month higher. ${ }^{17}$ In a typical OECD country like France, the least metropolitan region (Bourgogne) has about $20 \%$ of its population living in metropolitan areas and a corresponding average education of roughly 7.9 years. By contrast, the most metropolitan region in the country (Île-de-France) has an average education of 9.6 years, approximately $20 \%$ higher.

Regional disparities in human capital are much larger outside the EU and OECD. Here, the most metropolitan regions display a level of human capital that is, on average, more than 2.6 years higher than that in the least metropolitan regions. In this case, overall, a 10-percentage-point higher share of metropolitan population correlates with education levels being more than 2.5 months higher. ${ }^{18}$ Considering China as an example, the Guizhou province has about $27 \%$ of its inhabitants living in metropolitan areas and a corresponding average education level of approximately 5.8 years. By contrast, with more than $98 \%$ of the metropolitan population share, the most metropolitan region in China (Shanghai) exhibits an average education level of 8.9 years, more than $50 \%$ larger.

\section{Box 3.6. Human capital and regional development}

Many are the determinants of regional development. A non-exhaustive list includes geography, natural resource endowments, institutions, culture and human capital. The work by Gennaioli et al. (2013[48]) focuses on the latter. The authors build a newly constructed database of 1569 subnational regions from 110 countries to study the relationship between human capital and income.

Regional human capital, as measured by education, is a critical determinant of regional development, and it explains a substantial share of regional variation. Using data on several thousand firms located in these regions, authors find that regional education influences regional development through education of workers, education of entrepreneurs and regional externalities.

Data from the World Bank Enterprise Survey point directly to the role of the supply of educated entrepreneurs for the creation and productivity of firms. In fact, economic development occurs in regions that concentrate entrepreneurs who run productive firms. These entrepreneurs may also contribute to the exchange of ideas, leading to significant regional externalities. The observed large benefits of education through the creation of a supply of entrepreneurs and through externalities offer an optimistic assessment of the possibilities of economic development through raising educational attainment.

Source: Gennaioli, N. et al. (2013), "Human capital and regional development", http://dx.doi.org/10.1093/qje/qj5050; OECD (2018[55]), Productivity and Jobs in a Globalised World: (How) Can All Regions Benefit?, https://dx.doi.org/10.1787/9789264293137-en.

The income gaps between regions with small and large metropolitan population, documented in the section on regional economic development and the metropolitan system, partially reflects higher human capital in metropolitan regions. Human capital is a crucial determinant of economic development. More educated people tend to be more productive and this is reflected in higher wages as well as in larger per capita GDP (Ahrend and Lembcke, 2017[53]). An empirical analysis of more than 1500 regions in 110 countries shows that, on average, 1 extra year of education among a region's population is associated with almost $26 \%$ higher regional GDP levels in 2000 and with a 1.1 percentage points higher annual GDP growth rate between 1990 and 2000 (Box 3.6). ${ }^{19}$

The fact that more metropolitan regions attract more skilled and qualified individuals partly explains their high level of human capital. Amenities such as parks, theatres, museums, restaurants and universities make metropolitan regions attractive for skilled workers and they do so disproportionately more for highly educated individuals. Consequently, people with higher education levels tend to live in more urbanised 
regions, thus making those regions more productive. Regression analysis indicates that more than half of the difference in GDP levels and about half of the gap in GDP growth rates between more and less metropolitan regions are explained by the fact that residents in metropolitan regions are on average more educated. ${ }^{20}$ In other words, agglomeration economies and the attraction, accumulation and generation of human capital are both roughly equally important factors to explain why metropolitan areas tend to be richer. Migration is only one of the reasons for higher human capital in metropolitan regions

Higher human capital levels in metropolitan regions are typically not only driven by migration but also reflect that locals tend to be more educated in these places. Both in countries within the EU and OECD, as well as elsewhere, the native population in regions with higher proportions of metropolitan population is more educated than in less metropolitan regions. In particular, Figure 3.10 shows that locals in regions with more than $80 \%$ of their population living in metropolitan areas are more educated than those in the average region in the country, in the order of almost 1 year (EU+OECD) to 2 years (others).

While immigrants complement locals in terms of education in EU and OECD countries, their skills can be seen as a substitute for those of locals in other countries (Figure 3.10). In EU and OECD countries, the skills of migrants do not appear to differ significantly between regions with low or high population shares in metropolitan areas. Also, migrants do not appear to be systematically more educated than other local residents in metropolitan regions. However, relative to the local native population, migrants appear to be more skilled in regions with small metropolitan populations but less skilled in regions with large metropolitan populations. Thus, migrants appear to offer some skills complementarity with locals.

Figure 3.10. Human capital and migration by metropolitan population in regions

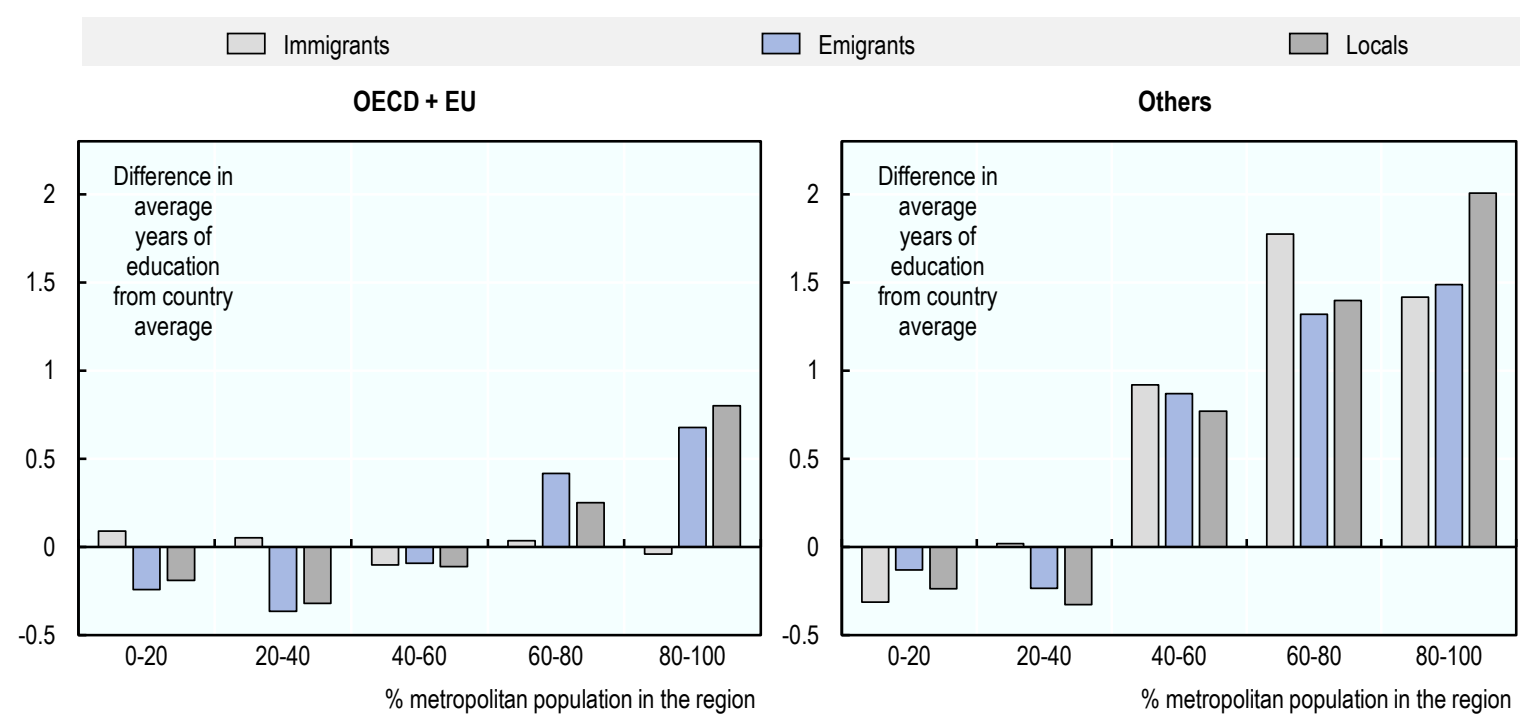

Note: Data on 291 regions in 10 EU+OECD countries and 392 regions in 22 other countries. Data refer to the years between 1990 and 2010. For each region, the most recent available year is considered. The bar charts show the average deviation from the country mean in the number of years of education for immigrants, emigrants and locals, separately, for each bin of metropolitan population share.

Source: OECD calculations based on education and migration data described in Annex 3.D and population data from the GHSL Data Package 2019, Florczyk, A. et al. (2019[2]), GHSL Data Package 2019 (database), http://dx.doi.org/10.2760/06297.

In non-EU and non-OECD countries, migrants appear to be more comparable to natives across regions. Here, immigrants in the most metropolitan regions are, on average, 1.5 years more educated than those who move to the average region in the country, which mimics the pattern observed for natives (Figure 3.10). Broadly speaking, both more skilled migrants and natives concentrate in regions with a larger metropolitan population. Metropolitan areas in countries outside of the EU and OECD are not only important hubs for the creation of human capital but also for attracting highly educated people from other 
places. This generates a substitution effect between their respective skill sets. Consistent with this observation, recent studies document that larger cities are skill-abundant and specialise in skill-intensive activities in developing countries (Dingel, Miscio and Davis, 2019 ${ }_{[56]}$ ).

Two facts may explain the peculiarity of EU+OECD countries in this respect. First, the substantial migration flows from underdeveloped and developing economies that richer countries have been experiencing over the last decades could explain lower education levels of migrants in metropolitan regions (OECD, 2019[57]). In this case, the overall lower levels of human capital of those migrants could offset the inflows of highskilled domestic workers that metropolitan areas might experience.

Second, incentives for high-skilled individuals to move to metropolitan regions could be lower in the most developed countries. This may occur because skill-intensive job opportunities, amenities and higher education facilities are more evenly distributed across regions in the EU and OECD than in other countries. In other words, the least metropolitan regions in EU and OECD countries offer a wider set of opportunities than similar regions in other economies. As a result, highly educated individuals do not necessarily have to move to the most metropolitan regions to benefit from higher returns to education.

Finally, emigrants with higher human capital levels tend to come from metropolitan regions. In particular, in areas where more than $80 \%$ of the population lives in metropolitan areas, emigrants are from 0.7 $(E U+O E C D)$ to 1.5 (non-EU+OECD) years more educated than in the average region. To some degree, this is a direct consequence of metropolitan regions having better-educated locals. However, while in countries outside of the EU and OECD, a larger share of educated emigrants in metropolitan regions seems to be compensated by a considerable in-flow of high skill immigrants, this is less true in EU+OECD countries.

To some extent, this might indicate that within EU and OECD countries, human capital tends to be more evenly redistributed from the most to the least metropolitan regions than in other countries, where most of the human capital flows happen to occur across larger and smaller metropolitan areas. Alternatively, the phenomenon could reflect the fact that in the EU and OECD, people move to metropolitan areas to study and some of them leave afterwards. In both cases, evidence from Figure 3.10 points out a crucial, yet somewhat different, role of metropolitan areas between EU and OECD countries and other countries.

\section{References}

Ahrend, R. et al. (2014), "What Makes Cities More Productive? Evidence on the Role of Urban Governance from Five OECD Countries", OECD Regional Development Working Papers, No. 2014/5, OECD Publishing, Paris, https://dx.doi.org/10.1787/5jz432cf2d8p-en.

Ahrend, R. and A. Lembcke (2017), "Does it pay to live in big(ger) cities? The role of agglomeration benefits, local amenities, and costs of living", SSRN Electronic Journal, http://dx.doi.org/10.2139/ssrn.2925676.

Allen, R. (2012), The British industrial revolution in global perspective, Cambridge University Press, http://dx.doi.org/10.1017/CBO9780511816680.

Barro, R. and X. Sala-I-Martin (1992), "Regional growth and migration: A Japan-United States comparison", Journal of the Japanese and International Economies, Vol. 6/4, pp. 312-346, https://doi.org/10.1016/0889-1583(92)90002-L.

Barro, R. and X. Sala-i-Martin (1991), "Convergence across states and regions", Brookings Papers on Economic Activity, https://www.brookings.edu/wpcontent/uploads/1991/01/1991a bpea barro salaimartin blanchard hall.pdf. 
Barth, E. et al. (2016), "It's where you work: Increases in the dispersion of earnings across establishments and individuals in the United States", Journal of Labor Economics, Vol. 34/S2, pp. S67-S97, http://dx.doi.org/10.1086/684045.

Boulant, J., M. Brezzi and P. Veneri (2016), "Income Levels And Inequality in Metropolitan Areas: A Comparative Approach in OECD Countries", OECD Regional Development Working Papers, No. 2016/6, OECD Publishing, Paris, https://dx.doi.org/10.1787/5j|wj02zz4mr-en.

Collier, P., P. Jones and D. Spijkerman (2018), Cities as Engines of Growth: Evidence from a New Global Sample of Cities, http://pubdocs.worldbank.org/en/356001527999188468/117Cities-as-Engines-of-Growth-Collier-et-al-28March2018.pdf (accessed on 7 November 2019).

Collier, P. et al. (2010), "Managing resource revenues in developing economies", IMF Staff Papers, Vol. 57/1, pp. 84-118, http://dx.doi.org/10.1057/imfsp.2009.16.

Combes, P., G. Duranton and L. Gobillon (2011), "The identification of agglomeration economies", Journal of Economic Geography, http://dx.doi.org/10.1093/jeg/lbq038.

Combes, P. et al. (2011), "The rise and fall of spatial inequalities in France: A long-run perspective", Explorations in Economic History, Vol. 48/2, pp. 243-271, http://dx.doi.org/10.1016/i.eeh.2010.12.004.

Davis, D. and J. Dingel (2015), “The comparative advantage of cities”, Mimeo, pp. 1-46, http://dx.doi.org/10.3386/w20602.

de la Roca, J. and D. Puga (2017), "Learning by working in big cities", Review of Economic Studies, http://dx.doi.org/10.1093/restud/rdw031.

Desmet, K. and J. Henderson (2015), "The geography of development within countries", in Handbook of Regional and Urban Economics, Elsevier B.V., http://dx.doi.org/10.1016/B978-0444-59531-7.00022-3.

Dijkstra, L., H. Poelman and P. Veneri (2019), "The EU-OECD definition of a functional urban area", OECD Regional Development Working Papers, No. 2019/11, OECD Publishing, Paris, https://doi.org/10.1787/d58cb34d-en (accessed on 21 October 2019).

Dingel, J., A. Miscio and D. Davis (2019), "Cities, lights, and skills in developing economies", Journal of Urban Economics, http://dx.doi.org/10.1016/j.jue.2019.05.005.

Duranton, G. (2015), "Growing through cities in developing countries", World Bank Research Observer, Vol. 30/1, pp. 39-73, http://dx.doi.org/10.1093/wbro/lku006.

Duranton, G. (2008), Viewpoint: From Cities to Productivity and Growth in Developing Countries, http://dx.doi.org/10.1111/j.1540-5982.2008.00482.x.

Duranton, G. and D. Puga (2004), "Micro-foundations of urban agglomeration economies", Handbook of Regional and Urban Economics, http://dx.doi.org/10.1016/S01697218(04)07048-0.

Ezcurra, R. and A. Rodriǵuez-Pose (2017), "Does ethnic segregation matter for spatial inequality?", Journal of Economic Geography, Vol. 17/6, pp. 1149-1178, http://dx.doi.org/10.1093/jeg//bx007. 
Fay, M. and C. Opal (1999), Urbanization Without Growth: A Not So Uncommon Phenomenon, http://dx.doi.org/10.1596/1813-9450-2412.

Florczyk, A. et al. (2019), GHSL Data Package 2019 (database), http://dx.doi.org/10.2760/062975.

Ganong, P. and D. Shoag (2017), "Why has regional income convergence in the U.S. declined?", Journal of Urban Economics, Vol. 102, pp. 76-90, http://dx.doi.org/10.1016/j.jue.2017.07.002.

Gennaioli, N. et al. (2014), "Growth in regions", Journal of Economic Growth, http://dx.doi.org/10.1007/s10887-014-9105-9.

Gennaioli, N. et al. (2013), "Human capital and regional development", Quarterly Journal of Economics, http://dx.doi.org/10.1093/qje/qis050.

Glaeser, E. (2014), "A world of cities: The causes and consequences of urbanization in poorer countries", Journal of the European Economic Association, Vol. 12/5, pp. 1154-1199, https://doi.org/10.1111/jeea.12100 (accessed on 7 November 2019).

Glaeser, E. and J. Gottlieb (2009), "The wealth of cities: Agglomeration economies and spatial equilibrium in the United States", Journal of Economic Literature, Vol. 47/4, pp. 983-1028, http://dx.doi.org/10.1257/jel.47.4.983.

Glaeser, E. et al. (1992), "Growth in cities", Journal of Political Economy, Vol. 100/6, pp. 11261152, http://dx.doi.org/10.1086/261856.

Gollin, D., R. Jedwab and D. Vollrath (2016), "Urbanization with and without industrialization", Journal of Economic Growth, Vol. 21/1, pp. 35-70, http://dx.doi.org/10.1007/s10887-0159121-4.

Gollin, D., S. Parente and R. Rogerson (2002), "The role of agriculture in development", American Economic Review, Vol. 92/2, pp. 160-164, http://dx.doi.org/10.1257/000282802320189177.

Hamnett, C. (1994), "Social polarisation in global cities: Theory and evidence", Urban Studies, Vol. 31/3, pp. 401-424, http://dx.doi.org/10.1080/00420989420080401.

Henderson, J. (2010), "Cities and development", Journal of Regional Science, Vol. 50/1, pp. 515540, http://dx.doi.org/10.1111/j.1467-9787.2009.00636.x.

Henderson, J. and S. Kriticos (2018), "The development of the African system of cities", Annual Review of Economics, Vol. 10/1, pp. 287-314, http://dx.doi.org/10.1146/annurev-economics$\underline{080217-053207 .}$.

Henderson, J., D. Nigmatulina and S. Kriticos (2018), Measuring Urban Economic Density, The World Bank, http://dx.doi.org/10.1596/1813-9450-8678.

Henderson, J., A. Storeygard and U. Deichmann (2016), "Has climate change driven urbanization in Africa?”, http://dx.doi.org/10.1016/j.jdeveco.2016.09.001.

Herrendorf, B., R. Rogerson and Á. Valentinyi (2014), "Growth and structural transformation”, in Handbook of Economic Growth, Elsevier B.V., http://dx.doi.org/10.1016/B978-0-444-53540$\underline{5.00006-9}$. 
Hobijn, B. and B. Jovanovic (2001), "The information-technology revolution and the stock market: Evidence”, American Economic Review, Vol. 91/5, pp. 1203-1220, http://dx.doi.org/10.1257/aer.91.5.1203.

Jedwab, R., L. Christiaensen and M. Gindelsky (2017), "Demography, urbanization and development: Rural push, urban pull and ... urban push?", Journal of Urban Economics, http://dx.doi.org/10.1016/j.jue.2015.09.002.

Jedwab, R. and D. Vollrath (2019), "The Urban Mortality Transition and Poor Country Urbanization”, American Economic Journal: Macroeconomics, Vol. 11/1, pp. 223-75.

Jedwab, R. and D. Vollrath (2015), Urbanization Without Growth in Historical Perspective, Academic Press Inc., http://dx.doi.org/10.1016/j.eeh.2015.09.002.

Kanbur, R. and A. Venables (2005), Spatial Inequality and Development, Oxford University Press, http://dx.doi.org/10.1093/0199278636.001.0001.

Kim, S. (2008), Spatial Inequality and Economic Development: Theories, Facts, and Policies.

Kim, S. and R. Margo (2004), "Chapter 66 Historical perspectives on U.S. economic geography", in Handbook of Regional and Urban Economics, Elsevier, http://dx.doi.org/10.1016/S15740080(04)80023-3.

Lall, S., J. Henderson and A. Venables (2017), Africa's Cities: Opening Doors to the World, The World Bank, http://dx.doi.org/10.1596/978-1-4648-1044-2.

Mcmillan, M., D. Rodrik and I. Verduzco-Gallo (2014), "Globalization, structural change, and productivity growth, with an update on Africa", World Development, Vol. 63, pp. 11-32, https://doi.org/10.1016/j.worlddev.2013.10.012.

Michaels, G., F. Rauch and S. Redding (2012), "Urbanization and structural transformation", Quarterly Journal of Economics, Vol. 127/2, pp. 535-586, http://dx.doi.org/10.1093/qje/qjs003.

Milanović, B. (2005), Worlds Apart: Measuring International and Global Inequality, Princeton University Press.

Moreno-Monroy, A., M. Schiavina and P. Veneri (2020), "Metropolitan areas in the world: Delineation and population trends", Journal of Urban Economics, https://doi.org/10.1016/j.jue.2020.103242.

OECD (2019), International Migration Outlook 2019, OECD Publishing, Paris, https://dx.doi.org/10.1787/c3e35eec-en.

OECD (2019), OECD Skills Strategy 2019: Skills to Shape a Better Future, OECD Publishing, Paris, https://dx.doi.org/10.1787/9789264313835-en.

OECD (2018), Divided Cities: Understanding Intra-urban Inequalities, OECD Publishing, Paris, https://dx.doi.org/10.1787/9789264300385-en.

OECD (2018), OECD Regions and Cities at a Glance 2018, OECD Publishing, Paris, https://dx.doi.org/10.1787/reg cit glance-2018-en.

OECD (2018), Productivity and Jobs in a Globalised World: (How) Can All Regions Benefit?, OECD Publishing, Paris, https://dx.doi.org/10.1787/9789264293137-en. 
OECD (2016), Making Cities Work for All: Data and Actions for Inclusive Growth, OECD

Publishing, Paris, https://dx.doi.org/10.1787/9789264263260-en.

OECD (2016), "The implications of Africa's urbanisation for structural transformation", in African Economic Outlook 2016: Sustainable Cities and Structural Transformation, OECD Publishing, Paris, https://dx.doi.org/10.1787/aeo-2016-10-en.

OECD (2015), In It Together: Why Less Inequality Benefits All, OECD Publishing, Paris, https://dx.doi.org/10.1787/9789264235120-en.

OECD (2015), The Metropolitan Century: Understanding Urbanisation and its Consequences, OECD Publishing, Paris, https://dx.doi.org/10.1787/9789264228733-en.

OECD (n.d.), OECD Metropolitan Database, OECD, Paris, https://stats.oecd.org/Index.aspx?.Datasetcode=CITIES.

Rostow, W. (1960), The Process of Economic Growth, http://www.sidalc.net/cgi-

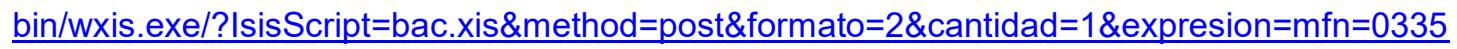
$\underline{49}$ (accessed on 7 November 2019).

Williamson, J. (1965), "Regional inequality and the process of national development: A description of the patterns", Economic Development and Cultural Change, Vol. 13/4, pp. 1-84, https://www.jstor.org/stable/1152097.

World Bank (2009), Reshaping Economic Geography, The International Bank for Reconstruction and Development. Washington, DC, http://dx.doi.org/10.1596/978-0-8213-7607-2.

\section{Notes}

${ }^{1}$ Boundaries of the latter have been estimated for the entire world (Moreno-Monroy, Schiavina and Veneri, 2020[61]).

2 "Metropolitan areas" is a term that is often used to identify cities plus their connected surroundings for large cities only. In this work, the concept of metropolitan areas is used to define cities and their surroundings, including cities of all sizes, with the minimum threshold of 50000 inhabitants.

${ }^{3}$ In Africa, farmers also disproportionately live in cities. Furthermore, rural areas have unusually low non-farm activities, which tend to progressively move to cities (Henderson and Kriticos, 2018[21]).

${ }^{4}$ In EU and OECD countries, a larger ratio of gross value-added (GVA) in services to GVA in manufacturing is associated with a more metropolitan population. The results are also confirmed by a regression analysis.

${ }^{5}$ For instance, studies have shown that the impact of IT, which are initially available in denser areas, is greater in services than in manufacturing (Hobijn and Jovanovic, 2001[59]). Even if the use of IT diffuses rapidly within countries, their more complex applications, such as e-commerce, predominantly locate and develop in metropolitan areas, which offer easier access to complementary inventions and activities.

${ }^{6}$ The regression controls for the share of value-added in manufacturing and services. 
${ }^{7}$ The Gini index is a measure of inequality that ranges between 0 and 1 . In this case, it is used to measure inequality in the distribution of the metropolitan population within a country. Higher values of the Gini coefficient indicate higher concentration of the country total metropolitan population in fewer (larger) metropolitan areas.

8 The results are confirmed using a regression analysis to test for the non-linear relationship between concentration and development. In particular, on the right-hand side, the regression includes log(GDP per capita), log(GDP per capita) squared and log(total population). The estimated coefficients on squared GDP suggest that results similar to those of Figure 3.4 hold when using different measures of concentration such as the coefficient of variation of the metropolitan population, the Herfindahl-Hirschman Index (HHI), and the coefficients from Zipf's law between rank and population for the largest ten metropolitan areas in the country.

${ }^{9} \mathrm{~A}$ similar regression analysis as the one described in the note above is used here, where the left-hand side is either primacy (the share of the largest metropolitan area in national metropolitan population) or the ratio between the largest and second-largest metropolitan areas.

10 The spatial Kuznets curve is about regional disparities in general. The presented analysis focuses on the role of metropolitan areas for regional disparities.

11 This is the estimated OLS coefficient on (the log of) GDP per capita in 2015 from a regression where the left-hand side variable is the share of metropolitan population. The regression includes country dummies. Standard errors are clustered at the country level (57 countries). The coefficient of interest is statistically significant at the $99 \%$ confidence level.

${ }^{12}$ Due to data availability, the dataset used here is a subset of the one used in the analysis of GDP levels.

${ }^{13}$ This is the estimated OLS coefficient on the share of metropolitan population from a regression where the left-hand side variable is the share of immigrant population. The regression includes country dummies. Standard errors are clustered at the country level. The coefficient of interest is statistically significant at the $99 \%$ confidence level.

14 This is the estimated OLS coefficient on the share of metropolitan population from a regression where the left-hand side variable is the share of emigrant population. The regression includes country dummies. Standard errors are clustered at the country level. The coefficient of interest is statistically significant at the $99 \%$ confidence level.

15 Some agglomeration benefits only develop over time. Training, networks and knowledge gained while living and working in a large city are a valuable experience that contributes to the wage premium in metropolitan areas. This is supported by evidence from Spain that even when workers move away from a bigger city, their experience is still reflected in their earnings (de la Roca and Puga, $2017_{[17]}$ ).

16 These estimates are in line with findings from recent studies on the spatial distribution of skills (Davis and Dingel, 2015[60]).

17 This is the estimated OLS coefficient on the share of metropolitan population from a regression where the left-hand side variable is the years of schooling in 2000. The regression includes country dummies. Standard errors are clustered at the country level. The coefficient of interest is statistically significant at the $99 \%$ confidence level.

${ }^{18}$ See endnote 10. 
19 These are the estimated OLS coefficients on the average years of education from a multivariate regression where the left-hand side variable is either Ln(regional GDP per capita) or the annual GDP per capita growth rate between 1990 and 2000. Country dummies and the share of metropolitan population are included, and additional controls are Ln(population), latitude, distance to coast, malaria indicator, Ln(oil and gas production), capital dummies. Standard errors are clustered at the country level. The coefficients of interest are statistically significant at the $99 \%$ confidence levels.

20 These are the OLS coefficients on the share of metropolitan population from a multivariate regression where the left-hand side variable is Ln(regional GDP per capita) or its growth rate, and Years of Education is added on the right-hand side. Country dummies are included and additional controls are Ln(population), latitude, distance to coast, malaria indicator, Ln(oil and gas production), capital dummies. Standard errors are clustered at the country level. The coefficient of interest is statistically significant at the $99 \%$ confidence level. 


\section{Annex 3.A. Economic development and different measures of urbanisation}

National economic development is more strongly associated with the share of people living in metropolitan areas (functional urban areas, FUAs) than with the proportion of population living cities, towns and semidense areas. To some extent, this result could be driven by the algorithm through which metropolitan areas are estimated. However, in OECD countries for which official data are available, this result is consistent and robust to the use of non-estimated population data. While metropolitan areas have a minimum population size of 50000 inhabitants, cities, towns and semi-dense areas include settlements from 5000 inhabitants. The right panel of Annex Figure 3.A.1 shows the steeper relationship between the metropolitan population share and GDP per capita for the same sample of 168 countries. For any given level of GDP per capita, the black line provides the expected share of the metropolitan population of a country based on the estimated relationship between the metropolitan population share and GDP. The line points out that, on average, a $1 \%$ rise in per capita GDP is associated with a 0.1 percentage point increase in the metropolitan population share. This is almost three times as large as the correlation with the share of people living in cities, towns and semi-dense areas.

\section{Annex Figure 3.A.1. Economic development and types of settlements, 2015}

Urbanisation and economic development go hand in hand
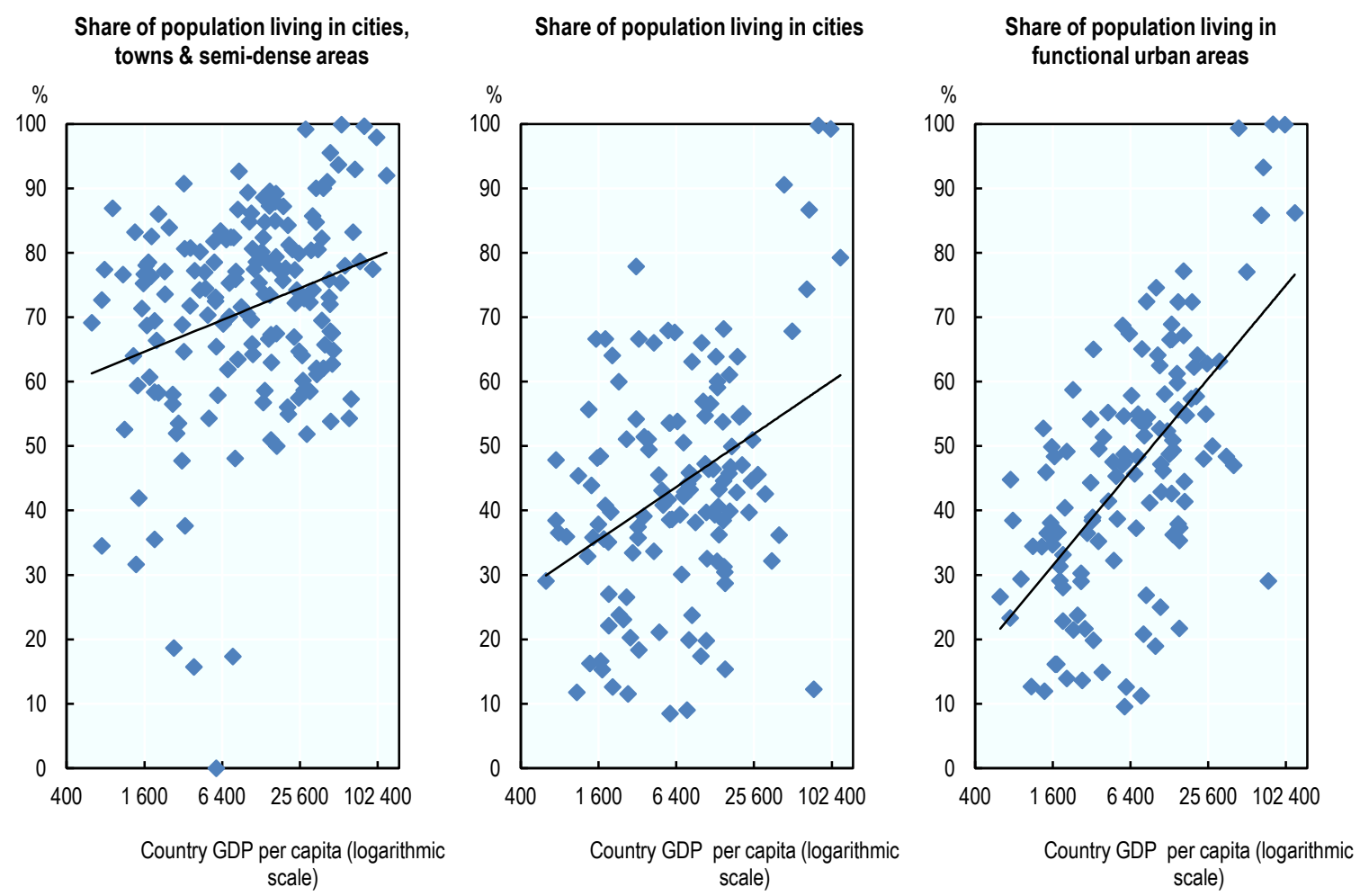

Note: 168 countries are included in each panel. The R-squared coefficients of the underlying regressions are 0.07 (left panel), 0.05 (central panel) and 0.38 (right panel). Similar patterns are obtained for years 1975, 1990 and 2000.

Source: OECD calculations based on GDP data from the World Bank and population data from the GHSL Data Package 2019, Florczyk, A. et al. (2019[2]), GHSL Data Package 2019 (database), http://dx.doi.org/10.2760/06297. 
The fact that economic development is more strongly associated with the share of population living in metropolitan areas reflects that the concept of FUAs is much broader and goes beyond the consideration of density and population size only. Being composed of a city and its commuting zone, metropolitan areas encompass the economic and functional extent of cities based on daily people's movements (Dijkstra, Poelman and Veneri, 2019[58]). Therefore, considering the share of a country's total population living in metropolitan areas allows measuring the extent to which national development is correlated with the fraction of people that are part of the cities' labour market in the country. For this reason, this chapter focuses on metropolitan areas and their population share. 


\section{Annex 3.B. Economic development and metropolitan population by country size}

As documented in Figure 3.1, more developed countries have more metropolitan populations. In particular, the more developed a country, the more people live in metropolitan areas of 1 million or more inhabitants. These patterns still seem to hold when restricting the sample to countries of more comparable sizes. The results of Figure 3.1 could be driven by the fact that many low-income countries are small and, in turn, cannot have very large metropolitan areas. However, robustness checks mitigate this concern. By splitting the sample of 168 countries according to their size into 4 quartiles (i.e. groups with about the same number of countries), it is possible to observe that the major increase in the share of people living in greater metropolitan areas occurs in larger countries (Annex Figure 3.B.1). The 4 panels show the correlation between the share of people living in metropolitan areas of different sizes and national GDP for countries with a total population below 3.5, between 3.5 and 10 , between 10 and 31 , and above 31 million inhabitants. If only countries with a total population above 31 million people are considered (i.e. the largest quartile of country size), these results continue to hold, albeit with smaller sample sizes and are in fact magnified. This sample includes 5 low-, 14 lower-middle, 14 upper-middle and 11 high-income countries. 


\section{Annex Figure 3.B.1. Economic development and the geography of metropolitan areas by country size, 2015}

Countries across the four graphs are split based on quartiles of their total population in 2015

FUA pop. $<0.5 \mathrm{M}$
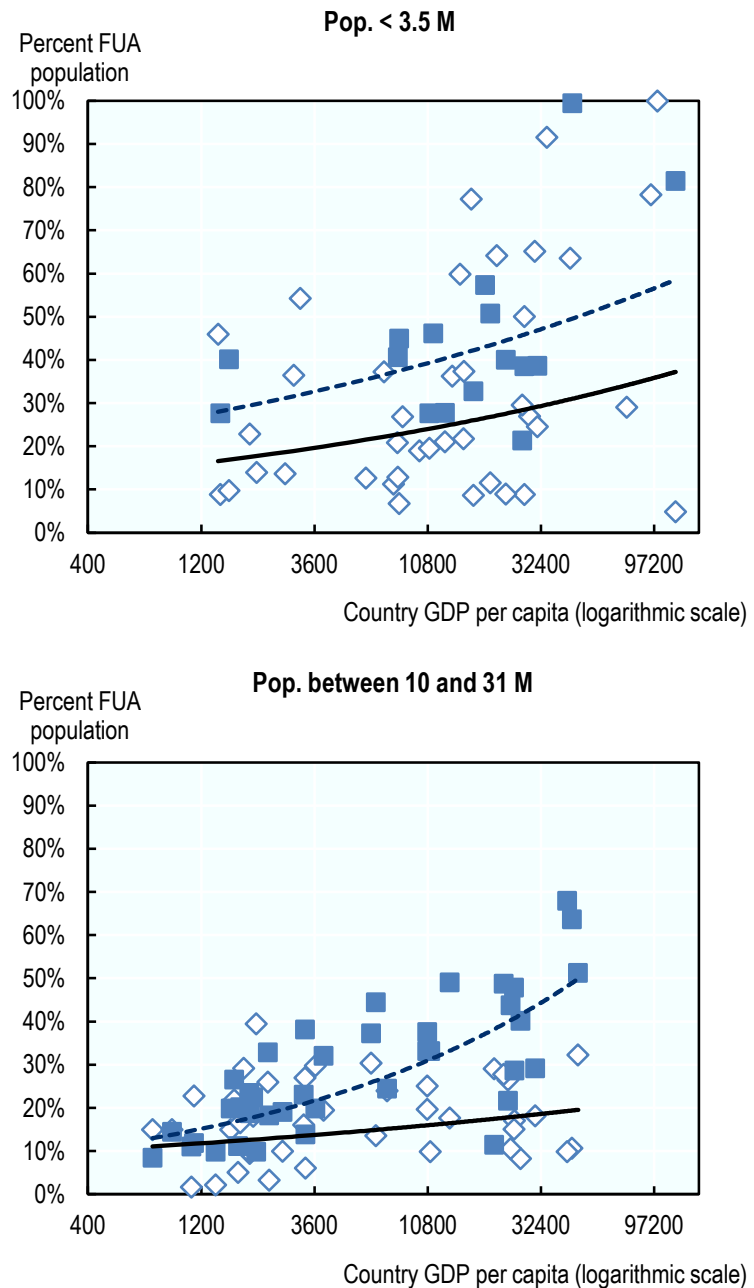

FUA pop. $>0.5 \mathrm{M}$

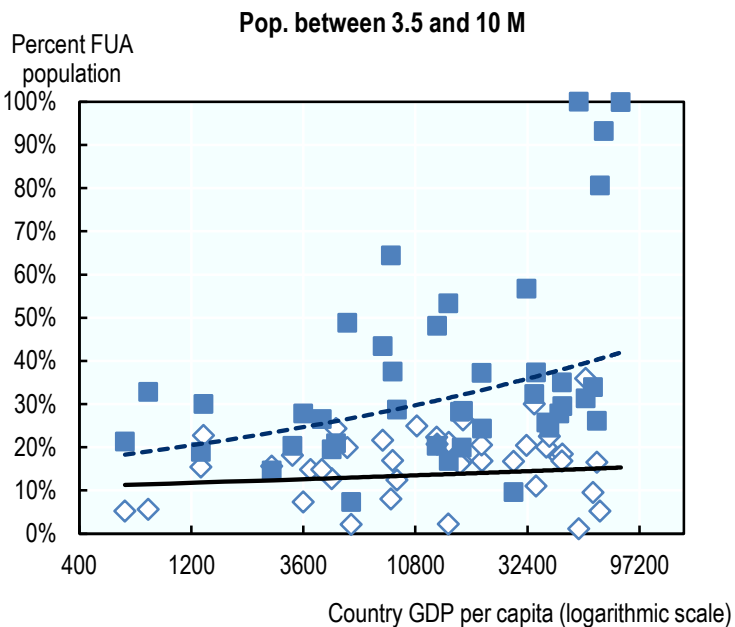

Pop. above $31 \mathrm{M}$

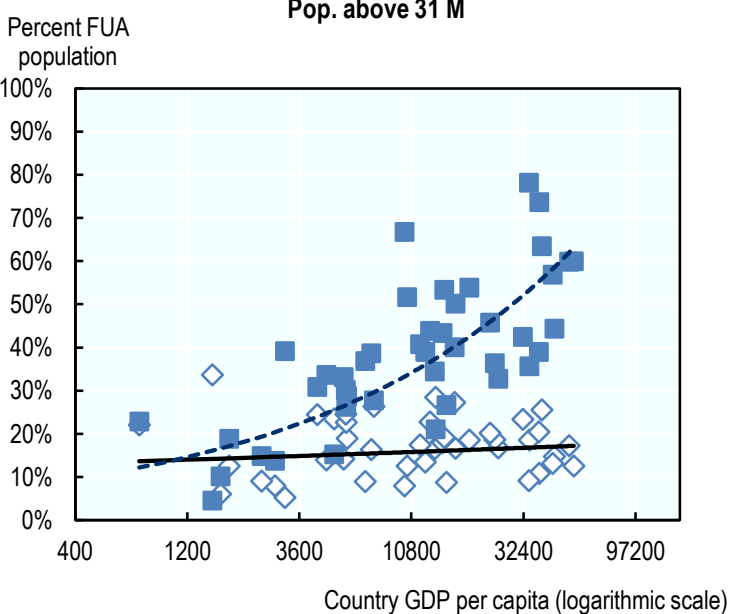

Note: 44 countries are reported in each panel. Similar patterns hold when looking at the share of the metropolitan population in 1990 and 2000. Source: OECD calculations based on GDP data from the World Bank and population data from the GHSL Data Package 2019, Florczyk, A. et al. (2019[2]), GHSL Data Package 2019 (database), http://dx.doi.org/10.2760/06297. 


\section{Annex 3.C. Resource vs. non-resource exporters}

\section{Annex Table 3.C.1. Natural resources and the urban system, 2015}

Coloured cells report regression coefficients that are statistically different from zero

\begin{tabular}{|c|c|c|c|c|}
\hline \multicolumn{5}{|c|}{ Dependent variable is the share of the metropolitan population ( 0 to 1$)$} \\
\hline & (1) & $(2)$ & (3) & (4) \\
\hline & \multicolumn{2}{|c|}{ EU+OECD } & \multicolumn{2}{|c|}{ Others } \\
\hline \multirow[t]{2}{*}{ Manufacturing ( $\%$ of GDP) } & 0.40 & 0.40 & -0.07 & $0.93^{* *}$ \\
\hline & $(0.53)$ & $(0.58)$ & $(0.34)$ & $(0.45)$ \\
\hline \multirow[t]{2}{*}{ Services ( $\%$ of GDP) } & $1.62^{+*+*}$ & $2.02^{+* * *}$ & $0.60^{\text {t*** }}$ & $0.48^{*}$ \\
\hline & $(0.51)$ & $(0.66)$ & $(0.20)$ & $(0.26)$ \\
\hline \multirow{3}{*}{$\begin{array}{l}\text { Natural resource exports } \\
\text { (\% of total merchandise exports) }\end{array}$} & 0.13 & 0.84 & $0.17^{\star \star * *}$ & 0.44 \\
\hline & & & & \\
\hline & $(0.19)$ & $(1.17)$ & $(0.05)$ & $(0.36)$ \\
\hline \multirow[t]{2}{*}{ Manufacturing x Natural resource exports } & & 3.50 & & $-2.00^{*+*}$ \\
\hline & & $(3.24)$ & & $(0.65)$ \\
\hline \multirow[t]{2}{*}{ Services x Resource exports } & & -1.53 & & -0.05 \\
\hline & & $(1.86)$ & & $(0.67)$ \\
\hline No. of countries & 36 & 36 & 82 & 82 \\
\hline R-squared & 0.63 & 0.65 & 0.50 & 0.54 \\
\hline
\end{tabular}

Note: Total country population and dummies for regions of the world are included. Only countries with available information on the sectoral composition are included. Heteroskedasticity-consistent standard errors in parentheses.

${ }^{*} p<0.1,{ }^{* *} p<0.05,{ }^{* * *} p<0.01$.

Source: Sectoral composition data from the World Bank and population data from the GHSL Data Package 2019, Florczyk, A. et al. (2019[2]), GHSL Data Package 2019 (database), http://dx.doi.org/10.2760/06297. 


\section{Annex Figure 3.C.1. Structural transformation and metropolitan population in developing countries}

There is no clear link between a move from services to manufacturing in more metropolitan regions
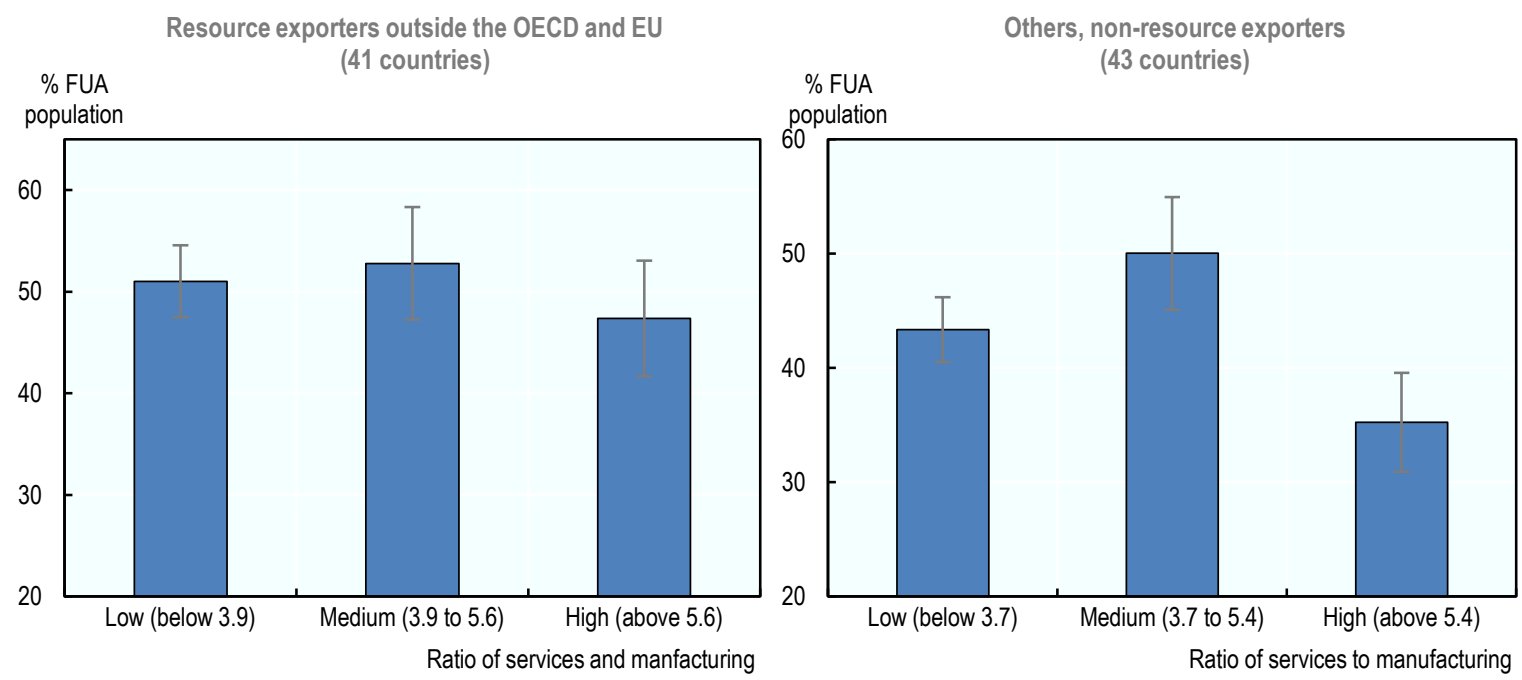

Note: Unweighted average of country values. Horizontal categories are defined using terciles of the ratio of value-added share in the manufacturing sector. Only countries with available sectoral information are included. $90 \%$ confidence intervals are reported. Resource exporting countries outside of the EU and OECD are defined using the median value of the share of natural resource exports out of total merchandise exports.

Source: OECD calculations based on sectoral composition data from the World Bank and population data from the GHSL Data Package 2019, Florczyk, A. et al. (2019[2]), GHSL Data Package 2019 (database), http://dx.doi.org/10.2760/06297.

\section{Annex Figure 3.C.2. The metropolitan system and manufacturing in resource-exporting and non- resource exporting developing countries}

Natural resources partly break the association between industrialisation and the growth of metropolitan areas

Resource exporters outside the OECD and EU

(41 countries)

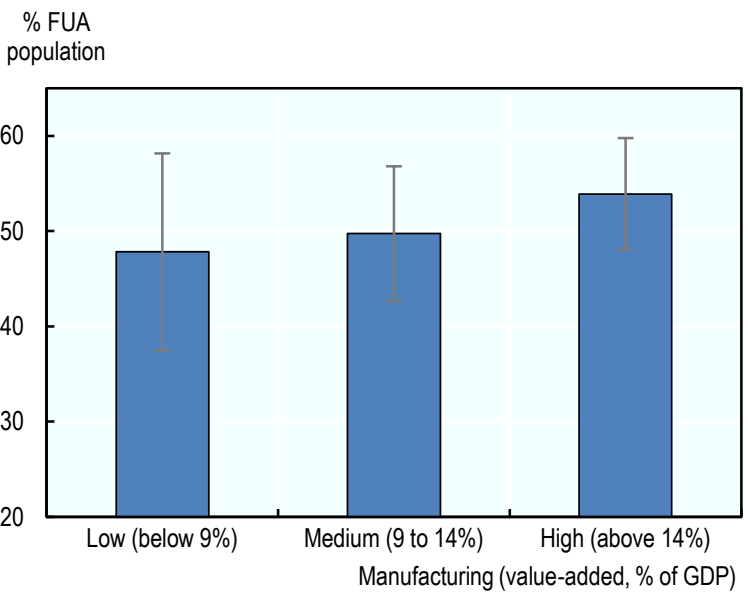

Others, non-resource exporters

(43 countries)

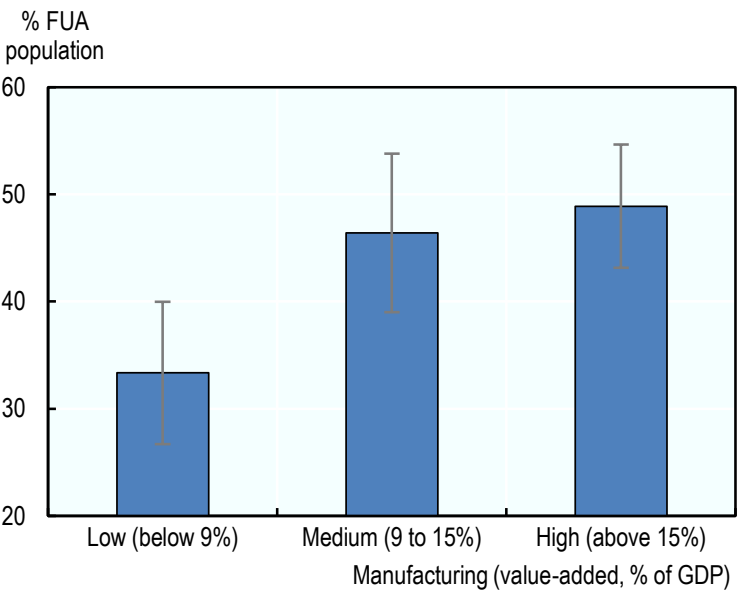

Note: Unweighted average of country values. Horizontal categories are defined using terciles of the ratio of value-added share in the manufacturing sector. Only countries with available sectoral information are included. $90 \%$ confidence intervals are reported. Resource exporting countries outside of the EU and OECD are defined using the median value of the share of natural resource exports out of total merchandise exports.

Source: OECD calculations based on sectoral composition data from the World Bank and population data from the GHSL Data Package 2019, Florczyk, A. et al. (2019[2]), GHSL Data Package 2019 (database), http://dx.doi.org/10.2760/06297. 


\section{Annex 3.D. Additional information and tables}

\section{Description and construction of regional data}

The dataset used for the empirical analysis is the result of the combination and harmonisation of data from different sources. The final product is a panel dataset covering 1522 regions in 82 countries $^{1}$ for the years $1975,1990,2000$ and 2015. The number of regions/countries included in the analysis may differ depending on the specific year under investigation. Due to limited data availability, different subnational administrative levels were used in different countries.

Information on regional GDP per capita in constant 2005 PPP USD and on years of education ${ }^{2}$ come from $^{2}$ Gennaioli et al. $\left(2014_{[47]}\right)$. This is an unbalanced panel covering at least two points in time between 1950 and 2010. For GDP per capita, a combination of official (National Statistical Offices) and - where unavailable - unofficial sources (estimated measures) was used. Years of education refer to the average years of schooling from primary school onwards for the population aged 15 years or older. This information comes from National Statistical Offices and/or the Integrated Public Use Microdata Series (IPUMS).

For most of the OECD countries ${ }^{3}$ in the dataset, the GDP values for years 2000-15 were updated and harmonised using the official estimates from the OECD statistical database. ${ }^{4}$ Then, for both GDP and education measures, interpolation and extrapolation methods were used to assign values consistently to the reference years 1975, 1990, 2000 and 2015, if not already available. In particular, linear interpolation between two or more points in time was used with no restrictions. By contrast, out-of-sample linear extrapolation was applied only if the reference year and the closest year with available information were maximum 5 years apart.

Total population and the share of people living in metropolitan areas were computed for each region. Control variables at the regional level such as latitude, distance to coast, malaria indicator, oil and gas production, and indicators for regions that are home to the capital were taken from Gennaioli et al. $\left(2014_{[47]}\right)$. For a subset of 687 regions in 33 countries the paper also provides data on the stock of immigrants and emigrants and their level of education at one point in time between 1990 and 2010 .

Annex Table 3.D.1. List of countries included in the regional dataset

\begin{tabular}{|c|c|c|c|c|c|}
\hline ISO code & Country name & ISO code & Country name & ISO code & Country name \\
\hline ALB & Albania & GTM & Guatemala & NOR & Norway \\
\hline ARE & United Arab Emirates & HND & Honduras & NPL & Nepal \\
\hline ARG & Argentina & HRV & Croatia & PAK & Pakistan \\
\hline AUS & Australia & HUN & Hungary & PAN & Panama \\
\hline AUT & Austria & IDN & Indonesia & PER & Peru \\
\hline BEL & Belgium & IND & India & PHL & Philippines \\
\hline BEN & Benin & IRL & Ireland & POL & Poland \\
\hline$B G D$ & Bangladesh & IRN & Iran & PRT & Portugal \\
\hline BGR & Bulgaria & ITA & Italy & PRY & Paraguay \\
\hline $\mathrm{BIH}$ & $\begin{array}{l}\text { Bosnia and } \\
\text { Herzegovina }\end{array}$ & JOR & Jordan & ROU & Romania \\
\hline $\mathrm{BOL}$ & Bolivia & JPN & Japan & RUS & Russian Federation \\
\hline
\end{tabular}




\begin{tabular}{|c|c|c|c|c|c|}
\hline ISO code & Country name & ISO code & Country name & ISO code & Country name \\
\hline BRA & Brazil & $\mathrm{KAZ}$ & Kazakhstan & SLV & El Salvador \\
\hline CAN & Canada & KEN & Kenya & SRB & Serbia \\
\hline $\mathrm{CHE}$ & Switzerland & KGZ & Kyrgyz Republic & SVK & Slovak Republic \\
\hline $\mathrm{CHL}$ & Chile & KOR & Korea & SVN & Slovenia \\
\hline $\mathrm{CHN}$ & China & LKA & Sri Lanka & SWE & Sweden \\
\hline $\mathrm{COL}$ & Colombia & LSO & Lesotho & THA & Thailand \\
\hline CZE & Czech Republic & LTU & Lithuania & TUR & Turkey \\
\hline DEU & Germany & LVA & Latvia & TZA & Tanzania \\
\hline DNK & Denmark & MAR & Morocco & UKR & Ukraine \\
\hline ECU & Ecuador & MEX & Mexico & URY & Uruguay \\
\hline EGY & Egypt & MKD & North Macedonia & USA & United States \\
\hline ESP & Spain & MNG & Mongolia & UZB & Uzbekistan \\
\hline EST & Estonia & $\mathrm{MOZ}$ & Mozambique & VEN & Venezuela \\
\hline FIN & Finland & MYS & Malaysia & VNM & Viet Nam \\
\hline FRA & France & NGA & Nigeria & ZAF & South Africa \\
\hline GBR & United Kingdom & $\mathrm{NIC}$ & Nicaragua & & \\
\hline GRC & Greece & NLD & Netherlands & & \\
\hline
\end{tabular}

Notes: 1. Of which 35 are EU and/or OECD members. The reader should refer to Annex Table 3.D.1 for the entire list of countries.

2. Information on years of education in 2000 is not available for 7 countries: BIH, GTM, NGA, NPL, UKR, UZB and VEN.

3. With the exception of CZE, DNK, EST and LVA, for which values from Gennaioli et al. (2014[47]) were used.

4. The procedure highlighted a few inconsistencies between the GDP values from the paper and the OECD measures due to the different GDP accounting standards used by different sources. For this reason, the following 5 regions were considered to be outliers and therefore removed from the sample: Antofagasta (CHL), Campeche (MEX), Oslo (NOR), Delaware (USA) and District of Columbia (USA). Nonetheless, results are robust to the inclusion of these regions.

Source: Gennaioli, N. et al. (2014[47]), "Growth in regions", http://dx.doi.org/10.1007/s10887-014-9105-9; Gennaioli, N. et al. (2013[48]), "Human capital and regional development", http://dx.doi.org/10.1093/qje/qjs050. 
Annex Figure 3.D.1. Per capita income in metropolitan areas relative to their countries, 2015

GDP per capita, OECD only

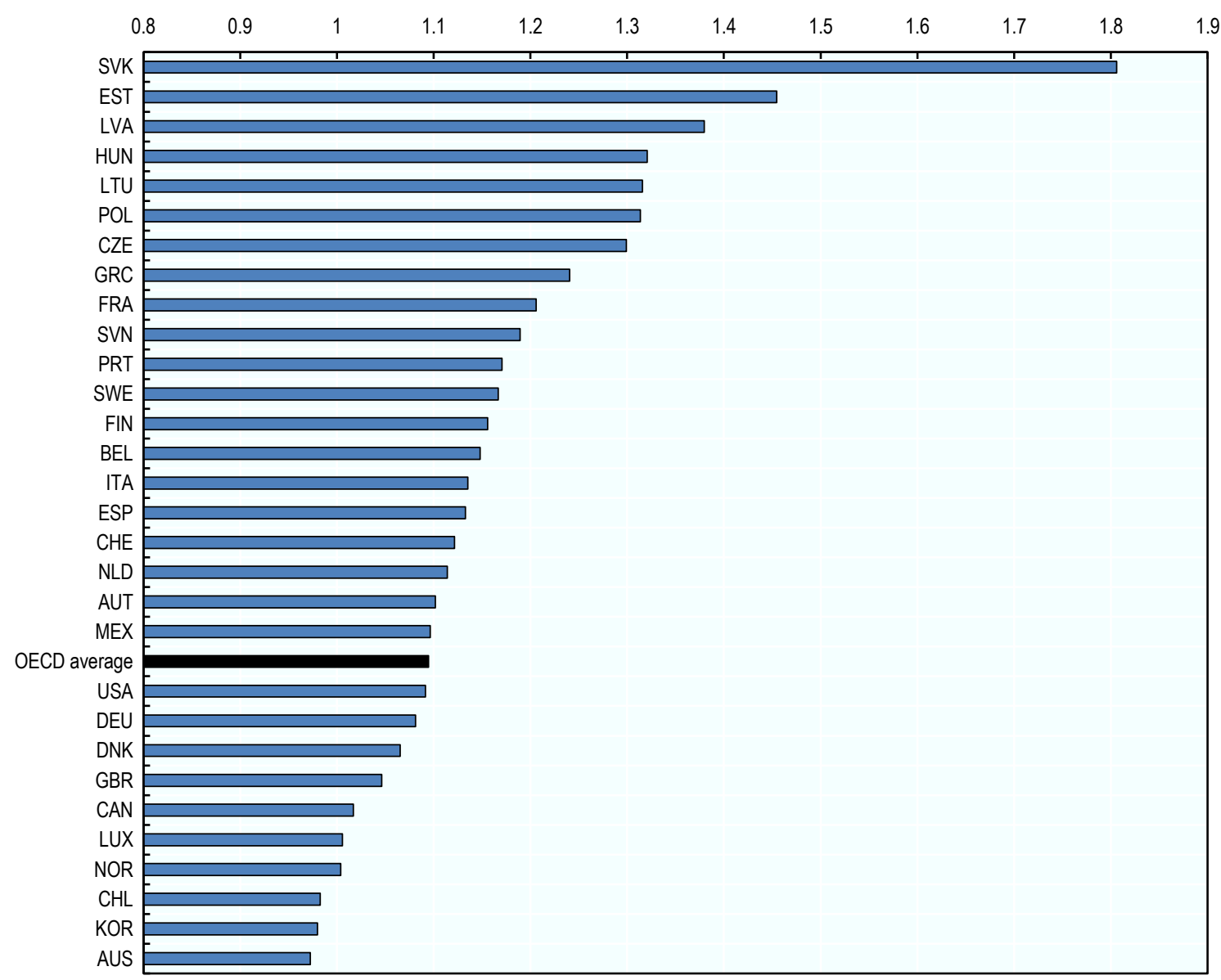

Note: Population-weighted averages of the ratio of GDP per capita in FUAs relative to that of their countries are reported.

Source: OECD (n.d.[52]), OECD Metropolitan Database, https://stats.oecd.org/Index.aspx?Datasetcode=CITIES. 


\section{The growth of metropolitan areas}

This chapter provides a new perspective of major trends and recent developments in the growth of metropolitan areas (cities and their commuting zones) over the past four decades. It documents the emergence of new metropolitan areas around the world. It analyses what type of metropolitan areas appear to be growing the fastest and how many and what type of metropolitan areas are shrinking in terms of population. Finally, it assesses some of the main factors that appear to explain the growth and decline of existing metropolitan areas. 


\section{Key messages}

- Population has grown in metropolitan areas of all sizes but most strongly in larger ones. Large metropolitan areas with over 1 million inhabitants grew half a percentage point faster per year than smaller metropolitan areas and have increased by over 400 million new inhabitants since 2000. The fastest growth occurred in metropolitan areas with populations above 5 million. Due to the growth of smaller metropolitan areas, the number of metropolitan areas with more than 5 million inhabitants doubled in just 25 years.

- Yet, overall population growth in developing countries, particularly in Africa and South Asia has also led to a proliferation of small metropolitan areas. As a result, many towns grew into metropolitan areas of at least 50000 inhabitants, and more than 100 million inhabitants in Africa and South Asia live in metropolitan areas that have emerged since 1990. This growth in small metropolitan areas presents distinct challenges for policymakers in these world regions, such as how and where to invest in infrastructure, and to maximise growth opportunities and poverty reduction.

- Globally, one-fifth of metropolitan areas shrank in population despite the overall growth of the urban population. Most of these are located in countries of East Asia and Europe where overall population growth is stagnating or the national population is in fact decreasing. Metropolitan areas with less than a million inhabitants are the most vulnerable to population loss; over onethird of them declined or stagnated between 2000 and 2015 in East Asia and Europe.

- A number of factors are associated with the population size and - to a lesser degree - with population growth of a metropolitan area. In particular, political status, access to markets and location are associated with metropolitan area size. Also, capital cities are growing 0.8 percentage points faster annually, on average, even after accounting for their size. Access to markets matters both for past and current growth. Cities on the coast and navigable rivers are not only larger, but in some world regions also continue to grow faster.

\section{Introduction}

How cities are measured is important for understanding their growth. Often, the process of urban and suburban expansion occurs outside of administrative boundaries or outside of the dense urban centre. This chapter uses the concept of functional urban areas (henceforth called metropolitan areas) as a unit of observation. Metropolitan areas are composed of a city of at least 50000 inhabitants and its surrounding commuting zone or travel-to-work area (i.e. the area surrounding a city from which a significant share of the population commutes into the city on a daily basis). Since commuting data is not available for a majority of countries across the globe, the extent of each metropolitan area has been estimated (see MorenoMonroy, Schiavina and Veneri $\left(2020_{[1]}\right)$ for details). Covering the entire metropolitan area instead of just the city makes a substantial difference. In 2015 , nearly $54 \%$ of the world lived in metropolitan areas compared to $48 \%$ in cities.

When analysing the evolution of metropolitan areas, four distinct patterns become visible. First, more developed countries have a larger population share in metropolitan areas (Figure 4.1). Chapter 3 examines the relationship between economic development and metropolitan areas in detail. Second, the world's population is increasingly concentrated in very large metropolitan areas. How to manage these large cities is of utmost importance since they now house over one-third of the world's population and they will continue to grow. Yet, third, the future does not lie exclusively in large metropolitan areas. Population growth in the developing world has led to the rapid expansion of small metropolitan areas across Africa and Asia. Fourth, 
a substantial number of metropolitan areas is experiencing population decline. In OECD countries and parts of East Asia, population growth is stagnating and a significant share of metropolitan areas, especially small- and medium-sized ones, is losing population. How to manage population decline is hence a pressing policy concern.

\section{Figure 4.1. Share of metropolitan population by country income class}

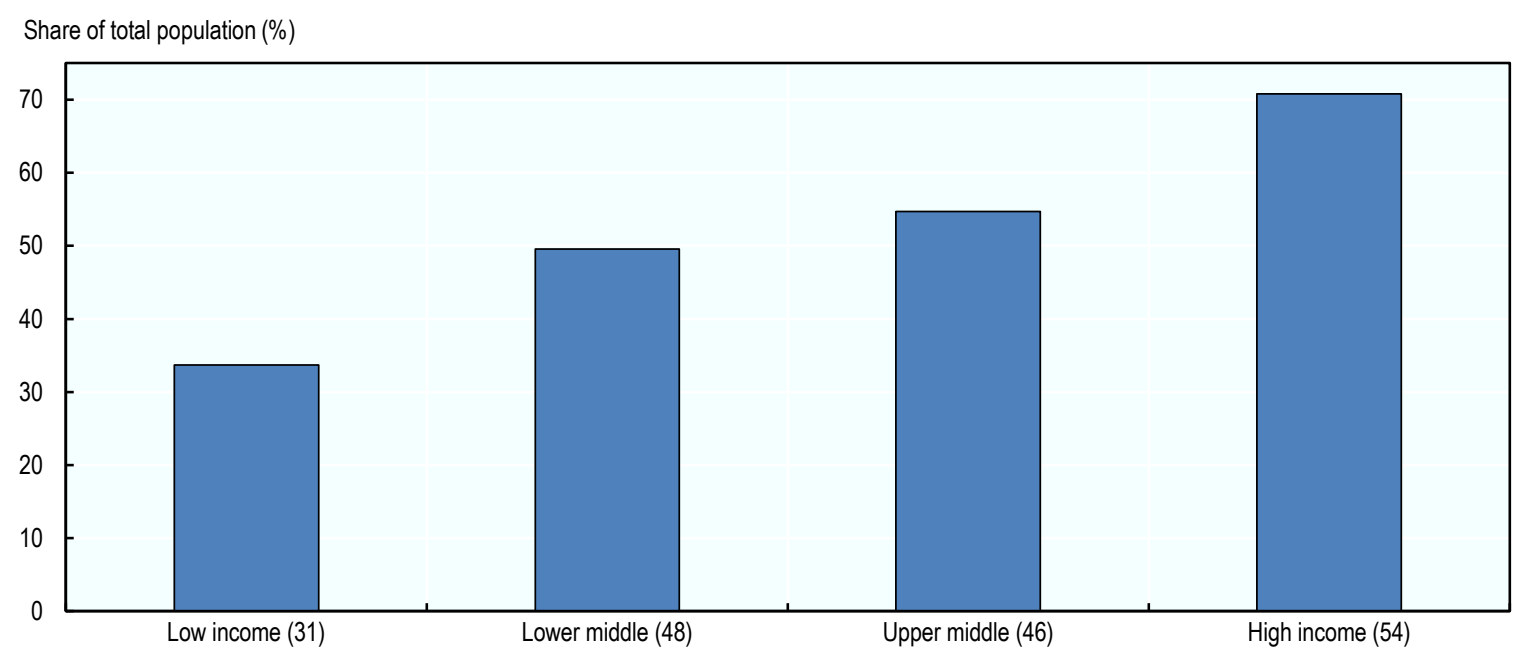

Note: This figure depicts the share of the total population that lives in metropolitan areas in 2015 by country income category. The income groups follow the World Bank classification of countries explained in the reader's guide.

Source: OECD calculations based on the Urban Centre Database GHS-UCDB R2019A, Florczyk, A. et al. (2019[2]), GHS Urban Centre Database 2015, Multitemporal and Multidimensional Attributes, R2019A, https://data.jrc.ec.europa.eu/dataset/53473144-b88c-44bc-b4a34583ed1f547e.

Around the world, there are over 9000 metropolitan areas that are home to almost 4 billion residents according to the global metropolitan area definition. Roughly $70 \%$ of these metropolitan areas have between 50000 and 250000 inhabitants. Yet, they are home to only $20 \%$ of the entire population in metropolitan areas. In contrast, just $1 \%$ of all metropolitan have more than 5 million inhabitants but these 94 metropolitan areas are home to $26 \%$ of the global population that lives in metropolitan areas. The remaining population in metropolitan areas is roughly evenly distributed between those with 250000 to 1 million inhabitants and 1 million to 5 million inhabitants (Table 4.1). Since metropolitan areas can contain multiple cities, the number of metropolitan areas can differ from the number of cities.

Table 4.1. Metropolitan areas size and population shares in 1990 and 2015

\begin{tabular}{l|c|c|c|c|c|c}
\hline \multicolumn{1}{|c|}{ Size } & $\begin{array}{c}\text { Population } \\
\text { (millions) }\end{array}$ & $\begin{array}{c}\text { Number of } \\
\text { metropolitan } \\
\text { areas }\end{array}$ & $\begin{array}{c}\text { Metropolitan area } \\
\text { population share } \\
(\%)\end{array}$ & $\begin{array}{c}\text { Population } \\
\text { (millions) }\end{array}$ & $\begin{array}{c}\text { Number of } \\
\text { metropolitan } \\
\text { areas }\end{array}$ & $\begin{array}{c}\text { Metropolitan area } \\
\text { population share } \\
(\%)\end{array}$ \\
\hline$<250000$ & 560 & 4545 & 21 & 772 & 6271 & 20 \\
\hline $250 \mathrm{k}-1 \mathrm{M}$ & 751 & 1625 & 28 & 969 & 2088 & 25 \\
\hline $1-5 \mathrm{M}$ & 821 & 413 & 31 & 1162 & 575 & 29 \\
\hline$>5 \mathrm{M}$ & 520 & 51 & 20 & 1026 & 94 & 26 \\
\hline Total & $\mathbf{2 6 5 2}$ & $\mathbf{6 6 3 4}$ & $\mathbf{1 0 0}$ & $\mathbf{3 9 2 9}$ & $\mathbf{9 0 2 8}$ & 100 \\
\hline
\end{tabular}

Note: In this table, for 1990, we exclude metropolitan areas that did not have an urban centre in 1990. In 2015, we include all metropolitan areas that have an urban centre in 2015. The boundaries of the metropolitan areas for which population is calculated are fixed in 2015 for both periods. Source: OECD calculations based on Urban Centre Database GHS-UCDB R2019A, Florczyk, A. et al. (2019[2]), GHS Urban Centre Database 2015, Multitemporal and Multidimensional Attributes, R2019A, https://data.jrc.ec.europa.eu/dataset/53473144-b88c-44bc-b4a3-4583ed1f547e. 
In most world regions, the share of metropolitan area residents living in very large ones has increased since 2000. North America and East Asia have the highest share (36\%) of metropolitan area residents living in very large metropolitan areas ( $>5$ million) in 2015. Yet, the high value in North America still represents a relative decline of 4 percentage points since 1990. In contrast, only $11 \%$ of Sub-Saharan Africa's metropolitan area population lives in very large metropolitan areas, while nearly $36 \%$ still live in small metropolitan areas. The low number for Sub-Saharan Africa reflects two facts. First, large-scale urbanisation in the region is a relatively recent phenomenon and its cities are therefore still smaller than in other parts of the world that have experienced longer periods of urbanisation. Second, it partly reflects the small size of many Sub-Saharan African countries.

The distribution of people in the different size classes of metropolitan areas is closely linked with economic development. The more developed a country is, the more is its metropolitan population in metropolitan areas of more than 1 million inhabitants (Figure 4.2). High-income countries have the highest share (66\%) of metropolitan residents living in very large and large metropolitan areas. In comparison, only $35 \%$ of residents in metropolitan areas in low-income countries live in large (1-5 million) or very large metropolitan areas ( $>5$ million).

Figure 4.2. The share of the metropolitan area population by size and income in 2015
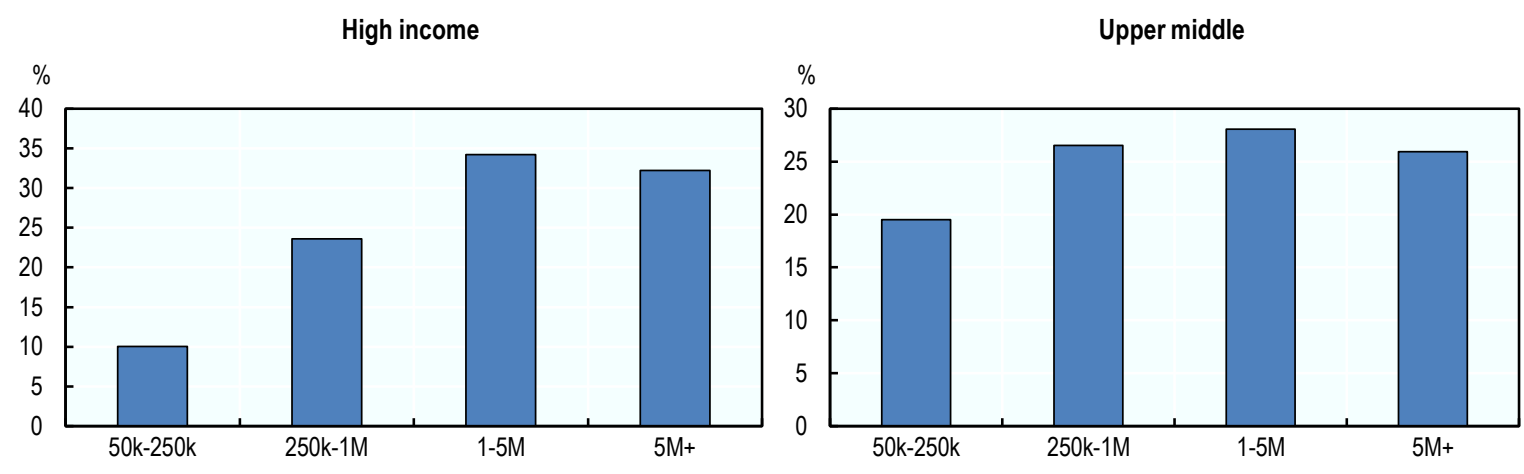

Lower middle
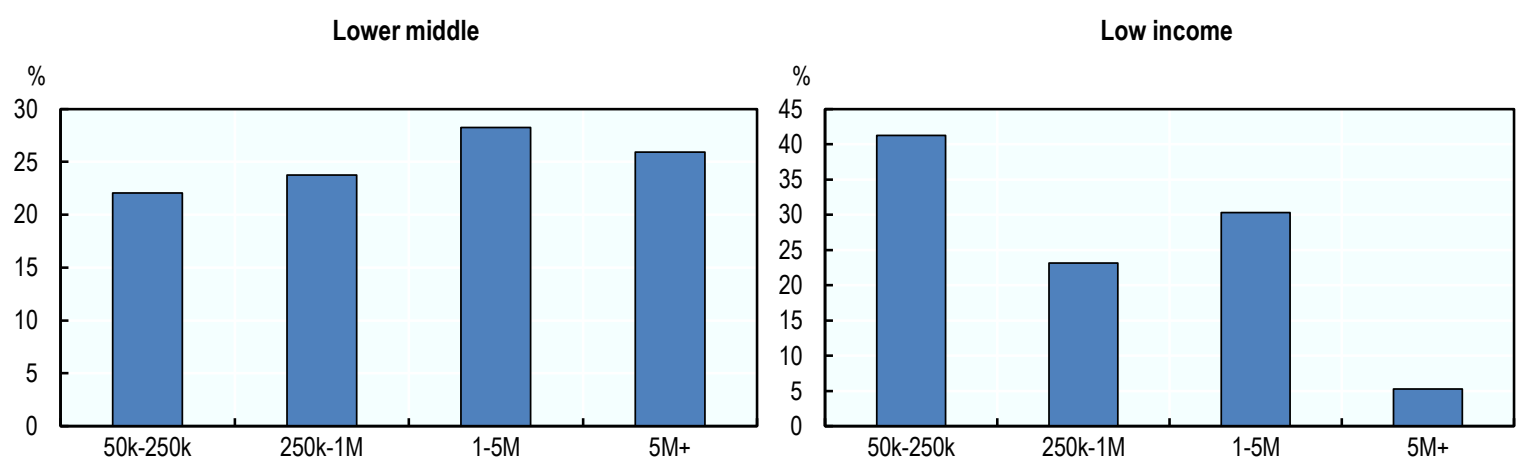

Note: This figure depicts the share of the total population in metropolitan areas by metropolitan area size class in 2015. The population is further disaggregated by income category. The metropolitan size categories are defined in 2015, using population within the 2015 borders.

Source: OECD calculations based on the Urban Centre Database GHS-UCDB R2019A, Florczyk, A. et al. (2019[2]), GHS Urban Centre Database 2015, Multitemporal and Multidimensional Attributes, R2019A, https://data.jrc.ec.europa.eu/dataset/53473144-b88c-44bc-b4a34583ed1f547e. 


\section{The emergence of 4000 new metropolitan areas}

The world is at a demographic turning point. After five decades of increasing population growth rates, declining birth rates in most parts of the world have led to a marked slowdown in population growth in many parts of the world. Yet, beneath these global dynamics lie major differences in demographic characteristics and trends at the country level. Some countries continue to experience high levels of fertility and population growth. In others, fertility rates have fallen to replacement levels, but population levels will continue to increase for several decades as a large number of young people can expect to live longer lives. In an increasing number of countries, birth rates have fallen below replacement rates and rapid ageing and gradual population contractions are expected in the coming decades, in certain cases compounded by migration to other countries.

Population growth trends at the national level are also reflected in population growth rates of metropolitan areas. Especially in fast-growing countries, population growth at the national level drives the growth of metropolitan areas across the size distribution. Figure 4.3 shows that population growth at the metropolitan level (taking only those metropolitan areas into account that already existed in 2000) mirrors population growth rates in non-metropolitan areas closely in most parts of the world. However, in all regions of the world apart from South Asia, annual population growth in metropolitan areas between 2000 and 2015 exceeded population growth outside metropolitan areas. In North America and East Asia and the Pacific, this difference was most pronounced, with population growth in metropolitan areas almost twice as high as outside metropolitan areas.

Figure 4.3. Total population growth rates and metropolitan area population growth rates by world region, 2000 and 2015

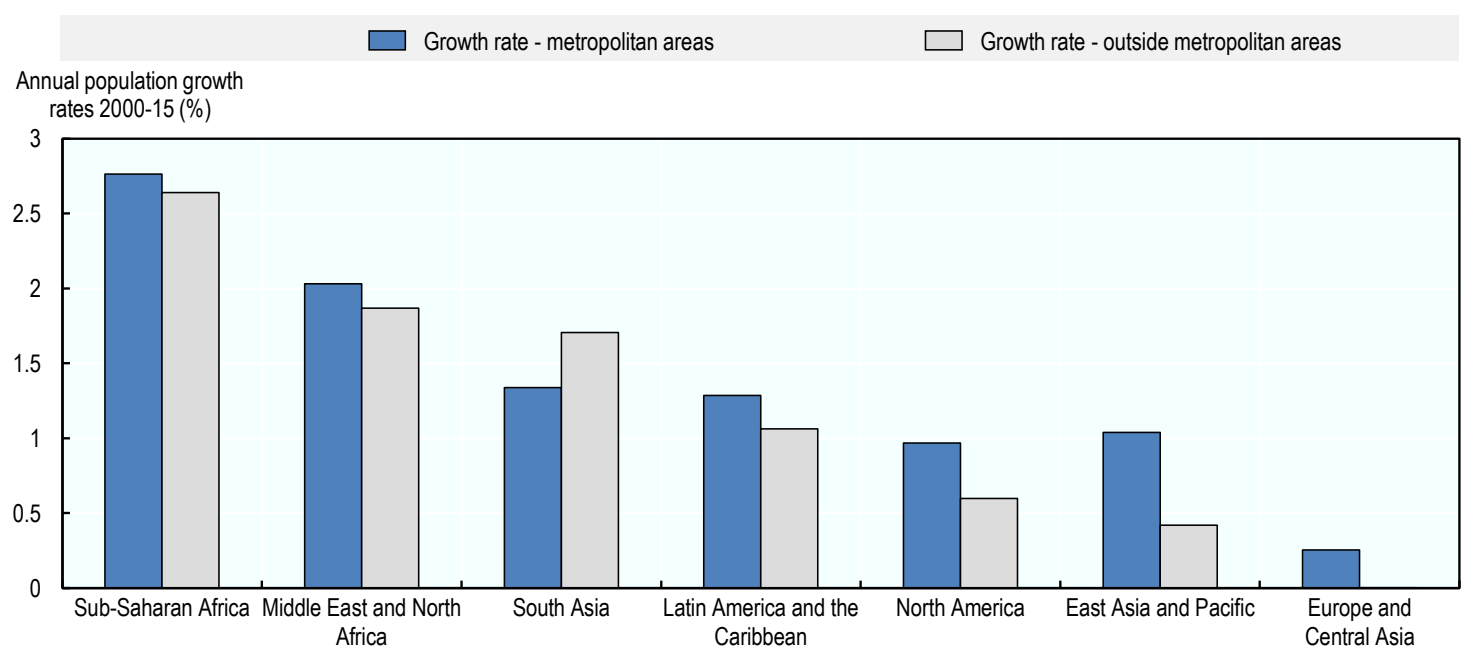

Note: This figure depicts annualised growth rates of the population in metropolitan areas that existed in 2000 and the population outside metropolitan areas by region between 2000 and 2015. The sample of existing metropolitan areas includes those that had an urban centre in 2000. These growth rates are calculated using the total population change by region and are therefore weighted by population. Borders of metropolitan areas are defined in 2015 and all population growth within metropolitan areas takes place within the 2015 borders.

Source: OECD calculations based on the Urban Centre Database GHS-UCDB R2019A, Florczyk, A. et al. (2019[2]), GHS Urban Centre Database 2015, Multitemporal and Multidimensional Attributes, R2019A, https://data.jrc.ec.europa.eu/dataset/53473144-b88c-44bc-b4a34583ed1f547e. 


\section{Rapid population growth has fostered growth in new and small metropolitan areas in Africa and South Asia}

One consequence of rapid population growth in the developing world in recent decades has been the precipitous emergence of new metropolitan areas. Like larger metropolitan areas, towns are growing rapidly in the developing world. This is driven by both natural population growth (due to high fertility rates combined with low mortality) and movement from people in rural areas to towns and small metropolitan areas. Between 1975 and 2015, many towns have exceeded the threshold to be considered a metropolitan area.

Between 1975 and 2015, roughly 4000 new metropolitan areas emerged. Thus, more than $40 \%$ of all existing metropolitan areas emerged over this 40-year period. Low- and lower-middle-income countries experienced the fastest growth in the number of new metropolitan areas over the past four decades. In low-income countries especially, located primarily in Sub-Saharan Africa, over half of the existing metropolitan areas were still a town in 1990 (Figure 4.4). This means that 50 million people in Sub-Saharan Africa are living in metropolitan areas that were towns in 1990.

While the narrative surrounding urbanisation in Africa focuses primarily on the largest metropolitan areas, the growth of small metropolitan areas presents a distinct challenge to urbanisation in Africa (see Box 4.1 for a discussion of the policy challenges of where to invest in Africa). It is a sign of the relatively early stage of urbanisation of the continent, in contrast to more developed world regions that have experienced urbanisation for decades or centuries. In high-income countries, such as countries from the OECD and EU, the majority of metropolitan areas already existed prior to 1975. Put differently, among those metropolitan areas that emerged after 1975, only $9 \%$ are located in the EU and OECD.

Box 4.1. Large metropolitan areas versus small towns: Where to invest for greater poverty reduction?

The expansive growth of small metropolitan areas presents a distinct challenge to urbanisation in Africa and the Middle East. Much of the discourse surrounding urbanisation in the developing world involves aggregate measures, with policy debates focusing primarily on the largest metropolitan areas. Yet, as this section has demonstrated, small metropolitan areas are growing rapidly and accounting for large shares of urban growth. In Africa and the Middle East, cities with less than 1 million absorbed over half of new metropolitan residents since 2000 .

With the potential for smaller metropolitan areas to reduce poverty, governments and policy makers are faced with the question of whether public investment should be targeted towards smaller metropolitan areas or the largest ones. While the largest metropolitan areas allow for higher increases in income and standards of living relative to smaller metropolitan areas, farmers who are taking up nonfarm employment are increasingly opting to move to smaller metropolitan areas. In Africa, some farmers move to cities even without changing their profession, becoming urban-based farmers. The role of these smaller metropolitan areas for poverty reduction is not clear. Recent cross-country and within-country evidence suggests a larger reduction in poverty when people move to large metropolitan areas. But, because of their high numbers and large share of population growth, small metropolitan areas may contribute to greater poverty reduction overall. In Tanzania, while moving to large metropolitan areas provides large income premiums and standards of living relative to smaller metropolitan areas, most people opt to move to smaller metropolitan areas and engage in local nonfarm employment (Christiaensen, De Weerdt and Kanbur, 2016[3]). As a result, secondary metropolitan areas may play a larger role in poverty reduction in the aggregate. In India, econometric analysis using night lights as a 
measure of urban growth has shown that growth of smaller metropolitan areas has had a larger impact on reducing rural poverty than the growth of big metropolitan areas (Gibson et al., 2017 ${ }_{[4]}$ ).

Source: Christiaensen, L. and R. Kanbur (2017[5]), "Secondary towns and poverty reduction: Refocusing the urbanization agenda", http://dx.doi.org/10.1146/annurev-resource-100516-053453; Christiaensen, L., J. De Weerdt and R. Kanbur (2016[3]), "Urbanization and poverty reduction: The role of secondary towns in Tanzania", IOB Analyses \& Policy Briefs; Gibson, J. et al. (2017[4]), "For India's rural poor, growing towns matter more than growing cities", http://dx.doi.org/10.1016/j.worlddev.2017.05.014.

\section{Figure 4.4. Age of metropolitan areas across income classes}

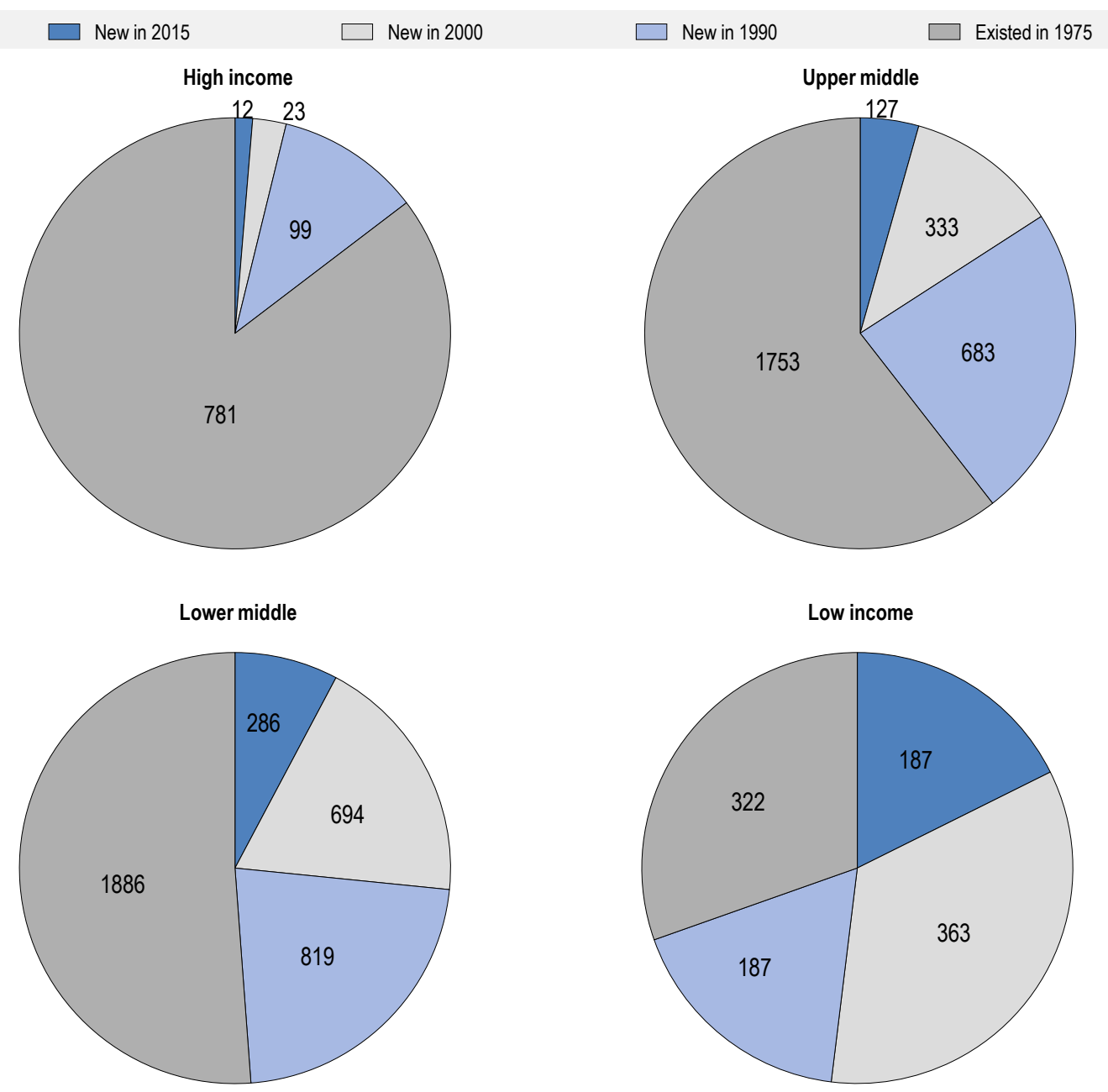

Note: This figure reports the share of metropolitan areas that achieved that status in each indicated time period as a share of the total metropolitan areas that existed in 2015 by income level.

Source: OECD calculations based on the Urban Centre Database GHS-UCDB R2019A, Florczyk, A. et al. (2019[2]), GHS Urban Centre Database 2015, Multitemporal and Multidimensional Attributes, R2019A, https://data.jrc.ec.europa.eu/dataset/53473144-b88c-44bc-b4a3$\underline{4583 e d 1 f 547 e .}$. 


\section{Growth of the metropolitan population}

\section{Population growth is concentrated in large metropolitan areas around the world}

Overall, the world's population is increasingly concentrated in large metropolitan areas. Not only are large metropolitan areas growing faster than medium- and small-sized metropolitan areas, but some medium and small ones also grow into large ones. At a global scale, the majority of metropolitan area population growth took place in large and very large metropolitan areas, regardless of whether countries experienced rapid population growth or population decline. Since 2000, metropolitan areas with over 1 million inhabitants outpaced non-metropolitan growth by 0.4 percentage points. They also grew faster than metropolitan areas with less than 1 million inhabitants (by 0.5 percentage points). As a result, almost $60 \%$ of the world's population growth in metropolitan areas occurred in the 542 metropolitan areas that had more than 1 million people in 2000, which represented around $50 \%$ of the metropolitan population in 2000. The largest metropolitan areas, those with over 5 million people, grew even faster. On average, these metropolitan areas grew a whole percentage point faster than medium-sized and small metropolitan areas.

Figure 4.5 shows the average annual growth rate of metropolitan area population from 2000 to 2015 by size category and income level. Apart from high-income countries, population growth rates were highest in the largest metropolitan areas, often significantly outpacing non-metropolitan population growth. The relationship between the population growth rates and the size of metropolitan areas is positive in all regions except for Latin America and the Caribbean. Amongst EU and OECD countries, while growth rates seem to be increasing between small and large metropolitan areas, the magnitude of these differences is small ( 0.12 percentage points) and the differences in growth across metropolitan area sizes are not statistically significant. Similarly, in Latin America, metropolitan areas are growing at similar speeds across the size distribution, on average.

Globally, more than half of the metropolitan areas with more than 5 million people are located in Asia; these are continuing to grow at over $2 \%$ annually, despite slower overall population growth across the region. Population growth in these metropolitan areas is outpacing growth in large metropolitan areas (between 1 and 5 million inhabitants) by over 1 percentage point in East Asia and a half of a percentage point in South Asia. The metropolitan areas with more than 5 million inhabitants alone increased by roughly 150 million new people between 2000 and 2015 . This represents $22 \%$ of global metropolitan growth while they were home to only $15 \%$ of the total world population in 2000 . Beyond China and India, the fastest growth occurred in lower-middle and upper-middle-income countries such as Myanmar, Pakistan, Thailand and Viet Nam. Countries that experienced natural disasters and conflict have also seen fast growth in large metropolitan areas, this including Afghanistan and Nepal. Growth in large metropolitan areas across East Asia, in particular, has occurred alongside a decline in overall population growth, which has disproportionately affected small- and medium-sized metropolitan areas (see section on shrinking metropolitan areas for a detailed discussion).

In Sub-Saharan Africa, large metropolitan areas have been growing a full percentage point faster than medium-sized metropolitan areas. Very high concentration of people in capital cities has characterised the rapid urbanisation at low-income levels in Africa and the Middle East. In these regions, the largest metropolitan areas are generally capitals with between 1 and 5 million inhabitants. Those that grew faster than 5\% include Abuja, Bamako, Beirut, Dar es Salaam, Dubai, Lilongwe, Luanda and Ouagadougou. Continuing at these growth rates, Bamako, Dubai, and Ouagadougou will all surpass 5 million inhabitants in the next decade. While large metropolitan areas are growing the fastest in Sub-Saharan Africa, medium and small metropolitan areas are not far behind. ${ }^{1}$ Thus, Sub-Saharan Africa might be moving from an earlier stage of urbanisation that was characterised by the emergence of new metropolitan areas to a stage that could be characterised by increasing growth and concentration in large metropolitan areas (see Chapter 3 for more details). 
Figure 4.5. Annual population growth rates of metropolitan areas by size and income, 2000-15
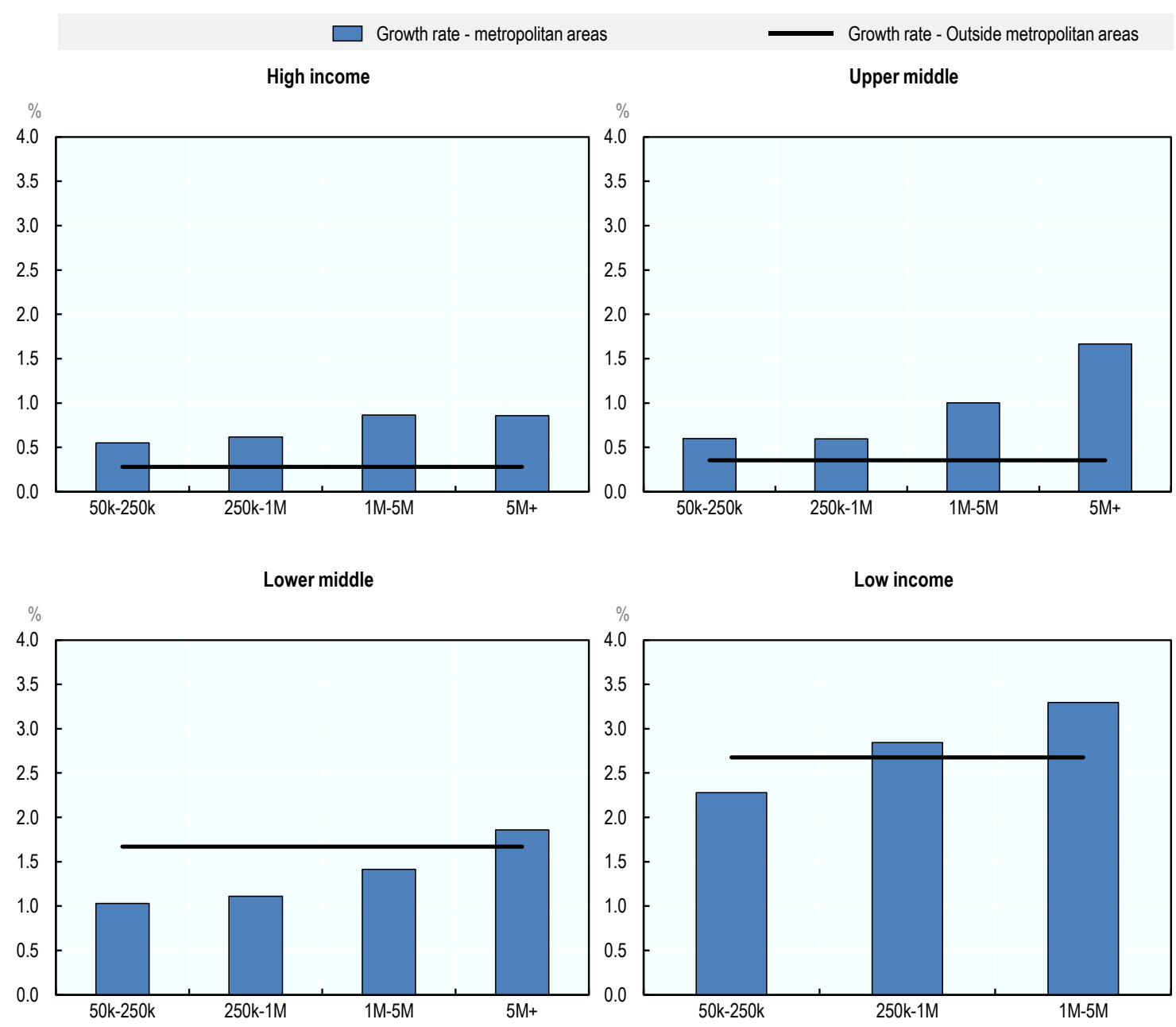

Note: This figure depicts the annual growth rates of metropolitan areas between 2000 and 2015. The sample excludes metropolitan areas that were classified as such in 2015, but not yet in 2000. The borders for the metropolitan areas are fixed in 2015. Growth rates are calculated by annualising the growth of the total population within each metropolitan area size and income group between 2000 and 2015. Metropolitan area size categories are calculated using the definition in 2000. Very large metropolitan areas (greater than 5 million inhabitants) are combined with large metropolitan areas in low-income countries due to the small numbers of observations in these countries.

Source: OECD calculations based on the Urban Centre Database GHS-UCDB, Florczyk, A. et al. (2019[2]), GHS Urban Centre Database 2015, Multitemporal and Multidimensional Attributes, R2019A, https://data.jrc.ec.europa.eu/dataset/53473144-b88c-44bc-b4a3-4583ed1f547e.

StatLink 제 Sh https://doi.org/10.1787/888934130398

One driver of the growth of large metropolitan areas in Sub-Saharan Africa is urban natural population increase. The so-called "urban push" is due to persistently high fertility in urban areas, while mortality has fallen to low levels. While fertility levels have traditionally fallen alongside urbanisation, they remain above 4 children per woman in African cities (see Box 4.2 for more details). Combined with migration from smaller metropolitan areas and rural areas, these trends are contributing to rapid metropolitan population growth in Sub-Saharan Africa. Researchers and policymakers have raised concerns that this growth can create a disconnect between urbanisation and growth (Jedwab, Christiaensen and Gindelsky, 2017[6]). First, poor metropolitan areas may expand even without an increase in standards of living. Second, because natural population increase accelerates urban growth, it can give rise to urban congestion effects, which may reduce the benefits of agglomeration. All in all, urban natural population increase in poor countries may 
directly contribute to the "urbanisation of poverty", the fact that the share of the world's poor living in urban areas has been rising over time. Although most existing research seems to alleviate this concern, urbanrural wage and income gaps in developing countries remain significant (Ravallion, 2002[7]; Ravallion, Chen and Sangraula, $\left.2007_{[8]}\right)$.

\section{Box 4.2. Fertility rates in cities in developing countries}

Fertility rates have fallen in most areas but remain very high in Africa, especially in rural areas but also in cities. Assessing fertility rates across the different degrees of urbanisation in 41 developing countries shows that fertility rates are up to $50 \%$ higher in rural areas than in cities. In general, fertility rates follow a clear rural-urban gradient, with highest rates in rural areas, the lowest in cities, and towns and semidense areas in between (Figure 4.6). In Sub-Saharan Africa and Latin America, spatial differences in fertility are particularly large. With differences of more than 2.5 children per woman, Angola, Burkina Faso and Côte d'Ivoire record the largest city-rural differences in fertility rates. In contrast, in Bangladesh and the Dominican Republic, the available data would suggest no considerable differences in fertility rates across the degree of urbanisation.

\section{Figure 4.6. Total fertility rates in cities, towns \& semi-dense areas, and rural areas}

Fertility rates across 41 developing countries in 2015.

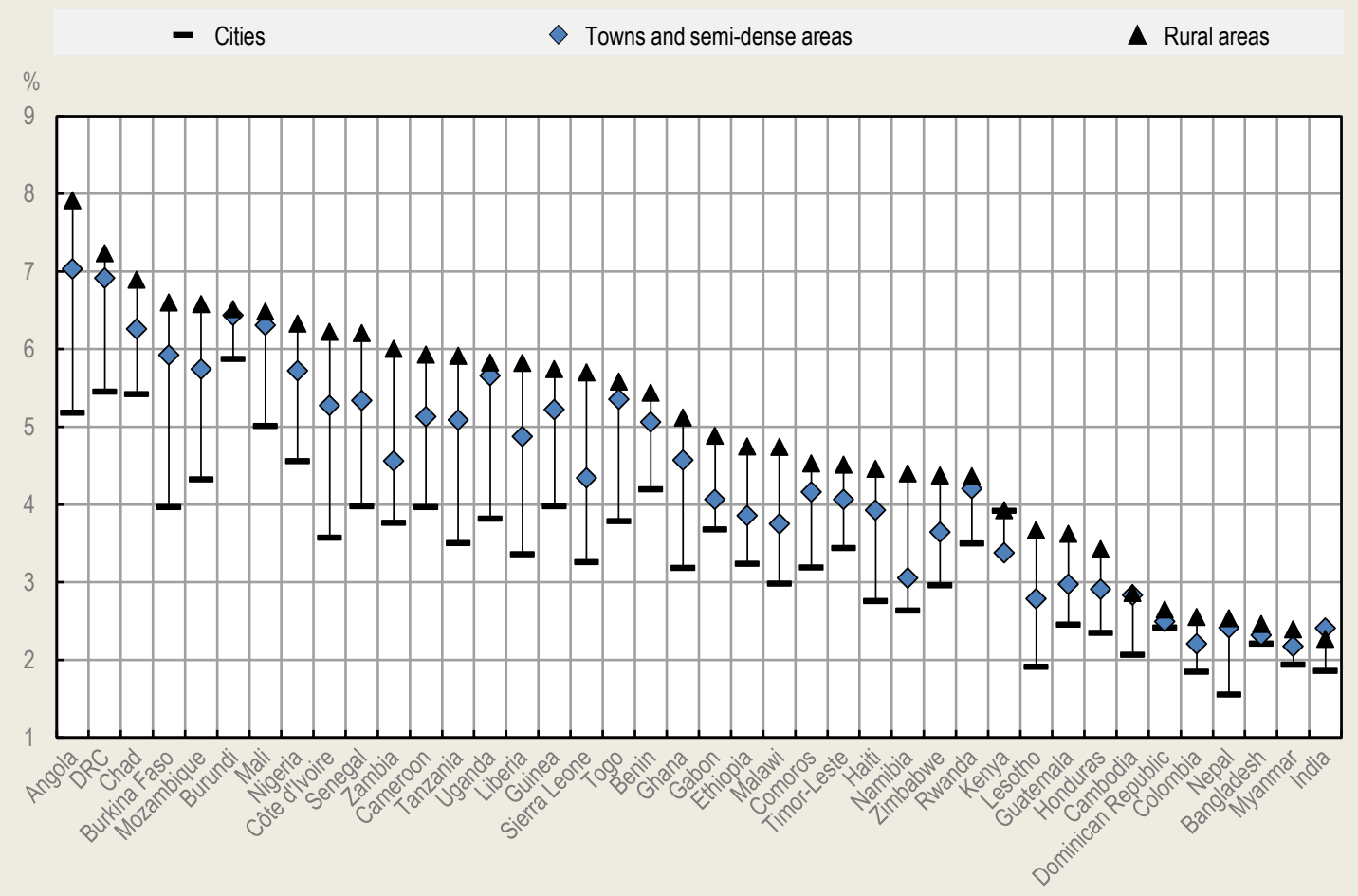

Note: TFR: sums the recent (past three years) fertility experience of women across five-year age groups (15-19, 20-24, 45-49) to measure the total number of children born to a hypothetical woman experiencing current-period, age-specific fertility levels throughout her childbearing years.

Source: DHS (ICF, 2016 $\left.{ }_{[9]}\right)$; Henderson, V. et al. (2019 $\left.{ }_{[10]}\right)$, "Urbanisation and demographic and health outcomes: Perspectives from a new classification of urban areas".

While fertility rates have fallen markedly in many areas, they remain extremely high in Sub-Saharan Africa, especially in rural areas. Average fertility in rural Africa still exceeds 5.5 children per woman in 
2015, though down from 6.2 in 2000. Even in African cities, total fertility rates average almost 4 children per woman, partly explaining the rapid growth of African cities and metropolitan areas. In contrast, in South Asian cities, fertility rates are approaching the replacement rate, falling from 3.0 to 2.1 between 2000 and 2015.

One consequence of fast-growing large metropolitan areas is the rise of megacities (i.e. metropolitan areas with more than 10 million inhabitants). Between 1990 and 2015, 10 new megacities emerged, located primarily in Sub-Saharan Africa and Asia. Six metropolitan areas over 5 million people grew faster than $3 \%$ annually, all of which are located in Asia. These are Bangalore, Beijing, Dhaka, Bangkok, Shanghai, and Ho Chi Minh City. In all six cases, total population growth in the country slowed down between 2000 and 2015, while population in the largest metropolitan areas continued to increase dramatically, suggesting a concentration of people in the largest metropolitan areas.

\section{The 20 largest metropolitan areas in 2015}

The largest metropolitan areas in the world are primarily located in Asia. Of the 20 largest metropolitan areas in 2015, 13 are in East Asia and the Pacific or South Asia (Table 4.2). These 20 metropolitan areas alone are home to more than 443 million inhabitants. Tokyo is the largest metropolitan area in the world with a population of more than 36 million, followed by Delhi and Jakarta with a population of around 30 million. The metropolitan areas outside of Asia among the 20 largest in the world are Cairo (23 million), Sao Paolo (22 million), Mexico City (21 million), New York-Newark (20 million), Moscow (16 million), Los Angeles (16 million) and Buenos Aires (15 million).

Table 4.2. Largest metropolitan areas of the world

\begin{tabular}{|c|c|c|c|c|}
\hline Rank & Metropolitan area & Population in 2015 & Country & Region \\
\hline 1 & Tokyo & 36.5 million & Japan & East Asia and the Pacific \\
\hline 2 & Delhi & 30.1 million & India & South Asia \\
\hline 3 & Jakarta & 29.8 million & Indonesia & East Asia and the Pacific \\
\hline 4 & Shanghai & 26.9 million & China & East Asia and the Pacific \\
\hline 5 & Manila & 25.0 million & Philippines & East Asia and the Pacific \\
\hline 6 & Seoul & 24.3 million & South Korea & East Asia and the Pacific \\
\hline 7 & Cairo & 23.5 million & Egypt & Middle East and North Africa \\
\hline 8 & Kolkata & 23.1 million & India & South Asia \\
\hline 9 & Mumbai & 22.3 million & India & South Asia \\
\hline 10 & Sao Paulo & 21.7 million & Brazil & Latin America and the Caribbean \\
\hline 11 & Mexico City & 21.4 million & Mexico & Latin America and the Caribbean \\
\hline 12 & Beijing & 21.3 million & China & East Asia and the Pacific \\
\hline 13 & Dhaka & 20.4 million & Bangladesh & South Asia \\
\hline 14 & New York-Newark & 19.5 million & United States & North America \\
\hline 15 & Osaka & 17.6 million & Japan & East Asia and the Pacific \\
\hline 16 & Guangzhou & 16.7 million & China & East Asia and the Pacific \\
\hline 17 & Moscow & 16.4 million & Russia & Europe and Central Asia \\
\hline 18 & Bangkok & 16.3 million & Thailand & East Asia and the Pacific \\
\hline 19 & Los Angeles & 15.7 million & United States & North America \\
\hline 20 & Buenos Aires & 15.0 million & Argentina & Latin America and the Caribbean \\
\hline
\end{tabular}

Note: This figure depicts the 15 largest metropolitan areas in the world in 2015.

Source: OECD calculations based on the Urban Centre Database GHS-UCDB R2019A, Florczyk, A. et al. (2019[2]), GHS Urban Centre Database 2015, Multitemporal and Multidimensional Attributes, R2019A, https://data.jrc.ec.europa.eu/dataset/53473144-b88c-44bc-b4a34583ed1f547e. 
Most of the 20 largest metropolitan areas of the world are growing faster than other metropolitan areas. Between 2000 and 2015, they grew on average by $29 \%$, which compares to $20 \%$ for other metropolitan areas around the world (Figure 4.7). Beijing, Bangkok, Shanghai and Dhaka grew the fastest between 2000 and 2015 , recording a respective population increase of $68 \%, 65 \%, 61 \%$, and $60 \%$. Osaka is the only metropolitan area among the 20 largest in the world that did not grow, instead stagnating in terms of population.

Figure 4.7. Growth of 20 largest metropolitan areas, 2000-15

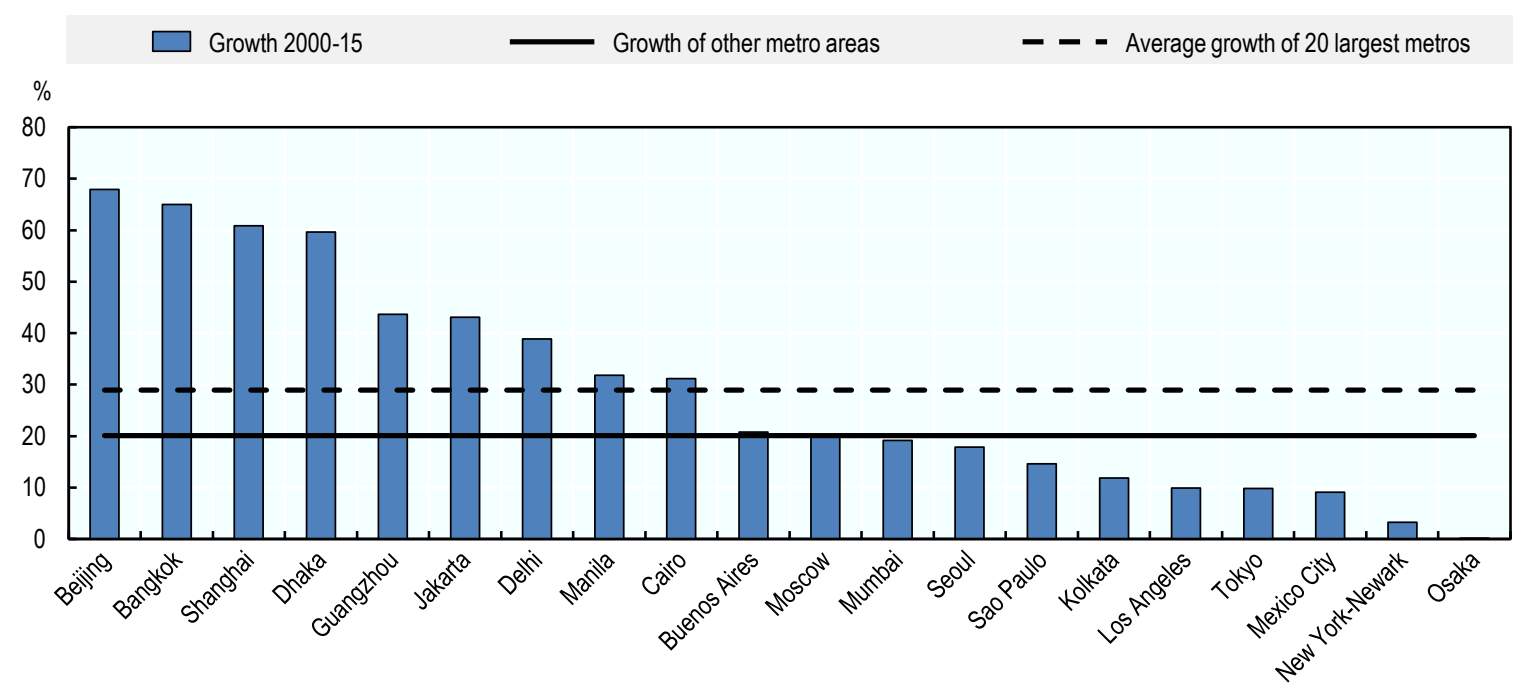

Note: This figure depicts the total growth between 2000 and 2015 of the 20 largest metropolitan areas in the world in 2015. It compares the average growth in 2000-15 of the 20 largest metropolitan areas of the world with the average growth of all other metropolitan areas over the same period.

Source: OECD calculations based on the Urban Centre Database GHS-UCDB R2019A, Florczyk, A. et al. (2019[2]), GHS Urban Centre Database 2015, Multitemporal and Multidimensional Attributes, R2019A, https://data.jrc.ec.europa.eu/dataset/53473144-b88c-44bc-b4a34583ed1f547e.

Very fast population growth of the largest metropolitan areas in Asia has changed the ranking of the world's largest metropolitan areas markedly. In 1975, there were only nine Asian metropolitan areas among the 20 largest in the world; now there are 13 (Table 4.3). Instead, with London, Paris and Chicago, two European and one North American metropolitan areas were among the largest in 1975 but by 2015 had dropped from this list, being surpassed by various Asian ones. New York was the second-largest metropolitan area in 1975 but just made it into the largest 15 metropolitan areas in 2015.

Table 4.3. The largest metropolitan areas in 1975

\begin{tabular}{c|l|c|c|l}
\hline Rank & Metropolitan area & Population in 1975 & Population in 2015 & \multicolumn{1}{c}{ Region } \\
\hline 1 & Tokyo & 25.1 million & 36.5 million & East Asia and the Pacific \\
\hline 2 & New York-Newark & 16.4 million & 19.5 million & North America \\
\hline 3 & Osaka & 15.5 million & 17.6 million & East Asia and the Pacific \\
\hline 4 & Kolkata & 14.5 million & 23.1 million & South Asia \\
\hline 5 & Ciudad de Mexico & 14.2 million & 21.4 million & Latin America and the Caribbean \\
\hline 6 & Seoul & 13.6 million & 24.3 million & East Asia and the Pacific \\
\hline 7 & Mumbai & 12.6 million & 22.3 million & South Asia \\
\hline 8 & Sao Paulo & 11.7 million & 21.7 million & Latin America and the Caribbean \\
\hline 9 & Delhi & 11.0 million & 30.1 million & South Asia \\
\hline 10 & Cairo & 10.4 million & 23.5 million & Middle East and North Africa \\
\hline
\end{tabular}




\begin{tabular}{c|l|c|c|l}
\hline Rank & Metropolitan area & Population in 1975 & Population in 2015 & \multicolumn{1}{|c}{ Region } \\
\hline 11 & Los Angeles & 10.1 million & 15.7 million & North America \\
\hline 12 & Jakarta & 9.6 million & 29.8 million & East Asia and the Pacific \\
\hline 13 & London & 9.3 million & 12.6 million & Europe and Central Asia \\
\hline 14 & Paris & 8.9 million & 11.2 million & Europe and Central Asia \\
\hline 15 & Moscow & 8.7 million & 16.4 million & Europe and Central Asia \\
\hline 16 & Buenos Aires & 8.5 million & 15.0 million & Latin America and the Caribbean \\
\hline 17 & Nagoya & 7.8 million & 9.6 million & East Asia and the Pacific \\
\hline 18 & Chicago & 7.6 million & 8.8 million & North America \\
\hline 19 & Surabaya & 6.5 million & 10.8 million & East Asia and the Pacific \\
\hline 20 & Rio de Janeiro & 6.4 million & 10.8 million & Latin America and the Caribbean \\
\hline
\end{tabular}

Note: This table presents the 15 largest metropolitan areas in the world in 1975 and depicts their population in 1975 and 2015.

Source: OECD calculations based on the Urban Centre Database GHS-UCDB R2019A, Florczyk, A. et al. (2019[2]), GHS Urban Centre Database 2015, Multitemporal and Multidimensional Attributes, R2019A, https://data.jrc.ec.europa.eu/dataset/53473144-b88c-44bc-b4a34583ed1f547e.

\section{Shrinking metropolitan areas}

The number of shrinking metropolitan areas is on the rise across the globe. Rapidly shrinking metropolitan areas may experience a reduction of economic activity, a decline in employment and increasing numbers of vacant and abandoned buildings. Numerous factors can influence where and when metropolitan areas decline, including outmigration, the loss of an industry and exhaustion of natural resources. In countries experiencing slow population growth, competition has increased amongst metropolitan areas for economic and intellectual resources and may have exacerbated the decline of some metropolitan areas. Larger metropolitan areas often attract population and productive workers while many small- and medium-sized metropolitan areas are experiencing outmigration and outflows of capital and human resources. Such a dynamic results in an increased concentration of metropolitan population (Table 4.4).

Table 4.4. Shrinking metropolitan areas, 2000-15

\begin{tabular}{|c|c|c|c|c|c|c|c|c|}
\hline \multirow[b]{2}{*}{ Size } & \multirow{2}{*}{$\begin{array}{l}\text { Total number of } \\
\text { metropolitan } \\
\text { areas }\end{array}$} & \multirow{2}{*}{$\begin{array}{l}\text { Share of shrinking } \\
\text { metropolitan areas } \\
\text { by size class (\%) }\end{array}$} & \multirow{2}{*}{$\begin{array}{c}\text { Number of } \\
\text { shrinking } \\
\text { metropolitan areas }\end{array}$} & \multicolumn{4}{|c|}{ Share of metropolitan areas with a total decline of } & \multirow[b]{2}{*}{$\begin{array}{c}\text { Total } \\
(\%)\end{array}$} \\
\hline & & & & $\begin{array}{c}\text { more than } \\
10 \%\end{array}$ & $\begin{array}{c}10 \% \text { to } \\
5 \%\end{array}$ & $\begin{array}{l}5 \% \text { to } \\
2.5 \%\end{array}$ & $\begin{array}{c}\text { less than } \\
2.5 \%\end{array}$ & \\
\hline$<250 k$ & 6256 & 19 & 1181 & 37 & 29 & 17 & 17 & 100 \\
\hline $250 \mathrm{k}-1 \mathrm{M}$ & 2086 & 20 & 426 & 37 & 32 & 13 & 18 & 100 \\
\hline $1-5 \mathrm{M}$ & 574 & 14 & 78 & 10 & 40 & 17 & 33 & 100 \\
\hline$>5 \mathrm{M}$ & 94 & 2 & 2 & 50 & 50 & 0 & 0 & 100 \\
\hline Total & 9010 & 19 & 1687 & 7 & 6 & 3 & 3 & \\
\hline
\end{tabular}

Note: This table provides the number of metropolitan areas that are shrinking by size between 2000 and 2015 . Further, it includes a breakdown of the share of shrinking metropolitan areas in each size category by the total decline over the period. The size definitions are determined by the population in 2000 and only metropolitan areas that were classified as such in 2000 are included in the statistics.

Source: OECD calculations based on the Urban Centre Database GHS-UCDB R2019A, Florczyk, A. et al. (2019[2]), GHS Urban Centre Database 2015, Multitemporal and Multidimensional Attributes, R2019A, https://data.jrc.ec.europa.eu/dataset/53473144-b88c-44bc-b4a34583ed1f547e.

The vast majority of shrinking metropolitan areas have a population of less than 1 million inhabitants. Small- and medium-sized metropolitan areas also tend to shrink at a faster pace (see next section for more details). Among the almost 1700 metropolitan areas that recorded population loss between 2000 and $2015,95 \%$ have a population of less than a million inhabitants. Thirty-seven percent of the shrinking small- 
and medium-sized metropolitan areas have lost more than $10 \%$ of their total population since 2000 . Another $30 \%$ lost between 5 and $10 \%$ of their population over the same period.

Unsurprisingly, the decline of metropolitan areas often goes hand in hand with demographic trends at the national level, particularly natural population loss and outmigration. As described at the beginning of the chapter, over the last half-century, global fertility rates have fallen dramatically. In many countries in Europe and the OECD, fertility rates have been below the replacement level for over two decades. Similar reductions in fertility have occurred in parts of East Asia, though fertility still mostly remained above the replacement rate. By 2002, the total fertility rate was below its "replacement" level in all OECD countries except Mexico and Turkey. ${ }^{2}$ The timing and pace of decline, however, varies widely from country to country. At the same time, international outmigration has reinforced demographic transitions in Central and Eastern Europe, as well as in some countries in South East Asia, furthering population loss and thereby metropolitan area decline. ${ }^{3}$ Combined, natural population increase or loss and migration rates at the national level alone explain $52 \%$ of Europe and Central Asia's metropolitan area population growth variance (Restrepo Cadavid et al., 2017[11]).

Globally, almost $20 \%$ of metropolitan areas declined in population over the past 15 years. These declining metropolitan areas had 45 million less people in 2015 than they did in 2000. Due to their large populations, over $70 \%$ of the 1700 metropolitan areas that declined since 2000 are located in just 6 countries - China, India, Indonesia, Japan, Russia and Ukraine (Figure 4.8). The issue of metropolitan area decline is not an isolated issue, but matters to hundreds of millions of people. As of 2015,440 million people lived in metropolitan areas that are experiencing population decline, which raises considerable challenges and implications for policymakers.

\section{Figure 4.8. Shrinking metropolitan areas across the world}

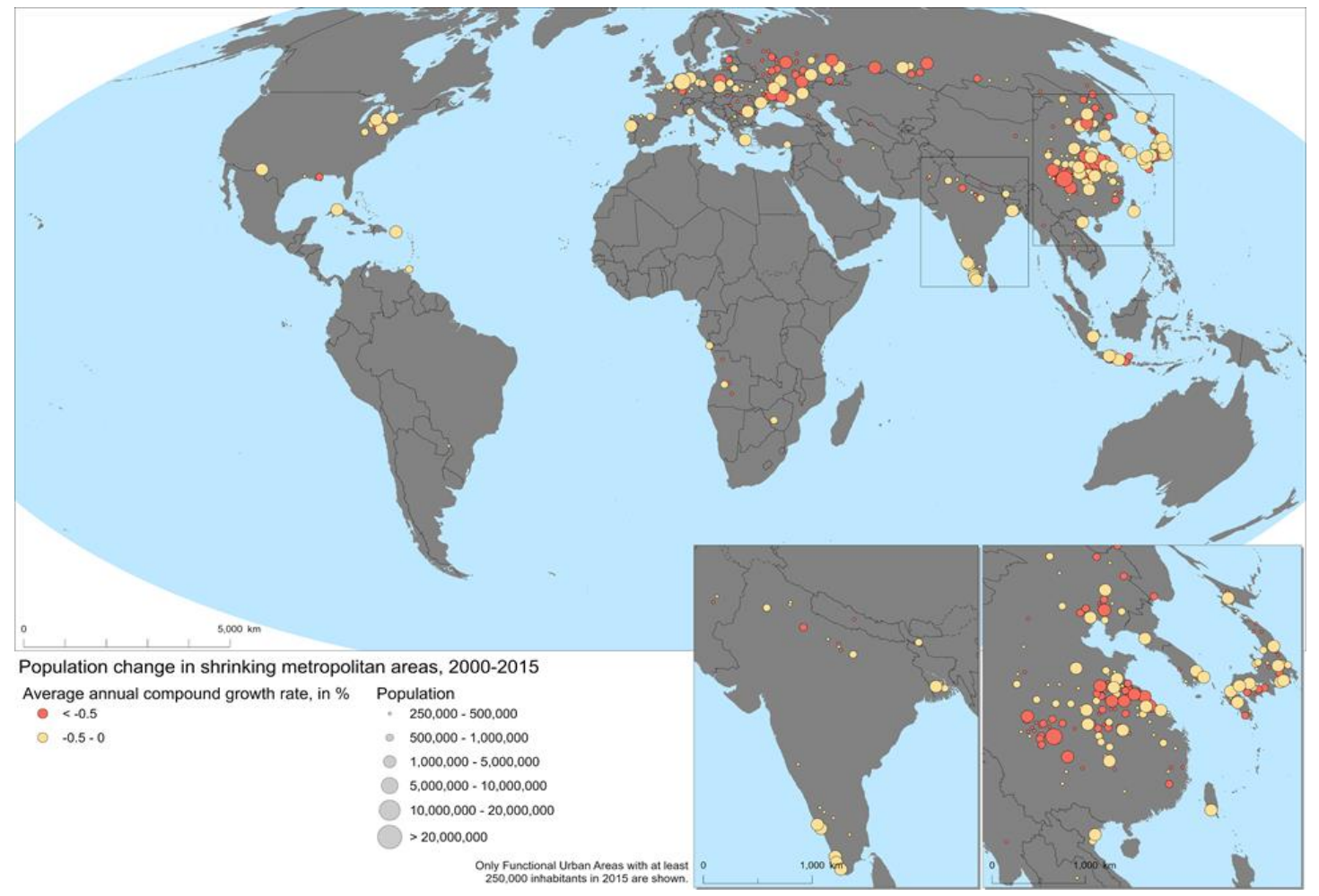

Note: This map shows all metropolitan areas with a population above 250000 that experienced population decline between 2000 and 2015. The annual population growth rate is calculated as the annual compound growth rate.

Source: OECD and EC based on the Urban Centre Database GHS-UCDB R2019A, Florczyk, A. et al. (2019[2]), GHS Urban Centre Database 2015, Multitemporal and Multidimensional Attributes, R2019A, https://data.jrc.ec.europa.eu/dataset/53473144-b88c-44bc-b4a3-4583ed1f547e. 
As expected, differences in the patterns of decline of urban systems are correlated with overall population change (Figure 4.9). East Asia and Europe have been hit the hardest by population loss in metropolitan areas due to demographic trends and internal migration as well as emigration to other countries. Countries such as Estonia, Romania and Serbia have experienced population loss in nearly all of their metropolitan areas. Yet, many metropolitan areas decline even in countries that have overall population growth, for example in France, Germany, Italy, Korea and Spain. Likewise, numerous Latin American and East Asian countries have experienced similar patterns of population loss in metropolitan areas alongside slow to moderate overall population growth.

Figure 4.9. Share of declining metropolitan areas relative to national population growth, 2000-15

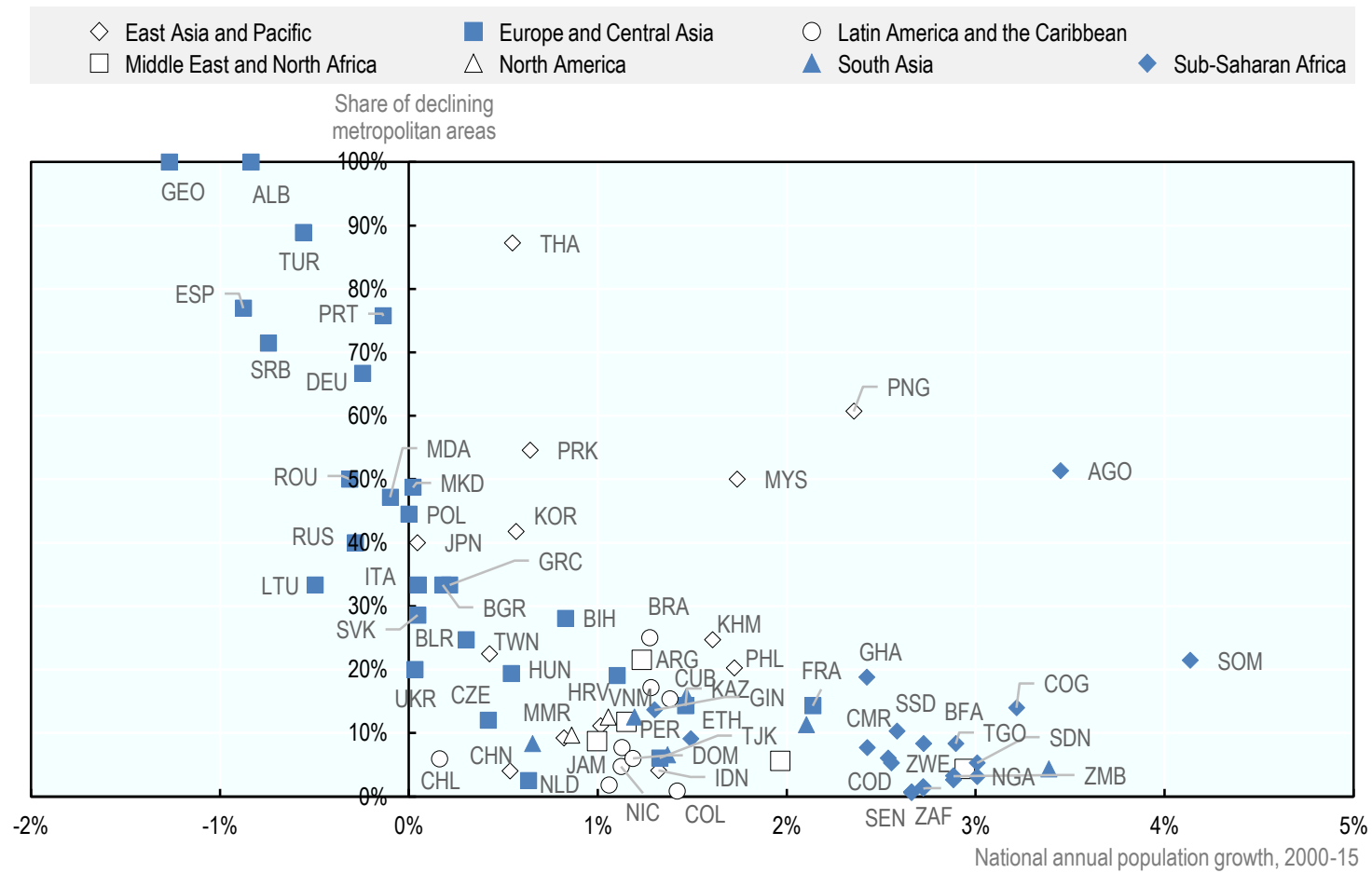

Note: This figure shows the relationship between national annual population growth over the period from 2000 to 2015 and the total share of declining metropolitan areas over the same period. The calculations include metropolitan areas that had an urban centre in 2000 . Countries with less than five metropolitan areas are excluded from the figure.

Source: OECD calculations based on the Urban Centre Database GHS-UCDB R2019A, Florczyk, A. et al. (2019[2]), GHS Urban Centre Database 2015, Multitemporal and Multidimensional Attributes, R2019A, https://data.jrc.ec.europa.eu/dataset/53473144-b88c-44bc-b4a34583ed1f547e.

\section{Metropolitan areas with less than 1 million inhabitants are the most likely to decline}

Whereas capital metropolitan areas, as well as larger metropolitan areas in general, have an advantage in attracting populations, smaller metropolitan areas are at risk of shrinking. With the exception of the Americas, metropolitan areas with less than 1 million inhabitants are at a much higher risk of shrinkage than larger ones (Figure 4.10). Yet, even large metropolitan areas in East Asia and Europe are at risk. The share of declining small- and medium-sized metropolitan areas is roughly the same in East Asia and Europe (36\% on average). Surprisingly, the share of declining large metropolitan areas is also similarly high (around $27 \%$ ) across those two world regions. Only very large metropolitan areas are shielded from 
the risk of population decline. Just two metropolitan areas with over 5 million inhabitants experienced decline: Chongqing in China and the Ruhr region in Germany (Restrepo Cadavid et al., 2017[11]).

Figure 4.10. Share of declining metropolitan areas by size and world region, 2000-15

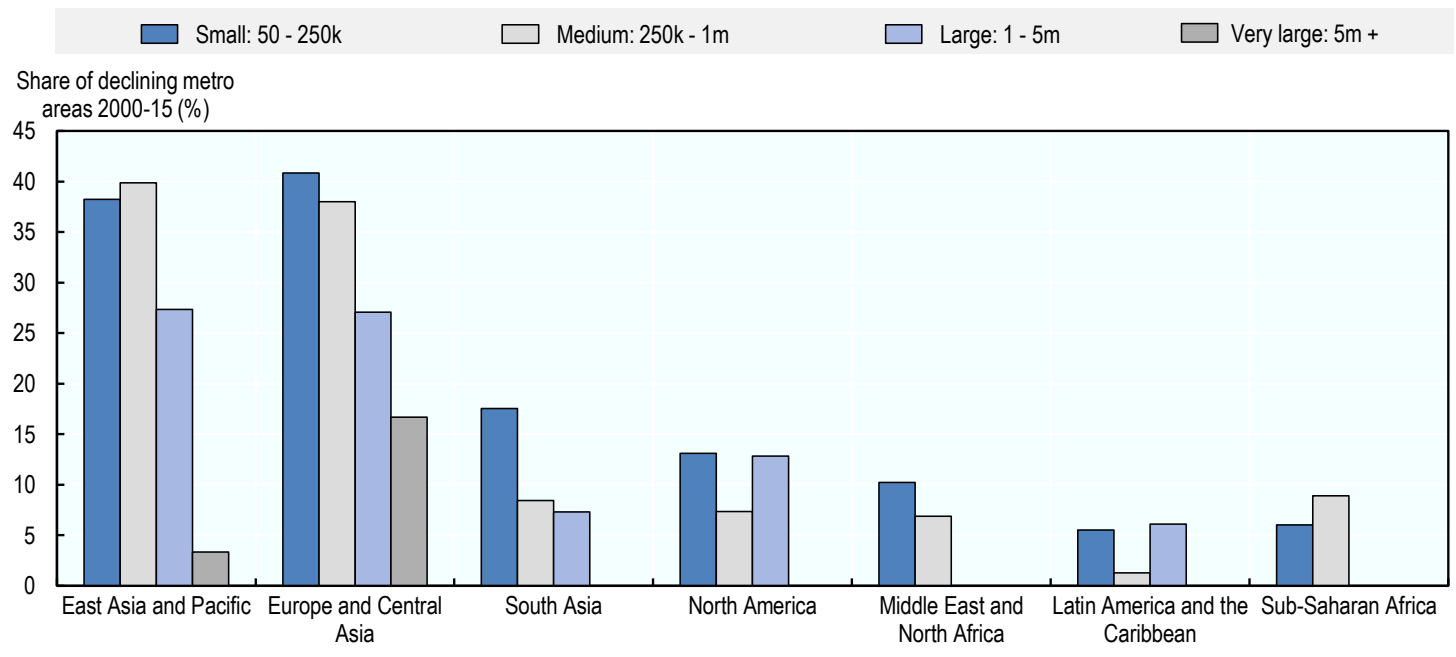

Note: This figure shows the share of metropolitan areas in each region, by population size, with negative population growth between 2000 and 2015. Metropolitan areas with no urban centre in 2000 are excluded from the calculations. Populations in 2000 and 2015 are defined as the total population within the extent of the 2015 border.

Source: OECD calculations based on the Urban Centre Database GHS-UCDB R2019A, Florczyk, A. et al. (2019[2]), GHS Urban Centre Database 2015, Multitemporal and Multidimensional Attributes, R2019A, https://data.jrc.ec.europa.eu/dataset/53473144-b88c-44bc-b4a34583ed1f547e.

\section{Box 4.3. Policy options for managing smart decline}

Managing urban decline takes place at both the local and national levels and must be carried out through a participative process between businesses, property owners, residents and different levels of government. Below is a list of recent policy options that countries have taken to manage their declines.

- Adapting land use. Metropolitan areas in the United States are adapting to population decline through adaptive land-use planning. In an effort to minimise property vacancy and urban blight, cities such as Flint, Michigan and Youngstown, Ohio, have focused public investment in providing services in high density neighbourhoods while converting vacant areas into green space. By providing more green space, these metropolitan areas have made the urban environment more liveable, stemming the tide of urban decline. In addition, Flint has established a land bank meant to ease the metropolitan area's ability to acquire vacant land and manage its usage. Rather than allowing for land speculation, the land bank combines vacant properties to be resold to developers.

- Finding new angles to increase metropolitan area competitiveness. Many declining metropolitan areas have tried to reorient their economic base by focusing on emerging economic sectors, such as technology, creative industries and/or tourism. A successful reorientation of the local economy can give declining cities new opportunities to manage decline in a smart way, even though it might not be sufficient to revert population decline altogether. One successful example of this approach is Bilbao, Spain. Bilbao had to make an enormous effort to transform its economic base, which had been suffering since the 1980 s with the decline 
of the steel and heavy metal industries. A dedicated agency, Bilbao Metropoli 30, was created to implement the strategic development plan for the metropolitan area that aimed for a serviceoriented economic base. One of the most well-known symbols under this development plan was the construction of the Guggenheim Museum. Under the plan, the metropolitan area also invested in the regeneration of old factories, such as converting them into art centres, and supported the development of complementary tourism infrastructure, technology parks and cluster associations to boost the consolidation of creative industries (e.g. information and communication technology [ICT] cluster, design and furniture).

- Revitalising inner metropolitan areas through private-public partnerships. Pittsburgh, United States, also faced decline and suburbanisation, with the inner metropolitan area suffering from population loss, segregation and poverty while the broader metropolitan region gained population. In the beginning of the 1980s, the metropolitan area switched its strategy towards a diversified economic foundation through services with an emphasis on higher education (using Carnegie Mellon University as a magnet) and healthcare.

Source: Cadavid, P. et al. (2017[12]), Cities in Eastern Europe and Central Asia: A Story of Urban Growth and Decline, http://documents.worldbank.org/curated/en/319131510892209158/Cities-in-Europe-and-Central-Asia-a-shifting-story-of-urban-growthand-decline.

\section{Determinants of metropolitan growth}

While population growth is a good indicator that a metropolitan area is attracting people and economic activity, it is unclear what determines such growth. In fact, metropolitan areas grow for a variety of reasons. Traditionally, the process of urban growth resulted both from push and pull factors. Productivity gains in agriculture reduced employment in rural areas and pushed it towards metropolitan areas. The rise of industrial sectors - for example driven by enhanced international trade - pulled people towards metropolitan areas as those sectors stand to gain from agglomeration economies. In addition to strong economic incentives, metropolitan areas provide access to numerous amenities that are valued by people that are willing to move there, including favourable climate, access to healthcare, public transportation, education and cultural opportunities (see Chapter 2). Some metropolitan areas also grow because the regulatory environment is more favourable to urban expansion than in other metropolitan areas within the same country.

While national population growth or decline strongly affects the growth of metropolitan areas, there remains substantial dispersion in growth rates within countries. The majority of countries have a measure of dispersion (the standard deviation) in metropolitan area growth rates of just below $1 \%$. While this does not sound much, it is important to consider that in many countries, average population growth rates are well below 1\% (Figure 4.11). Thus, the average dispersion in growth rates is just as high as the average growth rate. This is especially true in the EU and OECD, where most countries recorded low total population growth and small differences in the growth rate of metropolitan areas. ${ }^{4}$ Countries with faster population growth tend to have less uniform growth across metropolitan areas, especially in Sub-Saharan Africa. Countries with a very high dispersion in growth rates (above $2 \%$ ) tend to be affected by either protracted civil conflict or recent natural disasters including the Democratic Republic of the Congo, Myanmar, Nepal and South Sudan. The following subsections examine key factors that enhance or inhibit the growth of metropolitan areas. 
Figure 4.11. Relationship between dispersion in metropolitan area growth rates and national population growth, 2000-15

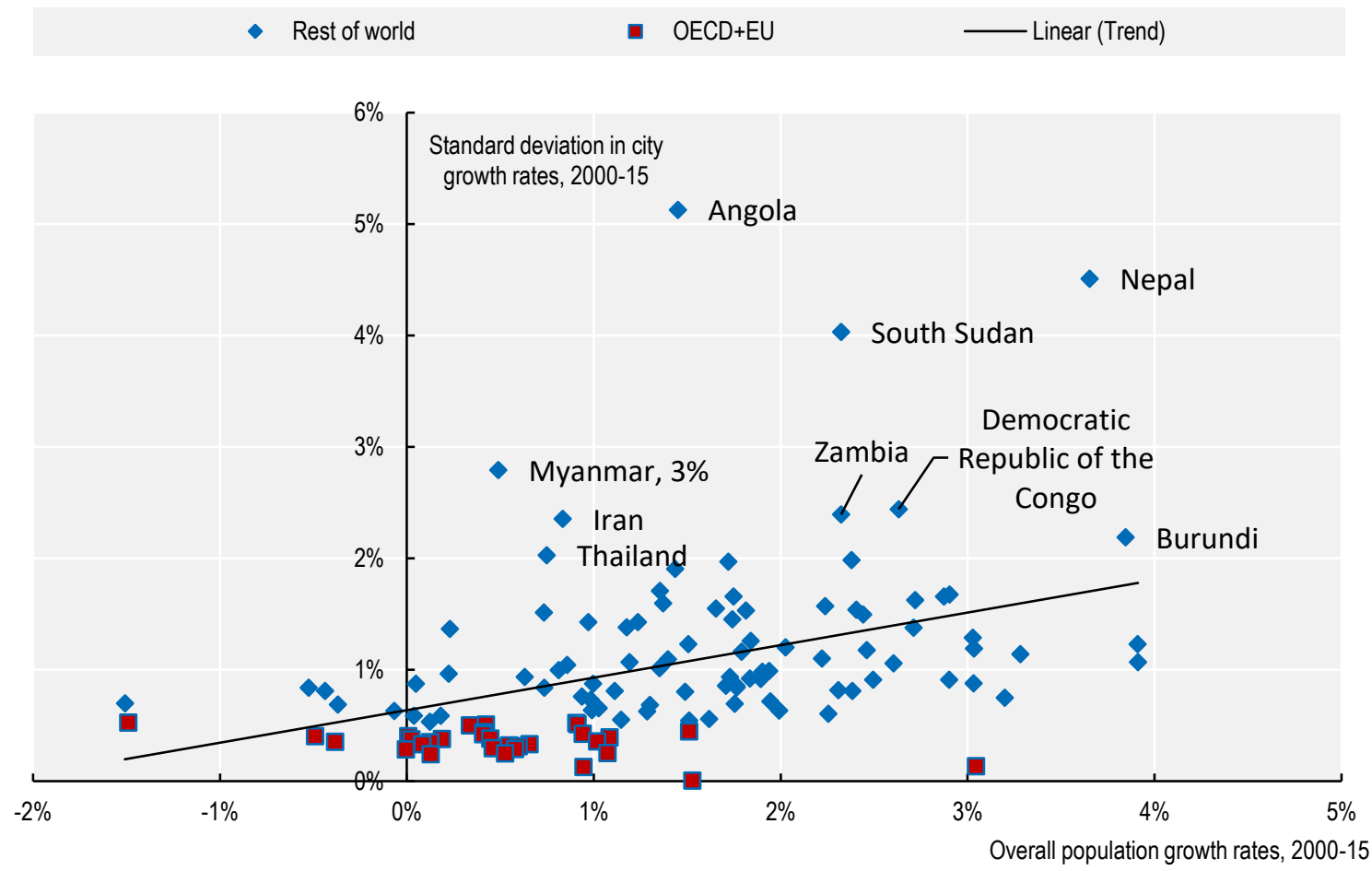

Note: This figure shows the standard deviation in metropolitan area growth rates by country. The sample in this figure consists of countries with at least four metropolitan areas in 2000. Metropolitan areas with no urban centre in 2000 are excluded from the calculations.

Source: OECD calculations based on the Urban Centre Database GHS-UCDB R2019A, Florczyk, A. et al. (2019[2]), GHS Urban Centre Database 2015, Multitemporal and Multidimensional Attributes, R2019A, https://data.jrc.ec.europa.eu/dataset/53473144-b88c-44bc-b4a34583ed1f547e.

\section{Administrative status of metropolitan areas}

In over $80 \%$ of countries in the world, capitals are the largest metropolitan area in the country and are roughly twice as large as the largest non-capital metropolitan area, on average. The world region with the largest capital metropolitan areas relative to the largest non-capital metropolitan area is Latin America and the Caribbean, followed by Sub-Saharan Africa and East Asia. In around 20 countries, capitals outsize the largest non-capital metropolitan area eightfold or more (Figure 4.13). ${ }^{5}$

Capitals grew faster between 2000 and 2015 in all world regions except for within the OECD. Capital metropolitan areas grew 0.8 percentage points faster annually, even after taking into account the fact that they are larger than other metropolitan areas. While it has been shown previously that capital metropolitan areas are larger globally, it is unclear why they continue to grow faster even after controlling for size. The largest growth premium in capital metropolitan areas exists in Sub-Saharan Africa and South Asia where capitals grow 1.7 percentage points faster annually (Figure 4.12).

Capital metropolitan areas tend to be much larger than the rest of the metropolitan areas in a country for a number of reasons. First, capital metropolitan areas provide access to jobs or amenities that are not available in other metropolitan areas. The government and numerous agencies and organisations that locate in the capital metropolitan area, such as international organisations, media and lobby groups, generate well-paid jobs. In addition, these workers bring their families along with an increased demand for services and amenities, including schools and restaurants. 
Figure 4.12. Capitals grow faster than the national population in most world regions

Annual population growth rate, $2000-15$

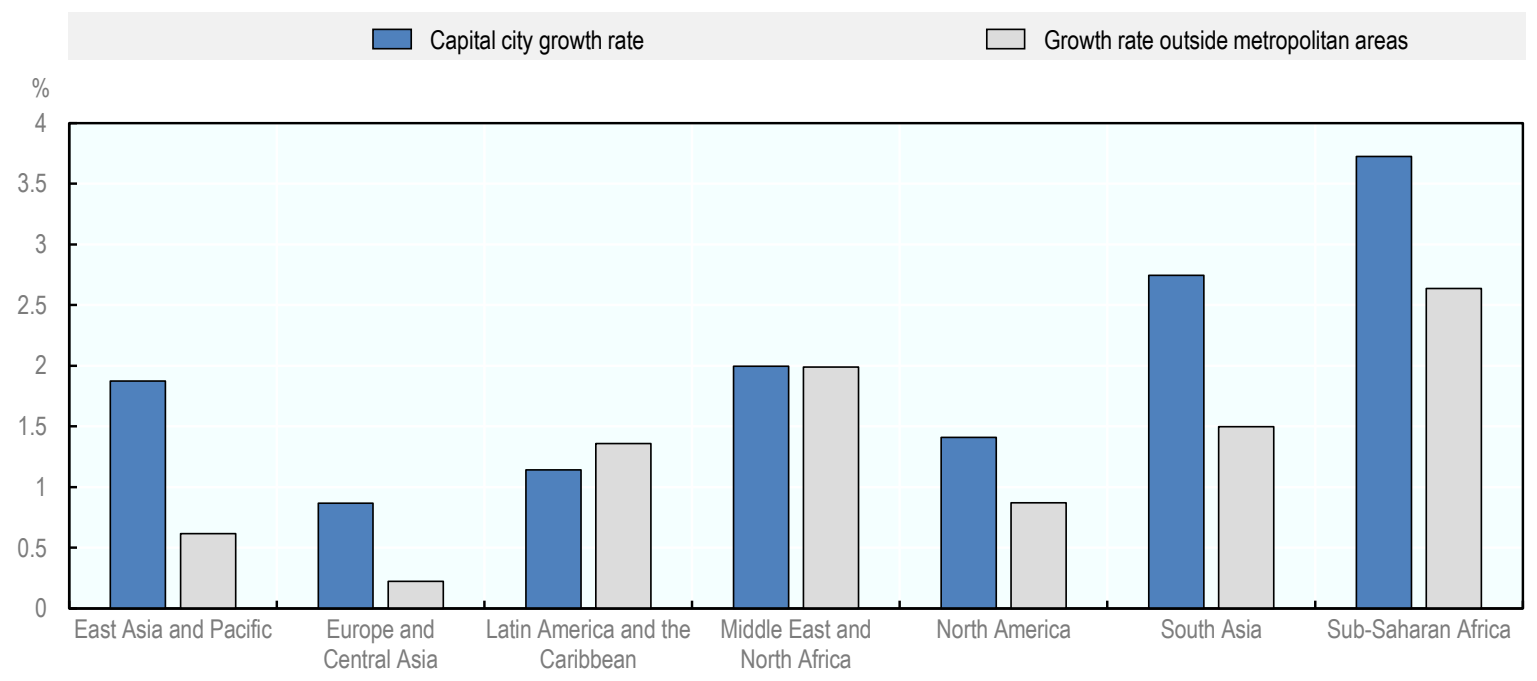

Note: This figure shows the average population growth in capital metropolitan areas and national population growth between 2000 and 2015. The growth rates are averaged at the level of world regions.

Source: OECD calculations based on the Urban Centre Database GHS-UCDB R2019A, Florczyk, A. et al. (2019[2]), GHS Urban Centre Database 2015, Multitemporal and Multidimensional Attributes, R2019A, https://data.jrc.ec.europa.eu/dataset/53473144-b88c-44bc-b4a34583ed1f547e.

Political institutions offer another explanation for the primacy of capitals. The size advantage that capitals enjoy is particularly large in non-democratic or more centralised countries, such as in certain parts of Africa or in centralised Western democracies. In autocratic regimes, where rent-seeking is especially strong, a large capital metropolitan area provides leaders with a political base where rents can be distributed easily (Ades and Glaeser, 1995[13]). This concentration further encourages people to move to the capital to take advantage of these rents. ${ }^{6}$ In democratic countries, demands from other regions lead to a more equitable distribution of resources, thus diminishing the primacy of the capital metropolitan area (Karayalcin and Ulubasoglu, 2020[14] $)$. This finding is also confirmed by the new data on and global definition of metropolitan areas used in this report.

Evidence from OECD countries suggests that - even in democratic countries - more centralised governments tend to have larger capitals relative to federal countries (OECD, $2015_{[15]}$ ). Figure 4.13 shows that unitary countries tend to have capitals with a larger population relative to other metropolitan areas in the same country, compared to federal countries (lighter bars). This pattern is true also when controlling for country size. ${ }^{7}$ While it could be that federal countries place their capitals in smaller cities, the pattern is consistent with the explanation that capitals that host more powerful governments tend to become larger. 
Figure 4.13. Ratio of the population of the capital metropolitan area of a country relative to the largest non-capital metropolitan area

Federal countries are depicted in a lighter shade and non-federal countries are depicted in a darker shade
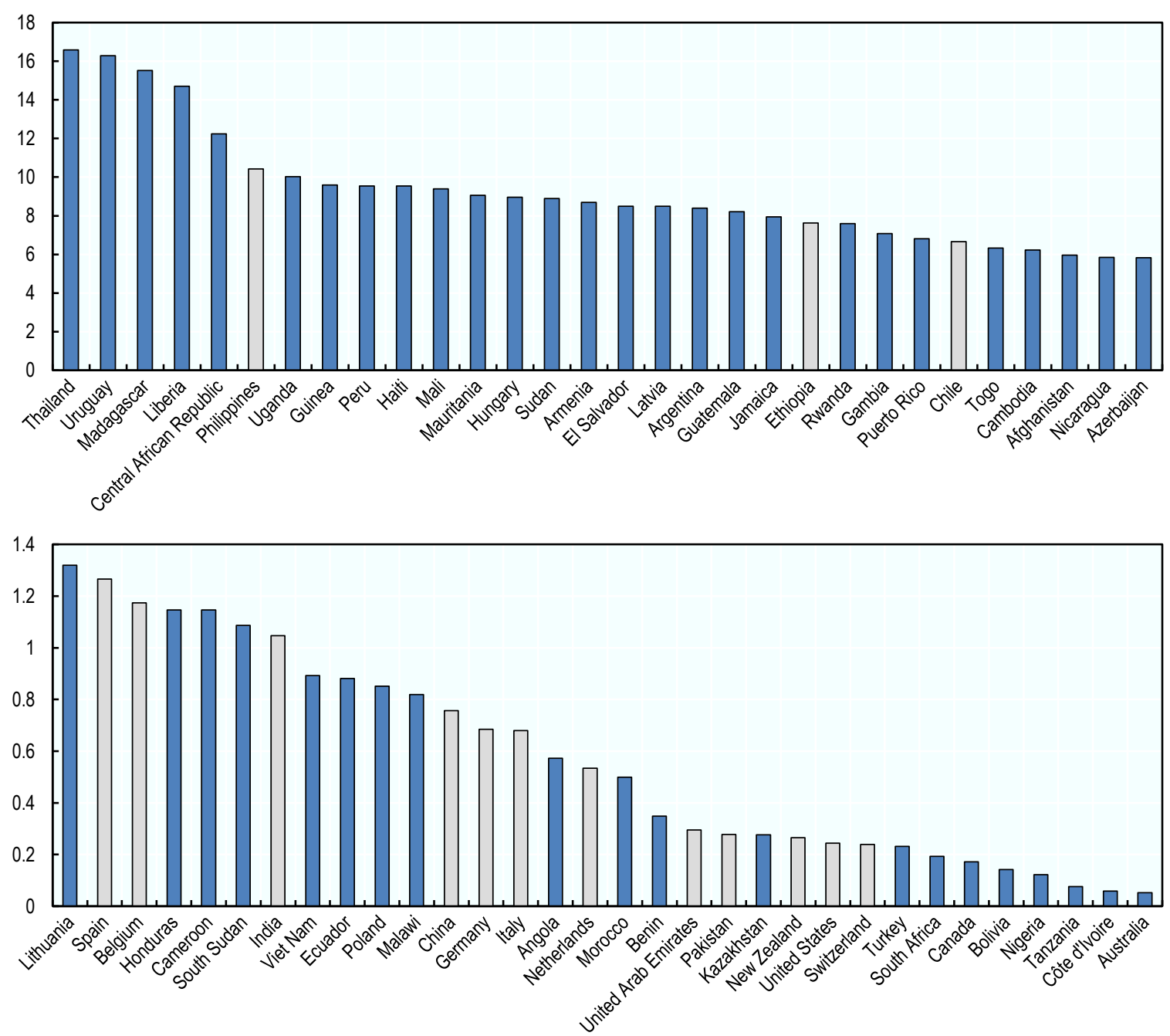

Note: This figure shows the population of the capital city divided by the population of the largest non-capital city. In some cases, capital cities are more than 16 times as large as the largest non-capital city in the country. Federal countries are shown in a lighter shade.

Source: OECD calculations based on the Urban Centre Database GHS-UCDB R2019A, Florczyk, A. et al. (2019[2]), GHS Urban Centre Database 2015, Multitemporal and Multidimensional Attributes, R2019A, https://data.jrc.ec.europa.eu/dataset/53473144-b88c-44bc-b4a34583ed1f547e.

\section{Impact of trade and market connectivity on size and growth}

Besides national demographics and administrative status, location is one of the primary determinants of the size of metropolitan areas. The location of a metropolitan area determines numerous factors that have affected population growth and economic development throughout history. Yet, the role of traditional factors of location is most likely declining. As a result of technological and economic change, the interaction between location and the success of a metropolitan area has evolved. Over time, changes in the cost of transportation, technology and how goods are traded changed the attractiveness of a given location. For example, as trade costs decline, food can be imported from greater distances, which lowers the importance of proximity to productive land, water resources and other geographic features. Recent evidence at the 
global level finds that the suitability of a region for agriculture as a determinant of economic activity has declined over time while the importance of its suitability for engaging in international trade has grown (Henderson et al., 2018[16]).

Globally, access to maritime and naval trade boost metropolitan area population size as both coastal metropolitan areas and metropolitan areas located on navigable rivers are larger than comparable metropolitan areas elsewhere (Annex Table 4.A.1 in Annex 4.A). Coastal locations provide potential economic opportunities associated with shipping and tourism, as well as higher quality of life. Even today, shipping continues to be the primary means through which countries send their products to customers overseas, as air transport remains too expensive for the majority of goods. Thus, proximity to ports provides a relative advantage for metropolitan areas by reducing the transport costs associated with exporting goods. Consequently, in most parts of the world, coastal metropolitan areas are on average $20 \%$ larger than metropolitan areas located in the interior. In Sub-Saharan Africa and South Asia in particular, coastal metropolitan areas are $30 \%$ larger, even after controlling for other characteristics including whether the metropolitan area is a capital. In the EU and OECD, coastal metropolitan areas have a smaller size advantage and the difference between coastal and inland metropolitan areas is only weakly significant.

Metropolitan areas located on navigable rivers are larger across the globe, especially in the EU and OECD. Historically, roads and railways were not widely available and goods were transported by water or overland. As a result, metropolitan areas were built along waterways when possible to facilitate trade. For example, every large metropolitan area in the United States at the beginning of the $20^{\text {th }}$ century was located on a waterway. Unsurprisingly, the largest impacts of being close to a river were found in world regions and countries with large river systems. In Argentina, Brazil, Egypt and Venezuela for example, metropolitan areas located on rivers are $30 \%$ to $100 \%$ larger than other metropolitan areas in the respective country.

While being located on a coast and navigable river are strong determinants of metropolitan area size, their impacts on recent population growth are mixed (Annex Table 4.A.2 in Annex 4.A). Being located on the coast is associated with metropolitan area growth in some world regions but correlated with a decline in others. Coastal metropolitan areas are growing in world regions undergoing urban change and structural transformation. In contrast, threats posed by climate change and globalisation have constrained the growth of coastal metropolitan areas in other world regions.

In recent decades, the decline in transport and communication costs has led to an expansion of international trade and globalisation. As a result, coastal metropolitan areas in Africa, Latin America and the Middle East benefit from easier access to trade routes where transport conditions are more favourable to growth. For example, coastal metropolitan areas in Africa and the Middle East grew a half of a percentage point faster per year between 2000 and 2015. However, in world regions where coastal metropolitan areas are prone to natural disasters and where there has been industrial decline, being on the coast is correlated with slower growth. For example, the slowest growing coastal metropolitan areas in India and the United States are located in areas that have been hit by large natural disasters in the past two decades. Metropolitan areas such as Biloxi and New Orleans were amongst the slowest growing metropolitan areas in the United States between 2000 and 2015, while numerous Indian metropolitan areas along the coast of Andhra Pradesh and Tamil Nadu had negative growth in places that have been affected by cyclones. Further, metropolitan areas on navigable rivers are growing considerably slower than other metropolitan areas, especially in Africa, North America and South Asia.

Market potential, as measured by the number of people living within a certain radius around a metropolitan area, affects metropolitan area growth across the globe. ${ }^{8}$ Surprisingly, metropolitan areas that have a large number of people living within a certain radius grew slower globally than those that had fewer people living nearby. This result probably illustrates the trade-off of having more metropolitan areas nearby. More neighbours can act as competitors that can attract away both customers and human capital. 


\section{References}

Ades, A. and E. Glaeser (1995), "Trade and circuses: Explaining urban giants", The Quarterly Journal of Economics, Vol. 110/1, pp. 195-227, https://academic.oup.com/qie/articleabstract/110/1/195/1893966.

Cadavid, P. et al. (2017), Cities in Eastern Europe and Central Asia: A Story of Urban Growth and Decline, World Bank, http://documents.worldbank.org/curated/en/319131510892209158/Cities-in-Europe-andCentral-Asia-a-shifting-story-of-urban-growth-and-decline.

Christiaensen, L., J. De Weerdt and R. Kanbur (2016), "Urbanization and poverty reduction: The role of secondary towns in Tanzania", IOB Analyses \& Policy Briefs.

Christiaensen, L. and R. Kanbur (2017), "Secondary towns and poverty reduction: Refocusing the urbanization agenda", Annual Review of Resource Economics, http://dx.doi.org/10.1146/annurev-resource-100516-053453.

Florczyk, A. et al. (2019), GHS Urban Centre Database 2015, Multitemporal and Multidimensional Attributes, R2019A, Joint Research Centre (JRC), European Commission, https://data.jrc.ec.europa.eu/dataset/53473144-b88c-44bc-b4a3-4583ed1f547e.

Gibson, J. et al. (2017), "For India's rural poor, growing towns matter more than growing cities", World Development, http://dx.doi.org/10.1016/j.worlddev.2017.05.014.

Henderson, J. et al. (2018), "The global distribution of economic activity: Nature, history, and the role of trade", Quarterly Journal of Economics, Vol. 133/1, pp. 357-406, http://dx.doi.org/10.1093/qje/qjx030.

Henderson, J. and H. Wang (2007), "Urbanization and city growth: The role of institutions", Regional Science and Urban Economics, Vol. 37/3, pp. 283-313, https://doi.org/10.1016/j.regsciurbeco.2006.11.008 (accessed on 14 August 2019).

Henderson, V. et al. (2019), Urbanisation and Demographic and Health Outcomes: Perspectives from a New Classification of Urban Areas.

ICF (2016), Demographic and Health Surveys (various datasets).

Jedwab, R., L. Christiaensen and M. Gindelsky (2017), "Demography, urbanization and development: Rural push, urban pull and ... urban push?", Journal of Urban Economics, http://dx.doi.org/10.1016/j.jue.2015.09.002.

Jones, B. et al. (forthcoming), Projecting Global Population Grids to 2100, Publications Office of the European Union.

Karayalcin, C. and M. Ulubasoglu (2020), "Romes without empires: Urban concentration, political competition, and economic growth", European Journal of Political Economy, Vol. 63, https://doi.org/10.1016/i.ejpoleco.2020.101870 (accessed on 14 August 2019).

Moreno-Monroy, A., M. Schiavina and P. Veneri (2020), "Metropolitan areas in the world: Delineation and population trends", Journal of Urban Economics, https://doi.org/10.1016/j.jue.2020.103242. 
OECD (2015), The Metropolitan Century: Understanding Urbanisation and its Consequences, OECD Publishing, Paris, https://dx.doi.org/10.1787/9789264228733-en.

OECD/SWAC (2020), Africa's Urbanisation Dynamics 2020: Africapolis, Mapping a New Urban Geography, West African Studies, OECD Publishing, Paris, https://dx.doi.org/10.1787/b6bccb81-en.

Ravallion, M. (2002), "On the urbanization of poverty", Journal of Development Economics, Vol. 68/2, pp. 435-442, https://doi.org/10.1016/S0304-3878(02)00021-4.

Ravallion, M., S. Chen and P. Sangraula (2007), "New evidence on the urbanization of global poverty", Population and Development Review, Vol. 33/4, pp. 667-701, https://doi.org/10.1111/j.1728-4457.2007.00193.x.

Restrepo Cadavid, P. et al. (2017), Cities in Europe and Central Asia: A Shifting Story of Urban Growth and Decline, http://hdl.handle.net/10986/28972 (accessed on 14 August 2019).

\section{Notes}

${ }^{1}$ Cities and metropolitan areas in Sub-Saharan Africa are projected to grow the fastest compared to other world regions until 2050 (Jones et al., forthcoming ${ }_{[18]}$ ). Most African cities have grown and will continue to grow further beyond their administrative boundaries, which highlights the need to use a spatial, grid-based definition such as the metropolitan area to fully understand their evolution (OECD/SWAC, 2020 $[17])$.

2 The replacement rate is 2.1 children born per woman. A cohort fertility rate of 2.1 would ensure the replacement of the previous generation and therefore population stability, under assumptions of no immigration and of no change in mortality rates.

${ }^{3}$ For several decades, Western Europe has attracted a significant number of migrants from Central and Eastern Europe.

${ }^{4}$ Only three OECD countries have a standard deviation in the growth rate of metropolitan areas above 1\%: Chile, South Korea and Turkey.

${ }^{5}$ To analyse the determinants of metropolitan growth in recent decades, metropolitan population growth rates between 2000 and 2015 are regressed on a geographic characteristic that measure the suitability of metros for living, engaging in domestic and foreign trade, and proximity to productive agricultural land. In addition, a measure of initial market potential is included to understand how access and proximity to surrounding urban agglomerations promotes or restricts metropolitan growth. The variables include measures of ruggedness, an index of malaria stability, proximity to the coast and large rivers, rainfall, precipitation, land suitability for agriculture and soil biome type. Country-fixed effects are included so that the results capture comparisons of the impact of geographical variation and market potential on metropolitan growth within the same country.

${ }^{6}$ See Henderson and Wang $\left(2007_{[19]}\right)$ for further discussion on the role of institutions in metropolitan growth. 
${ }^{7}$ To analyse the impacts of political system on capital city size, the ratio of the capital city size to the next largest city is regressed on an indicator variable that equals 1 if the country is federal. Controls include the total population of the country and regional dummies.

${ }^{8}$ Market potential used in this analysis is defined by summing the total population within a five-hour driving distance from the centre of the metropolitan area. The own population of the metropolitan area is excluded from the calculation. 


\section{Annex 4.A. Regression tables}

\section{Annex Table 4.A.1. Regression results on the determinants of metropolitan area size in 2015}

Dependent variable is Log(Population in 2015)

\begin{tabular}{|c|c|c|}
\hline & (1) & (2) \\
\hline & $\mathrm{EU}+\mathrm{OECD}$ & Rest of world \\
\hline \multirow[t]{2}{*}{ Capital } & $2.268^{* * *}$ & $2.374^{* * *}$ \\
\hline & $(0.182)$ & $(0.122)$ \\
\hline \multirow[t]{2}{*}{ Log(TT capital) } & $-0.314^{*}$ & $-0.285^{* *}$ \\
\hline & $(0.155)$ & $(0.143)$ \\
\hline \multirow[t]{2}{*}{ Malaria } & $0.244^{* * *}$ & 0.005 \\
\hline & $(0.042)$ & $(0.008)$ \\
\hline \multirow[t]{2}{*}{ Ruggedness } & 0.075 & $-0.214^{* * *}$ \\
\hline & $(0.063)$ & $(0.063)$ \\
\hline \multirow[t]{2}{*}{ Coast $<25 k$} & 0.094 & $0.279^{* * *}$ \\
\hline & $(0.100)$ & $(0.062)$ \\
\hline \multirow[t]{2}{*}{ Log(Coast dist.) } & -0.099 & -0.154 \\
\hline & $(0.189)$ & $(0.184)$ \\
\hline \multirow[t]{2}{*}{ Lake<25k } & 0.148 & $-0.303^{* *}$ \\
\hline & $(0.372)$ & $(0.149)$ \\
\hline \multirow[t]{2}{*}{ River $<25 \mathrm{k}$} & $0.278^{* *}$ & $0.269^{* *+*}$ \\
\hline & $(0.113)$ & $(0.069)$ \\
\hline \multirow[t]{2}{*}{ Harbor $<25 k$} & 0.027 & $0.339^{* *}$ \\
\hline & $(0.107)$ & $(0.137)$ \\
\hline \multirow[t]{2}{*}{ Temp. } & $0.151^{* * *}$ & 0.029 \\
\hline & $(0.041)$ & $(0.028)$ \\
\hline \multirow[t]{2}{*}{ Temp. sq. } & $-0.005^{*+* x}$ & -0.001 \\
\hline & $(0.001)$ & $(0.001)$ \\
\hline \multirow[t]{2}{*}{ Precipitation } & -0.266 & $0.122^{*}$ \\
\hline & $(0.195)$ & $(0.063)$ \\
\hline \multirow[t]{2}{*}{ Growing days } & $0.209^{* *}$ & -0.099 \\
\hline & $(0.084)$ & $(0.115)$ \\
\hline \multirow[t]{2}{*}{ Land suitability } & 0.008 & $0.300^{* *}$ \\
\hline & $(0.130)$ & $(0.127)$ \\
\hline \multirow[t]{2}{*}{ Min elevation } & -0.219 & $-0.132^{* *}$ \\
\hline & $(0.179)$ & $(0.055)$ \\
\hline Country fixed effects & Yes & Yes \\
\hline No. of metropolitan areas & 1340 & 7590 \\
\hline R-squared & 0.279 & 0.222 \\
\hline
\end{tabular}

Note: This table provides estimates of the impact of geographical characteristics on metropolitan area size in 2015, differentiated by EU+OECD and the rest of the world. The dependent variable is the log of the metropolitan area population in 2015. The controls included but not shown are indicators for the biome (natural vegetation expected in an area, based on research by biologists). Standard errors in parentheses are clustered at the country level. Asterisks denote the statistical significance level: ${ }^{*} p<0.1,{ }^{* *} p<0.05,{ }^{* * *} p<0.01$.

Source: OECD calculations based on the Urban Centre Database GHS-UCDB R2019A, Florczyk, A. et al. (2019[2]), GHS Urban Centre Database 2015, Multitemporal and Multidimensional Attributes, R2019A, https://data.jrc.ec.europa.eu/dataset/53473144-b88c-44bc-b4a3$\underline{4583 e d 1 f 547 \text { e. }}$ 
Annex Table 4.A.2. Regression results on the determinants of metropolitan area growth between 2000 and 2015

Dependent variable: Annual population growth 2000-15

\begin{tabular}{|c|c|c|}
\hline & (1) & $(2)$ \\
\hline & $\mathrm{EU}+\mathrm{OECD}$ & Rest of World \\
\hline \multirow[t]{2}{*}{ Log(Pop. 2000) } & 0.045 & $0.186^{* *}$ \\
\hline & $(0.040)$ & $(0.079)$ \\
\hline \multirow[t]{2}{*}{ Log(Mkt. potential) } & -0.006 & $-0.383^{*+* x}$ \\
\hline & $(0.093)$ & $(0.138)$ \\
\hline \multirow[t]{2}{*}{ Capital } & $0.220^{* *}$ & 0.813 \\
\hline & $(0.089)$ & $(0.497)$ \\
\hline \multirow[t]{2}{*}{ Log(TT capital) } & 0.328 & $-0.607^{* *}$ \\
\hline & $(0.229)$ & $(0.286)$ \\
\hline \multirow[t]{2}{*}{ Malaria } & -0.142 & 0.023 \\
\hline & $(0.121)$ & $(0.030)$ \\
\hline \multirow[t]{2}{*}{ Ruggedness } & 0.060 & -0.149 \\
\hline & $(0.131)$ & $(0.221)$ \\
\hline \multirow[t]{2}{*}{ Coast $<25 \mathrm{k}$} & $-0.212^{* *}$ & 0.084 \\
\hline & $(0.078)$ & $(0.138)$ \\
\hline \multirow[t]{2}{*}{ Log(Coast dist.) } & -0.116 & -0.375 \\
\hline & $(0.252)$ & $(0.398)$ \\
\hline \multirow[t]{2}{*}{ Lake<25k } & $-0.475^{*+*}$ & $0.445^{* *}$ \\
\hline & $(0.084)$ & $(0.194)$ \\
\hline \multirow[t]{2}{*}{ River $<25 \mathrm{k}$} & -0.242 & 0.060 \\
\hline & $(0.156)$ & $(0.164)$ \\
\hline \multirow[t]{2}{*}{ Temp. } & -0.009 & $0.478^{* *}$ \\
\hline & $(0.091)$ & $(0.228)$ \\
\hline \multirow[t]{2}{*}{ Temp. sq. } & 0.030 & 0.070 \\
\hline & $(0.070)$ & $(0.049)$ \\
\hline \multirow[t]{2}{*}{ Precipitation } & 0.002 & -0.001 \\
\hline & $(0.002)$ & $(0.002)$ \\
\hline \multirow[t]{2}{*}{ Growing days } & -0.078 & 0.103 \\
\hline & $(0.117)$ & $(0.266)$ \\
\hline \multirow[t]{2}{*}{ Land suitability } & $-0.279^{*}$ & -0.149 \\
\hline & $(0.140)$ & $(0.217)$ \\
\hline \multirow[t]{2}{*}{ Min elevation } & 0.027 & 0.175 \\
\hline & $(0.137)$ & $(0.252)$ \\
\hline Country FE & $0.536^{* * *}$ & 0.203 \\
\hline No. of metropolitan areas & $(0.093)$ & $(0.200)$ \\
\hline R-squared & 0.263 & 0.558 \\
\hline
\end{tabular}

Note: This table provides estimates of the impact of geographical characteristics on metropolitan area population growth between 2000 and 2015 , differentiated by global macro-region. The dependent variable is the annual metropolitan area population growth from 2000 to 2015 . The controls included but not shown are indicators for the biome (natural vegetation expected in an area, based on research by biologists). Standard errors in parentheses are clustered at the country level. Asterisks denote the statistical significance level: ${ }^{*} p<0.1,{ }^{* *} p<0.05,{ }^{* * *} p<0.01$.

Source: OECD calculations based on the Urban Centre Database GHS-UCDB R2019A, Florczyk, A. et al. (2019[2]), GHS Urban Centre Database 2015, Multitemporal and Multidimensional Attributes, R2019A, https://data.jrc.ec.europa.eu/dataset/53473144-b88c-44bc-b4a34583ed1f547e. 


\section{The shape of cities and sustainable development}

Using the new global definitions of cities and metropolitan areas, this chapter analyses the changing shape of cities around the world. It examines how densification and expansion of cities affect sustainable development. It sheds light on the extent to which metropolitan areas decentralise, i.e. grow faster in commuting zones than in the city itself. In discussing and analysing these developments, the chapter assesses their impact on urban mobility and people's exposure to pollution, flooding, storms and sea level rise. 


\section{Key messages}

- The population living in cities has more than doubled between 1975 and 2015. This increase led to a doubling of the number of cities, an expansion of existing cities and the densification of the original cities. Because cities expanded less quickly in area than in population, city densities went up, especially in large cities (1 million inhabitants or more). Small cities (less than 250000 inhabitants) were the exception where densities dropped over time.

- In virtually all growing metropolitan areas, the population in the commuting zone grows faster. Even in shrinking metropolitan areas, commuting zones either still grow or shrink less quickly than the city, leading to a smaller and more dispersed metropolitan population.

- Rapidly growing cities, especially in low-income countries, have struggled to keep up construction with population growth. As a result, one in four low-income cities has a low and shrinking level of capital stock per person; in other words, they became more crowded and underdeveloped. At the other extreme, two out of five cities in high-income countries had a high and growing capital stock per person, which is expensive. This indicates that many cities in poor countries are faced with underinvestment, while certain cities in rich countries may face heavy investments largely to compensate for a more dispersed population structure.

- Access to public transport differs widely between cities. Many European cities provide access to frequent public transport to a large share of their population. Other cities provide mostly access to low-frequency departures, for example in North America. Some low-income cities do provide high-frequency access but only to a small share of the population, as is the case in some African cities.

- Low-density cities need to spend more on road infrastructure and public transport to offer the same level of service. Especially the shift from moderate to low density leads to a big increase in costs, while shifts between high and moderate levels of density have less of an impact.

- Cities are more polluted than less densely populated areas. Large and low-income cities tend to have particularly high levels of air pollution, such as fine particulate matter (PM 2.5). Unsurprisingly, people living in cities are less satisfied with air quality than those living in towns and semi-dense areas or rural areas. This also the case in high-income countries, where pollution levels tend to be lower.

- Cities are exposed to floods, storms and sea level rise. One in five city residents is exposed to a 100 -year flood. Over 600 cities risk being fully inundated by a 100 -year flood. City population in low elevation coastal zones has been growing faster than the city population in other zones. As a result, $14 \%$ of the city population lives in zones that are vulnerable to storm surges and rising sea levels. Of the population in towns and semi-dense areas, $10 \%$ is exposed and $6 \%$ of the rural population.

\section{Introduction}

The shape of cities and their impact on sustainable development is heavily scrutinised and debated (see for example OECD $\left(2018_{[1]}\right)$ ). Cities have a somewhat paradoxical relationship with environmental sustainability. On the one hand, cities allow people to lead lives which pollute relatively little, for example, by facilitating walking, cycling and efficient public transport. In cities, people also tend to live in smaller dwellings, which require less energy to heat and cool (see for example Owen (2009[2])). On the other hand, city dwellers are often exposed to high levels of pollution through fine particle matter (PM 2.5) or nitrogen dioxide (NO2). ${ }^{1}$ 
Concerns that a lower-density and thus more spread-out city would lead to worse environmental outcomes have led to many national and local policies trying to limit the spatial expansion of cities and maintaining or even increasing population density, even in countries where densities were already high. In the past, the lack of a global definition of a city made it difficult to reliably compare cities. The population density was notoriously difficult to compare because it is so sensitive to where the boundary of a city is drawn. This may explain why a lot of literature focused more on the changes over time than density levels.

This report uses that new definition to compare population density levels, before assessing how it has changed over time. It does the same with the amount of land dedicated to buildings and infrastructure. Instead of recommending densification and limiting all costs, this report identifies different priorities from building more - to accommodate a rapidly growing population - to building less and promoting the more efficient use of what has already been built. City and neighbourhood density have a big impact on the cost of public transport provision and how many residents can easily access it. Thus, the report makes recommendations ranging from expanding public transport networks to encouraging high densities close to public transport.

This chapter explores city densities and how they have changed over time. Subsequently, it takes a metropolitan view to look at population changes in the commuting zones and the city. Next, it describes how the shape of a city influences its need for investments in buildings, roads and public transport networks. It concludes by highlighting cities' exposure to pollution, flooding and storms.

\section{City densification and expansion}

\section{Cities densities differ by income level and world region}

In general, the higher the income of a country, the lower the densities of its cities. As seen in Chapter 1, cities in low-income countries have the highest densities, close to 10000 inhabitants per $\mathrm{km}^{2}$, compared to 7200 in lower-middle-income countries, 5300 in upper-middle-income and only 2800 in high-income countries. As a result, cities in low-income countries are almost four times denser than the cities in highincome countries. These averages hide many exceptions, for example, Santiago in Chile, Seoul and Singapore have densities of at least 7500 inhabitants per $\mathrm{km}^{2}$ but they are also in high-income countries.

City density does not only vary by income but also by region (Figure 5.1). In North America, cities have a density of 1700 inhabitants per $\mathrm{km}^{2}$, compared to close to 4000 in Central Asia and Europe, 5000 in East Asia and the Pacific, 6000 in North Africa, Latin America and the Caribbean, and the Middle East and 8000 in Sub-Saharan Africa and South Asia. As a consequence, for a given population size, a city in North America will be four times bigger in area than in Sub-Saharan Africa or South Asia and twice as big as a city in Europe and Central Asia.

On average, the larger the city, the denser it is (Figure 5.2). This density gradient is clearly visible in highand upper-middle-income countries and to a lesser degree in lower-middle-income countries. In low-income countries, however, this gradient is absent: cities in the four size groups are all very dense. The high density of cities in low-income countries may be due to a combination of small dwellings and a high share of trips done on foot, as well as to public policies limiting the expansion of cities. The differences in density between the income groups are so big that it offsets the effect of city size. For example, a small city in a low-income country is more than twice as dense as a very large city in a high-income country.

\section{Cities are becoming denser, except for the small ones}

The comparison of city density and income for one point in time suggests that as income goes up, city density should drop and the density in small cities should drop faster. Globally, however, city densities have increased not dropped. This is mainly driven by the increasing density of the large and very large 
cities, which increased in all four income groups (Figure 5.2). Densities in large cities increased more in low- and middle-income countries than in high-income countries. In contrast, small cities did see a reduction in density and this reduction was much bigger in low- and middle-income countries than in highincome countries. This means that over time the difference in densities of (very) large cities between different income groups has been growing, while it has been shrinking for small cities.

\section{Figure 5.1. Population density of cities, 2015}

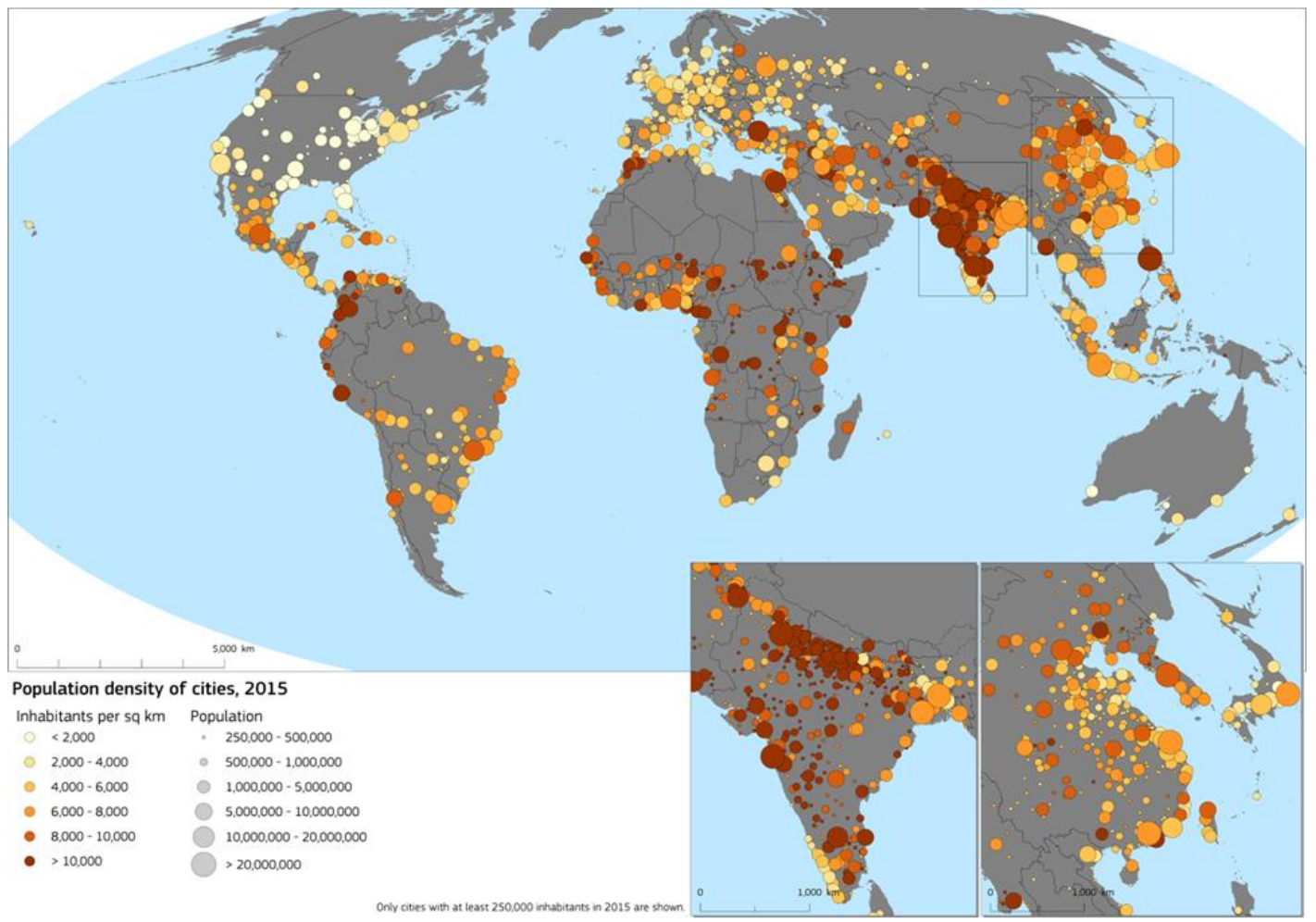

Source: Florczyk, A. et al. (2019[3]), GHS Urban Centre Database 2015, Multitemporal and Multidimensional Attributes, R2019A (dataset), https://data.jrc.ec.europa.eu/dataset/53473144-b88c-44bc-b4a3-4583ed1f547e.

Cities in high-income countries had a low density back in 1975 (Figure 5.2). Historically, these cities did have higher densities but to observe those, one would have to go back further into time. The introduction of large tram, train and metro systems in the late $19^{\text {th }}$ century and early $20^{\text {th }}$ century allowed the population to live further away from the city (Gonzalez-Navarro and Turner, 2019[4]). From the 1950s onwards, the increasing car ownership and the creation of a dense network of roads and highways has further reduced city densities (LeRoy and Sonstelie, 1983[5]). The United States (US) was at the forefront of this trend and today has the lowest city density in the world: 1640 inhabitants per $\mathrm{km}^{2}$.

City densities have changed rapidly in the last four decades. For example, in 1975, Australia, New Zealand and the US had city densities around 1500 inhabitants per $\mathrm{km}^{2}$. By 2015, Australia and New Zealand increased densities to around 2000 . City densities in the US also increased but only slightly to 1640 inhabitants per km². Cities in Canada were denser than American cities in 1975 (1900 inhabitants per $\mathrm{km}^{2}$ ) and their densities increased to 2500 by 2015, with most of that increase happening in the last 15 years. Other countries saw significant reductions in their city densities because they grew more in area than in population or in a few cases because population shrank. For example, cities in South Korea reduced their density from 8000 in 1975 to 7000 in 2015, while the population of these cities grew. In contrast, Romanian cities saw their densities drop from 6000 to 5000 , in part because their population shrank. 
Figure 5.2. Population density by city size and income, 1975-2015

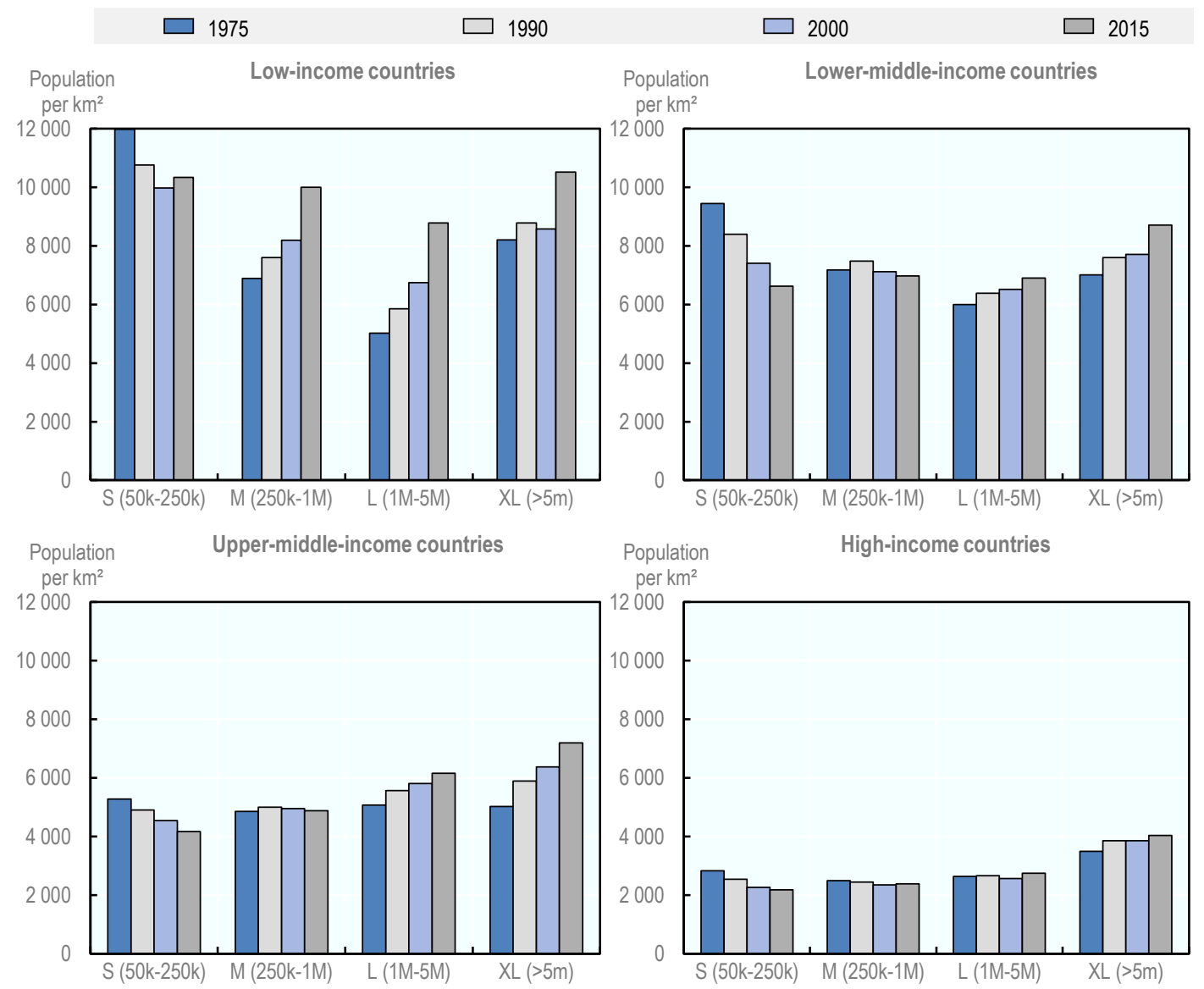

Note: The spatial extent of the city was classified for each reference year. Densities are calculated based on the total city area and city population of the reference year in each size class. Cities have been classified by their population size in 2015 , to avoid changes in density caused by cities switching size classes. New cities were included in the year that they emerged.

Source: Florczyk, A. et al. (2019[3]), GHS Urban Centre Database 2015, Multitemporal and Multidimensional Attributes, R2019A (dataset), https://data.jrc.ec.europa.eu/dataset/53473144-b88c-44bc-b4a3-4583ed1f547e.

StatLink जiाls https://doi.org/10.1787/888934130417

City expansion in most countries did not reduce overall city densities. In four out of five countries, city densities increased between 1975 and 2015. The overall increase in city densities implies that the density increases within the initial city boundary are not offset by the lower densities of the areas added to the city.

\section{Densities drop further from the centre}

Comparing how densities drop by distance to the city centre shows a few universal patterns and few differences. There are two well-known universal patterns, which our data confirm. The further away from the city centre, the lower the densities are. The larger the city, the more distance is needed for densities to drop (Figure 5.3).

Two differences stand out. Depending on the country, the density close to the centre varies from less than 2000 inhabitants per $\mathrm{km}^{2}$ for cities under 10 million inhabitants in North America to around 6000 in SubSaharan Africa, 8000 in East Asia and the Pacific and even higher in South Asia. The other aspect that varies is how quickly density declines. In Africa and Asia, most densities tend to decline very rapidly. In Latin America and Europe, densities decline more slowly, while in North America the density declines very slowly. 
Figure 5.3. Density by distance to the city centre by city size and by world region, 2015
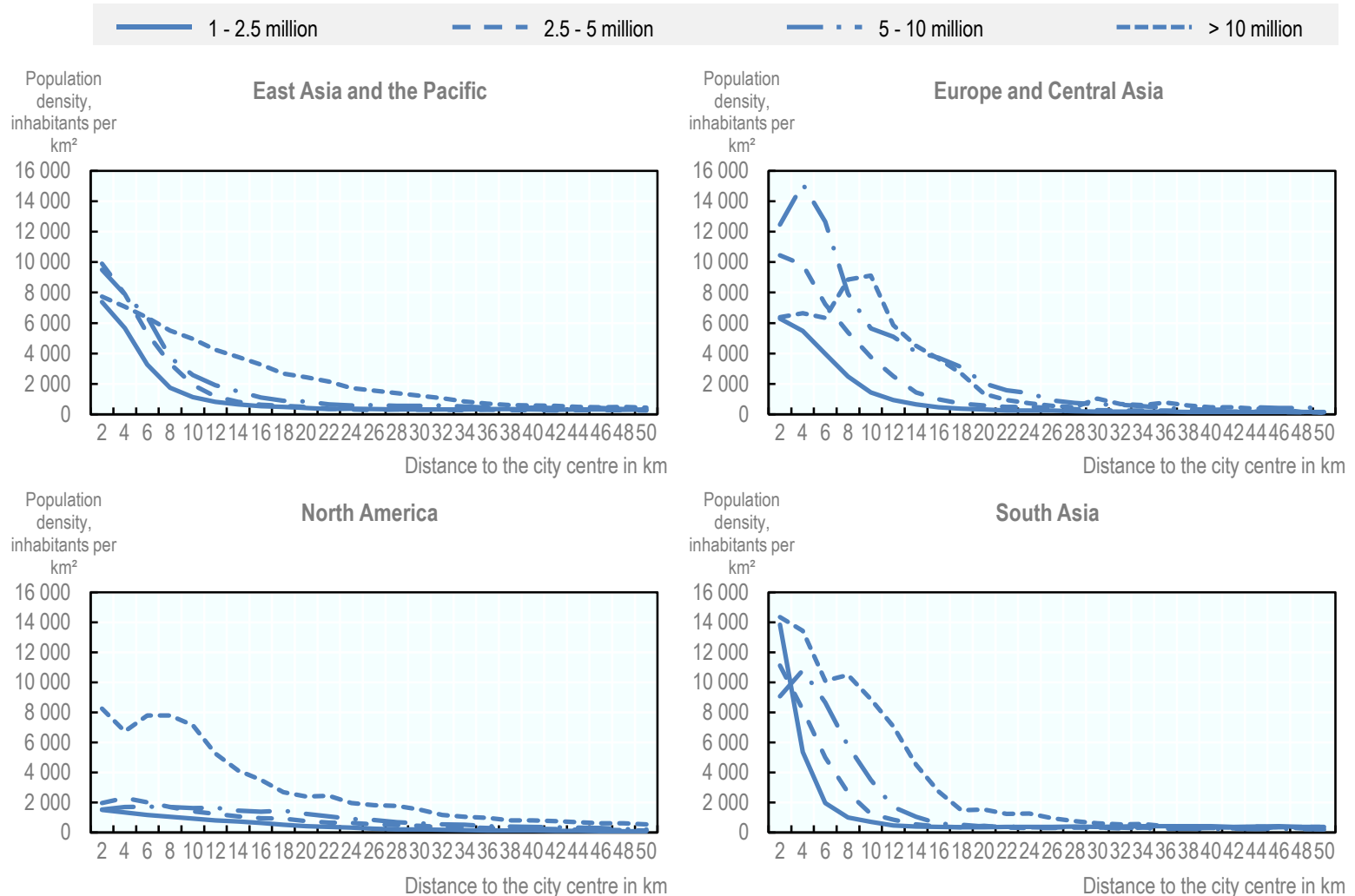

inhabitants per
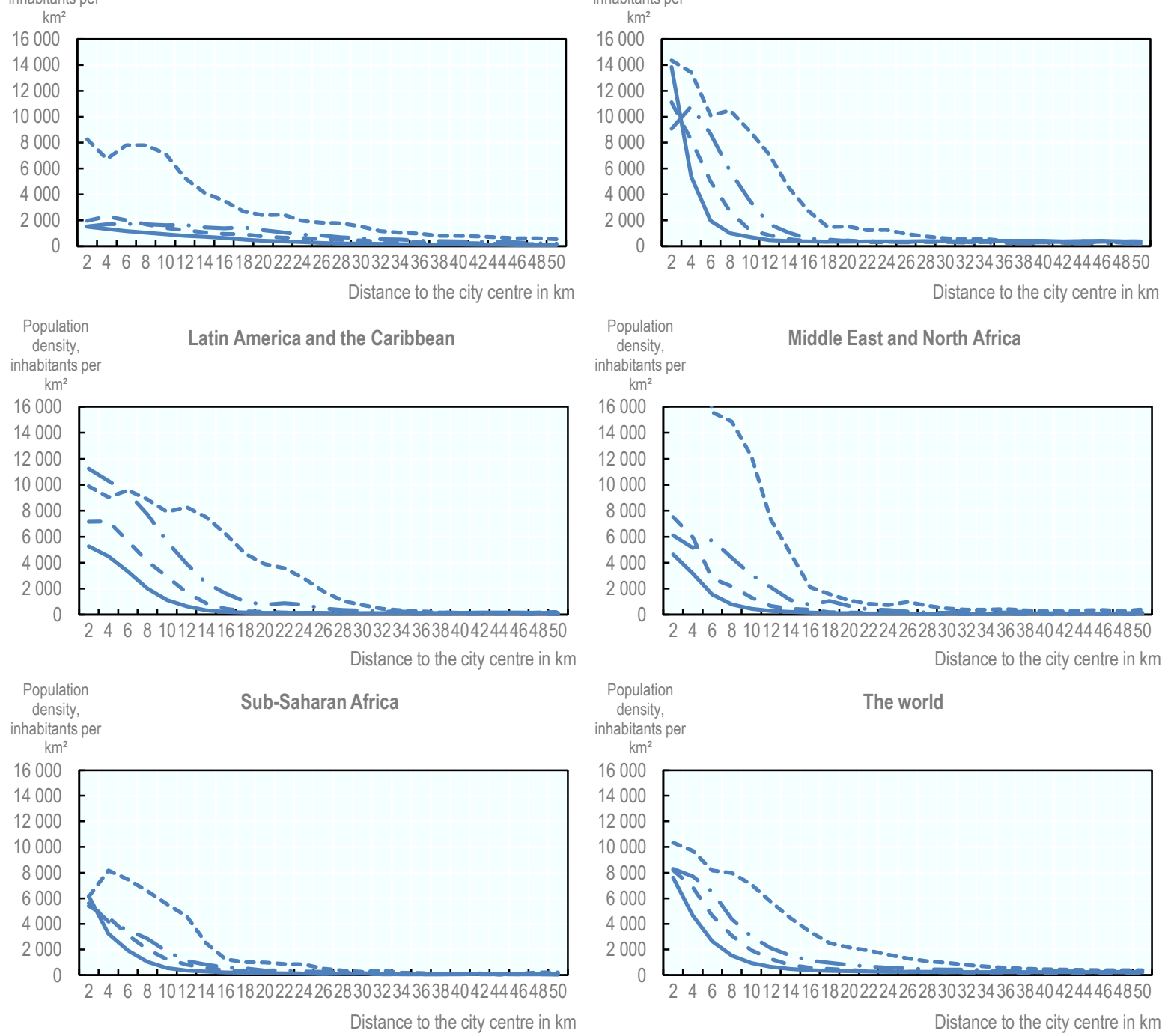

Source: Calculations using the population-weighted centroids of cities in Florczyk, A. et al. (2019[3]), GHS Urban Centre Database 2015, Multitemporal and Multidimensional Attributes, R2019A (dataset), https://data.jrc.ec.europa.eu/dataset/53473144-b88c-44bc-b4a34583ed1f547e and Florczyk, A. et al. (2019[6]), GHSL Data Package 2019 (database), http://dx.doi.org/10.2760/062975. 


\section{Cities are growing and expanding}

Three factors contribute to the rapid growth of the population living in cities and this section will deal with them in turn: i) towns growing into cities; ii) city expansion; and iii) city densification. The main source of growth is densification, which captures between $50 \%$ and $60 \%$ of the additional city population (Table 5.1). City expansion is the second most important source which covers around $25 \%$ of the additional city population. Increases in city population from towns growing into cities have become less important over time. In 1990 , towns becoming cities was responsible for $24 \%$ of the growth in city population, dropping to only $16 \%$ in 2015 . Because city densification - by definition - does not require the city to acquire any additional land, the main source of area change is city expansion.

\section{Table 5.1. Sources of city population growth, $1975-2015$}

\begin{tabular}{c|c|c|c|c}
\hline Time period & Towns growing into cities & City expansion & City densification & Total \\
\hline $1975-90$ & 23.9 & Population change $(\%)$ & & 100 \\
\hline $1990-2000$ & 18.3 & 26.4 & 49.7 & 100 \\
\hline $2000-15$ & 15.5 & 29.3 & 52.4 & 100 \\
\hline $1975-90$ & 30.5 & 24.8 & 59.7 & 100 \\
\hline $1990-2000$ & 22.8 & Area change $(\%)$ & 0 & 100 \\
\hline $2000-15$ & 22.6 & 69.5 & 0 & 100 \\
\hline
\end{tabular}

Source: Florczyk, A. et al. (2019[3]), GHS Urban Centre Database 2015, Multitemporal and Multidimensional Attributes, R2019A (dataset), https://data.jrc.ec.europa.eu/dataset/53473144-b88c-44bc-b4a3-4583ed1f547e.

As the population of a town grows past 50000 , the town becomes a city. Between 1975 and 2015, the number of cities in the world doubled from around 5000 to 10000 (Table 5.2). This growth in the number of cities is linked to the income of countries. Low-income countries saw their number of cities triple from 1975 to 2015 , compared to a doubling in middle-income countries and an increase of $50 \%$ in high-income countries. Virtually all these cities were first a town. The number of new cities has been slowing down over time. Between 1975 and 1990, the number of cities increased by 41\%, while between 2000 and 2015, it only increased by $19 \%$. This reduction in the number of new cities also meant that their share of all land that became part of a city dropped (Table 5.1).

Table 5.2 Number of cities by income group, 1975-2015

\begin{tabular}{l|c|c|c|c|c}
\hline & 1975 & 1990 & 2000 & 2015 & $2015 / 1975$ \\
\hline Low income & 326 & 518 & 703 & 942 & 2.9 \\
\hline Lower middle & 2025 & 2981 & 3577 & 4266 & 2.1 \\
\hline Upper middle & 1908 & 2740 & 3201 & 3704 & 1.9 \\
\hline High income & 911 & 1050 & 1184 & 1391 & 1.5 \\
\hline World & $\mathbf{5 1 7 0}$ & $\mathbf{7 2 8 9}$ & $\mathbf{8 6 6 5}$ & $\mathbf{1 0 3 0 3}$ & $\mathbf{2 0}$ \\
\hline
\end{tabular}

Source: Florczyk, A. et al. (2019[3]), GHS Urban Centre Database 2015, Multitemporal and Multidimensional Attributes, R2019A (dataset), https://data.jrc.ec.europa.eu/dataset/53473144-b88c-44bc-b4a3-4583ed1f547e. 
Cities expand by building new dense neighbourhoods at the edge of the city or densifying existing suburbs. Expansion means a city's population grows by incorporating the population already living in these areas and by adding more people to this new part of the city. In low-income countries, the initial population of these expansion areas is very low. In contrast, in high-income countries more than half of the population added to the city was already living there in the previous period.

City expansion is most pronounced in low-income and lower-middle-income countries with annual area growth rates of $2 \%$ to $3 \%$ (Figure 5.4). This means that the areas double or treble within 40 years. The small cities tend to expand faster, but this also includes towns growing into cities. In upper-middle- and high-income countries, on the other hand, city expansion is much lower and has been slowing down. Cities in upper-middle-income countries expanded by only 1\% a year between 2000 and 2015 (except the small cities). In high-income countries, cities expanded approximately $0.8 \%$ and $0.5 \%$ a year (except the small cities, which grew between $2 \%$ and $3 \%$, see Figure 5.4 ). With a growth rate of $0.5 \%$ a year, it takes almost 150 years to double in size.

City expansion also means a wider area that requires infrastructure and public services. The high speed of city expansion in low-income countries is especially challenging as they need to invest large amounts quickly, merely to keep providing the same level of service to the population in their growing area.

Densification means that the population grows within the initial boundary of the city. This densification comes in different forms: crowding, infilling and scaling up. Crowding means more people have to fit in the same number of houses. This may occur when a city receives a big inflow of people due to a natural disaster or armed conflict. Infilling means building on land that was not yet developed within the city. This could be land that was initially in a less desirable location or more expensive to develop. Scaling up means that low-rise buildings are replaced by mid- or high-rise buildings. Both infilling and scaling up have the benefit that they do not reduce the amount of floor space per household. The data used in this report, unfortunately, does not capture building height. As a result, it cannot distinguish scaling up from crowding. By analysing the changes in built-up area, however, the report can identify to what extent infilling is occurring, which is the focus of the section on crowded and sprawling cities below.

\section{Decentralisation}

Whereas the previous section looked at the changes within a city, this section zooms out to include the changes in the commuting zones. Population growth in commuting zones implies that cities need to extend their road and public transport networks to reach these areas. If this development is relatively concentrated, for example in satellite towns, it requires less investment to provide good access for the people living there. If this development, however, is more dispersed, it requires more roads and it becomes difficult to provide good public transport access.

\section{Metropolitan areas have larger commuting zones in high-income countries}

Population in commuting zones represent $17 \%$ of the overall metropolitan population and $9 \%$ of the total world population. This share is linked to a country's income level (Figure 5.5). The share of the metropolitan population in commuting zones is biggest (31\%) in high-income countries, while it decreases to $18 \%$ and $10 \%$ in upper-middle- and lower-middle-income countries respectively. In low-income countries, commuting zones represent less than $4 \%$ of the metropolitan population.

In high-income countries, the population has tended to shift from the city to the commuting zone in most metropolitan areas. As suggested by the literature, this outward shift of population and employment from the city to the surrounding towns \& semi-dense and rural areas took place due to a variety of factors, including lower costs of land, lower taxes, preferences for single-family dwellings and greener 
surroundings. As car ownership grew, more roads were constructed and public transport improved, people were able to live further out (Gordon and Richardson, 1996 ${ }_{[7]}$; Gonzalez-Navarro and Turner, 2019[4]).

Figure 5.4 Growth in city area by city size and income group, 1975-2015
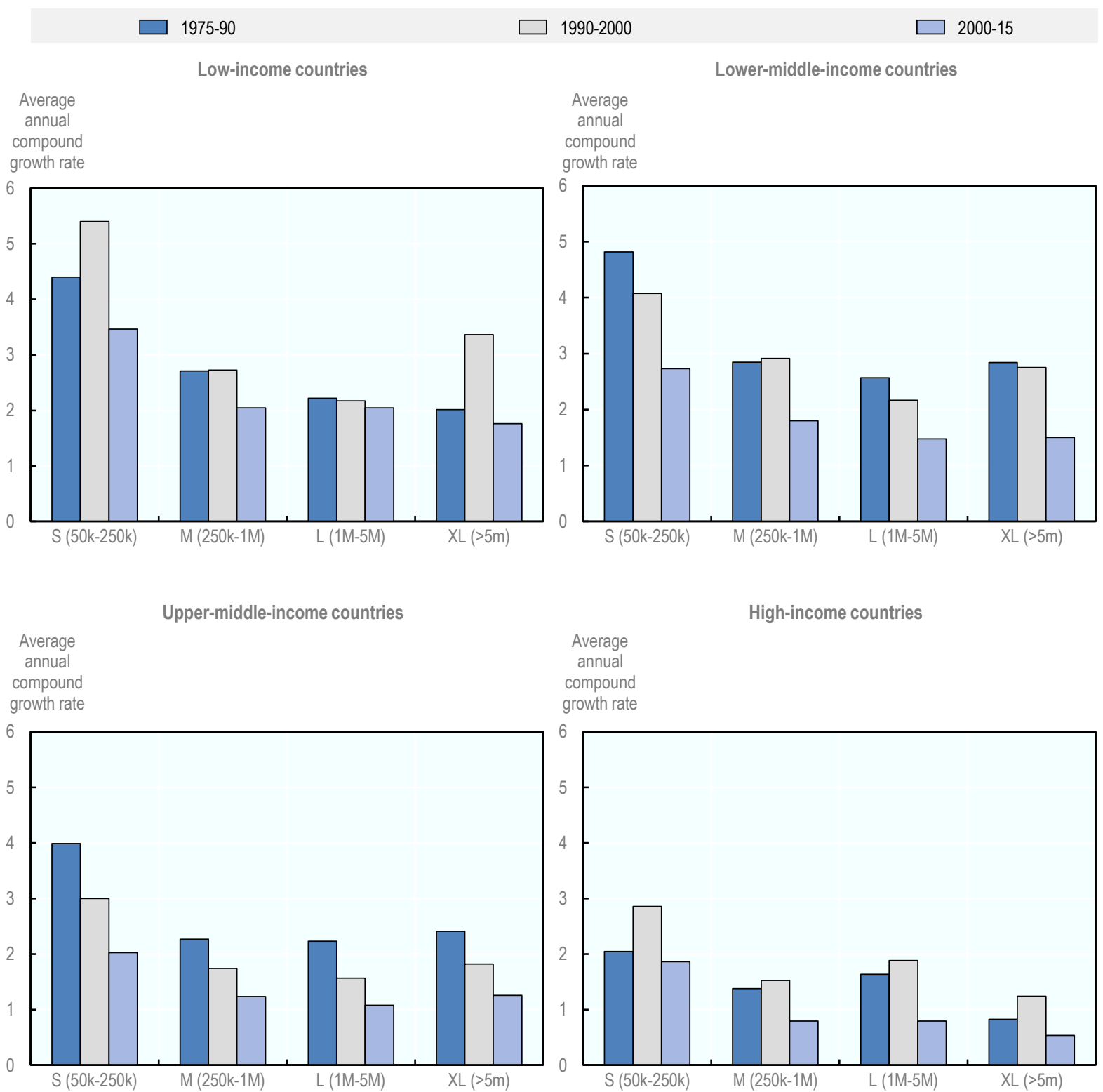

Source: Florczyk, A. et al. (2019[3]), GHS Urban Centre Database 2015, Multitemporal and Multidimensional Attributes, R2019A (dataset), https://data.jrc.ec.europa.eu/dataset/53473144-b88c-44bc-b4a3-4583ed1f547e.

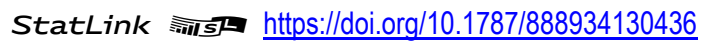


Figure 5.5 Country income and importance of commuting zone, 2015

Bubbles are proportional to the population size of the metropolitan area

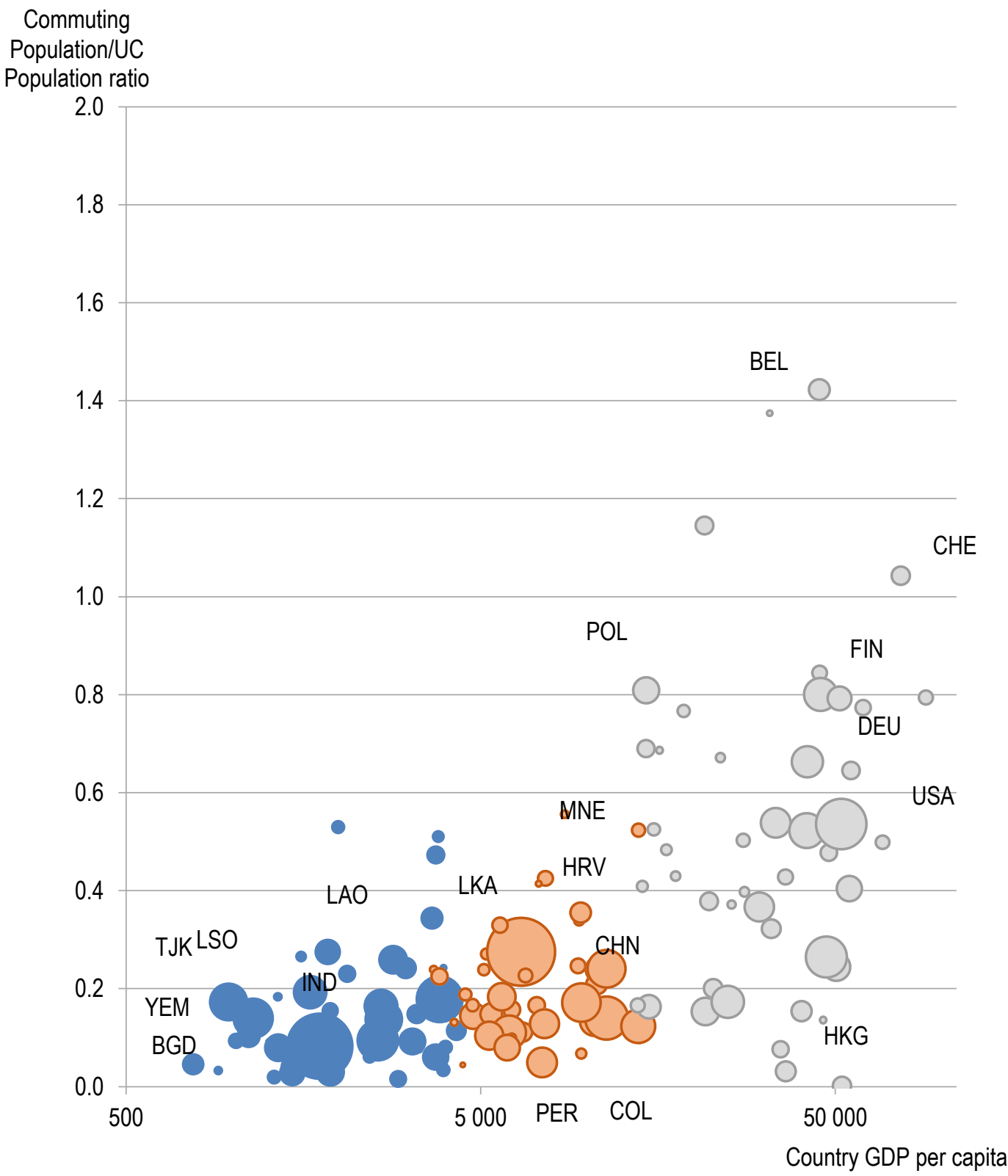

Source: Adapted from Moreno-Monroy, A., M. Schiavina and P. Veneri (2020[8]), "Metropolitan areas in the world. Delineation and population trends", Journal of Urban Economics, https://doi.org/10.1016/j.jue.2020.103242.

\section{Commuting zones grow faster than their city}

Of all metropolitan areas in 2000, 78\% experienced population growth between 2000 and 2015. Of these growing metropolitan areas, $85 \%$ experienced growth in both their city and commuting zone (Table 5.3). In $7 \%$ of these metropolitan areas, the city lost population but the growth in the commuting zone offset this reduction. In contrast, $8 \%$ of growing metropolitan areas experienced growth in the city but a decline in its commuting zone. 
Among the growing metropolitan areas, $89 \%$ had faster population growth in the commuting zone than in the city between 2000 and 2015, confirming previous evidence from OECD countries (Veneri, 2018[9]). The observed patterns suggest a slow but widespread pattern of decentralisation of the metropolitan population towards the commuting zones. In rapidly growing cities, it may be that people have to move to the commuting zone because not enough housing is being built in the city itself.

Table 5.3. Metropolitan areas by growth or decline in the city and commuting zone, 2000-15

\begin{tabular}{|c|c|c|c|c|c|c|}
\hline & & $\begin{array}{l}\text { Both city and } \\
\text { commuting zone grow }\end{array}$ & $\begin{array}{c}\text { City shrinks and } \\
\text { commuting zone } \\
\text { grows }\end{array}$ & $\begin{array}{l}\text { City grows and } \\
\text { commuting zone } \\
\text { shrinks }\end{array}$ & $\begin{array}{l}\text { Both city and } \\
\text { commuting zone } \\
\text { shrink }\end{array}$ & Total \\
\hline \multirow{2}{*}{$\begin{array}{l}\text { Growing } \\
\text { metropolitan } \\
\text { areas }\end{array}$} & Number & 5252 & 398 & 500 & & 6150 \\
\hline & Share $(\%)$ & 85.4 & 6.5 & 8.1 & & 100 \\
\hline \multirow{2}{*}{$\begin{array}{l}\text { Declining } \\
\text { metropolitan } \\
\text { areas }\end{array}$} & Number & & 859 & 15 & 819 & 1693 \\
\hline & Share $(\%)$ & & 50.7 & 0.9 & 48.4 & 100 \\
\hline
\end{tabular}

Note: Only metropolitan areas with a city in 2000 were included.

Source: EC calculations based on Florczyk, A. et al. (2019[6] $)$, GHSL Data Package 2019 (database), http://dx.doi.org/10.2760/062975 and the boundaries of Moreno-Monroy, A., M. Schiavina and P. Veneri (2020[8]), "Metropolitan areas in the world. Delineation and population trends", Journal of Urban Economics, https://doi.org/10.1016/j.jue.2020.103242.

Population growth in a commuting zone can pose serious planning challenges, especially if the growth is highly dispersed. Providing sufficient infrastructure and services to the population outside the city requires significant investments. In Africa, however, some fast-growing cities are caught in a low development trap and are unable to attract investment. To overcome low investor expectations and encourage economic growth, governments can implement policies towards formalising land markets, clarifying property rights and investing in effective urban planning. Further, in the absence of regulated markets, governments should make early and co-ordinated infrastructure investments to link workers with businesses and services and signal to investors that it will make these investments. While these solutions will prove particularly challenging in countries with extremely limited financial resources and public capacity, the success of cities in other regions provides evidence on the value of co-ordinated and sustained action (Lall, Henderson and Venables, 2017 ${ }_{[10]}$ ).

\section{Some commuting zones lose population}

Of the metropolitan areas in 2000, 22\% lost population between 2000 and 2015. In half of these shrinking metropolitan areas, both the city and the commuting zone lost population. In the other half of shrinking metropolitan areas, the city lost population while the commuting zone still grew, but the population growth in the commuting zone was insufficient to avoid an overall decline (Table 5.3). Population growth in the city was extremely rare among shrinking metropolitan areas: only $1 \%$ or 15 metropolitan areas experienced this. This meant that virtually all shrinking metropolitan areas saw densities drop in their city.

Among the shrinking metropolitan areas, $85 \%$ had a faster population growth (or slower decline) in its commuting zone as compared to its city. This mirrors the trend in growing metropolitan areas but here, this is not because the city cannot accommodate more population. On the contrary, the universal drop in city population means that even when the pressure on the housing market of a city drops, people still prefer to live outside the city. It may be that the shrinking population reduces travel time to the city and thus reduces people's incentive to move. 


\section{Box 5.1. Commuting zones grow faster than cities in France}

Measuring population changes within metropolitan areas makes it possible to identify when the city is shrinking but the commuting zone is growing fast enough to offset the population loss in the city. In such a case, rather than describing this as population decline, it would be more appropriate to talk about population decentralisation. In many metropolitan areas in the developed world, it is common to observe a stable or growing metropolitan population characterised by decentralisation from the dense city.

France's overall annual population growth rate of $0.54 \%$ is equal to the OECD average and its fertility rate (around 2) is one of the highest in the OECD. Nevertheless, the country is experiencing shrinking cities. Out of 64 French metropolitan areas, 38 had a shrinking population within its city (Figure 5.6). The figure shows a striking relationship in which over half of French cities are declining, while growth in the surrounding commuting zones is positive and, in two-thirds of the cases, offsetting the city decline. Such a pattern of population growth in the commuting zone offsetting the decline in the city occurs primarily in smaller cities, although examples of cities with over a half a million inhabitants include Grenoble, Lille, Rennes and Rouen. In the 26 French metropolitan areas with a growing city population, the population in the commuting zones grew faster in all but one. Also, in other OECD countries including Poland, the Slovak Republic, Slovenia and South Korea, the population in the commuting zone tends to grow faster than in the city.

Only, 13 metropolitan areas experience population decline. They are primarily located in former mining and industrial regions in the north and northeast of France. This spatial pattern confirms a tendency towards urban shrinkage in regions with declining economic sectors.

\section{Figure 5.6 Population growth in cities and commuting zones in France, 2000-15}

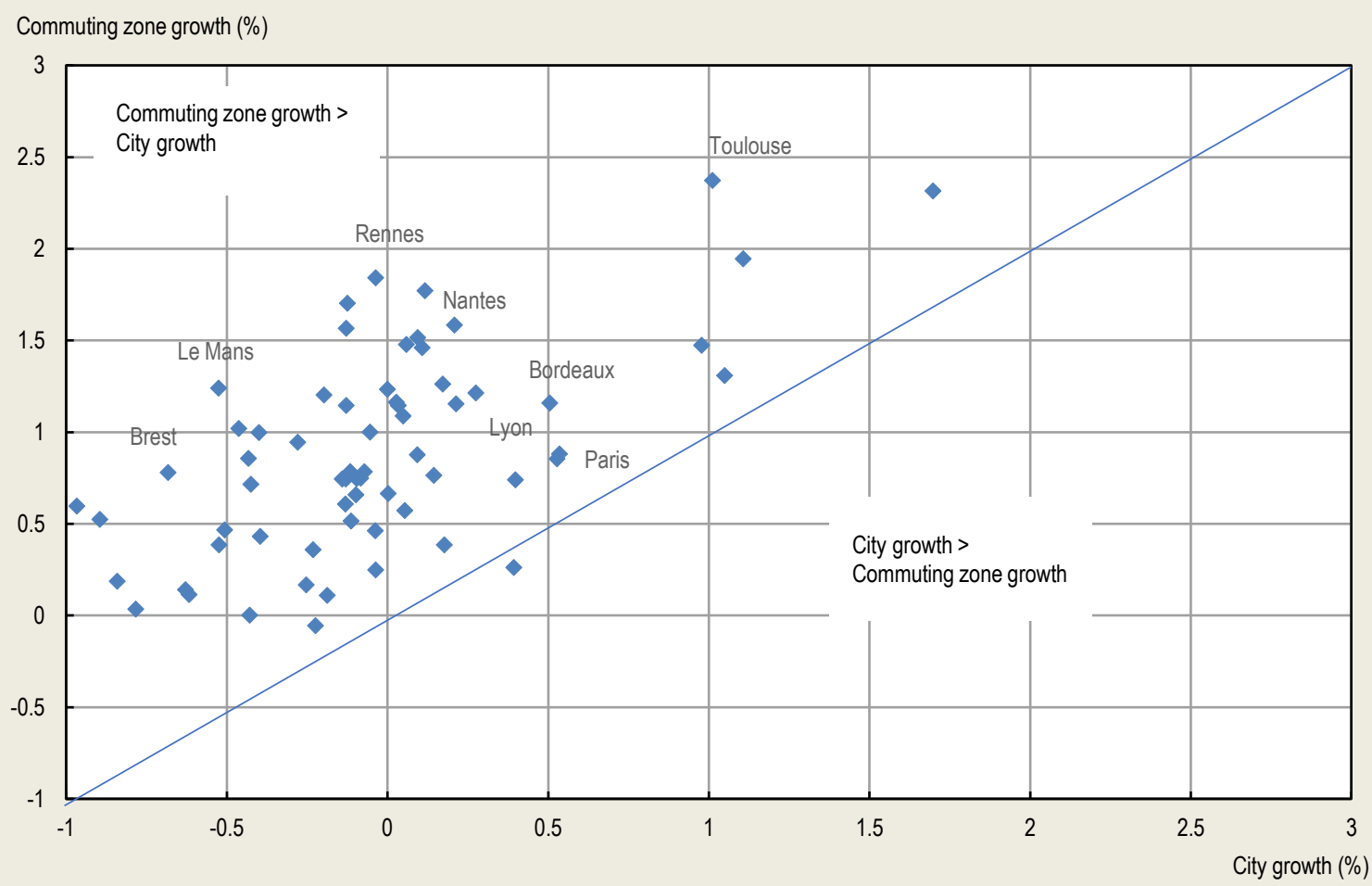

Source: OECD calculations based on Florczyk, A. et al. (2019[3]), GHS Urban Centre Database 2015, Multitemporal and Multidimensional Attributes, R2019A (dataset), https://data.jrc.ec.europa.eu/dataset/53473144-b88c-44bc-b4a3-4583ed1f547e. 


\section{Crowded metropolitan areas and sprawling metropolitan areas}

Cities with a rapidly growing population often struggle to build the infrastructure to accommodate such a surge. Consequently, some cities are extremely crowded and lack sufficient infrastructure. Public transport and roads struggle to accommodate high levels of demand. People live in small houses with many persons to a room. They work and shop in cramped conditions. These high levels of crowding and congestion can reduce the quality of life and the economic performance of that city.

In contrast, some rich cities have very high levels of infrastructure provision with an extensive road network, spacious houses, large shopping malls and big office parks. This high level of infrastructure provision, however, has a number of drawbacks. It is costly to build and maintain an extensive road network and its accompanying water, electricity and information and communication technology (ICT) networks. It also tends to lead to a very spread-out population, which makes it more expensive to provide public transport and reduces the number of destinations that can easily be reached on foot or by bicycle. This type of urban development is often referred to as urban sprawl.

Although there is no consensus on the optimal level of infrastructure provision for a city or metropolitan area, the amount of land dedicated to buildings and infrastructure varies massively. Many metropolitan areas have less than $25 \mathrm{~m}^{2}$ of land per person dedicated to buildings and infrastructure (Figure 5.7) compared to a global average of 100 , while others have more than 300 using built-up area as detected by GHS-BUILT (see Box 5.2). Nevertheless, there are clear cases of under-provision. Several fast-growing metropolitan areas in developing countries struggle with high levels of congestion and a growing share of the population without access to piped drinking water. Overprovision is less clear cut. A metropolitan area with a dispersed population will generate more and longer car trips than one with a more concentrated population. As a result, despite the considerably longer road network per person in a dispersed metropolitan area, it may still encounter some congestion. Furthermore, metropolitan areas with a shrinking population will see their local revenues drop exactly when they need to downsize their infrastructure. As a result, such metropolitan areas may end up with too many buildings and too much infrastructure for their population size that they can ill afford to maintain.

The goal of preventing urban sprawl is a prominent part of the United Nation's New Urban Agenda ${ }^{2}$ and its Sustainable Development Goal 11. Goal 11 includes an indicator that compares changes in land use and changes in population. The interpretation of this indicator, however, depends on the starting position of a city. If a city lacks enough buildings and infrastructure for the people living and working there, it should aim to build these faster than the population grows to ease crowding and congestion. In a city with sufficient buildings and infrastructure, a similar growth rate of buildings and infrastructure would be ideal. In a metropolitan area with an overprovision, ideally, the population would increase faster than buildings and infrastructure to ensure a higher and thus efficient use of this infrastructure and make its maintenance more affordable.

In a way, the amount of buildings and infrastructure per person in a metropolitan area is similar to the body mass index or BMI. As a result, the amount of built-up area per person indicator could be seen as a "City Mass Index" where cities with low levels should seek to build more and cities with high levels should seek to build less. One crucial limitation of this approach, however, is that it does not consider building heights. Replacing low-rise with high-rise buildings can reduce crowding without increasing the amount of built-up land. Globally consistent data on building heights is, unfortunately, not yet available. Improvements in remote-sensing or more detailed digital building cadastres may in the future be able to fill this gap. 
Figure 5.7. Built-up area per person in metropolitan areas, 2015

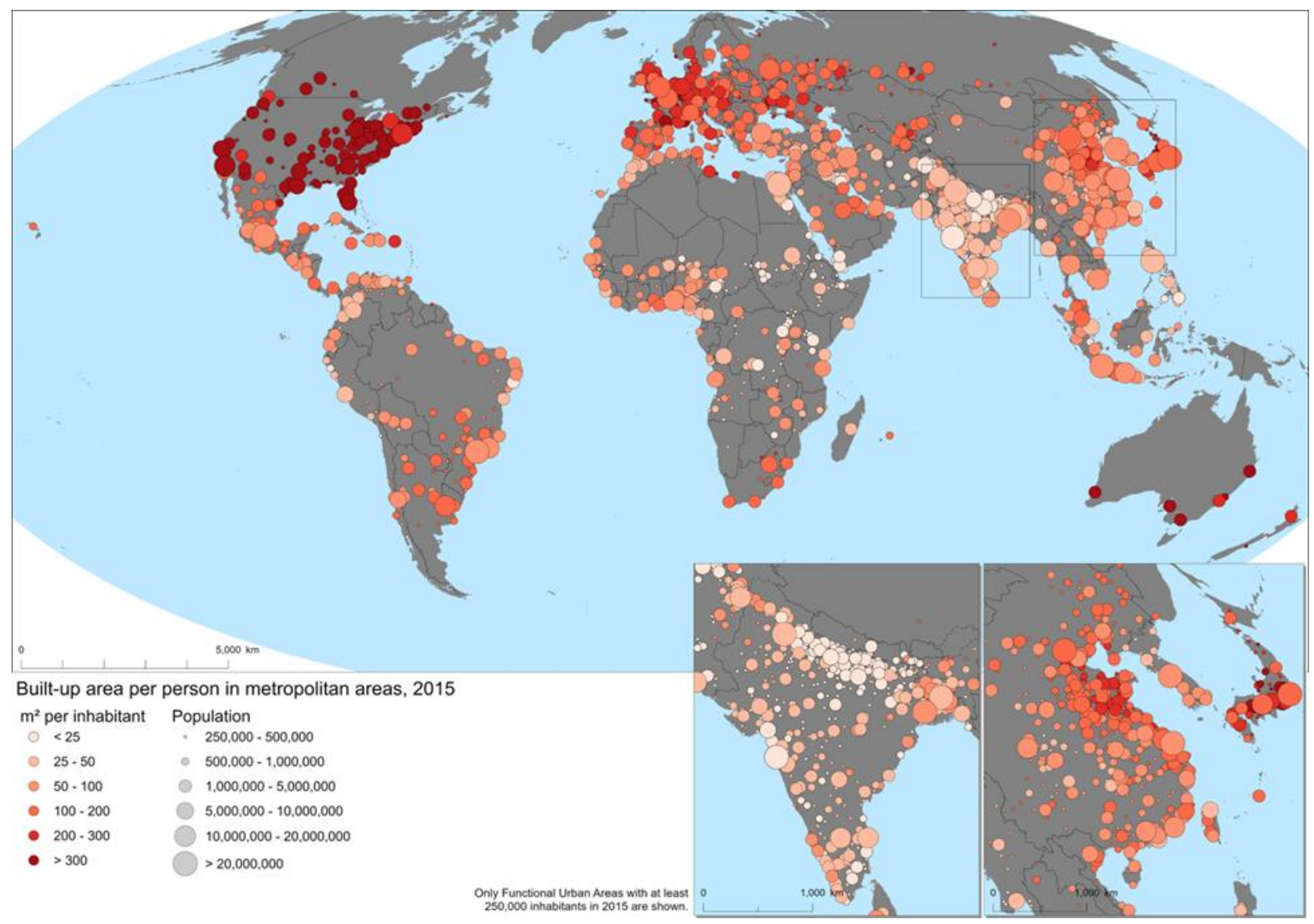

Source: EC calculations based on Florczyk, A. et al. (2019[6] $)$, GHSL Data Package 2019 (database), http://dx.doi.org/10.2760/062975 and the boundaries of Moreno-Monroy, A., M. Schiavina and P. Veneri (2020[8]), "Metropolitan areas in the world. Delineation and population trends", Journal of Urban Economics, https://doi.org/10.1016/j.jue.2020.103242.

To demonstrate this City Mass Index approach, metropolitan areas were classified as having a low amount of buildings and infrastructure if they had less than $100 \mathrm{~m}^{2}$ of built-up area per person, medium if they had between 100 and 200 and high if they had more than 200 in 2000. Changes in built-up area per person between 2000 and 2015 were classified as shrinking if it dropped by more than $5 \mathrm{~m}^{2}$ per person, growing if it increased by more than $5 \mathrm{~m}^{2}$ per person. The metropolitan areas where it changed by less than $5 \mathrm{~m}^{2}$ per person were classified as stable. This classification shows that virtually all metropolitan areas in lowincome and lower-middle-income countries have a low level of built-up area per person (Table 5.4) while two-thirds of the metropolitan areas in high-income countries have a high level. Half the metropolitan areas in upper-middle- and high-income countries have a growing built-up area per person, while this is rare in the other countries.

The combination of the two classifications shows that in high-income countries, two out of five metropolitan areas have a high and growing level of built-up areas per person (Table 5.5). In other countries, however, this is virtually absent. In other words, urban sprawl seems to be a problem only in high-income countries. Fortunately, one in five metropolitan areas in a high-income county had a high level of built-up area per person in 2000 but reduced it between 2000 and 2015 (Figure 5.8). In other words, these metropolitan areas were reducing the City Mass Index and are becoming less sprawled. 
Table 5.4 Share of metropolitan areas by income group, built-up area per person and built-up area per person change

\begin{tabular}{l|c|c|c|c|c|c|c|c|}
\hline & \multicolumn{4}{|c|}{ Built-up area per person, 2000 (\%) } & \multicolumn{3}{c}{ Change in built-up area per person, 2000-15 } \\
\hline & Low & Medium & High & Total & Shrinking & Stable & Growing & Total \\
\hline Low income & 95.2 & 4.5 & 0.3 & 100 & 29.7 & 66.9 & 3.4 & 100 \\
\hline Lower-middle income & 92.4 & 5.9 & 1.7 & 100 & 16.7 & 68.6 & 14.7 & 100 \\
\hline Upper-middle income & 55.4 & 39.4 & 5.2 & 100 & 26.6 & 20.2 & 53.2 & 100 \\
\hline High income & 9.7 & 23.0 & 67.3 & 100 & 27.8 & 17.2 & 55.0 & 100 \\
\hline World & 68.4 & 20.2 & 11.4 & 100 & 22.9 & 44.1 & 33.0 & 100 \\
\hline
\end{tabular}

Note: Only metropolitan areas with a city in 2000 were included in this table.

Source: EC calculations based on Florczyk, A. et al. (2019[6]), GHSL Data Package 2019 (database), http://dx.doi.org/10.2760/062975 and the boundaries of Moreno-Monroy, A., M. Schiavina and P. Veneri (2020[8]), "Metropolitan areas in the world. Delineation and population trends", Journal of Urban Economics, https://doi.org/10.1016/j.jue.2020.103242.

In contrast, metropolitan areas with a low and shrinking level of built-up area per person are most prevalent in low-income and middle-income, and almost absent in high-income countries. In other words, crowded cities where investments in buildings and infrastructure fail to keep up with population growth are most common in low-income countries. Fortunately, some metropolitan areas are increasing investments faster than population growth, especially in upper-middle-income countries, where $30 \%$ of the metropolitan areas have a low but growing built-up area per person.

Table 5.5 Share of metropolitan areas by built-up area per person levels, 2000, and change, 2000-15, by income group

\begin{tabular}{l|c|c|c|c|c}
\hline & $\begin{array}{c}\text { Low and growing } \\
(\%)\end{array}$ & $\begin{array}{c}\text { High and shrinking } \\
(\%)\end{array}$ & $\begin{array}{c}\text { Medium and/or } \\
\text { stable (\%) }\end{array}$ & $\begin{array}{c}\text { Low and shrinking } \\
(\%)\end{array}$ & $\begin{array}{c}\text { High and growing } \\
(\%)\end{array}$ \\
\hline Low income & 3.4 & 0.3 & 71.4 & 24.9 & 0.0 \\
\hline Lower-middle income & 12.1 & 0.7 & 73.8 & 12.4 & 1.0 \\
\hline Upper-middle income & 30.2 & 2.3 & 54.4 & 10.5 & 2.6 \\
\hline High income & 3.0 & 19.0 & 35.7 & 3.1 & 39.2 \\
\hline World & 16.8 & 3.6 & 61.5 & 11.7 & 6.4 \\
\hline
\end{tabular}

Note: Only metropolitan areas with a city in 2000 were included in this table.

Source: EC calculations based on Florczyk, A. et al. (2019[6]), GHSL Data Package 2019 (database), http://dx.doi.org/10.2760/062975 and the boundaries of Moreno-Monroy, A., M. Schiavina and P. Veneri (2020[8]), "Metropolitan areas in the world. Delineation and population trends", Journal of Urban Economics, https://doi.org/10.1016/i.jue.2020.103242. 
Figure 5.8. Difference in built-up area per person in metropolitan areas, 2000-15

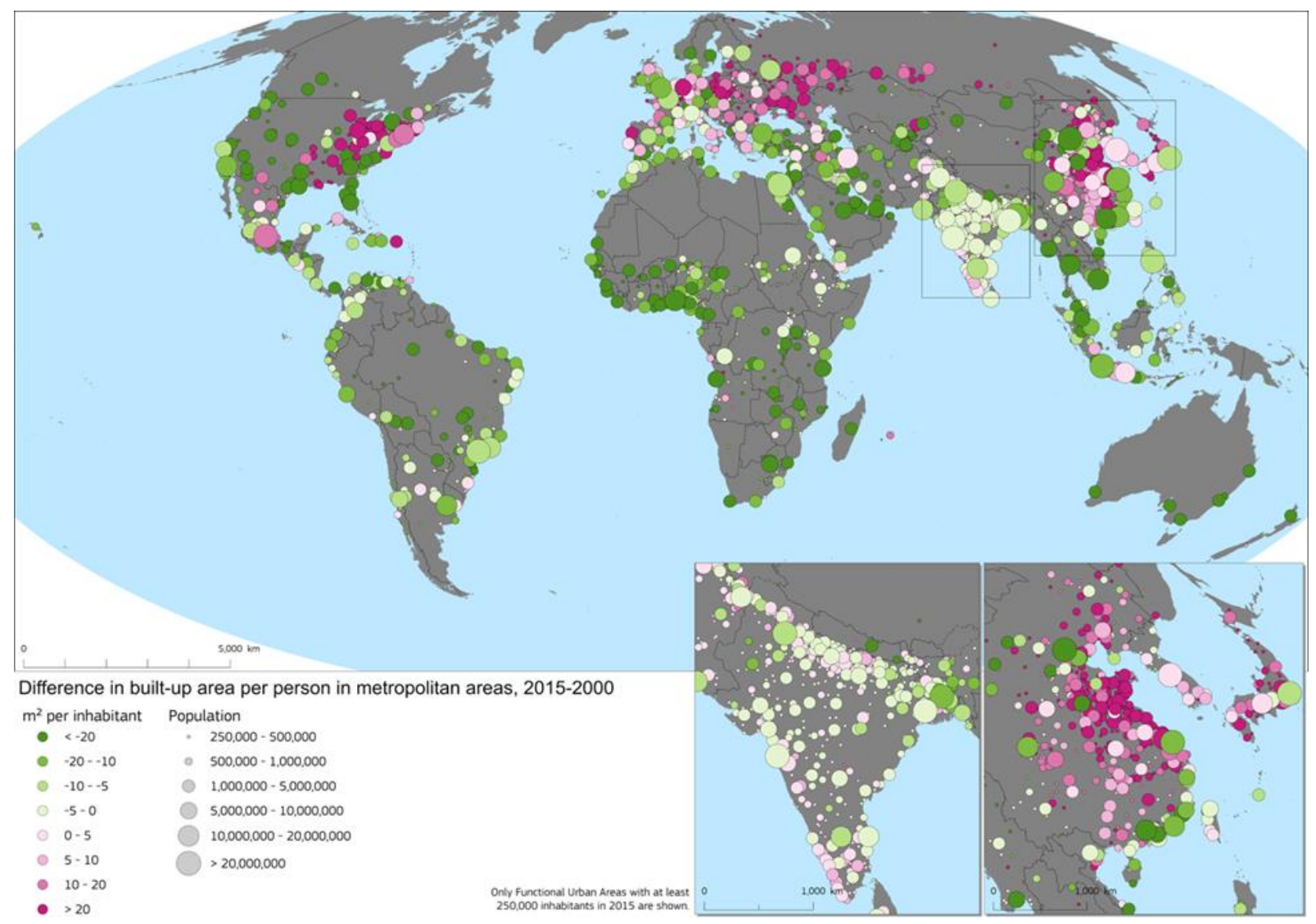

Source: EC calculations based on Florczyk, A. et al. (2019[6] $)$, GHSL Data Package 2019 (database), http://dx.doi.org/10.2760/062975 and the boundaries of Moreno-Monroy, A., M. Schiavina and P. Veneri (2020[8]), "Metropolitan areas in the world. Delineation and population trends", Journal of Urban Economics, https://doi.org/10.1016/j.jue.2020.103242.

\section{Box 5.2. The GHS-BUILT multi-temporal classification of built-up areas}

The Global Human Settlement Built-Up Grid (GHS-BU) measures the presence of built-up areas (at $30 \mathrm{~m}$ spatial resolution) for $1975,1990,2000$ and 2015 . The data was processed by fully automatic and reproducible methods (Corbane et al., 2017[11]) based on statistical learning (Symbolic Machine Learning) (Pesaresi, Syrris and Julea, 2016[12]). No manual or ad-hoc rule-based editing of the results was applied in the post-processing.

It is based on the processing of individual Landsat data collections (Landsat8, collection 2000, collection 1990, collection 1975), previously tiled and mosaicked. The built-up areas of the most recent year (2015) are considered as the most reliable (Corbane et al., 2019[13]). Earlier years are created by removing built-up from 2015 when Landsat imagery shows no evidence of any built-up area for that year. This means that built-up areas can only grow over time and not decline. This assumption makes the data more robust and is valid in the vast majority of cases.

Built-up areas are the spatial generalisation of a building defined as: "areas (spatial units) where buildings can be found". The "built-up area" as defined in the GHSL framework is "the union of all the satellite data samples that corresponds to a roofed construction above ground which is intended or 
used for the shelter of humans, animals, things, the production of economic goods or the delivery of services" (Pesaresi et al., 2013[14]).

The classification of the $30 \mathrm{~m}$ by $30 \mathrm{~m}$ cells is dichotomous: built up or not built up. Evidence of (a small part of) a building will lead to classifying the entire cells as built-up. As a result, more areas will be classified as built-up as compared to higher resolution data on building footprints. Imperviousness or sealed surfaces includes buildings as well as areas that are covered by asphalt, concrete, brick or stone, such as roads, sidewalks, driveways and parking lots (European Environment Agency, 2015[15]). GHS-BUILT does not include roads infrastructure in areas with an only limited amount of buildings. In areas with a high density of buildings, road infrastructure will typically be included as part of the builtup. As a result, within a city, GHS-BUILT should be seen as the area that is (partially) covered by buildings or road infrastructure.

Source: Corbane, C. et al. (2017 $[11])$, "Big earth data analytics on Sentinel-1 and Landsat imagery in support to global human settlements mapping”, http://dx.doi.org/10.1080/20964471.2017.1397899; Pesaresi, M., V. Syrris and A. Julea (2016[12]), "A new method for earth observation data analytics based on symbolic machine learning", http://dx.doi.org/10.3390/rs8050399; Corbane, C. et al. (2019[13]), "Automated global delineation of human settlements from 40 years of Landsat satellite data archives", Big Earth Data, Vol. 3/2, pp. 140169; Pesaresi, M. et al. (2013[14]), "A global human settlement layer from optical HR/VHR RS data: Concept and first results", IEEE Journal of Selected Topics in Applied Earth Observations and Remote Sensing, Vol. 6/5, pp. 2102-2131; European Environment Agency (2015[15]), "Imperviousness and imperviousness change", https://www.eea.europa.eu/data-and-maps/indicators/imperviousness-change-

1/assessment (accessed on 21 March 2020).

\section{Urban mobility and accessibility}

Cities and metropolitan areas present a unique mix of challenges and opportunities for mobility. The globally consistent definition of a city and its commuting zone used in this report allows for a more meaningful comparison of transport options. The high population density of cities can facilitate walking but some trips may be too long to walk, especially in large metropolitan areas, and road infrastructure may not be designed for pedestrians. Many (large) metropolitan areas have a highly developed public transport network with most residents close to high-frequency stops. In many cities, however, most people drive to reach their destinations but the high number of drivers can overwhelm the road infrastructure capacity leading to high levels of congestion, delays and pollution.

This section focuses primarily on the provision of public transport, as good information on walking and cycling conditions is still difficult to obtain. Increasingly the road network in cities has been mapped but good information on its capacity and use is often not available. As a result, this section only briefly touches on driving.

The section starts by analysing public transport in cities using two SDG indicators and the new EC-ITFOECD urban accessibility framework. It focuses on cities first because they have the density and the critical mass of potential users that should support a dense and frequent public transport service. Finally, it considers the impact of the shape of the metropolitan area, i.e. a city plus its commuting zone, on the costs of public transport provision.

\section{Cities can provide easy access to public transport}

Large cities need public transport to ensure people can get where they need to go as distances become too big to easily walk or cycle to their destinations. Many city residents are too young or too old to drive. Some simply prefer to use public transport, while others cannot afford a car. Furthermore, a high share of car trips is likely to lead to high levels of congestion. Good public transport is critical to reducing congestion, 
air pollution and greenhouse gas emissions from transportation as well as providing better accessibility for all, including the young, the old and the poor.

The United Nations (UN) Sustainable Development Goal 11 includes an indicator that measures the proportion of the population that has convenient access to public transport. In its simplest formulation, it measures what share of the city population lives within a 500-metre walk of a public transport stop. The benefit of this indicator is that it takes into account the spatial distribution of the stops and the population and does not require a large amount of data: just the location of the stops and the population per block or grid cell. Nevertheless, data on the location of public transport stops, including informal transit, is often unavailable.

Comparing 68 cities across the globe with available data shows that in most of European cities, more than $90 \%$ of the population lives within a 500 -metre walk of a public transport stop (Figure 5.9). By contrast, in most African cities included in this analysis, this share is below $50 \%$, despite including informal transit. The shares for the cities included from North America and Asia vary from less than $50 \%$ to over $90 \%$. The 4 cities included from South America and Oceania (Buenos Aires and São Paolo, Auckland and Sydney), all have more than $80 \%$ of their population close to a public transport stop.

\section{Figure 5.9 Population within a $500 \mathrm{~m}$ walk to a public transport stop in selected cities in the world}

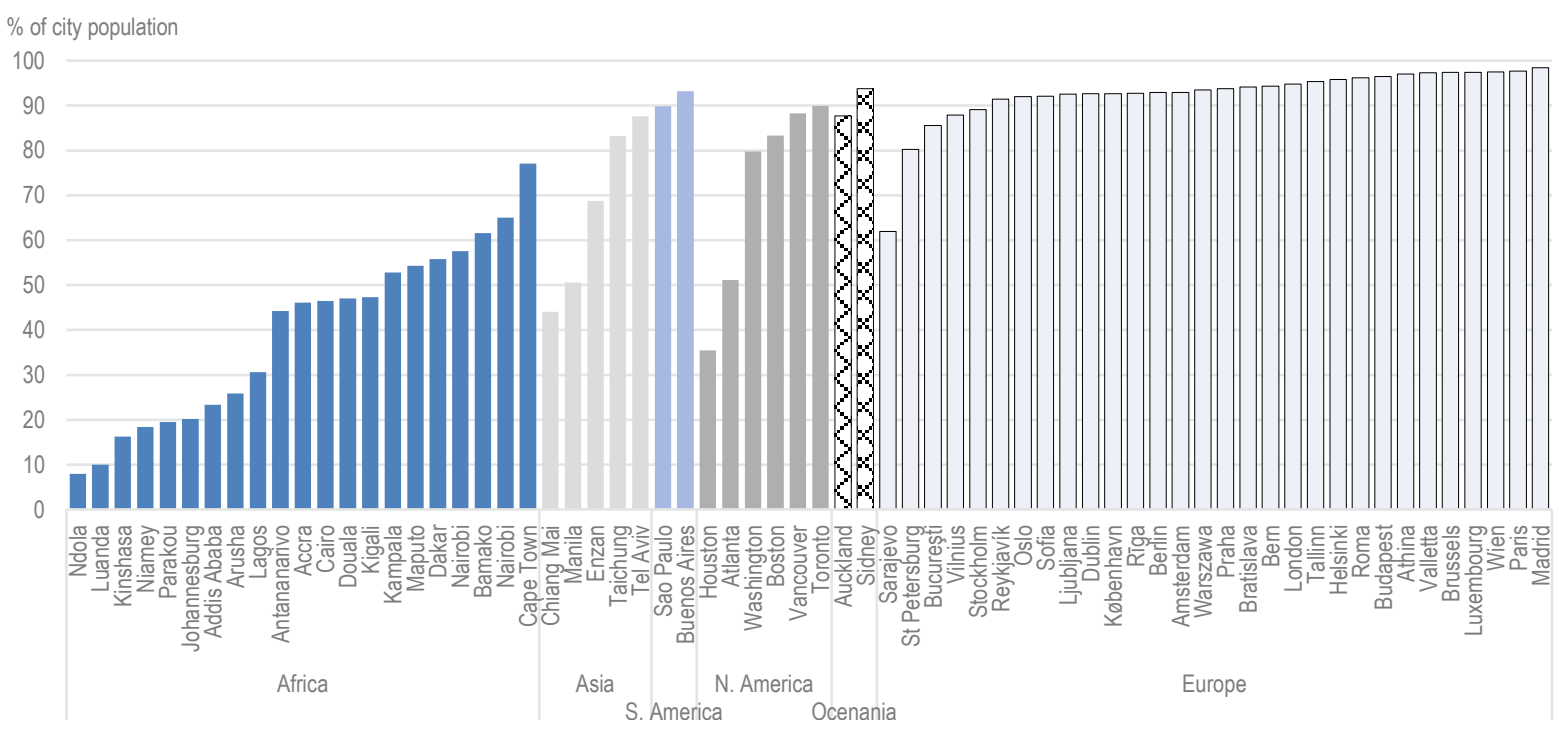

Source: ITF, UN-Habitat and EC calculations using the boundaries of the GHS Urban Centre Database, Florczyk, A. et al. (2019 $\left.9_{[3]}\right)$, GHS Urban Centre Database 2015, Multitemporal and Multidimensional Attributes, R2019A (dataset), https://data.jrc.ec.europa.eu/dataset/53473144-b88c44bc-b4a3-4583ed1f547e.

A city can improve access to public transport by adding transport stops in neighbourhoods without access and/or increasing population densities around public transport stops, often referred to as transit-oriented development. Cities with low access to public transport and high densities should focus more on expanding the public transport network to neighbourhoods without access. For example, only $16 \%$ of the population of Kinshasa lives close to a public transport stop but it has a neighbourhood density of 30000 inhabitants per $\mathrm{km}^{2}$. Cities with low access and low densities should focus more on boosting densities and transitoriented development; especially as public transport in low-density neighbourhoods tend to attract a low number of riders. In Atlanta, for example, $50 \%$ of the population lives close to public transport but neighbourhood density is only 1100 inhabitants per $\mathrm{km}^{2}$. A low population share with access to public transport together with high neighbourhood densities suggest an underdeveloped public transport network, 
while low access combined with low neighbourhood densities implies a lack of density around public transport stops.

\section{Access to high-frequency public transport varies strongly across cities}

A more demanding but also more informative indicator differentiates by frequency and by public transport mode. It distinguishes access to a stop with more than ten departures an hour (high access), between four and ten in an hour (medium access), less than four (low access) or without convenient access (no access). For slower modes such as buses and trams, it uses the same 500-metre walk, while for higher speed and capacity modes such as metro, train, bus rapid transit (BRT) and ferry, it uses a 1000-metre walk. This approach is mentioned as a complementary indicator in the metadata of SDG Indicator 11.2.1, as defined by the United Nations. ${ }^{3}$

This indicator shows a far more differentiated picture. Comparing Figure 5.9 to Figure 5.10 shows more variation with Europe. For example, Dublin and Reykjavik have high overall access but access to a stop with a high frequency of departures is relatively rare. On the other hand, the South American cities of Buenos Aires and São Paulo offer a high level of access to more than $80 \%$ of their residents. The cities in North America and Oceania in this figure stand out with relatively low population shares with access to high-frequency departures.

Figure 5.10 Population by frequency of public transport departures in selected cities in the world

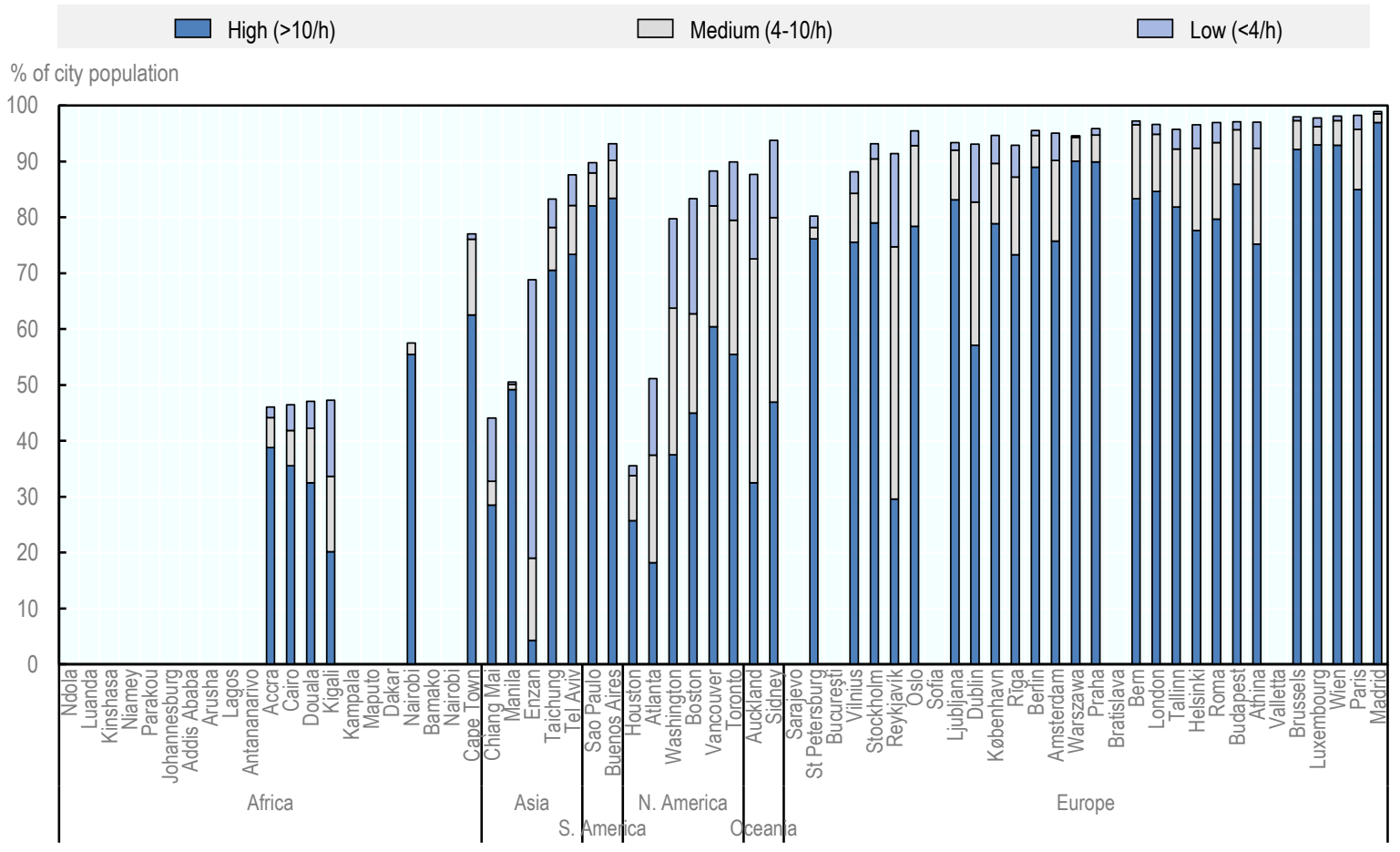

Source: ITF and DG REGIO calculations based on GTFS data from a variety of sources using the boundaries of Florczyk, A. et al. (2019[3]), GHS Urban Centre Database 2015, Multitemporal and Multidimensional Attributes, R2019A (dataset), https://data.jrc.ec.europa.eu/dataset/53473144-b88c44bc-b4a3-4583ed1f547e. 


\section{Public transport performance is higher in European and South American cities}

The two indicators described above are based on the supply of public transport services at a stop but this does not take into account where a person can travel to. This section relies on the new urban accessibility framework developed by the European Commission, International Transport Forum and $\mathrm{OECD}^{4}$ to measure how well public transport allows people to get to their destination. It uses two overlapping concepts to measure the performance of a mode of transport. The first component is the accessibility, which is the total number of destinations that can be reached by public transport within a fixed period of time. Destinations are identified in terms of population because comprehensive data on other destinations is not available. Accessible population, i.e. how many people can be reached in 45 -minutes of travel by public transport, was calculated for each inhabited grid cell of $500 \mathrm{~m}$ by $500 \mathrm{~m}$ in a city. The second component is called proximity and corresponds to the number of nearby destinations. Proximity or the nearby population, i.e. the number of people within a radius of $12 \mathrm{~km}$, was calculated for each grid cell. Finally, transport performance is the ratio between the accessible population and the nearby population (multiplied by 100). It shows how well public transport provides access to nearby destinations for each grid cell in a city. The city-level indicator is the population-weighted average of all the grid cells in the city.

Figure 5.11 shows these three indicators for 31 cities across the globe. For example, in London, the average accessible population is more than 4 million people. Cities with only a million inhabitants can never reach such a high level of accessibility because it simply lacks a large enough population. This underlines that the accessible population is heavily influenced by the population size of the city and should not be used to assess public transport. The nearby population is high in several cities. For example, it is between 3 and 4 million in Manilla, Paris and St Petersburg. The nearby population will be high in large, dense cities and lower in smaller or less dense cities.

Comparing the accessible population to the nearby population makes it possible to eliminate the effect of city size and to assess the performance of public transport more comparably. While only large cities can have a high level of accessible population, smaller cities can score well in terms of public transport performance. For example, Brussels or Tel Aviv score better than Paris in terms of transport performance.

Transport performance depends on how many people live close to a stop, the frequency and the speed of public transport vehicles and the design of the network. Cities with a high share of their population living close to a stop with frequent, high-speed transport will perform better. Cities with a metro network will perform better all other things being equal (see section on metro systems). Providing dedicated rights of way to buses and trams will also improve performance. Bus rapid transit systems, such as the one in Bogota, will also improve performance as it allows for higher speeds and frequencies for the buses in that system.

If neighbourhood densities are low, a longer network is needed to provide access to public transport to a large share of the population. Longer networks, however, are more expensive to build and operate and the distances between origin and destinations are higher too. As a result, cities with a low neighbourhood density tend to offer a lower level of access, lower frequencies and a lower performance. To improve both accessibility and performance, cities with a low neighbourhood density may wish to increase these densities, in particular close to public transport nodes. Cities with a high neighbourhood density, but a low public transport performance, should focus more on increasing the network, speed and frequencies of public transport to improve accessibility.

Good public transport is key to the quality of life and the economy of a large city. Access to public transport shows how many people can walk to a stop and which cities do lack a large enough network. Access by frequency shows how many departures an hour people can choose from. Low frequencies of departures tend to make public transport less attractive as it will take people longer to get to their destination. Neither of these indicators, however, show what destinations one can reach with public transport. The urban accessibility framework provides a new approach to comparing the performance of public transport in 
cities. It compares the accessible population to the nearby population to assess the performance of public transport. It shows which cities should focus on increasing the network, departures and speed to improve accessibility and which ones should (also) focus on reducing the distance between people and more generally between origins and destinations.

Figure 5.11. Accessible population, nearby population and public transport performance in selected cities in the world, 2019

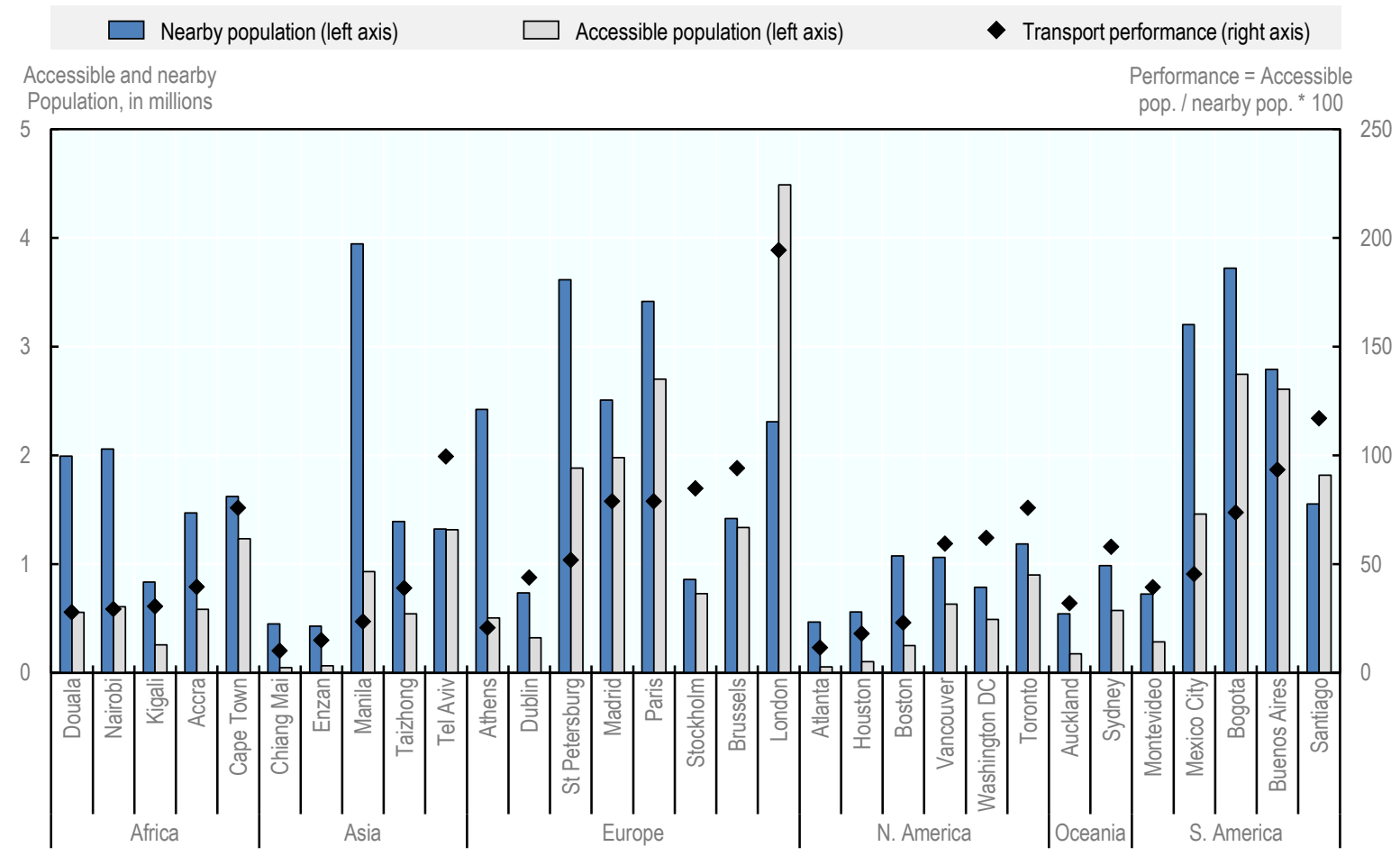

Source: ITF calculations using the boundaries of Florczyk, A. et al. (2019 $\left.{ }_{[3]}\right)$, GHS Urban Centre Database 2015, Multitemporal and Multidimensional Attributes, R2019A (dataset), https://data.jrc.ec.europa.eu/dataset/53473144-b88c-44bc-b4a3-4583ed1f547e.

\section{Metro systems are mostly present in large cities in high-income countries}

Metro systems offer a relatively high-speed and high-capacity form of public transport. The cost of constructing a metro system, however, is also high. Metro systems are typically constructed in large cities and do not extend into the suburbs (as defined by the degree of urbanisation). In high-income countries, $60 \%$ of the cities over 1 million inhabitants have a metro system, compared to only $7 \%$ in lower-middleincome countries (Table 5.6).

The metro systems in high-income countries started much earlier than in middle-income countries. Several metro lines were opened in the $19^{\text {th }}$ century: Boston, Budapest, Chicago, London, Paris and Tokyo. Since the 2000s, the number of metro systems opened each decade has increased. Between 1970 and 2010, about 20 systems were opened each decade. Between 2010 and 2018 even 37 were opened, primarily in China which opened 20 of them and India which opened 7.

The metros in high-income countries have four times the stations per inhabitants and three times the network length per inhabitants as compared to those in lower-middle-income countries. They have more than twice the number of trips per capita compared to lower-middle-income countries but its stations are less busy. 
Table 5.6. Cities with metro systems and their characteristics, 2018

\begin{tabular}{l|c|c|c|c|c|c}
\hline & \multirow{2}{*}{$\begin{array}{c}\text { Share of cities with } \\
\text { 1 million inhabitants with } \\
\text { a metro system (\%) }\end{array}$} & $\begin{array}{c}\text { Stations per } \\
100000 \text { inhab. }\end{array}$ & $\begin{array}{c}\text { Metro length } \\
\text { in km per } \\
100000 \text { inhab. }\end{array}$ & $\begin{array}{c}\text { Annual trips per } \\
\text { inhab. }\end{array}$ & $\begin{array}{c}\text { Million annual } \\
\text { trips per station }\end{array}$ & $\begin{array}{c}\text { Average year } \\
\text { metro opened }\end{array}$ \\
\hline Low income & 3 & 0.8 & 1.2 & 13 & 2.3 & 1973 \\
\hline Lower middle & 7 & 0.6 & 0.8 & 31 & 5.2 & 1996 \\
\hline Upper middle & 40 & 1.1 & 1.5 & 40 & 4.5 & 1999 \\
\hline High income & 60 & 2.5 & 2.8 & 72 & 3.8 & 1965 \\
\hline
\end{tabular}

Note: In low-income countries, only one city has a metro: Pyongyang, North Korea.

Source: EC calculations based on UITP (2018[16]), World Metro Figures 2018, Union Internationale des Transports Publics/International Association of Public Transport, Brussels, using the boundaries of Florczyk, A. et al. (2019[3]), GHS Urban Centre Database 2015, Multitemporal and Multidimensional Attributes, R2019A (dataset), https://data.jrc.ec.europa.eu/dataset/53473144-b88c-44bc-b4a3-4583ed1f547e.

Looking at 12 selected cities shows the strong correlation between the share of the population within $1 \mathrm{~km}$ of a metro station and the trips per inhabitant (Table 5.7). This share explains $63 \%$ of the variation in the trips per inhabitant. In Chicago, São Paulo and Toronto, only $15 \%$ or less of the inhabitants are within $1 \mathrm{~km}$ of a metro station and the number of metro trips a year per inhabitant is only between 35 and 70 . In cities where at least $30 \%$ lives within $1 \mathrm{~km}$, the number of trips per inhabitant is up to four times higher: between 108 and 173 trips per inhabitant.

Table 5.7 Metro system, ridership and access to a metro station in 12 selected cities, 2015

\begin{tabular}{l|l|c|c|c|c|c}
\hline City name & Country name & $\begin{array}{c}\text { Population } \\
\text { (millions) }\end{array}$ & $\begin{array}{c}\text { Length in km } \\
\text { per } \\
100000 \text { inhab. }\end{array}$ & $\begin{array}{c}\text { Stations per } \\
100000 \text { inhab. }\end{array}$ & $\begin{array}{c}\text { Annual trips per } \\
\text { inhabitant }\end{array}$ & $\begin{array}{c}\text { Share of inhabitants } \\
\text { within 1km walk of a } \\
\text { station }(\%)\end{array}$ \\
\hline Sao Paulo & Brazil & 19.1 & 0.4 & 0.4 & 70 & 8 \\
\hline Toronto & Canada & 6.0 & 1.4 & 1.2 & 48 & 12 \\
\hline Chicago & United States & 6.8 & 2.4 & 2.1 & 34 & 15 \\
\hline Mexico City & Mexico & 19.6 & 1.2 & 0.8 & 86 & 16 \\
\hline Milan & Italy & 2.9 & 3.1 & 3.8 & 164 & 25 \\
\hline St. Petersburg & Russia & 4.2 & 2.7 & 1.6 & 173 & 30 \\
\hline London & United Kingdom & 9.6 & 4.5 & 3.2 & 156 & 172 \\
\hline Berlin & Germany & 3.3 & 4.5 & 5.3 & 154 & 30 \\
\hline Paris & France & 9.7 & 2.1 & 3.1 & 108 & 34 \\
\hline Brussels & Belgium & 1.4 & 3.2 & 4.3 & 119 & 35 \\
\hline New York & United States & 16.0 & 2.7 & 3.2 & 132 & 36 \\
\hline Madrid & Spain & 4.7 & 6.2 & 5.0 & & 38 \\
\hline
\end{tabular}

Source: EC calculations based on UITP (2018[16]), World Metro Figures 2018, Union Internationale des Transports Publics/International Association of Public Transport, Brussels, using the boundaries of Florczyk, A. et al. (2019 $\left.9_{[3]}\right)$, GHS Urban Centre Database 2015, Multitemporal and Multidimensional Attributes, R2019A (dataset), https://data.jrc.ec.europa.eu/dataset/53473144-b88c-44bc-b4a3-4583ed1f547e.

\section{The shape of a metropolitan area changes the cost of providing public transport}

The spatial distribution of the population within a metropolitan area can have a big impact on the cost of providing public transport. The literature on sprawl typically relies on the assumption that low density and discontinuous urban development increase these costs. This report takes a different approach and tries to assess the costs of public transport by measuring and modelling the length of the public transport network 
in 37 large metropolitan areas in all continents (see Annex 5.A). The results reveal big differences. Hong Kong and Mumbai can provide public transport to $80 \%$ of its residents with a network of only $6 \mathrm{~km}$ per 100000 inhabitants. Houston needs 26 times more $(155 \mathrm{~km})$ and Atlanta needs 45 times more $(273 \mathrm{~km})$. This would substantially raise the cost of constructing and operating such a network if it were ever constructed. In practice, it usually means that a much lower share of the population has access to public transport in cities like Houston and Atlanta.

The main determinant of the length of the public transport network in this model is the neighbourhood density (the weighted population density using $1 \mathrm{~km}^{2}$ cells), while the overall population density of the metropolitan area becomes insignificant once neighbourhood density is factored in. The only other indicator that has some significance is the share of the population in the commuting zone, with higher shares leading to longer networks. The relationship between neighbourhood density and the public transport network lengths is not linear, but exponential. A change in neighbourhood density can have a bigger or smaller impact on total costs depending on the initial density. For example, reducing the density from 15000 to 12000 inhabitants per $\mathrm{km}^{2}$ increases costs by 30\%, while reducing it from 6000 to 3000 increases costs by $120 \%$. The same reduction in density has a four times bigger impact.

The average neighbourhood density in metropolitan areas with at least 1 million inhabitants globally is 14000 inhabitants per km². In South America, densities are 11000 , which would imply costs that are $30 \%$ higher as compared to the global average. In Europe and Central Asia, the density is around 8000 which would imply costs that are $90 \%$ higher. In North America, however, densities are only 3300 , which would imply costs that are $400 \%$ higher than the global average. Densities in metropolitan areas of 1 million or more in North Africa, Sub-Saharan Africa and the Middle East (15000) are slightly above the global average and densities in East Asia and the Pacific (13 000) slightly below it.

Figure 5.12. Simulated public transport network length in 37 metropolitan areas, 2015

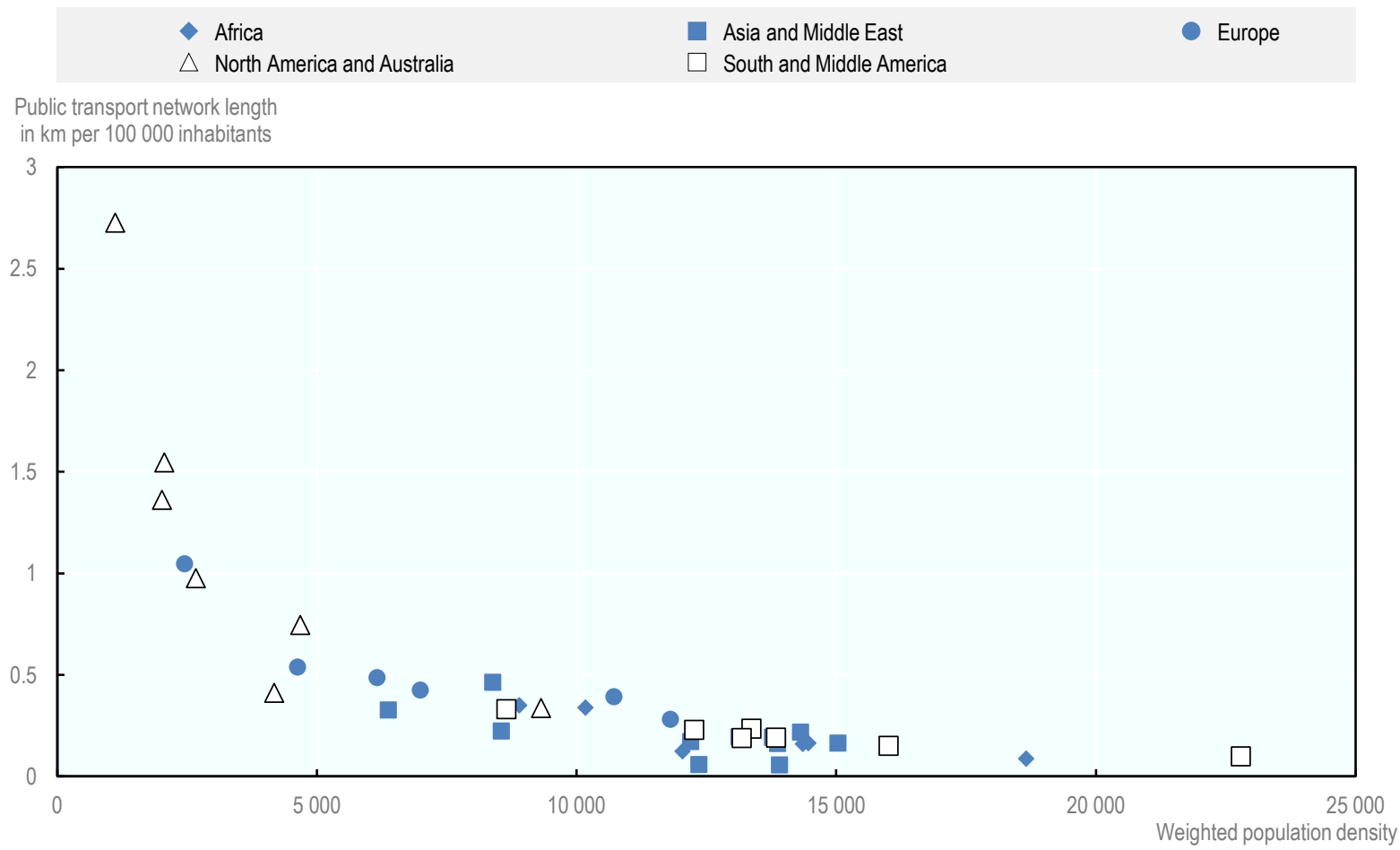

Source: See Jacobs-Crisioni, C., L. Dijkstra and A. Kucas (forthcoming $\left.{ }_{[17]}\right)$, "Does density foster efficient public transport? A network expansion simulation approach" (manuscript submitted for publication). Work is based on the boundaries of Moreno-Monroy, A., M. Schiavina and P. Veneri (2020[8]), "Metropolitan areas in the world. Delineation and population trends", https://doi.org/10.1016/i.jue.2020.103242. 


\section{Pollution, natural hazards and climate change}

Cities concentrate people and wealth. This high concentration has costs as well as benefits. People living in cities suffer from air pollution, floods and are more exposed to storms and sea level rise.

\section{People living in cities are exposed to higher levels of air pollution}

City residents are least satisfied with their air quality. In all four country income groups, people living in cities are less satisfied with air quality than those living in towns and semi-dense areas, which in turn are less satisfied than those in rural areas (Figure 5.13). With higher income levels, satisfaction improves in rural areas, but less in towns and semi-dense areas and not in cities. In part, this reflects the fact that higher income levels do not automatically lead to better air quality in cities, for example, as the use of individual cars typically rises with income. It also reflects that as incomes grow, more people may become concerned about air pollution, even at relatively low pollution levels.

Figure 5.13. Satisfaction (in percentage) with air quality by the degree of urbanisation

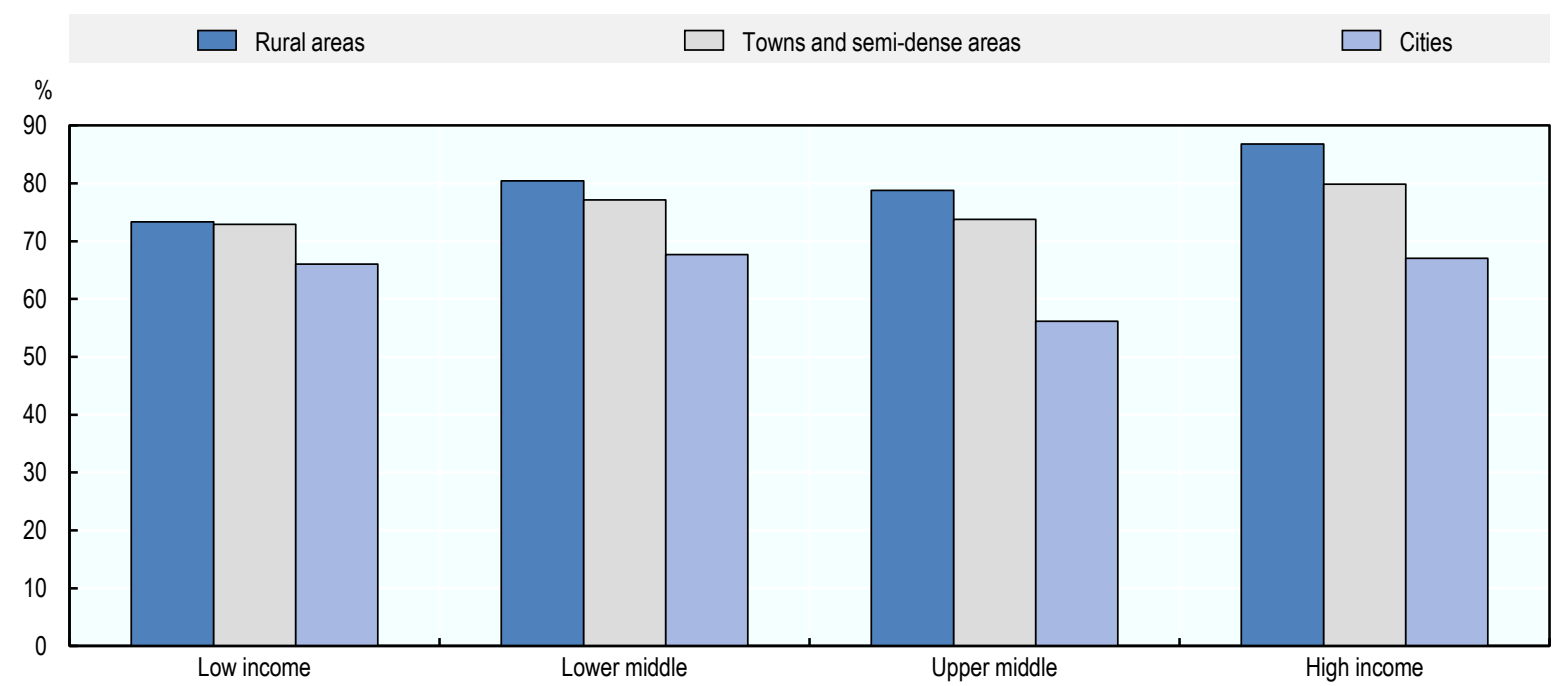

Source: Based on Gallup (2017[18]), Gallup World Poll, 2016-17, https://www.gallup.com/analytics/232838/world-poll.aspx, elaborated by OECD, 2019.

Air pollution in cities depends on local emissions, geography, wind and emissions nearby. The concentration of PM 2.5 is particularly high in cities in parts of India and the industrial coastal cities in China (Figure 5.14). Although most cities in North America, South America, and Europe record lower levels of air pollution, these levels remain above the $10 \mu \mathrm{g} / \mathrm{m}^{3}$ guideline value proposed by WHO. ${ }^{5}$ Improving air quality requires a co-ordinated approach covering emissions from different sectors, including industry, transport, agriculture and households, and covering both local and nearby emissions. For example, a significant share of air pollution in cities in the European Union comes from emissions in neighbouring regions, from agriculture or from freight ships at coastal locations. 
Figure 5.14. Concentration of PM2.5 in cities, 2014

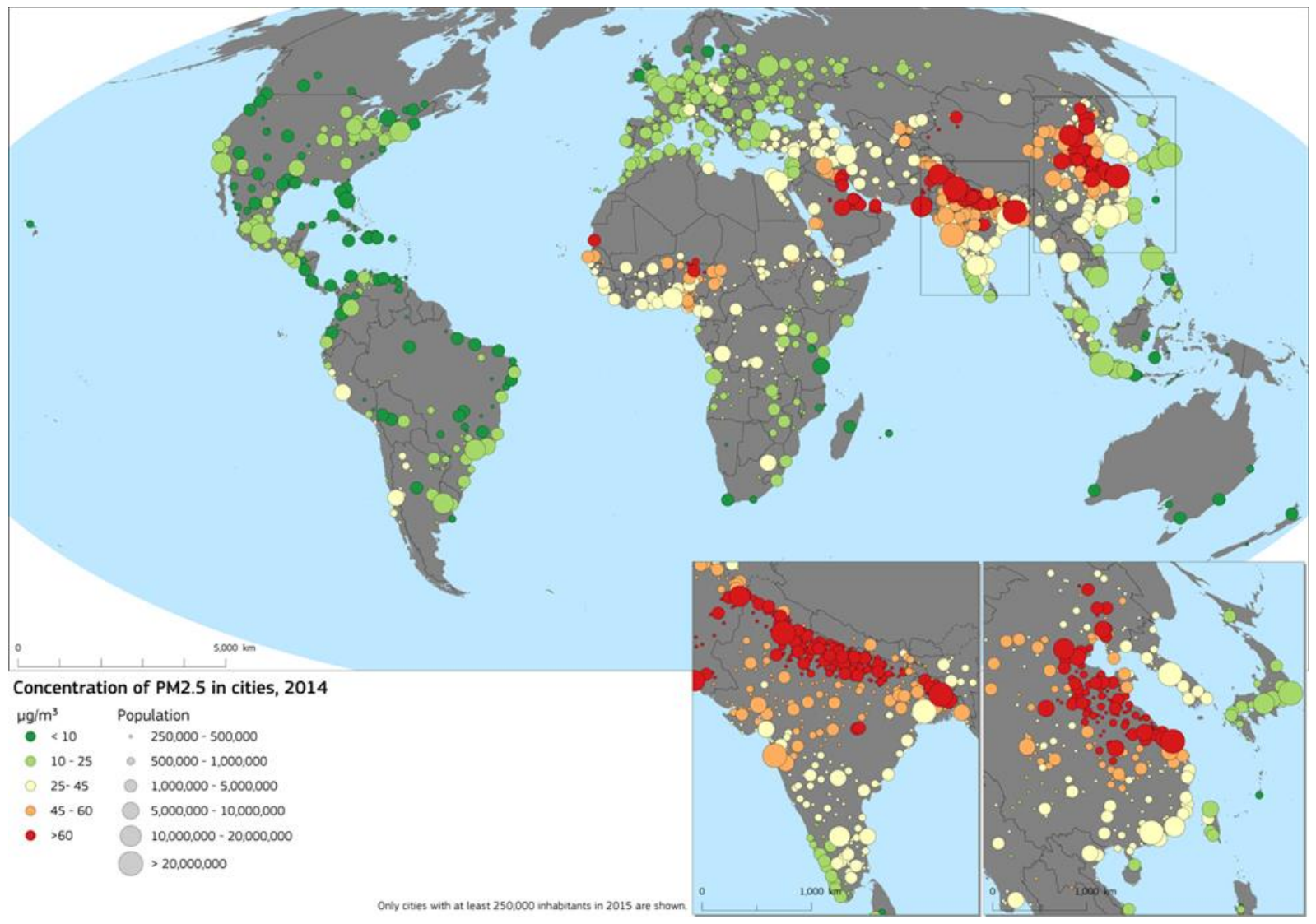

Source: Florczyk, A. et al. (2019[3]), GHS Urban Centre Database 2015, Multitemporal and Multidimensional Attributes, R2019A (dataset), https://data.jrc.ec.europa.eu/dataset/53473144-b88c-44bc-b4a3-4583ed1f547e.

\section{Flood risks threaten cities on all continents}

One in five people living in cities, or 613 million people, are exposed to a 100-year flood (Dottori et al., $\left.2016_{[19]}\right) .{ }^{6}$ This exposure is heavily concentrated in a few cities (Figure 5.15). Of all cities, $70 \%$ are not exposed while $6 \%$ (630 cities) risk being entirely flooded. The cities with the biggest number of people exposed to a 100-year flood are mostly located in Asia, in part because a high number of the largest cities are located in Asia (Table 5.8). Climate change is likely to increase this risk of 100-year floods due to more extreme weather. Reducing flood risks requires changes both within and beyond the city. Cities can take action to minimise the impact on the people and infrastructure when water rises through flood barriers and considering flood risk when building new housing and infrastructure. Changes along the river can help to manage the speed of the flow and create places where flood water can be channelled with minimal consequences.

Table 5.8. The 20 cities with the highest population exposed to a 100-year flood, 2015

\begin{tabular}{l|l|c|c}
\hline \multicolumn{1}{c|}{ City } & \multicolumn{1}{c|}{ Country } & Exposed population, 2015 & Percentage of population exposed, 2015 \\
\hline Shanghai & China & 21503000 & 88 \\
\hline Guangzhou & China & 17640000 & 43 \\
\hline Kolkata & India & 17164000 & 79 \\
\hline Dhaka & Bangladesh & 15269000 & 64 \\
\hline
\end{tabular}




\begin{tabular}{l|l|c|c}
\hline \multicolumn{1}{c|}{ City } & \multicolumn{1}{|c|}{ Country } & Exposed population, 2015 & Percentage of population exposed, 2015 \\
\hline Bangkok & Thailand & 14647000 & 99 \\
\hline Delhi & India & 14151000 & 47 \\
\hline Cairo & Egypt & 9251000 & 100 \\
\hline Tianjin & China & 6642000 & 86 \\
\hline Wuhan & China & 6338000 & 63 \\
\hline Suzhou & China & 5418000 & 97 \\
\hline Surat & India & 5330000 & 24 \\
\hline Seoul & South Korea & 5268000 & 96 \\
\hline Baghdad & Iraq & 5140000 & 43 \\
\hline Ho Chi Minh City & Viet Nam & 4958000 & 31 \\
\hline Osaka-Kyoto & Japan & 4827000 & 85 \\
\hline Hanoi & Viet Nam & 4533000 & 42 \\
\hline Jieyang & China & 4425000 & 22 \\
\hline Mexico City & Mexico & 4398000 & 65 \\
\hline Chattogram & Bangladesh & 3418000 & 56 \\
\hline Khartoum & Sudan & 3270000 & 5 \\
\hline
\end{tabular}

Source: Florczyk, A. et al. (2019 $\left.{ }_{[3]}\right)$, GHS Urban Centre Database 2015, Multitemporal and Multidimensional Attributes, R2019A (dataset), https://data.jrc.ec.europa.eu/dataset/53473144-b88c-44bc-b4a3-4583ed1f547e.

\section{Figure 5.15. Population exposed to floods in cities, 2015}

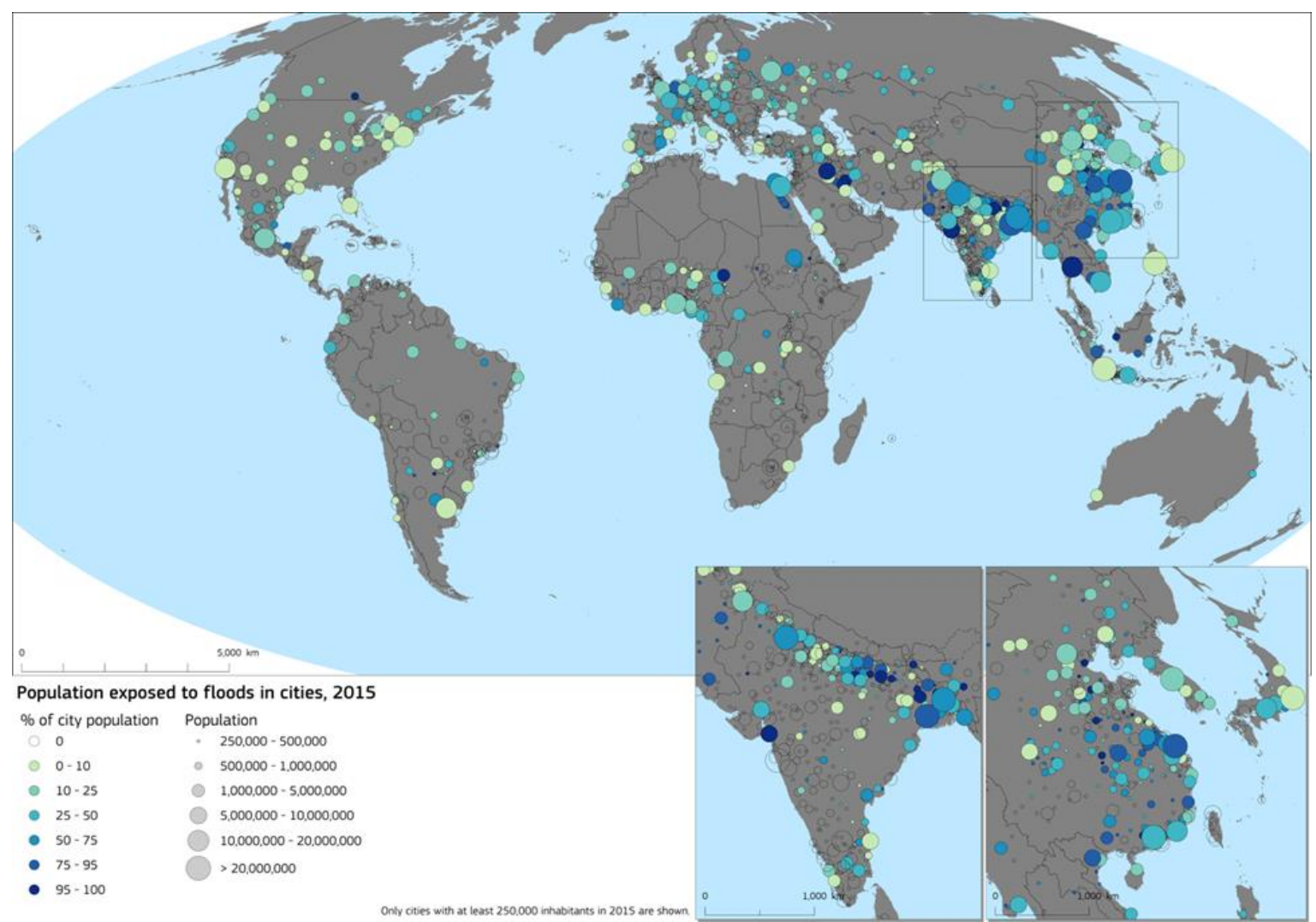

Source: Florczyk, A. et al. (2019 $\left.{ }_{[3]}\right)$, GHS Urban Centre Database 2015, Multitemporal and Multidimensional Attributes, R2019A (dataset), https://data.jrc.ec.europa.eu/dataset/53473144-b88c-44bc-b4a3-4583ed1f547e. 


\section{Cities are more exposed sea level rise and storm surges}

In $2015,14 \%$ of city dwellers were living in a low elevation coastal zone compared to $11 \%$ of the population in towns and semi-dense areas and $6 \%$ of the rural population (Figure 5.16). Low elevation coastal zones (LECZs) are areas below 10-metre elevation and contiguous with the seacoast (see (MacManus et al., $\left.2019_{[20]}\right)$, based on Yamazaki et al. $\left(2017_{[21]}\right)$ ). Of the city population in these zones, one in three city dwellers was living in the zone most exposed to storms and sea level rise (below $5 \mathrm{~m}$, Figure 5.16).

Figure 5.16. Population in low elevation coastal zones by degree of urbanisation, 2015

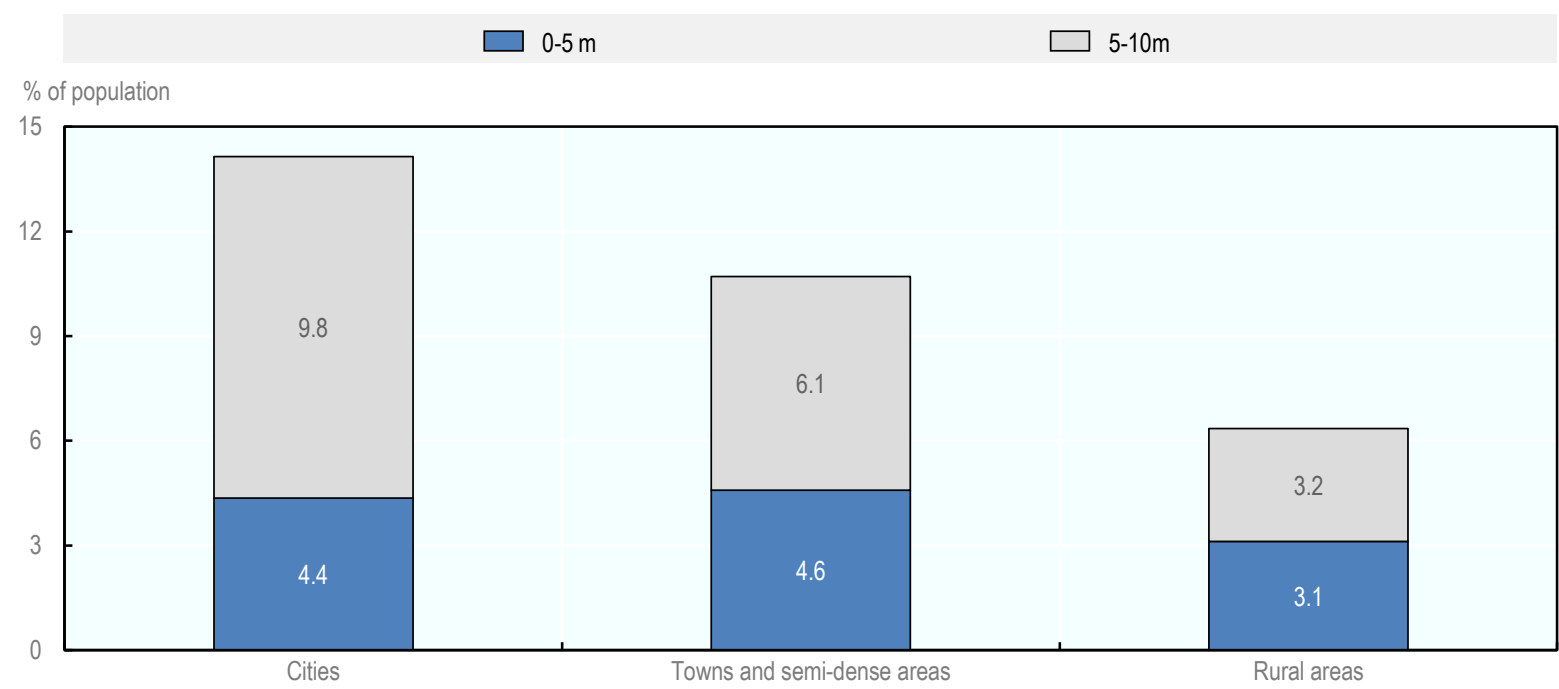

Source: (MacManus et al., 2019[20] $)$ based on Florczyk, A. et al. (2019 $\left.9_{[3]}\right)$, GHS Urban Centre Database 2015, Multitemporal and Multidimensional Attributes, R2019A (dataset), https://data.jrc.ec.europa.eu/dataset/53473144-b88c-44bc-b4a3-4583ed1f547e.

StatLink त्ञात https://doi.org/10.1787/888934130455

In cities, the population living in low elevation coastal zones has also been growing faster as in towns and semi-dense areas and in rural areas, especially in the highest risk zone (Figure 5.17). Population growth in towns \& semi-dense areas and in rural areas has been faster outside the low coastal elevation zones. This means that over time the exposure to this risk has been shrinking outside cities while it has been growing within cities.

Chinese cities have 128 million people living in a low elevation coastal zone, the highest city population exposed (Table 5.9), followed by India with 54 million people. More than one in five city dwellers in Bangladesh, China, Indonesia, Japan and the Philippines live in a LECZ. Thailand and Viet Nam, have $82 \%$ and $63 \%$ respectively of their city population within a low elevation coastal zone. While total numbers of city dwellers are much smaller, several Latin American and Caribbean nations have their entire (or nearly) city population within the LECZ: Belize, Guyana, Suriname (at 100\%) and the Bahamas (80\%). In addition, several small developing island states, including the Cayman Islands, the Maldives, the Marshall Islands and Tuvalu have the three-quarters of their population in a low elevation coastal zone.

Current protection against storms varies widely between these cities. Dutch cities benefit from a strong centrally funded infrastructure. Many others, including some in high-income countries like New Orleans, are highly exposed to storms and rising sea levels. The high level of exposure highlights the need for national adaptation plans. Given that $60 \%$ of the 815 million people in a low elevation coastal zone live in a city and that this population is growing quickly, developing city adaptation plans should be a priority. 
Figure 5.17. Population change in low elevation coastal zones by degree of urbanisation, 1990-2000 and 2000-15

$0-5 \mathrm{~m}$

$1990-2000$

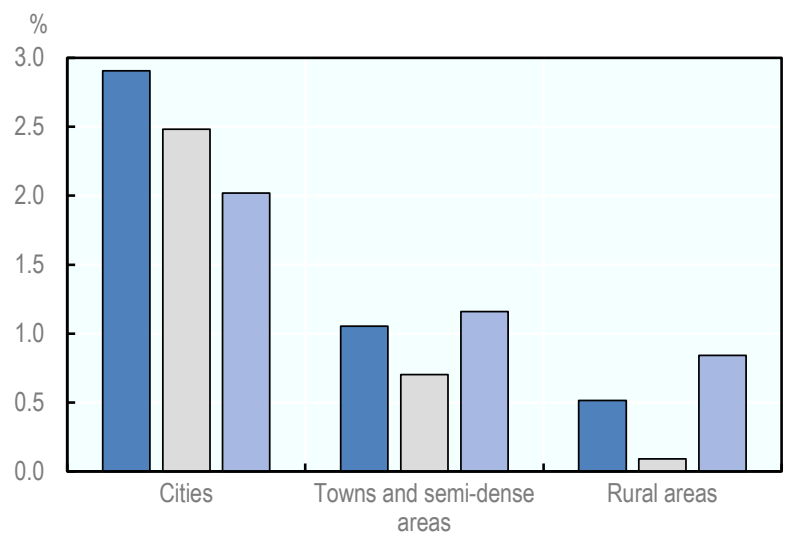

$5-10 \mathrm{~m}$

$\%$

$\%$

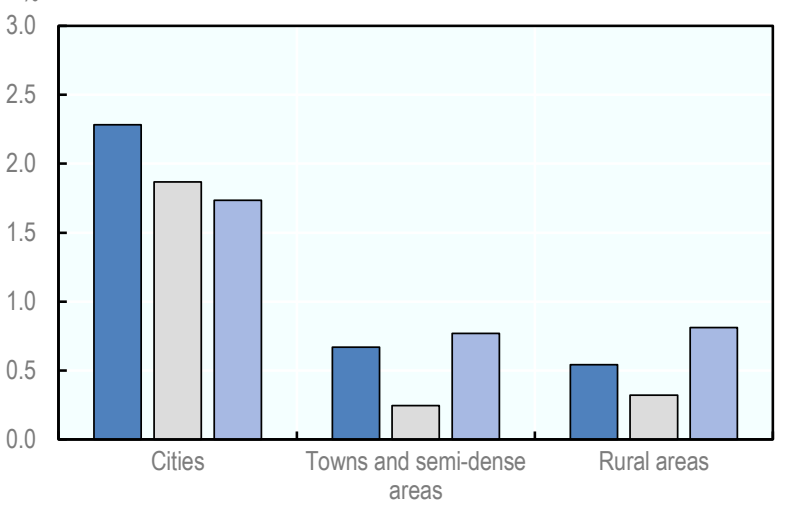

Source: (MacManus et al., 2019[20] $)$ based on Florczyk, A. etal. (2019 $\left.{ }_{[3]}\right)$, GHS Urban Centre Database 2015, Multitemporal and Multidimensional Attributes, R2019A (dataset), https://data.jrc.ec.europa.eu/dataset/53473144-b88c-44bc-b4a3-4583ed1f547e.

Table 5.9. Top ten countries ranked by city population and city population share in the low elevation coastal zones, 2015

\begin{tabular}{|c|c|c|c|c|c|c|}
\hline \multirow[b]{2}{*}{ Rank } & \multicolumn{3}{|c|}{$\begin{array}{c}\text { Panel A. Ranked by total population living in cities in low } \\
\text { elevation coastal zones }\end{array}$} & \multicolumn{3}{|c|}{$\begin{array}{c}\text { Panel B. Ranked by share of population living in cities in lon } \\
\text { elevation coastal zones }\end{array}$} \\
\hline & Country & $\begin{array}{l}\text { Population in the } \\
\text { LECZ (thousands) }\end{array}$ & $\%$ & Country & $\begin{array}{l}\text { Population in the } \\
\text { LECZ (thousands) }\end{array}$ & $\%$ \\
\hline 1 & China & 127792 & 23 & Suriname & 200 & 100 \\
\hline 2 & India & 54456 & 8 & Belize & 69 & 100 \\
\hline 3 & Bangladesh & 40286 & 48 & Guyana & 224 & 100 \\
\hline 4 & Indonesia & 34209 & 24 & Thailand & 16747 & 82 \\
\hline 5 & Japan & 26467 & 32 & Bahamas & 164 & 80 \\
\hline 6 & Viet Nam & 23767 & 63 & Mauritania & 1170 & 80 \\
\hline 7 & Thailand & 16747 & 82 & Netherlands & 5979 & 77 \\
\hline 8 & United States & 15912 & 10 & Djibouti & 421 & 70 \\
\hline 9 & Egypt & 14038 & 24 & Liberia & 1055 & 65 \\
\hline 10 & Philippines & 12763 & 33 & Viet Nam & 23767 & 63 \\
\hline
\end{tabular}

Note: Countries with a total population of under 100000 people or smaller than 1000 square kilometres were excluded from this list. Source: (MacManus et al., 2019[20] ) based on Florczyk, A. et al. (2019[3]), GHS Urban Centre Database 2015, Multitemporal and Multidimensional Attributes, R2019A (dataset), https://data.jrc.ec.europa.eu/dataset/53473144-b88c-44bc-b4a3-4583ed1f547e. 


\section{References}

Corbane, C. et al. (2019), "Automated global delineation of human settlements from 40 years of Landsat satellite data archives", Big Earth Data, Vol. 3/2, pp. 140-169, https://doi.org/10.1080/20964471.2019.1625528.

Corbane, C. et al. (2017), "Big earth data analytics on Sentinel-1 and Landsat imagery in support to global human settlements mapping", Big Earth Data, Vol. 1/1-2, pp. 118-144, http://dx.doi.org/10.1080/20964471.2017.1397899.

Dottori, F. et al. (2016), "Development and evaluation of a framework for global flood hazard mapping", Advances in Water Resources, Vol. 94, pp. 87-102, https://doi.org/10.1016/j.advwatres.2016.05.002.

European Environment Agency (2015), "Imperviousness and imperviousness change", https://www.eea.europa.eu/data-and-maps/indicators/imperviousness-change-1/assessment (accessed on 21 March 2020).

Florczyk, A. et al. (2019), GHSL Data Package 2019 (database), http://dx.doi.org/10.2760/062975.

Florczyk, A. et al. (2019), GHS Urban Centre Database 2015, Multitemporal and Multidimensional Attributes, R2019A (dataset), Joint Research Centre (JRC), European Commission, https://data.jrc.ec.europa.eu/dataset/53473144-b88c-44bc-b4a3-4583ed1f547e.

Gallup (2017), Gallup World Poll, 2016-17, https://www.gallup.com/analytics/232838/worldpoll.aspx.

Gonzalez-Navarro, M. and M. Turner (2019), "Subways and urban growth: Evidence from earth", Journal of Urban Economics, Vol. 108/C, pp. 85-106, https://doi.org/10.1016/j.jue.2018.09.002.

Goodchild, M. (1977), "An evaluation of lattice solutions to the corridor location problem", Environment and Planning A, Vol. 9/7, pp. 727-738, https://doi.org/10.1068/a090727.

Gordon, P. and H. Richardson (1996), "Beyond polycentricity: The dispersed metropolis, Los Angeles, 1970-1990", Journal of the American Planning Association, Vol. 62, pp. 289-295, https://doi.org/10.1080/01944369608975695.

Jacobs-Crisioni, C. (2016), Spatial data analyses of urban land use and accessibility.

Jacobs-Crisioni, C., L. Dijkstra and A. Kucas (forthcoming), "Does density foster efficient public transport? A network expansion simulation approach", Manuscript submitted for publication.

Lall, S., J. Henderson and A. Venables (2017), Africa's Cities: Opening Doors to the World, The World Bank, http://dx.doi.org/10.1596/978-1-4648-1044-2.

LeRoy, S. and J. Sonstelie (1983), "Paradise lost and regained: Transportation innovation, income, and residential location", Journal of Urban Economics, Vol. 13/1, pp. 67-89, https://doi.org/10.1016/0094-1190(83)90046-3.

MacManus, K. et al. (2019), Population and land area at risk of coastal hazards: New Estimates of the Low Elevation Coastal Zone along an urban-rural continuum, 1990-2015. 
Moreno-Monroy, A., M. Schiavina and P. Veneri (2020), "Metropolitan areas in the world.

Delineation and population trends", Journal of Urban Economics, https://doi.org/10.1016/j.jue.2020.103242.

OECD (2018), Rethinking Urban Sprawl: Moving Towards Sustainable Cities, OECD Publishing, Paris, https://doi.org/10.1787/9789264189881-en.

Owen, D. (2009), Green Metropolis. Why Living Smaller, Living Closer, and Driving Less Are the Keys to Sustainability, Penguin Books.

Pesaresi, M. et al. (2013), "A global human settlement layer from optical HR/VHR RS data: Concept and first results", IEEE Journal of Selected Topics in Applied Earth Observations and Remote Sensing, Vol. 6/5, pp. 2102-2131, http://dx.doi.org/10.1109/JSTARS.2013.2271445.

Pesaresi, M., V. Syrris and A. Julea (2016), "A new method for earth observation data analytics based on symbolic machine learning", Remote Sensing, Vol. 8/5, http://dx.doi.org/10.3390/rs8050399.

UITP (2018), World Metro Figures 2018, Union Internationale des Transports Publics/International Association of Public Transport, Brussels.

Veneri, P. (2018), "Urban spatial structure in OECD cities: Is urban population decentralising or clustering?", Papers in Regional Science, Vol. 97/4, pp. 1355-1374, https://doi.org/10.1111/pirs.12300.

Yamazaki, D. et al. (2017), "A high accuracy map of global terrain elevations", Geophysical Research Letters, Vol. 44, pp. 5844-5853, https://doi.org/10.1002/2017GL072874.

\section{Notes}

${ }^{1}$ https://www.who.int/airpollution/data/cities/en/.

2 http://habitat3.org/wp-content/uploads/NUA-English.pdf.

${ }^{3}$ https://unstats.un.org/sdgs/metadata/files/Metadata-11-02-01.pdf.

${ }^{4}$ ITF/OECD (2019). Benchmarking Accessibility in Cities. Measuring the Impact of Proximity and Transport Performance, https://www.itf-oecd.org/sites/default/files/docs/accessibility-proximity-transportperformance.pdf .

${ }^{5}$ According to the Clean Air Outlook for Europe (https://ec.europa.eu/environment/air/clean air/outlook.htm), "for fine particulate matter (PM2.5), up to $8 \%$ of the urban population was exposed to concentrations above the EU limit value of $25 \mu \mathrm{g} / \mathrm{m} 3$, and more than $82 \%$ to levels above the much stricter WHO guideline value of $10 \mu \mathrm{g} / \mathrm{m} 3$."

${ }^{6}$ A 100 -year flood or a flood with a 100-year return period is a flood that is likely to happen once every 100 years. Climate change is already leading to more extreme weather patterns which may increase the frequency of floods, including those with a 100 -year return period. 


\section{Annex 5.A. Technical annex}

\section{Neighbourhood density or population-weighted population density}

Neighbourhood density or population-weighted population density (weighted density) captures the experience of an average resident. It establishes the neighbourhood density for each resident and averages those densities. In this report, we use $1 \mathrm{~km}^{2}$ cells to measure neighbourhood density and we report it at both the city and functional urban area level.

The formula is: $\sum_{i=0}^{n}\left(\right.$ density $_{i} *$ population $\left._{i}\right) / \sum_{i=0}^{n}$ population $_{i}$

In simpler terms, for all the neighbourhoods in a city, sum up its density multiplied by its population and divide it by the total population of the city.

Taking a random sample of residents from a city and calculating the average of the density of the neighbourhood they live in produces the same result.

The neighbourhood density is always equal or higher than the city density. If every neighbourhood had the same density, it would be the same as the city density. When neighbourhood densities vary, the population weighting ensures that the neighbourhood density is higher than the city density.

The benefit of the neighbourhood density is that it ignores areas without population (because they get a weight of zero). This ensures that the indicator does not reduce density because a large park or undeveloped area is included within the city boundary. As a result, it also makes it less sensitive to where the boundary of a city or metropolitan area is drawn.

\section{Modelling public transport networks}

Through shape and density, the urban form has a profound impact on the efficiency and mobility potential of urban transport. A comparison of existing public transport network lengths, however, cannot reveal whether the shape and density of a particular city are efficient because political preferences, income levels and physical geography will play an important role in the extent of those networks (Jacobs-Crisioni, 2016[22]).

Simulated optimal public transport networks can show which cities can provide public transport at a lower cost. The approach ensures that $80 \%$ of every functional urban area population has access to public transport. The simulation starts by creating a base network meant to describe all possible network links in the city. Each inhabited grid cells of $1 \mathrm{~km}^{2}$ is connected to all other inhabited grid cells within $2 \mathrm{~km}$. All lines are attributed to a relatively low speed of $4 \mathrm{~km} / \mathrm{h}$, which is considered a realistic walking speed. Grid cells that do not have any neighbours within the $2 \mathrm{~km}$ are given single lines to the closest neighbour(s).

\section{Step 1: Origin-destination matrix-based selection}

Travel time between all grids is calculated using the shortest path algorithm through the created base network. With grid cell population and travel times, passenger flows on the network are estimated. For each origin-destination pair, costs and benefits of a public transport network connection are estimated. Public transport is assumed to operate at an average speed of $30 \mathrm{~km} / \mathrm{h}$. Costs are a combination of fixed costs and a variable cost element based on the length of the connection. Benefits are estimated based on expected gains in passenger-kilometres. Finally, the pair with the highest benefit-cost rate is selected as a connection to upgrade. 
Step 2: Find the most attractive path

For the selected connection, the most attractive path is selected using a corridor allocation solving approach (see (Goodchild, 1977[23])). This allows, within set limits, a connection to take a longer path if that yields more passenger-kilometres, thus identifying the most plausible path between origin and destination. The path with the highest total passenger-kilometres is selected.

Step 3: Add a path to the network and evaluate the percentage of the population that is connected

The selected path is added to the network with a speed of $30 \mathrm{~km} / \mathrm{h}$, instead of the base $4 \mathrm{~km} / \mathrm{h}$ travel speeds on walking links. The simulation continues by returning to Step 1 , searching another connection to upgrade, until at least $80 \%$ of the population lives in a grid cell with a public transport stop. 


\section{OECD Urban Studies}

\section{Cities in the World}

\section{A NEW PERSPECTIVE ON URBANISATION}

Cities are not only home to around half of the global population but also major centers of economic activity and innovation. Yet, so far there has been no consensus of what a city really is. Substantial differences in the way cities, metropolitan, urban, and rural areas are defined across countries hinder robust international comparisons and an accurate monitoring of SDGs. The report Cities in the World: A New Perspective on Urbanisation addresses this void and provides new insights on urbanisation by applying for the first time two new definitions of human settlements to the entire globe: the Degree of Urbanisation and the Functional Urban Area. Based on the definitions, the report presents new evidence of recent and future urbanisation trends and sheds light on the evolution of metropolitan areas around the globe. It examines whether and why quality of life differs between cities and other types of settlements. It analyses the relationship between economic development and the metropolitan system in countries around the world. Finally, it presents new evidence on the changing shape of cities and its impact on sustainability. The report demonstrates how globally consistent definitions of cities and metropolitan areas can contribute to more effective policy design. 